
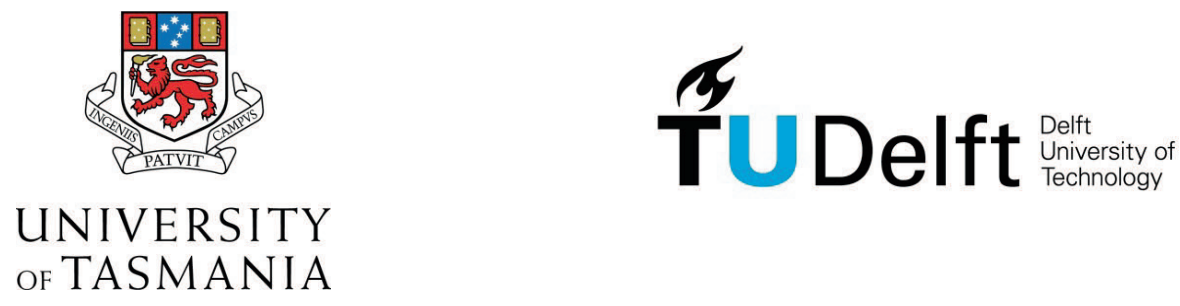

\title{
Limitations On The Creation of Continuously Surfable Waves Generated By A Pressure Source Moving In A Circular Path
}

by

\section{Steven Anthony Schmied}

Bachelor of Engineering (Aerospace) (Honours), Master of Business Administration, Master of Engineering (Computing), Chartered Professional Engineer, Engineering Executive, Fellow of Engineers Australia

Submitted in fulfilment of the requirements for the Degrees of Doctorate of Philosophy

at

the University of Tasmania (UTAS) Australian Maritime College (AMC)

and

Doctorate of Engineering

at

Delft University of Technology (TU Delft) 


\title{
Limitations On The Creation of Continuously Surfable Waves Generated By A Pressure Source Moving In A Circular Path
}

\author{
Proefschrift \\ ter verkrijging van de graad van doctor \\ aan de Technische Universiteit Delft, \\ op gezag van de Rector Magnificus prof. ir. K.C.A.M. Luyben, \\ voorzitter van het College voor Promoties, \\ in het openbaar te verdedigen op 29 januari 2014 om 10.00 uur \\ door
}

Steven Anthony SCHMIED

Bachelor of Engineering (Aerospace) (Honours), Master of Business Administration, Master of Engineering (Computing), Chartered Professional Engineer, Engineering Executive, Fellow of Engineers Australia.

geboren te Melbourne, Australië. 


\section{Dit proefschrift is goedgekeurd door de promotor:}

Prof. dr. ir. R.H.M. Huijsmans.

\section{Samenstelling promotiecommissie:}

Rector Magnificus

Prof.dr.ir. R.H.M. Huijsmans

Prof. M.R. Renilson

Prof. dr. ir. M.J.F. Stive

Prof. dr. ir. G.S. Stelling

Prof. dr. ir. H.W.M. Hoeijmakers

Dr. J.R. Binns

Dr. J. Hennig

Prof. dr. ir. T.J.C. van Terwisga voorzitter

Technische Universiteit Delft, $3 \mathrm{mE}$, promotor

Universiteit Tasmanië Australische Maritieme College and Technische Hogere Colleges, Verenigde Arabische Emiraten

Technische Universiteit Delft, CiTG

Technische Universiteit Delft, CiTG

Universiteit Twente

Universiteit Tasmanië Australische Maritieme College

Maritiem Research Instituut Nederland (MARIN)

Technische Universiteit Delft, $3 \mathrm{mE}$, reservelid

Universiteit Tasmanië Australische Maritieme College Associëren Prof. G. Thomas and Dr. G. Macfarlane, heeft als begeleider in belangrijke mate aan de totstandkoming van het proefschrift bijgedragen.

ISBN: 978-1-86295-934-7

Copyright (C) 2014 by S.A. Schmied.

All rights reserved.

Published by the University of Tasmania and Delft University of Technology.

Printed by: Gildeprint Drukkerijen - www.gildeprint.nl.

Cover illustration of Webber Wave Pool by Paul Roget. 
Page iv

\section{Signed Statement}

The thesis contains no material which has been accepted for a degree or diploma by the University of Tasmania, Delft University of Technology or any other institution, except by way of background information and duly acknowledged in the thesis, and to the best of my knowledge and belief, no material previously published or written by another person except where due acknowledgement is made in the text of the thesis, nor does the thesis contain any material that infringes copyright.

This thesis is not to be made available for loan or copying for two years following the date this statement was signed. Following that time the thesis may be made available for loan and limited copying and communication in accordance with the Copyright Act 1968.

Signed:

Date: 29 September 2013 


\section{Abstract \\ Limitations On The Creation of Continuously Surfable Waves Generated By A Pressure Source Moving In A Circular Path}

The aim of the research presented in this work was to investigate the novel idea to produce continuous breaking waves, whereby a pressure source was rotated within an annular wave pool. The concept was that the pressure source generates non-breaking waves that propagate inward to the inner ring of the annulus, where a sloping bathymetry (beach) triggers wave breaking. In order to refine the technique, research was conducted to better understand the mechanics of waves generated by moving pressure sources in a constrained waterway, the transformation of these waves as they travel across the channel and the effect of the sloping beach on the wave quality for surfing.

The quality of the waves was defined in terms of wave height, speed and shape, with the aim to create plunging waves, known as "barrels", that are highly desired by surfers. Surfers also require a long steep crestline or "wall", to allow a full range of manoeuvres to be performed. Finally, the pool was required to create waves suitable for surfers from beginner to expert level.

The major finding was that the design parameters were generally in competition, and to determine a balance of limiting values, the parameters could not be considered in isolation. Therefore, a set of empirical relationships between the design parameters were developed to allow the pool to be designed for a combination of desired wave height and shape in a given pool radius.

In the early stages of the study, a pressure source operating in a very constrained waterway with high levels of blockage, travelling in a circular track at high depth Froude numbers was found to exhibit highly nonlinear behaviour. This behaviour appeared to invalidate the use of linear and simpler non-linear potential flow numerical modeling tools to analysis the wave pool design. Even considering simplified configurations (such as a linear track, no blockage, 
Page vi

and no beach), the predicted wave heights and shape generally did not correlate well with initial experimental results.

Thus, a predominantly experimental approach was undertaken. A method of qualitative scoring wave shape from a surfer's perspective was developed and proved valuable for focusing the research effort. At the end of the test series, high quality continuous breaking waves with the desired plunging shape were able to be generated, with these waves being desirable for surfing. However, it was determined that only a very small range of design parameter values produced the desired high, plunging waves in the very constrained waterway under consideration, and the wave quality was shown to be extremely sensitive to changes in the design parameters.

Steven Schmied

29 September 2013 


\section{Samenvatting}

\section{Beperkingen op het creëren van voortdurende surfbare golven voortgebracht door een bewegende kracht bron in een cirkelvormige baan.}

Het doel van dit onderzoek was, om uit te vinden of het mogelijk zou zijn om continu brekende golven te produceren door middel van een draaiende kracht bron in een ringvormig golfslagbad. Het begrip was gebasseerd op een kracht bron, die niet-brekende golven inwendig verspreid in de binnenste ring van het grensgebied van twee concentrische cirkels waarbij een schuinstaande zee bodem een golfbreking veroorzaakt. Om deze techniek te verfijnen, werd er onderzoek uitgevoerd om een beter inzicht te verkrijgen in het gedrag van golven als we bewegende kracht bronnen in een beperkte waterweg produceren, als ook de verandering van deze golven als ze zich voortbewegen over het kanaal en het effect van de schuine zee bodem op de golf kwaliteit die nodig is om te surfen.

De kwaliteit van de golven wordt gedefinieerd door golfhoogte, snelheid en vorm met het gewenste doel stort golven te maken die zeer gewenst zijn voor surfers. Surfers vereisen ook een lange steile golf koppen, zodat ze een volledig assortiment van kunstgrepen kunnen worden uitgevoerd. Ten slotte is het zeer belangrijk, om een golfslagbad te creeren dat geschikt is voor zowel beginnende als bedreven surfers.

De belangrijkste bevinding was, dat de ontwerp parameters niet samenwerkten en om een evenwicht te verkrijgen van de grenswaarden was het onmogelijk om deze op zich zelf konden staan. Daardoor werd er een reeks experimentele relaties ontwikkeld tussen de ontwerp parameters om een zwembad te ontwerpen in combinatie met de gewenste golfhoogte en vorm in een gegeven zwembad radius.

In het begin van de studie, een krachtpunt werkende in een zeer beperkte waterweg met hoog blokkerings niveau, bewegend in een cirkelvormige baan op grote diepte bleek onrealistische getallen en in hoge mate niet-lineair gedrag te vertonen. Dit gedrag bleek voor het gebruik 
Page viii

van lineaire en niet-lineaire potentiaal stroming numerieke analystische instrumenten ongeldig in het golfslagbad design. Zelfs het overwegen van vereenvoudigde configuraties (zoals een lineair spoor, geen blokkade en geen strand) de voorspelde golfhoogte en vorm was niet in verhouding met de eerste experimentele resultaten. Als gevolg hiervan werd een overwegend experimentele benadering uitgevoerd. Een methode van kwalitatief behaalde golf vormen vanuit het perspectief van een surfer werd hierdoor ontwikkeld en bewees waardevol genoeg om het onderzoek hierop te concentreren. Aan het einde van de test series, hoge kwaliteit voortdurend brekende golven met de gewenste vorm konden worden voortgtebracht die wenselijk zijn om te surfen. Echter werd er vastgesteld dat slechts een zeer klein bereik van ontwerp parameters de gewenste hoge, diepe golven in een beperkte waterweg in overweging kan worden genomen en de golf kwaliteit bleek uiterst gevoelig voor veranderingen in de ontwerp parameters.

Steven Schmied

29 September 2013 


\section{Acknowledgements}

This thesis would not have been possible without the kind patience over the many years shown by my supervisors Dr. Jonathan Binns, Prof. Martin Renilson, Prof. Dr. Ir. Rene Huijsmans, Associate Prof. Giles Thomas, and Dr. Gregor Macfarlane.

I take this opportunity to thank Greg Webber, whose idea of making a continuously breaking surfing wave pool sent us all on this journey of discovery. I also thank all the team at Liquid Time Pty Ltd (Webber Wave Pools) for their support and encouragement, and especially my friend Richard Pierce who designed the scale model drive system. I especially thank my family and friends for patiently listening to my stories of wave pools and surfing.

Hearty thanks to the many students at the UTAS AMC, TU Delft and the University of Sydney who have contributed and participated in the research, and that I had the privilege of supervising on behalf of Liquid Time Pty Ltd: Mohammadreza Javanmardi, Sanne van Essen, Matthieu de Schipper, Sierd de Vries, Nathan Doyle, James Erbacher, Andrew Hartley, Marcus Vanderharst and Scott Van Munster. I would like to thank the other international exchange staff and interns who assisted with the test sessions: Dr. Pepijn de Jong (TU Delft), Teo Kohonen, and Arnaud Duquesnel.

Further, I thank all the staff at UTAS AMC and TU Delft, who have been so welcoming and supportive, especially the technical support staff: Kirk Meyer, Liam Honeychurch, Mike Underhill and Peter Tomic.

I would like to express to my appreciation to the following institutions and staff for their professional support and encouragement: TU Delft Prof. Marcel Stive and Henk de Koning Gans, Adelaide University Leo Lazauskas, Engineers Australia, the Royal Institution of Naval Architects (RINA), University of California, Berkeley Prof. Ronald W. Yeung, Tallinn University of Technology Prof. Tarmo Soomere, the conveners of the International Conferences on Ocean, Offshore and Arctic Engineering (OMAE) and Pacific 2012, and the editors of the Journal of OMAE (JOMAE), the Marine Technology Society Journal and the Old Boys Association of Melbourne High School. 
Page $x$

I would like to thank the Australian Research Council (ARC) for awarding a Linkage Project grant to the joint Liquid Time Pty Ltd, UTAS AMC and TU Delft team. This grant included an APAI scholarship that we were proud to award to Mohammadreza.

Finally, to my darling wife Pauline; you have been more than supportive over the last few years. I don't know if I can ever repay you for your good humour, and constant patience in listening to my wave pool stories, and even helping out during the testing. It is with all my admiration and appreciation that I dedicate this thesis to you. 


\section{Contents}

$\begin{array}{ll}\text { Chapter } 1 \text { Introduction } & 1\end{array}$

1.1 Motivation 1

$\begin{array}{lll}1.2 & \text { Previous and related work } & 7\end{array}$

1.3 Author's contribution 9

$1.4 \quad$ Outline of thesis 12

$\begin{array}{lr}\text { Chapter } 2 \text { Surfing waves and wave pool design parameters } & 13\end{array}$

$\begin{array}{lll}2.1 & \text { Chapter introduction } & 13\end{array}$

$\begin{array}{lll}2.2 & \text { Surfing waves } & 13\end{array}$

$\begin{array}{lll}2.3 & \text { Ship waves } & 30\end{array}$

$2.4 \quad$ Wave pool design parameters 36

$\begin{array}{lll}2.5 & \text { Discussion } & 58\end{array}$

Chapter 3 Experimental approach $\quad \mathbf{5 9}$

$\begin{array}{ll}3.1 & \text { Chapter introduction }\end{array}$

$\begin{array}{lll}3.2 & \text { Aims } & 59\end{array}$

$\begin{array}{lll}3.3 & \text { Facilities } & 59\end{array}$

$\begin{array}{lll}3.4 & \text { Pressure source models } & 62\end{array}$

$\begin{array}{lll}3.5 & \text { Error analysis } & 65\end{array}$

$\begin{array}{lll}3.6 & \text { Analysed results } & 67\end{array}$

$\begin{array}{ll}\text { Chapter } 4 \text { Pressure sources and wave generation } & 71\end{array}$

$\begin{array}{lll}4.1 & \text { Chapter introduction } & 71\end{array}$

$\begin{array}{lll}4.2 & \text { Pressure source shape } & 73\end{array}$

$\begin{array}{lll}4.3 & \text { Near-field region } & 73\end{array}$

4.4 Blockage and Depth Froude Number $\quad 75$

$\begin{array}{lll}4.5 & \text { Entry angle and waterline length } & 81\end{array}$

$\begin{array}{lll}4.6 & \text { Beam } & 89\end{array}$

$\begin{array}{lll}4.7 & \text { Draught } & 91\end{array}$

$\begin{array}{lll}4.8 & \text { Pressure source symmetry } & 93\end{array}$

$\begin{array}{ll}4.9 & \text { Linear and circular tracks }\end{array}$

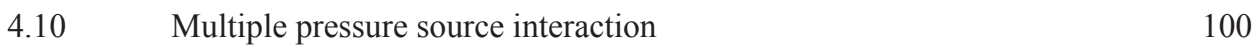


$\begin{array}{lll}4.11 & \text { Discussion } & 104\end{array}$

$\begin{array}{lr}\text { Chapter } 5 \text { Bathymetry and wave breaking } & 105\end{array}$

$\begin{array}{lll}5.1 & \text { Chapter introduction } & 105\end{array}$

$\begin{array}{lll}5.2 & 106\end{array}$

$\begin{array}{ll}5.3 & \text { Lateral distance to the start of the beach }\end{array}$

$\begin{array}{lll}5.4 & \text { Beach slope } & 117\end{array}$

5.5 Water depth at the start of the beach and the outer wall 122

$\begin{array}{lll}5.6 & 123\end{array}$

$\begin{array}{lll}5.7 & \text { Currents } & 124\end{array}$

$\begin{array}{lll}5.8 & \text { Discussion } & 133\end{array}$

$\begin{array}{ll}\text { Chapter } 6 \text { Summary, concluding remarks and further work } & 135\end{array}$

$\begin{array}{lll}6.1 & \text { Summary } & 135\end{array}$

$\begin{array}{ll}6.2 & 135\end{array}$

$\begin{array}{lll}6.3 & \text { Further work } & 137\end{array}$ 


\section{List of Figures}

Figure 1-1. An example of overcrowding at popular surf breaks causing tension and reducing surfer enjoyment (http://swellnet.com.au). Snapper Rocks is a very popular surf break in Queensland Australia that provides extremely long, high quality, plunging waves. This online comment also highlights that the minority of better surfers ride the majority of naturally occurring waves

Figure 1-2. Traditional wave pool (http://wn.com/Siam_Park_Tenerife) (top) and Flowriders (www.waveloch.com) (bottom).

Figure 1-3: Cross-section (top) and plan view (bottom) of circular path in the proposed wave pool design by Webber Wave Pools (reproduced with permission of Liquid Time Pty Ltd). The pressure sources are travelling anticlockwise, generating right-handed waves. 5

Figure 1-4: Wave pool concept (reproduced with permission of Liquid Time Pty Ltd).

Figure 1-5. Artist's impression of the wave pool for a water park complex (reproduced with permission of Liquid Time Pty Ltd). The pressure sources are travelling anticlockwise, generating left-handed waves

Figure 2-1. An artist's impression of a fantasy surfing location (source unknown)

Figure 2-2. Wavelength and height. The waves are travelling from right to left.

Figure 2-3. Wave life-cycle illustrated in the circular scale model; condition 45 model 11-12 at $F r_{h 0}=0.975$ with $B=275 \mathrm{~mm}, d^{*}=0.2$ and $h_{0}=250 \mathrm{~mm}$. The model was travelling towards the camera.

Figure 2-4. Circular track bathymetry parameters.

Figure 2-5. Spilling wave generated by condition 48 run 402 model $12-02$ with $\xi=0.4, d^{*}=$ 0.2 in $h_{0}=250 \mathrm{~mm}$ at $F r_{h 0}=0.95$ and $s=9^{\mathrm{O}}$ and $y_{\text {beach }}{ }^{*}=1.4$. The pressure source was travelling towards the camera.

Figure 2-6. Plunging waves (first and second waves) generated by condition 56 model 12-02

with $\xi=1, d^{*}=0.2$ in $h_{0}=250 \mathrm{~mm}$ at $F r_{h 0}=0.95$ and $s=17^{\circ}$ and $y_{\text {beach }}{ }^{*}=1.9$ 20 
Figure 2-7. Collapsing breakers (first and second waves) generated by condition 52 model 12-02 with $\xi=2.3, d^{*}=0.2$ in $h_{0}=250 \mathrm{~mm}$ at $F r_{h 0}=0.95, s=23^{\circ}$ and $y_{\text {beach }} *=1.9$.

Figure 2-8. Surging waves generated by condition 50 model $12-02$ with $\xi=3.3, d^{*}=0.2$ in $h_{0}$ $=250 \mathrm{~mm}$ at $F r_{h 0}=0.9, s=23^{\mathrm{O}}$ and $y_{\text {beach }}{ }^{*}=1.4$.

Figure 2-9. Surfer riding plunging "barrelling" wave of $H_{\text {beach }} \approx 2 \mathrm{~m}$.

Figure 2-10. A high quality wave shape. The elements of the wave as described by Mead et. al. [34] are shown

Figure 2-11. Surfing speed components.

Figure 2-12. "Close-out" wave with $\theta_{\text {peel }}=0^{\mathrm{O}}$

Figure 2-13. "Slow" wave with $\theta_{\text {peel }}=90^{\circ}$.

Figure 2-14. Lorne point with breaking waves (both elevation and plan view). The crest lines are indicated by the red lines, with the wave direction of travel perpendicular to the crest line (blue arrow). The black arrow indicates the surfer's and the breakpoint path, moving parallel to the shoreline at the "board speed" $\left(c_{\text {surfer }}\right)$. (Images captured from www.swellnet.com.au and GoogleMaps). 26

Figure 2-15. Surfer skill as a function of the peel angle $\left(\theta_{\text {peel }}\right)$ and wave height $\left(H_{\text {beach }}\right)$ (reproduced from Hutt et al. [38]).

Figure 2-16. Dally [57] and Hutt et. al. [38] observed mean wave speed $\left(c_{p}\right)$ for surfing....... 28

Figure 2-17. Deep water wave field. Locus cusps of the diverging and transverse waves lie on the Locus cusp line which encloses an angle $\theta_{\text {cusp }}=19^{\mathrm{O}}$ with the sailing line. The angle between the sailing line and the propagation of the divergent ("featherlet") waves $(\varnothing) \approx 55^{\circ}$. $u_{0}$ is the pressure source velocity and $c_{p}$ was wave phase speed.

Figure 2-18. As $\mathrm{Fr}_{h} \rightarrow$ 1, a soliton may form in front of the pressure source and the transverse waves reduce. $\theta_{\text {cusp }}$ increases as a function of $F r_{h}$. 
Figure 2-19. Bhattacharya's approach to the problem of curved path wave patterns, showing the empirical Ring of Influence [62] traced by the inner half of the normal linear Kelvin wave pattern. (Reproduced as presented in Doyle [43]).

Figure 2-20: Soding's numerical prediction of a curved path wave pattern [14]. Photograph taken from Stoker [61] supporting Soding's work. (Reproduced as presented in Doyle [43]).34

Figure 2-21. Trials using a fishing vessel on a river to generate surfable waves (reproduced with permission of Liquid Time Pty Ltd). 35

Figure 2-22: Pressure source parameters for a linear track.

Figure 2-23: Circular track pressure source parameters. 38

Figure 2-24: Circular track wavedozer pressure source parameters. 38

Figure 2-25: Bathymetry parameters for the linear track.

Figure 2-26. Pressure source and wave velocity components. The $x$-axis was parallel with the pressure source centre-line of travel and the $y$ axis was perpendicular (radial) with the pressure source centre-line of travel. 45

Figure 2-27. Near field and preferred surfing regions. 50

Figure 2-28. The wave steepness, $H / \lambda$, increases as a function of the water depth to a point where the wave breaks [63]. 51

Figure 2-29. Pressure source to wave relationship at $F r_{l}=0.56$

Figure 2-30. Wavelength components and featherlet angle $\left(\varnothing_{\text {beach }}\right)$ 55

Figure 3-1: Linear track tow tank channel cross-section. 60

Figure 3-2. Linear track tow tank setup. The wave probe array is shown. 61

Figure 3-3. Circular track scale model installed in the UTAS AMC Model Test Basin. 62

Figure 3-4: Linear track scale model 09-34 parabolic pressure source with 700mm length, $600 \mathrm{~mm}$ beam and, $500 \mathrm{~mm}$ height. 
Figure 3-5: Linear track scale model 09-35 wavedozer with $1500 \mathrm{~mm}$ length, $300 \mathrm{~mm}$ beam and $\alpha=14^{\mathrm{O}}$.

Figure 3-6: Circular track series 3 model 12-02 wavedozer with $1200 \mathrm{~mm}$ length, $275 \mathrm{~mm}$ beam and $\alpha=7^{\mathrm{O}}$.

Figure 3-7: Example of time trace of $u_{0}$ for condition 6 model 2 with $d^{*}=0.2$ in $h_{0}=250 \mathrm{~mm}$ at $F r_{h 0}=0.975$ with a ramp rate of $5 \%$ per second. The passing of arm number 1 recorded by the laser is shown. .66

Figure 3-8. Example of barely surfable quality waves for condition 48 model 12-02 with $d^{*}=$ 0.2 in $h_{0}=250 \mathrm{~mm}$ at $F r_{h 0}=0.95, \kappa=0.07, s=17^{\circ}$, and $y_{\text {beach }}{ }^{*}=1.4$. The pressure source was travelling towards the camera.

Figure 3-9. Example of fair quality waves for condition 57 model $12-02$ with $d^{*}=0.2$ in $h_{0}=$ $250 \mathrm{~mm}$ at $F r_{h 0}=0.95, \kappa=0.06, s=17^{\circ}$, and $y_{\text {beach }}{ }^{*}=1.9$.

Figure 3-10. Example of an average quality wave for condition 48 model 12-02 with $d^{*}=0.2$ in $h_{0}=250 \mathrm{~mm}$ at $F r_{h 0}=0.95, \kappa=0.07, s=17^{\mathrm{O}}$ and $y_{\text {beach }} *=1.4$.

Figure 3-11. Example of a good quality wave for condition 55 model $12-02$ with $d^{*}=0.2$ in $h_{0}=250 \mathrm{~mm}$ at $F r_{h 0}=0.95, \kappa=0.07, s=17^{\mathrm{O}}$ and $y_{\text {beach }}{ }^{*}=1.4$.

Figure 3-12. Example of excellent quality waves for condition 45 model 11-12 with $d^{*}=0.2$ in $h_{0}=250 \mathrm{~mm}$ at $F r_{h 0}=0.975, \kappa=0.06, s=17^{\circ}$ and $y_{\text {beach }} *=1.9$

Figure 4-1. $Y_{N F} *=2$ for condition 56 model $12-02$ with $d^{*}=0.2$ in $h_{0}=250 \mathrm{~mm}$ at $F r_{h 0}=$ 0.95 .

Figure 4-2. $Y_{N F} *$ as a function of $F r_{h 0}$ for condition 62 model $12-02$ with $d^{*}=0.2$ in $h_{0}=$ $250 \mathrm{~mm}$ and $\kappa \approx 0$.

Figure 4-3. $\kappa$ as a function of $F r_{h}$ (Lyakhovitsky [23]). 76

Figure 4-4. Sub-critical (open triangles) and critical (solid diamonds) configurations plotted against Lyakhovitsky [23] critical boundary..... 
Figure 4-5. $H^{*}$ as a function of $y^{*}$ for different values of $\kappa$ for model 12-02 with $d^{*}=0.2$ in $h_{0}=250 \mathrm{~mm}$ at $F r_{h 0}=0.95$; condition $62 \kappa \approx 0$ and condition $56 \kappa=0.07$ and $y_{\text {beach }}{ }^{*}=1.9 \ldots 78$

Figure 4-6. Determining whether the test point was "sub-critical" or "critical" for condition 56 model $12-02$ at $F r_{h 0}=0.95$ with $\kappa=0.07$ and $d^{*}=0.2$ in $h_{0}=250 \mathrm{~mm}$. 78

Figure 4-7. $H^{*}$ as a function of $F r_{h 0}$ at $y^{*}=0.9$ for model $12-02$ with $d^{*}=0.2$ in $h_{0}=250 \mathrm{~mm}$ with different $\kappa$ and $y_{\text {beach }} *$.

Figure 4-8. Time traces of $\zeta^{*}$ at $y^{*}=0.9(W P 1)$ for model 12-02 with condition $62 \kappa \approx 0$ and condition $56 s=17^{\mathrm{O}}$ and $\kappa=0.07$ at $F r_{h 0}=0.95$ with $d^{*}=0.2$ in $h_{0}=250 \mathrm{~mm}$. Model 11-12 was time shifted to align with model 12-02. The pressure source bow passed the wave probe at time $=24.5$ seconds

Figure 4-9. $H^{*}$ as a function of $F r_{h 0}$ at $y=375 \mathrm{~mm}(W P 1)$ with different values of $\alpha$ for model $11-10 B=75 \mathrm{~mm}$ (left) with $d^{*}=0.2$ in $h_{0}=250 \mathrm{~mm}$ and $\kappa \approx 0$.

Figure 4-10. $H^{*}$ as a function of $F r_{h 0}$ at $y=375 \mathrm{~mm}(W P 1)$ with different values of $\alpha$ for model $11-12 B=275 \mathrm{~mm}$ (right) with $d^{*}=0.2$ in $h_{0}=250 \mathrm{~mm}$ at $F r_{h 0}=0.99$ and $\kappa \approx 0$.

Figure 4-11. $H^{*}$ as a function of $\alpha$ at $y=375 \mathrm{~mm}(W P 1)$ for models $11-10 B=75 \mathrm{~mm}$ and model $11-12 B=275 \mathrm{~mm}$ with $d^{*}=0.2$ in $h_{0}=250 \mathrm{~mm}$ at $F r_{h 0}=0.99$ and $\kappa \approx 0$ 84

Figure 4-12. $H^{*}$ as a function of $F r_{l}$ at $y=375 \mathrm{~mm}(W P 1)$ with different values of $\alpha$ for model $11-10 B=75 \mathrm{~mm}$ with $d^{*}=0.2$ in $h_{0}=250 \mathrm{~mm}$ and $\kappa \approx 0$.

Figure 4-13. $H^{*}$ as a function of $F r_{l}$ at $y=375 \mathrm{~mm}(W P 1)$ with different values of $\alpha$ for model $11-12 B=275 \mathrm{~mm}$ with $d^{*}=0.2$ in $h_{0}=250 \mathrm{~mm}$ at $F r_{h 0}=0.99$ and $\kappa \approx 0$. 86

Figure 4-14. Time traces of $\zeta$ for model $11-12 B=275 \mathrm{~mm}$ at $y=375 \mathrm{~mm}(W P 1)$ with different values of $\alpha$ with $d^{*}=0.2$ in $h_{0}=250 \mathrm{~mm}$ at $F r_{h 0}=0.99$ and $\kappa \approx 0$. For comparison $\alpha=4^{\mathrm{O}}$ and $7^{\mathrm{O}}$ were time shifted to align with $\alpha=14^{\mathrm{O}}$

Figure 4-15. Wave quality for model $11-12 B=275 \mathrm{~mm}$ with $d^{*}=0.2$ in $h_{0}=250 \mathrm{~mm}$ and $\kappa \approx$ 0 at $F r_{h 0}=0.99$ at with $\alpha=14^{\mathrm{O}}$ rear view at water level. The arrow indicates local wave breaking. 88 
Figure 4-16. Waves generated by model $11-12 B=275 \mathrm{~mm}$ with $d=50 \mathrm{~mm}$ in $h_{0}=250 \mathrm{~mm}$ and $\kappa \approx 0$ at $F r_{h}=0.99$ with $\alpha$ of $14^{\mathrm{O}}$ (top), $7^{\mathrm{O}}$ (middle) and $4^{\mathrm{O}}$ (bottom). Note for $\alpha=4^{\mathrm{o}}$, the bow was slightly submerged.

Figure 4-17. $H^{*}$ as a function of $B^{*}$ (models $11-10,11-11$ and 11-12) at $y^{*}=0.9$ at different values of $F r_{h 0}$ with $d^{*}=0.2$ in $h_{0}=250 \mathrm{~mm}$ and $\kappa \approx 0$.

Figure 4-18. $H^{*}$ as a function of $d^{*}$ at $y=375 \mathrm{~mm}(W P 1)$ for conditions 59 and 60 model 12$02 \alpha=7^{\circ}$ in $h_{0}=250 \mathrm{~mm}$ at $F r_{h 0}=0.975$ and $y_{\text {beach }}=950 \mathrm{~mm}$.

Figure 4-19. $H^{*}$ as a function of $F r_{l}$ at $y=375 \mathrm{~mm}(W P I)$ for conditions 59 and 60 model 1202 in $h_{0}=250 \mathrm{~mm}$ at $F r_{h 0}=0.975$ and $y_{\text {beach }}=950 \mathrm{~mm}$.

Figure 4-20. "Rooster tail" generated by condition 46 model 09-35 dry transom with $\alpha=14^{\mathrm{O}}$ with $d^{*}=0.07$ in $h_{0}=1500 \mathrm{~mm}$ at $F r_{h 0}=0.95\left(u_{0}=3.6 \mathrm{~m} / \mathrm{s}\right)$.

Figure 4-21. $H^{*}$ as a function of $F r_{h 0}$ at $y=375 \mathrm{~mm}(W P 1)$ for model 10-25 asymmetrical and model 10-27 symmetrical with $d^{*}=0.2$ in $h_{0}=250 \mathrm{~mm}$ and $\kappa \approx 0$.

Figure 4-22. $H^{*}$ as a function of $F r_{l}$ at $y=375 \mathrm{~mm}(W P 1)$ for model 10-25 asymmetrical and model 10-27 symmetrical with $d^{*}=0.2$ in $h_{0}=250 \mathrm{~mm}$ and $\kappa \approx 0$. 96

Figure 4-23. Time traces of $\zeta$ at $F r_{h 0}=0.95$ at $y=375 \mathrm{~mm}(W P 1)$ for model $10-25$ asymmetrical and model 10-27 symmetrical with $d^{*}=0.2$ in $h_{0}=250 \mathrm{~mm}$ and $\kappa \approx 0$. For comparison, model 10-27 was time shifted to align with model 10-25.

Figure 4-24. $H^{*}$ as a function of $F r_{h 0}$ at $y^{*}=5.2$ and $\kappa=0.01$ for linear track model 09-35 $R_{0} * \rightarrow \infty$ with $d^{*}=0.2$ in $h_{0}=500 \mathrm{~mm}$ and compared to circular track model $11-10 R_{0} *=25$ with $d^{*}=0.2$ in $h_{0}=250 \mathrm{~mm}$ and model $11-13 R_{0} *=12$ with $d^{*}=0.2$ in $h_{0}=500 \mathrm{~mm} \ldots \ldots . .98$

Figure 4-25. Time trace of the surface elevation $\zeta^{*}$ at $y^{*}=5.2$ and $F r_{h 0}=0.9$ with $\kappa=0.01$ and $\alpha=14^{\circ}$ for linear track model 09-35 $R_{0} * \rightarrow \infty$ with $d^{*}=0.2$ in $h_{0}=500 \mathrm{~mm}$ and compared to circular track model 11-10 $R_{0} *=25$ with $d^{*}=0.2$ in $h_{0}=250 \mathrm{~mm}$ and model $11-13 R_{0} *=$ 12 with $d^{*}=0.2$ in $h_{0}=500 \mathrm{~mm}$. Model 09-35 and model 11-13 were time shifted and Froude scaled to align with model 11-10. 99 
Figure 4-26. Minimum and maximum surface elevation $\zeta^{*}$ and wave height $H^{*}$ at $y^{*}=5.2$ and $F r_{h 0}=0.9$ with $\kappa=0.01$ for linear track model 09-35 $R_{0} * \rightarrow \infty$ with $d^{*}=0.2$ in $h_{0}=$ $500 \mathrm{~mm}$ compared to circular track model $11-10 R_{0} *=25$ with $d^{*}=0.2$ in $h_{0}=250 \mathrm{~mm}$ and model $11-13 R_{0}^{*}=12$ with $d^{*}=0.2$ in $h_{0}=500 \mathrm{~mm}$. 100

Figure 4-27. Time trace of $\zeta_{w p l}$ at $y^{*}=0.9(W P 1)$ for condition 56 model 12-02 with $d^{*}=0.2$ in $h_{0}=250 \mathrm{~mm}$ and $\kappa=0.06$ at $F r_{h 0}=0.95$.

Figure 4-28. Time traces of $\zeta_{w p l}$ at $y^{*}=0.9(W P l)$ for $d^{*}=0.2$ in $h_{0}=250 \mathrm{~mm}$ and $\kappa \approx 0$ at $F r_{h 0}=0.95$ for condition 6 model 10-25 (left), condition 14 models 10-25 and 10-27 (centre), and condition 15 models 10-24, 10-25, 10-26 and 10-27. 103

Figure 5-1. $H^{*}$ as a function of $F r_{h 0}$ at $y_{\text {beach }}{ }^{*}=1.9$ with $\kappa=0.07$ for condition 56 model 12$02 R_{0} *=12$ with $d^{*}=0.2$ in $h_{0}=250 \mathrm{~mm}$ and condition 63 model 12-03 $R_{0} *=6$ with $d^{*}=$ 0.2 in $h_{0}=500 \mathrm{~mm}$. 107

Figure 5-2. $H^{*}$ as a function of $y^{*}$ for $F r_{h 0}=0.95, \kappa=0.07$ and $y_{\text {beach }} *=1.9$ for condition 56 model 12-02 $R_{0} *=12$ with $d^{*}=0.2$ in $h_{0}=250 \mathrm{~mm}$ and condition 63 model $12-03 R_{0} *=6$ with $d^{*}=0.2$ in $h_{0}=500 \mathrm{~mm}$. 108

Figure 5-3. Time trace of the surface elevation $\zeta_{\text {beach }}{ }^{*}$ at $y_{\text {beach }}{ }^{*}=1.9$ for $F r_{h 0}=0.95$ and $\kappa=$ 0.07 for condition 56 model $12-02 R_{0} *=12$ with $d^{*}=0.2$ in $h_{0}=250 \mathrm{~mm}$ and condition 63 model 12-03 $R_{0} *=6$ with $d^{*}=0.2$ in $h_{0}=500 \mathrm{~mm}$. Model 12-02 was time shifted and Froude scaled to align with Model 12-03. 109

Figure 5-4. Minimum and maximum surface elevation $\zeta_{\text {beach }} *$ and wave height $H_{\text {beach }}{ }^{*}$ at $y_{\text {beach }} *=1.9$ for $F r_{h 0}=0.95$ and $\kappa=0.07$ for condition 56 model $12-02 R_{0} *=12$ with $d^{*}=$ 0.2 in $h_{0}=250 \mathrm{~mm}$ and condition 63 model $12-03 R_{0} *=6$ with $d^{*}=0.2$ in $h_{0}=500 \mathrm{~mm} \ldots 110$

Figure 5-5. First wave score as a function of $F r_{h 0}$ for condition 56 model 12-02 $R_{0} *=6$ compared to condition 56 model 12-03 $R_{0} *=12$.

Figure 5-6. Second wave score as a function of $F r_{h 0}$ for condition 56 model 12-02 $R_{0} *=6$ compared to condition 56 model 12-03 $R_{0} *=12$. 
Figure 5-7. Plunging waves generated by condition 56 model $12-02 R_{0} *=12$ and $\kappa=0.07$ with $d^{*}=0.2$ in $h_{0}=250 \mathrm{~mm}$ water depth, $y_{\text {beach }} *=1.9$ at $F r_{h 0}=0.95$

Figure 5-8. Spilling waves generated by condition 63 model $12-03 R_{0} *=6$ and $\kappa=0.07$ with $d^{*}=0.2$ in $h_{0}=500 \mathrm{~mm}$ water depth, $y_{\text {beach }} *=1.9$ at $F r_{h 0}=0.95$.

Figure 5-9. $H^{*}$ as a function of $y^{*}$ for different values of $y_{\text {beach }} *$ for model $12-02$ with $d^{*}=$ 0.2 in $h_{0}=250 \mathrm{~mm}$ at $F r_{h 0}=0.95$. $H_{\text {beach }} *$ for each condition is circled.

Figure 5-10. First wave scores as a function of $F r_{h 0}$ for different values of $y_{\text {beach }} *$ for model $12-02$ with $d^{*}=0.2$ in $h_{0}=250 \mathrm{~mm}$.

Figure 5-11. Second wave scores as a function of $F r_{h 0}$ for different values of $y_{\text {beach }} *$ for model $12-02$ with $d^{*}=0.2$ in $h_{0}=250 \mathrm{~mm}$.

Figure 5-12. $H^{*}$ as a function of $y^{*}$ at for different values of $s$ for model 12-02 with $d^{*}=0.2$ in $h_{0}=250 \mathrm{~mm}$. 118

Figure 5-13. First wave scores as a function of $F r_{h 0}$ for different values of $s$ for model 12-02 with $d^{*}=0.2$ and $y_{\text {beach }} *=2.4$.

Figure 5-14. Second wave scores as a function of $F r_{h 0}$ for different values of $s$ for model 12 02 with $d^{*}=0.2$ and $y_{\text {beach }} *=2.4$. 120

Figure 5-15. Time traces of $\zeta^{*}$ at $y^{*}=0.9$ showing the solitons and / or surge generated by model 12-02with $d^{*}=0.2$ in $h_{0}=250 \mathrm{~mm}$ at $F r_{h 0}=0.95$ for condition $49 s=9^{\mathrm{O}}$, condition 56 $s=17^{\circ}$, and condition $52 s=23^{\circ}$. Conditions 52 and 56 were time shifted to align with Condition 49.

Figure 5-16. Rapid wave dissipation post breaking for condition 49 model 12-02 with $d^{*}=$ 0.2 in $h_{0}=250 \mathrm{~mm}$ and $y_{\text {beach }}{ }^{*}=0.15$ at $F r_{h 0}=0.95$.

Figure 5-17. $H^{*}$ as a function of $y^{*}$ for condition 49 model $12-02$ with $d^{*}=0.2$ in $h_{0}=$ $250 \mathrm{~mm}$ and $y_{\text {beach }} *=1.9$ at $F r_{h 0}=0.95$.

Figure 5-18. $u_{c}{ }^{*}$ as a function of $F r_{h 0}$ measured by the ADV at $y^{*}=0.9$ and $Z^{*}=0.28$ for conditions 48 to 56 and 59 model 12-02 with $d^{*}=0.2$ in $h_{0}=250 \mathrm{~mm}$ 
Figure 5-19. $u_{c} *$ as a function of $y^{*}$ measured by the $\mathrm{ADV}$ for different $Z^{*}$ for condition 59 model 12-02 with $d^{*}=0.2$ and $y_{\text {beach }} *=2.4$ in $h_{0}=250 \mathrm{~mm}$ at $F r_{h 0}=0.975$ and $\kappa=0.05 \ldots 128$ Figure 5-20. $u_{c}{ }^{*}$ on the surface observed with the surface floats as a function of $y^{*}$ for condition 6 model 10-25 at $F r_{h 0}=0.975, y_{\text {beach }} *=1.4$ and $\kappa=0.07$. 129

Figure 5-21. $u_{c}{ }^{*}$ as a function of $\kappa$ measured by the $\mathrm{ADV}$ at $y^{*}=0.9$ and $Z^{*}=0.28$ for conditions 48 to 60 model $12-02$ with $d^{*}=0.2$ in $h_{0}=250 \mathrm{~mm}$ at $F r_{h 0}=0.95$. 131

Figure 5-22. $u_{c}{ }^{*}$ as a function of $d^{*}$ measured by the ADV at $y^{*}=0.9$ and $Z^{*}=0.28$ for condition 60 model 12-02 with different values of $d^{*}$ in $h_{0}=250 \mathrm{~mm}$ at $F r_{h 0}=0.975$. 132 


\section{List of Tables}

Table 2-1. Breaker type and $\xi$ (from Battjes [55]).

Table 2-2. River testing boat configuration.

Table 3-1. Pressure sources.

Table 3-2. Time for $\mathrm{u} 0$ to reach a steady state for different ramp rates. 66

Table 3-3. Wave scores (Harey [39])

Table 4-1. Time between consecutive pressure sources for $\mathrm{h} 0=250 \mathrm{~mm}$, and Frh $0=0.95 . .104$

Table 5-1: Current measured by the ADV for Frh0 $=0.975$ with $1(\kappa=0.05), 2(\kappa=0.06)$ and $4(\kappa=0.07)$ pressure sources.

Table 5-2: uc* as a function of $\mathrm{y}^{*}$ for condition 6 model 10-25 at Frh $=0.975$, ybeach* $=1.4$ and $\kappa=0.07$. 129 


\section{Nomenclature}

\section{Greek symbols}

$\alpha \quad$ Pressure source entry angle [deg]

$\theta_{\text {peel }} \quad$ Peel angle [deg ]

$\theta_{\text {cusp }} \quad$ Inference cusps line angle [deg ]

$\zeta \quad$ Surface elevation $[\mathrm{m}]$

$\zeta^{*} \quad$ Non-dimensionalised surface elevation $\quad \frac{\zeta}{\sqrt[3]{\nabla}}$

$\zeta_{\text {beach }} \quad$ Surface elevation measured at the start of the beach $\left(y_{\text {beach }}\right) \quad[\mathrm{m}]$

$\zeta_{\text {beach }}{ }^{*} \quad$ Non-dimensionalised surface elevation $\quad \frac{\zeta_{\text {beach }}}{\sqrt[3]{\nabla}}$

$\zeta_{\max } \quad$ Maximum surface elevation of the wave crest $\quad[\mathrm{m}]$

$\zeta_{\min } \quad$ Minimum surface elevation of the wave trough $\quad[\mathrm{m}]$

$\zeta_{\max } * \quad$ Non-dimensionalised maximum surface elevation $\quad \frac{\zeta_{\max }}{\sqrt[3]{\nabla}}$

$\zeta_{\min } * \quad$ Non-dimensionalised minimum surface elevation $\quad \frac{\zeta_{\min }}{\sqrt[3]{\nabla}}$

$\gamma \quad$ Breaking water depth constant $\quad \frac{\mathrm{h}_{\text {beach }}}{\mathrm{H}_{\text {beach }}}$

$\kappa \quad$ Blockage $\quad \frac{A_{\mathrm{S}}}{\mathrm{A}_{\mathrm{c}}}$

$\nabla \quad$ Volume displacement $\left[\mathrm{m}^{3}\right]$

$\xi \quad$ Inshore Iribarren Number

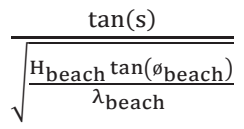

$\lambda \quad$ Wavelength $\quad[\mathrm{m}]$

$\lambda 0 \quad$ Wavelength at the pool outer wall (R0) [m]

$\lambda_{\text {beach }} \quad$ Wavelength parallel to beach slope at the start of the beach [m]

$\lambda_{s} \quad$ Wavelength perpendicular to the beach slope $\quad[\mathrm{m}]$

$\lambda_{y} \quad$ Wavelength at the lateral distance from pressure source centreline of travel $(y)[\mathrm{m}]$ 
$\varnothing \quad$ Interference cusp angle

$\varpi_{0} \quad$ Interference cusp angle at the pool outer wall

$\varnothing_{\text {beach }} \quad$ Interference cusp angle at the start of the beach

\section{Latin symbols}

$A_{c} \quad$ Channel cross-section area

$A_{s} \quad$ Pressure source cross-section area

$\left[\mathrm{m}^{2}\right]$

B $\quad$ Pressure source beam

$[\mathrm{m}]$

$B^{*} \quad$ Non-dimensionalised pressure source beam

$c \quad$ Wave speed (celerity)

$c_{g} \quad$ Wave group speed

$c_{p} \quad$ Wave phase speed

$c_{\text {surfer }} \quad$ Surfer's speed

$d$

Pressure source draught

[m]

$d^{*} \quad$ Normalised pressure source draught

$\frac{d}{h_{0}}$

$F r_{l} \quad$ Length Froude number

$\frac{u}{\sqrt{g \cdot L W L}}$

$\mathrm{Fr}_{h} \quad$ Depth Froude number

$\frac{u}{\sqrt{g \cdot h}}$

$\mathrm{Fr}_{h 0} \quad$ Depth Froude number at the pool outer wall

$\frac{u_{0}}{\sqrt{g \cdot h_{0}}}$

$g \quad$ Acceleration due to gravity

$\left[\mathrm{m} / \mathrm{s}^{2}\right]$

H Wave height

$[\mathrm{m}]$

$H^{*} \quad$ Non-dimensionalised wave height

$\frac{H}{\sqrt[3]{\nabla}}$

$H_{0} \quad$ Wave height at the pool outer wall [m]

$H_{\text {beach }} \quad$ Breaking wave height at the start of the beach 
$H_{\text {beach }}{ }^{*} \quad$ Non-dimensionalised breaking wave height at the start of the beach $\frac{H_{\text {beach }}}{\sqrt[3]{\nabla}}$

$H_{\text {break }} \quad$ Wave height at the breakpoint [m]

$H_{y} \quad$ Wave height at the lateral distance from pressure source centreline of travel $\quad[\mathrm{m}]$

$h \quad$ Water depth $\quad[\mathrm{m}]$

$h_{0} \quad$ Water depth at the pool outer wall [m]

$h_{\text {beach }} \quad$ Water depth at the start of the beach [m]

$h_{\text {beach }}{ }^{*} \quad$ Normalised water depth at the start of the beach $\frac{h_{\text {beach }}}{h_{0}}$

$h_{\text {break }} \quad$ Water depth at the breakpoint $\quad[\mathrm{m}]$

$h_{y} \quad$ Water depth at lateral distance $(y) \quad[\mathrm{m}]$

$\begin{array}{lll}k & \text { Wave number } & {[\mathrm{rad} / \mathrm{m}]}\end{array}$

LWL Pressure source waterline length [m]

n Coefficient of lateral wave decay [ - ]

$R \quad$ Radius $\quad$ [m]

$R_{0} \quad$ Radius of the pool outer wall [m]

$R_{\text {beach }} \quad$ Radius of the start of the beach [m]

$R_{\text {beach }}{ }^{*} \quad$ Normalised radius at the start of the beach $\quad \frac{R_{\text {beach }}}{L W L}$

$R_{0} * \quad$ Non-dimensionalised radius of the pool outer wall $\frac{R_{0}}{L W L}$

$\begin{array}{lll}R_{y} & \text { Radius of lateral distance }(y) & {[\mathrm{m}]}\end{array}$

$s \quad$ Beach slope [deg]

$\begin{array}{lll}T & \text { Wave period }\end{array}$

$u, v, w \quad$ velocity vector components $\quad[\mathrm{m} / \mathrm{s}]$

$u_{0} \quad$ Pressure source velocity at the pool outer wall $\quad[\mathrm{m} / \mathrm{s}]$

$u_{0}{ }^{\prime} \quad$ Effective pressure source velocity at the pool outer wall $\quad[\mathrm{m} / \mathrm{s}]$

ubeach Wave velocity at the start of the beach [m/s]

$\begin{array}{lll}u_{c} & \text { Current velocity } & {[\mathrm{m} / \mathrm{s}]}\end{array}$ 
$u_{c}^{*} \quad$ Normalised current velocity $\quad \frac{u_{c}}{u_{0}}$

$u_{y} \quad$ Wave velocity at the lateral distance from pressure source centreline of travel $[\mathrm{m} / \mathrm{s}]$

$v_{\text {peel }} \quad$ Wave peel velocity $[\mathrm{m} / \mathrm{s}]$

$x, y, z \quad$ Wave field coordinates [m]

Y Channel width [m]

$Y_{\text {beach }}$ Beach width [m]

$Y_{\text {beach }} * \quad$ Normalised beach width $\quad \frac{Y_{\text {beach }}}{L W L}$

$\begin{array}{lll}Y_{N F} \quad \text { Near field effect width } & {[\mathrm{m}]}\end{array}$

$Y_{N F}{ }^{*} \quad$ Non-dimensionalised near field effect width $\quad \frac{Y_{N F}}{B}$

$\begin{array}{lll}Y_{\text {wall }} & \text { Surfable wall width }\end{array}$

$Y_{\text {wall }} * \quad$ Non-dimensionalised surfable wall width $\quad \frac{Y_{\text {wall }}}{H_{\text {beach }}}$

$y \quad$ Lateral distance from pressure source centreline of travel $\quad[\mathrm{m}]$

$y^{*} \quad$ Normalised lateral distance from the pool outer wall $\quad \frac{y}{L W L}$

$y_{\text {beach }}$ Lateral distance to the start of the beach from the pool outer wall [m]

$y_{\text {beach }} * \quad$ Normalised lateral distance to the start of the beach from the pool outer wall $\frac{y_{\text {beach }}}{L W L}$

$\begin{array}{lll}Z & \text { Distance above bottom of channel }\end{array}$

Z* Normalised distance above bottom of channel $\quad \frac{Z}{h_{0}}$

Z Beach height [m] 


\section{Subscripts}

$0 \quad$ Pool outer wall

beach Start of the beach location

break Wave breaking location

NF $\quad$ Near field

$t \quad$ Tangential to the pressure source centreline of travel

wall Surfable crest width (wall)

$y \quad$ Lateral distance from the pressure source centreline of travel

\section{Subscripts}

Normalised / non-dimensionalised

Effective 
Page xxviii

\section{Abbreviations}

AMC Australian Maritime College

ARC Australian Research Council

Eq. Equation

TU Delft Delft University of Technology

UTAS University of Tasmania

WP Wave probe 


\section{Chapter 1 Introduction}

\subsection{Motivation}

Surfing is fun. However, it is also extremely difficult to learn and master. This difficulty is not helped by ever changing nature and generally short duration of the breaking waves; with the waves changing both day to day with the weather, tide, and as the wave breaks on the shore. It has been observed the average ride time per wave is less than 7 seconds, resulting in surfers generally limited to riding waves for less than $8 \%$ of their time spent in the water [1]. Therefore, the dream of every surfer is for consistent, long lasting, high quality waves. This search concentrates surfers on to those areas of coastline that are exposed to regular surf, and with a bathymetry suitable to cause the wave to break in a consistent manner and provide a long ride.

Many surfers do not have the luxury of living near surf breaks, and must travel long distances in order to surf. As coastal populations increase, and surfing becomes more popular, existing surf breaks become overcrowded, reducing the number of waves a surfer can catch, and shortening their overall riding time even further; Figure 1-1. Surfers have responded by traveling to more distant and remote locations to chase uncrowded and better waves [2], even though this increases the cost of surfing. Another solution has been to create more surf breaks by building artificial reefs in the ocean; however these still rely on the natural wave conditions. In this uncontrolled environment, the waves are affected by the constantly changing and potential adverse effects of the weather, including wave direction and period, wind (direction and strength), tide, and currents. A third solution is to generate waves in a controlled environment: the wave pool. 


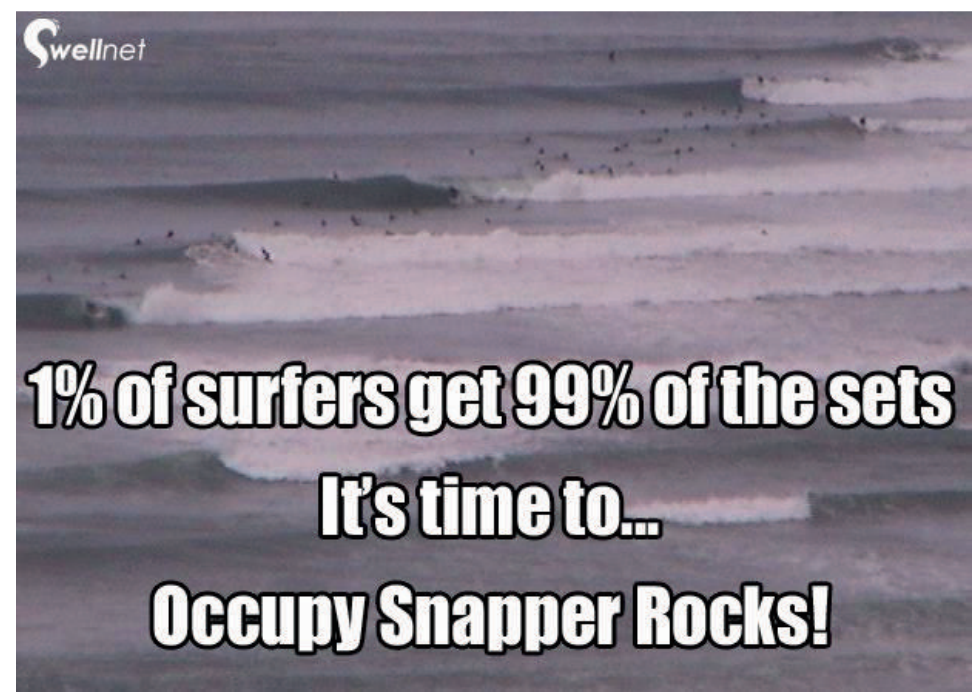

Figure 1-1. An example of overcrowding at popular surf breaks causing tension and reducing surfer enjoyment (http://swellnet.com.au). Snapper Rocks is a very popular surf break in Queensland Australia that provides extremely long, high quality, plunging waves. This online comment also highlights that the minority of better surfers ride the majority of naturally occurring waves.

\subsubsection{Current status of wave pools}

Wave pools are not a new concept. In 1934, the Wembley Swimming Pool in London was the first to thrill its visitors with small artificial waves. In 1966, the first indoor surfers rode waisthigh waves in the Summerland wave pool in Tokyo, Japan [3]. Since then, more surf pools have been built around the world, receiving mixed reviews from surfers. The original linear wave pools, where the waves are generated at one end and travel to a beach at the other end, try to mimic naturally occurring waves with piston-driven paddles or similar mechanical devices. Such man-made waves are not very appealing to surfers as the rides are short, and the waves generally weak and poorly shaped; Figure 1-2.

Some manufacturers bend the pool around a curve to concentrate the swell, or shape the pool floor to improve the wave height [4]. Another method used to simulate surfing waves is to shoot a thin sheet of water over a wave shaped surface. However, this method does not provide an authentic surfing experience (a moving wave breaking along a shoreline) and, like the linear pools, generally only allows one rider at a time [5]. A third concept aims to draw an 
object though shallow water along a linear track creating waves in front of the object [6]. As the existing techniques generate the waves by moving large volumes of water, they are power intensive. Instead, the novel method discussed in this thesis more efficiently generates the waves by the pressure source imparting wave energy into water with minimal water movement.

Key deficiencies with these approaches involve both the lack of an authentic, scalable surfing wave motion of a moving wave breaking on a shoreline, the large power requirements to generate the waves and a limitation of a single rider being able to surf at one time, limiting the financial viability of the pool.
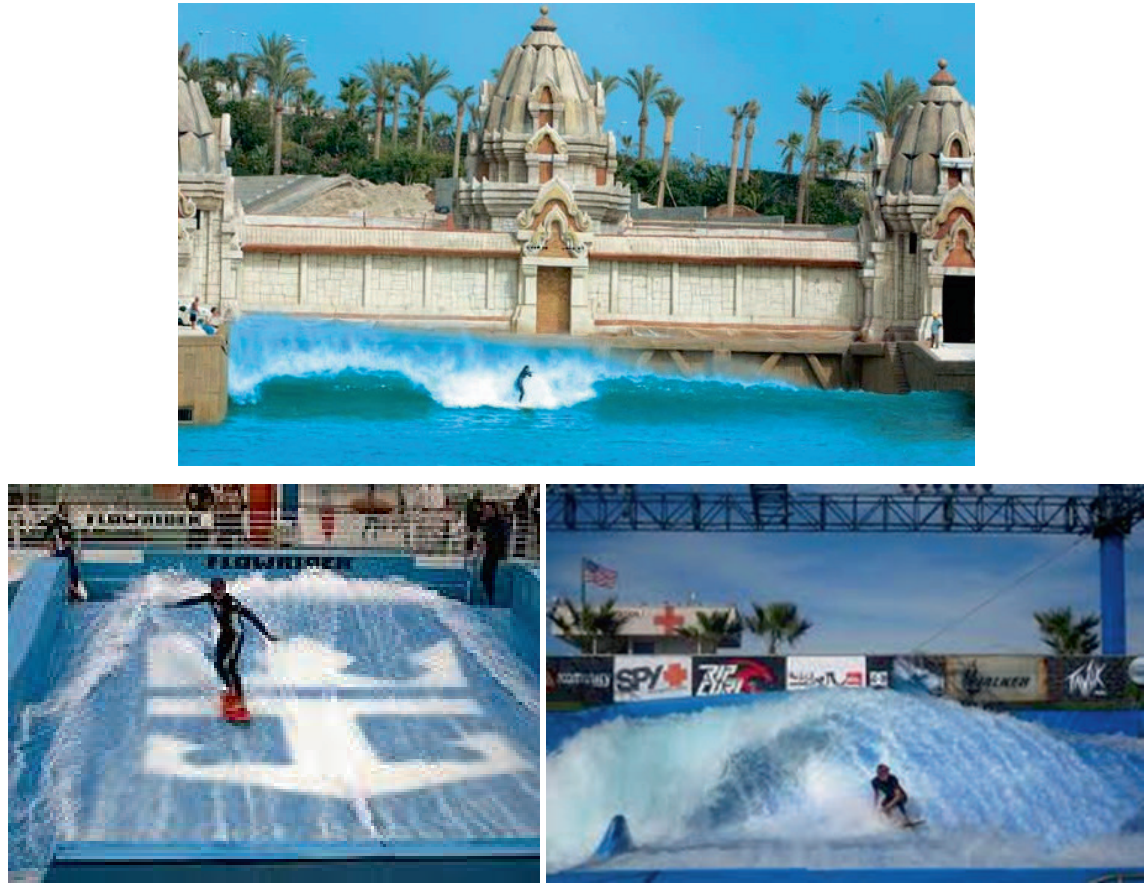

Figure 1-2. Traditional wave pool (http://wn.com/Siam_Park_Tenerife) (top) and Flowriders (www.waveloch.com) (bottom). 


\subsubsection{Webber Wave Pool concept}

In order to find the solution to these problems with current wave pool technology, a novel idea to produce continuous surfable breaking waves has been patented by Liquid Time Pty Ltd [7], the Webber Wave Pool, whereby one or more pressure sources are rotated within an annular wave pool; Figure 1-3. The pressure source is any object that disrupts the water surface, such as a ship-like hull or submerged body. Ideally, the pressure source should generate high, smooth waves.

The inner ring of the annulus has a sloping bathymetry (i.e. a beach) to induce the waves to break, with the break point following the circular path around the central island at a given water depth $\left(h_{\text {break }}\right)$ proportional to the wave height $\left(H_{\text {break }}\right)$. Should the pressure sources be symmetrical about their centre, the waves may be generated in either the clockwise or anticlockwise directions; that is, rotating the pressure sources clockwise will form left-handed waves, whilst anti-clockwise will produce right-handed waves. An artist's impression of the concept and a commercial application are shown in

Figure 1-4 and Figure 1-5 respectively, with the pressure sources travelling anticlockwise, generating left-handed waves.

It is intended that by providing a safe learning environment with repeatable wave conditions and long (unlimited) ride lengths, the overall surfing ability of the participants can quickly improve. 


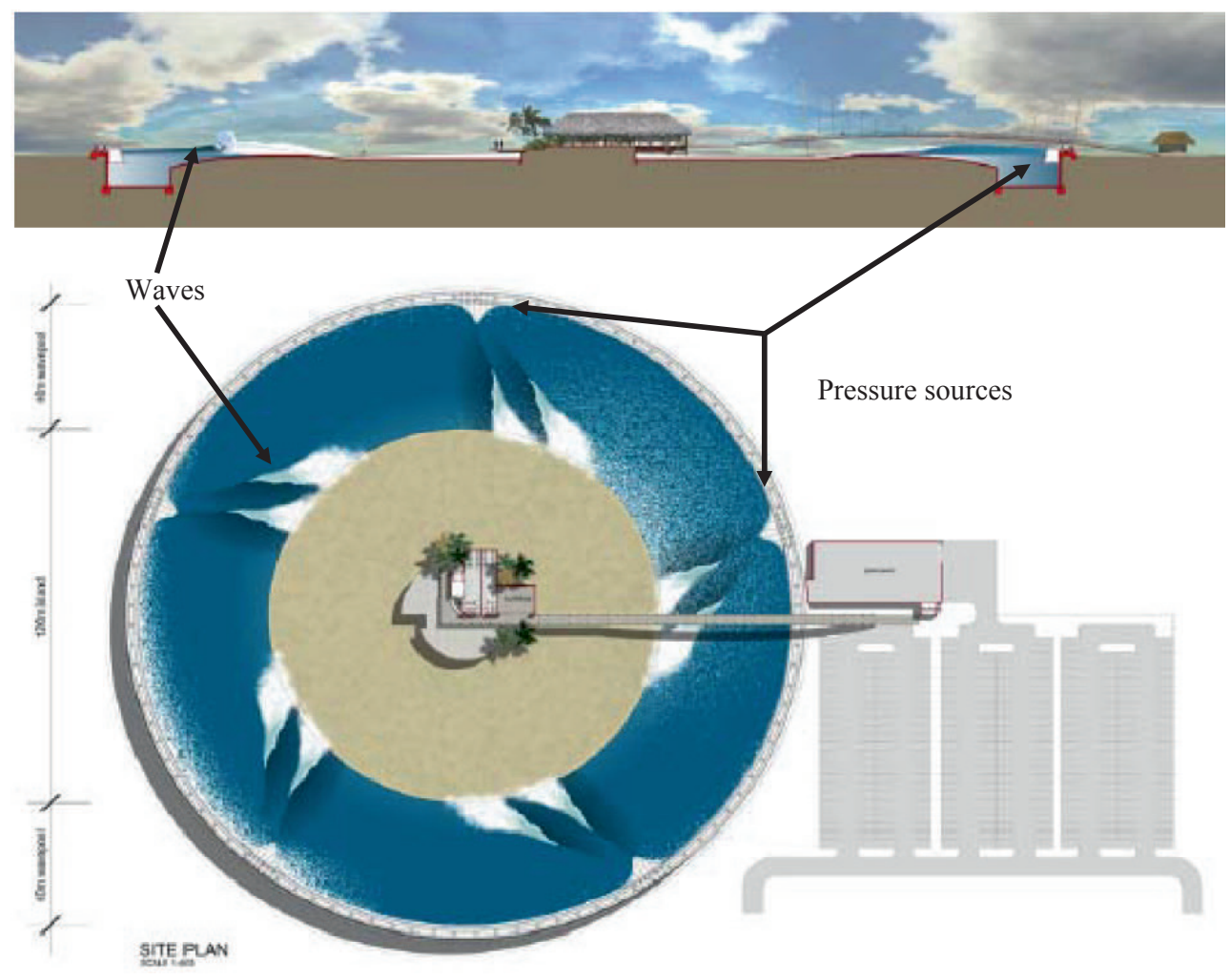

Figure 1-3: Cross-section (top) and plan view (bottom) of circular path in the proposed wave pool design by Webber Wave Pools (reproduced with permission of Liquid Time Pty Ltd).

The pressure sources are travelling anticlockwise, generating right-handed waves. 

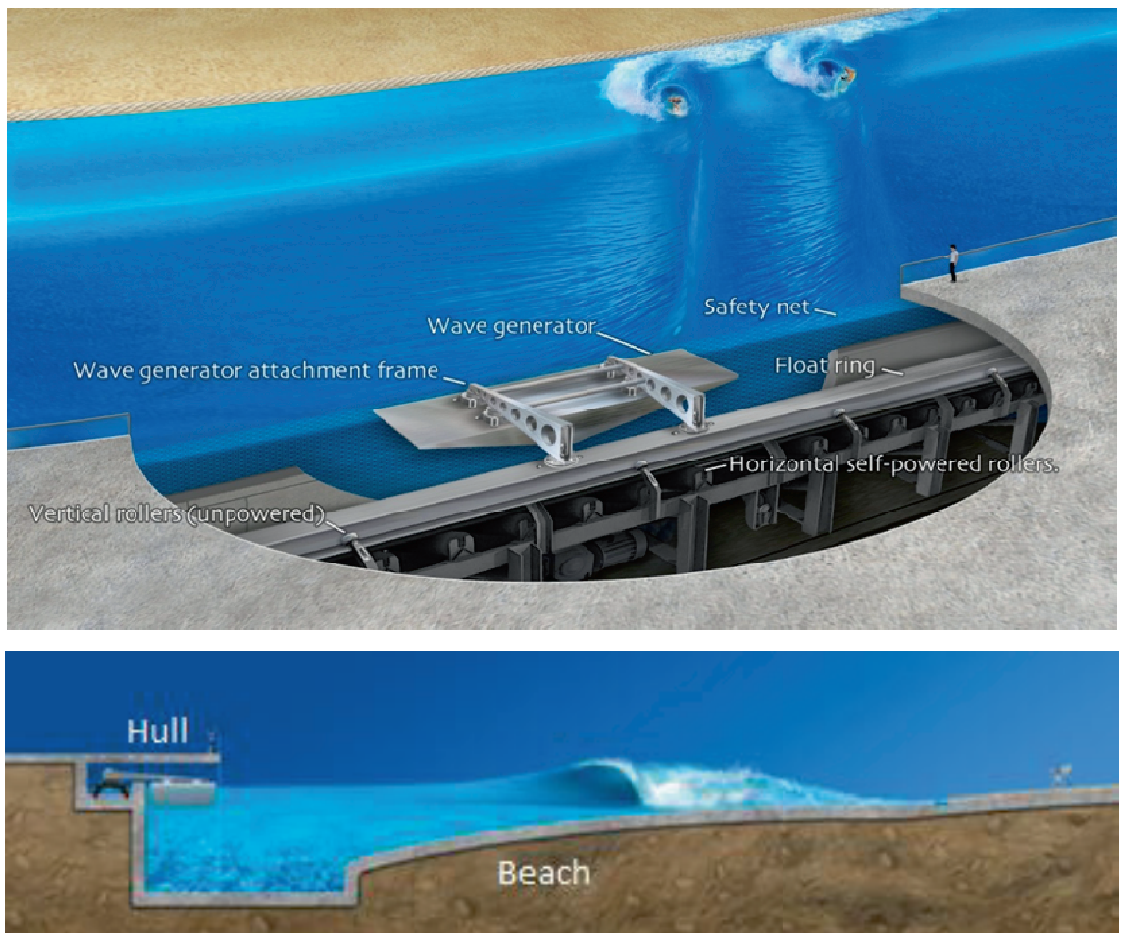

Figure 1-4: Wave pool concept (reproduced with permission of Liquid Time Pty Ltd).

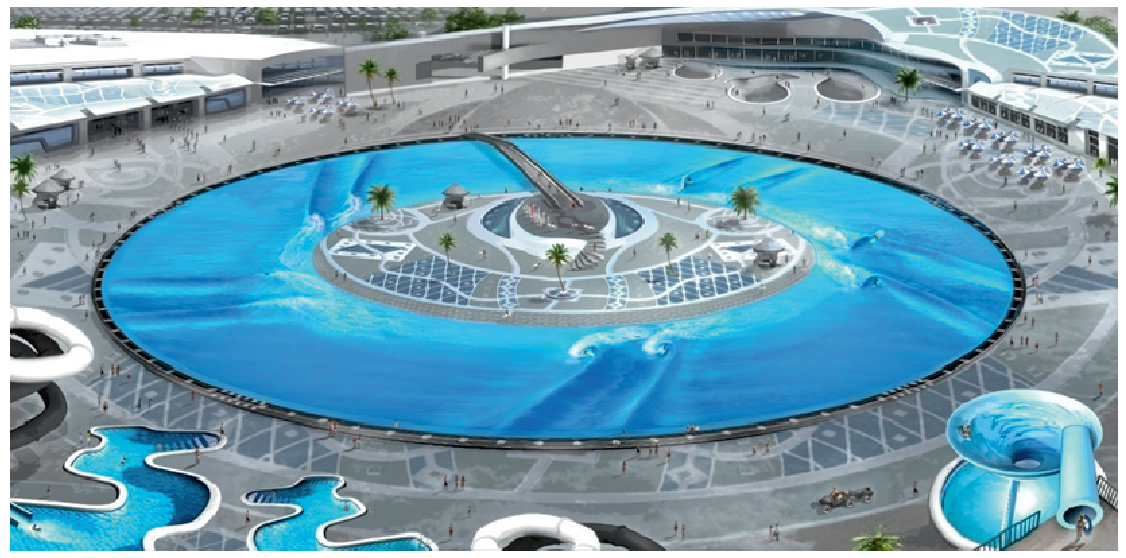

Figure 1-5. Artist's impression of the wave pool for a water park complex (reproduced with permission of Liquid Time Pty Ltd). The pressure sources are travelling anticlockwise, generating left-handed waves. 


\subsection{Previous and related work}

The understanding and control of ship waves has been considered a key aspect of ship operations, and the focus being on controlling and minimising wave generation. The first investigations on ship wave generation date back to the work of Lord Kelvin [8], Froude [9], Michell [10] and Lamb [11]. Froude's observations led him to describe the resistance of a shape as being a function of the waves caused by varying pressures around the hull as it moves through the water. Thus a hull may be considered a pressure source. Froude defined the relationship between ship velocity, water depth and wave generation; the depth Froude Number $\left(F r_{h}\right)$ and ship velocity, waterline length and wave generation; the length Froude Number $\left(F r_{l}\right)$. Motion of the pressure source in a circular path was addressed by Wehausen and Laitone [12], and further by Bhattacharya [13], Soding [14], Havelock [15] and others.

The operation of ships in constrained waterways has been of particular concern for both ship wave resistance [16] [17], nuisance to other users of the waterway [18] and destructive waveshore interaction [19]. The blockage ratio $(\kappa)$, defined as the ratio of the pressure source crosssectional area $\left(A_{s}\right)$ to the channel cross-sectional area $\left(A_{c}\right)$, was found to have a significant effect on wave generation, including the generation of solitary waves or "solitons". Soliton formation was described by Russell [20], who observed a solitary wave in the Union Canal in Scotland, and characterised by the wave crest being perpendicular to the pressure source direction of travel and with the wave speed proportional to both the water depth and wave height. He reproduced the phenomenon in a wave tank and named it the "Wave of Translation". The conditions for soliton formation has been further defined by many other authors, including Lap [21] and Kryukov [22]. Blockage $(\kappa)$ was thoroughly investigated by experiments performed by Lap [21] in a towing tank, where he concluded that it had a significant impact on the range of $F r_{h}$ in which solitons were generated. With a small $\kappa$, solitons were only produced with $F r_{h}$ very close to unity, whereas solitons were observed at lower $\mathrm{Fr}_{h}$ for large $\kappa$. Further work has been conducted to define this "critical zone", including work by Lyakhovitsky [23] and Robbins et. al. [24].

Most studies into ship wave generation have focused on minimising the wave generation [14] [25] [26], thus reducing the ship wave making resistance and impact of the waves on 
shorelines in constrained waterways [17] [24] [27] [28] [29]. A more efficient pressure source shape, being a wavedozer, was investigated by Standing [30], and further developed by Driscoll and Renilson [31] and Renilson [32]. The wavedozer is also a very simple structure to form, essentially simply being an inclined flat plate.

Research has been conducted to understand breaking waves with the aim of designing and installing artificial reefs to improve the surf in the ocean [33] [34]. The earliest work on defining wave breaking relationships was conducted by Miche [35] and Iribarren et al. [36], with Iribarren et al. developing the Inshore Iribarren Number ( $)$, to quantify the wave breaking shape in terms of "wave breaking intensity". Further work on wave breaking has been conducted by Elkeberry and Battjes [37], and by Hutt et al. [38] defining the ranges of wave shape and height for different level of surfer skill. Hartley [39] defined the wave quality in terms of a wave score, based on $\xi$, wave width (termed the wave "wall"), and wave steepness. These parameters provided a starting point for the design of the wave pool.

Subsequently, Vries [40] and Schipper [41] conducted initial potential flow predictions using the DELKELV linear potential flow model, with the model validated using results from linear scale model testing of two parabolic pressure sources with different beams. A further numerical approach used to consider the effect of wavedozer beam and entry angle on the generated wave height was conducted by Essen [42] using the RAPID non-linear potential flow model.

Finally, a numerical approach to model the circular pool without a beach was undertaken by Doyle [43] using ANSYS-CFX / FLUENT. Doyle found that the ratio of the wave heights at a set distance from the outer wall for any two turning radii is proportional to the square root of the ratio of the radial location of these points. Doyle also found that outside of the near-field wave pattern the experimentally derived wave heights diverge from ANSYS-CFX / FLUENT results, and assumed this to be the result of ANSYS-CFX / FLUENT using a finite volume method (FVM) over dampened the waves in the far-field region, and that the model over dampened the two different radius pool models at a different rate. For this reason a comparative study was invalid in the far-field region. Javanmardi [44] has been developing the ANSYS-CFX / FLUENT model with a beach in place to allow the breaking wave shape to 
be predicted and to compensate for the numerical dissipation that resulted in the reduction in the wave height in the far-field experienced by Doyle [43]. Javanmardi [44] also conducted initial scale model experiments to determine the drag on the wavedozer, and validate his model to allow the pressure source propulsion power requirement for the full size pools to be predicted.

\subsection{Author's contribution}

The thesis addressed the immediate research aims:

a. To physically and numerically produce predetermined continuously generated surfable breaking waves in a circular pool.

b. To design the optimum pressure source for wave generation.

c. To control the transformation of the wave from the pressure source on the perimeter of the pool to the breaking point.

Without this research the novel concept of generating continuously breaking surfing waves in a circular pool will not be achievable. A number of issues were addressed to allow the pool to be designed:

a. The impact of bathymetry under and close to the pressure source on wave generation and transformation.

b. The influence of the pressure source's circular track on wave generation.

c. The effect of local currents in the pool on the breaking wave characteristics.

Most research into ship waves has aimed to minimise the wave making resistance [24] [25] [26] [27], thus drag and fuel consumption, and reduce the impact of the waves on the 
shoreline [17] [28] [29]. The research presented in this thesis and the wave pool is believed to be novel as to the author's knowledge, no one has aimed to generate such large smooth ship waves in a constrained channel and to control the breakpoint on the beach to generate the desire breaking wave shape. The author's contribution may be divided into three parts: empirical relationships, numerical approach and experimental results.

The first part of the author's contribution was devoted to the empirical analysis to determine a series of relationships between wave pool parameters. The empirical analysis combined existing relationship defining the effect of the pressure source shape and operating conditions, and bathymetry on the wave life cycle. To support the empirical analysis, field observations of waves with the preferred wave shape and quality were conducted at Lorne Point [45]. Full scale validation that pressure source generated waves can be surfed was conducted using a fish boat in a river, generating high quality waves suitable for surfing.

A numerical approach was undertaken using the Michlet linear potential flow model [46]. An efficient modeling method was required to conduct an initial analysis of the waves generated by the pressure sources given the freedom to control many of the design parameters, including pressure source configuration (shape, waterline length, beam, draught, and displacement), water depth, and pressure source velocity. Michlet had the advantage of being able to efficiently model a large number of test conditions.

As detailed in Michell [10], the waves are created by a pressure source where there is a longitudinal change in the pressure source cross-sectional area. Therefore, the initial focus was on determining whether a pressure source design that had a continually changing crosssectional area would efficiently generate large waves. Examples of this design were the hyperbolic tangent waterline pressure sources, used in initial investigation by Schipper [41] and Vries [40].

To provide experimental data to validate the desired ability to accurately predict the wave heights using Michlet, the author conducted a series of linear tow tank experiments using three different pressure source models (two different beam parabolic pressure sources and a wavedozer [30]), with combinations of velocity, water depth and draught. Unfortunately, 
Michlet was not able to be used to accurately predict the wave heights. These early results were published by the author [45] [47] [48], with the work presented at conferences [49] [50] [51] and other venues.

Subsequently, the author changed the focus of the investigation to an experimental approach, given the limitations of the potential flow numerical approach and with the more complex FVM approach undertaken by Javanmardi [44]. The third part of the author's contribution was devoted to the experimental validation of the empirical relationships between the design parameters, determination of the limiting parameter values, and the provision of experimental results for the circular track to validate Javanmardi's numerical model [44]. For this purpose, a scale model of the circular pool with a beach was constructed and a series of three circular track scale model experiments were performed. The wavedozer was found to be the most efficient pressure source, making smooth high waves. The wavedozers used differed from those previously tested by Standing [30], Driscoll and Renilson [31] [32], that spanned the channel, where the wavedozer tested by the author had limited beam. The wavedozer entry angle $(\alpha)$ was initially set to $14^{\mathrm{O}}$, as used by Driscoll and Renilson [31] [32], however a shallower angle of $7^{\circ}$ was found to produce better quality waves.

The present work started in 2006 in the context of starting to commercialise the Webber Wave Pool patent [7]. Through the present work, the patent is in the process of being commericalised. The collaborative program between TU Delft and UTAS AMC was established in 2008, with an Australian Research Council (ARC) Linkage Project grant LP0990307 awarded to the UTAS AMC, TU Delft and Liquid Time Pty Ltd team in 2009. This grant, along with Liquid Time Pty Ltd support, funded the experimental program conducted by the author. 


\subsection{Outline of thesis}

The structure of the thesis addresses the research aims and issues.

Chapter 2 deals with the requirements of the wave pool from the end-user perspective; being the surfer. The desired wave qualities of height, shape, and speed were defined, and related to the surfer skill level from beginner to expert. An analysis of the wave life-cycle, from generation, through transformation to breaking was conducted. A series of empirical relationships between the pressure shape, operating conditions and the pool bathymetry that allow the pool to be designed to create the required waves.

Chapter 3, with annexes A Scale model experiments and B Scale model experiments run sheet summary, details the test program, model setup, instrumentation, testing procedure, treatment of the results and the error analysis. To provide a qualitative assessment of the breaking wave shape, a wave quality scoring system was defined based on the criteria used for professional surfing competitions, with the results presented in Annex C.

Chapter 4 addresses the experimental results for the effect on wave generation of the pressure source shape, operating conditions and bathymetry design parameters. Results for each of the design parameters are presented, and limiting values discussed.

Chapter 5 focuses on the effect of the bathymetry on the breaking wave shape and quality, the currents generated by the pressure source were determined, the effect on the wave quality discussed and methods to reduce the current velocity were proposed.

The last chapter gives a summary of the achieved results and conclusions that were drawn. Suggestions for future work are also presented. 


\section{Chapter 2 Surfing waves and wave pool design parameters}

\subsection{Chapter introduction}

This chapter details the definition of surfing waves and the empirical analysis of the wave pool design parameter to produce high quality surfing waves.

Wave parameters that define wave quality from the surfer's perspective are presented. Wave height, shape, width, speed and angle to the shore all determine the suitability of a wave for surfing. Further, a wave suitable for an experienced surfer may be totally unsuitable for a beginner. Therefore, the competing and common requirements for each of these groups are discussed.

With the wave breaking requirements set, the waves needed to be generated and transformed into the required wave breaking shape; the surf. The investigation initially had the freedom to use any range of values for design parameters. No particular pressure source shape, operating conditions or bathymetry was predetermined. Further, as the pressure source was able to be fixed in position relative to the water surface, the design was not even limited by the pressure source having to be positively buoyant or stable.

To begin to constrain the design to one that was able to produce high quality, breaking waves in a constrained waterway, an empirical analysis of the wave life-cycle, from generation, through transformation to breaking was conducted. The outcome is a series of empirical relationships between the pressure shape, operating conditions and the pool bathymetry design parameters.

\subsection{Surfing waves}

With the design initially unconstrained, the first question to be answered was: "what defines a great surfing wave?" There was no point generating waves that surfers would only consider to be okay; the waves generated had to be of a shape and quality that surfers could only previously fantasise about; Figure 2-1, the kind of waves that surfers would pay to surf. The 
failure to produce high "quality" surfing waves has led to the financial failure of previous wave pools [52].

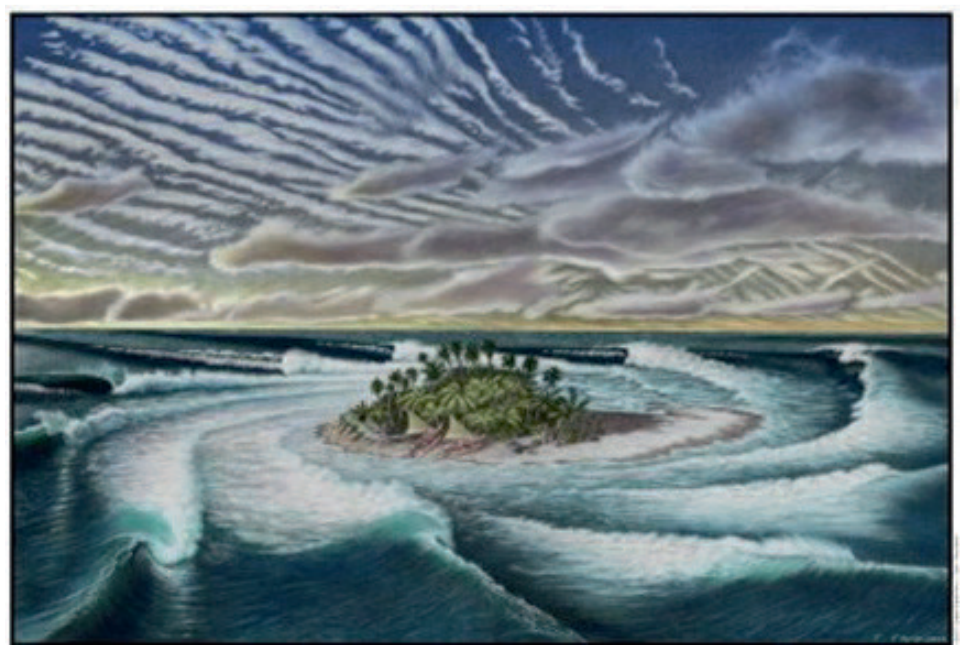

Figure 2-1. An artist's impression of a fantasy surfing location (source unknown).

\subsubsection{Wave height}

When talking about surf, the first question that surfers ask is "how big are the waves?" However, the answer to this question is not straight forward, as surfers still cannot agree on how to measure wave height, whether it is the wave face (on which the surfer rides) [53], the wave height in deep water before the wave breaks (that is measured using swell buoys and detailed in weather reports), or some other measure.

For the purposes of this work, the wave height $(H)$ was defined as the surface elevation of the preceding trough $\left(\zeta_{\min }\right)$ to the surface elevation of the next crest $\left(\zeta_{\max }\right)$, as surface elevation was able to be experimentally measured using conventional wave probes. Further, the wavelength $(\lambda)$, being the horizontal distance between two successive wave crests, and the wave period $(T)$, being the time between two waves crests passing a fixed point, was determined; Figure 2-2. 
In the wave pool, the wave height changes as it travels across the channel from being generated at the pressure source, to breaking on the beach, to dissipating following breaking; Figure 2-3. The parameters that define the circular track bathymetry, and therefore the wave transformation and breaking, are shown in Figure 2-4:

a. Radius of the pool outer wall $\left(R_{0}\right)$.

b. Radius of the start of the beach $\left(R_{\text {beach }}\right)$.

c. Lateral distance from the outer wall to the start of the beach $\left(y_{\text {beach }}\right)$.

d. Water depth at the pool outer wall $\left(h_{0}\right)$.

e. Water depth at the start of the beach slope $\left(h_{\text {beach }}\right)$.

f. Beach slope $(s)$.

g. Lateral width of the beach $\left(Y_{\text {beach }}\right)$.

h. Vertical height of start of the beach $\left(Z_{\text {beach }}\right)$.

Further details on the bathymetry parameters are provided in Section 2.4.2.

In conducting the empirical analysis, the waves were assumed to break at the start of the beach $\left(y_{\text {beach }}\right)$ with wave height of $H_{\text {beach }}$. For a thrilling desirable ride, the wave must be large enough for the average surfer. As an initial design requirement, $H_{\text {beach }} \geq 2 \mathrm{~m}$ was desirable as it was overhead for the average height surfer (assumed as $1.75 \mathrm{~m}$ ), providing an exciting riding experience. Smaller waves are also very enjoyable to ride, so the flexibility to generate smaller waves is desirable, especially for less skilled surfers; that is smaller diameter, cheaper wave pools that generate waves of $H_{\text {beach }}<2$ m may also be viable. 


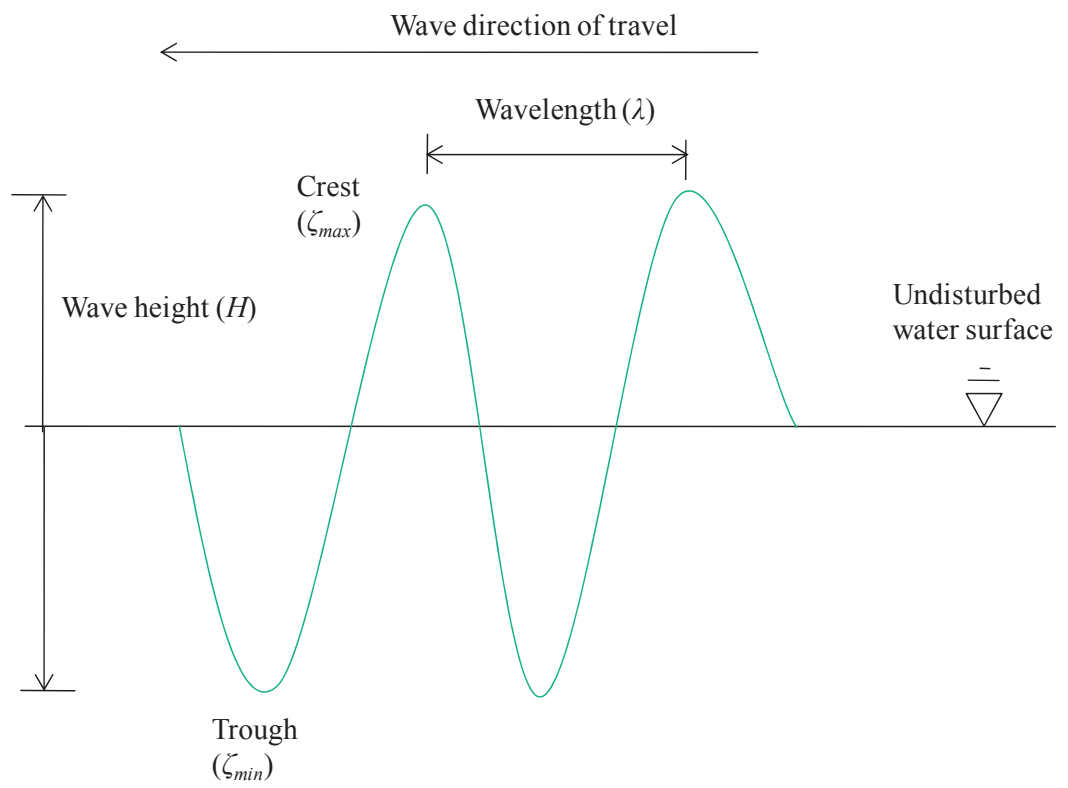

Figure 2-2. Wavelength and height. The waves are travelling from right to left.

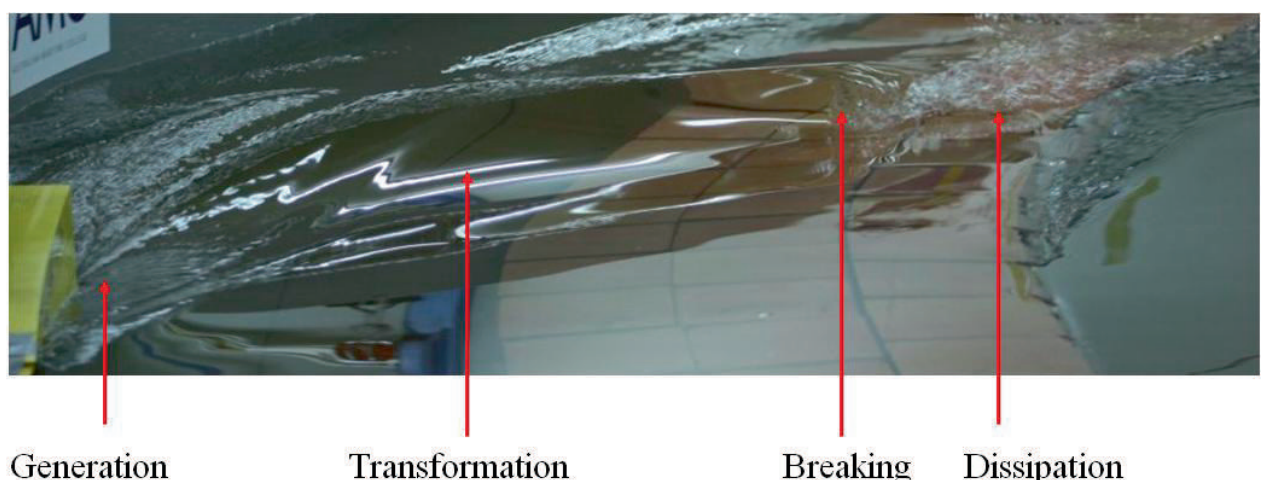

Generation

Transformation

Breaking Dissipation

Figure 2-3. Wave life-cycle illustrated in the circular scale model; condition 45 model 11-12 at $F r_{h 0}=0.975$ with $B=275 \mathrm{~mm}, d^{*}=0.2$ and $h_{0}=250 \mathrm{~mm}$. The model was travelling towards the camera. 


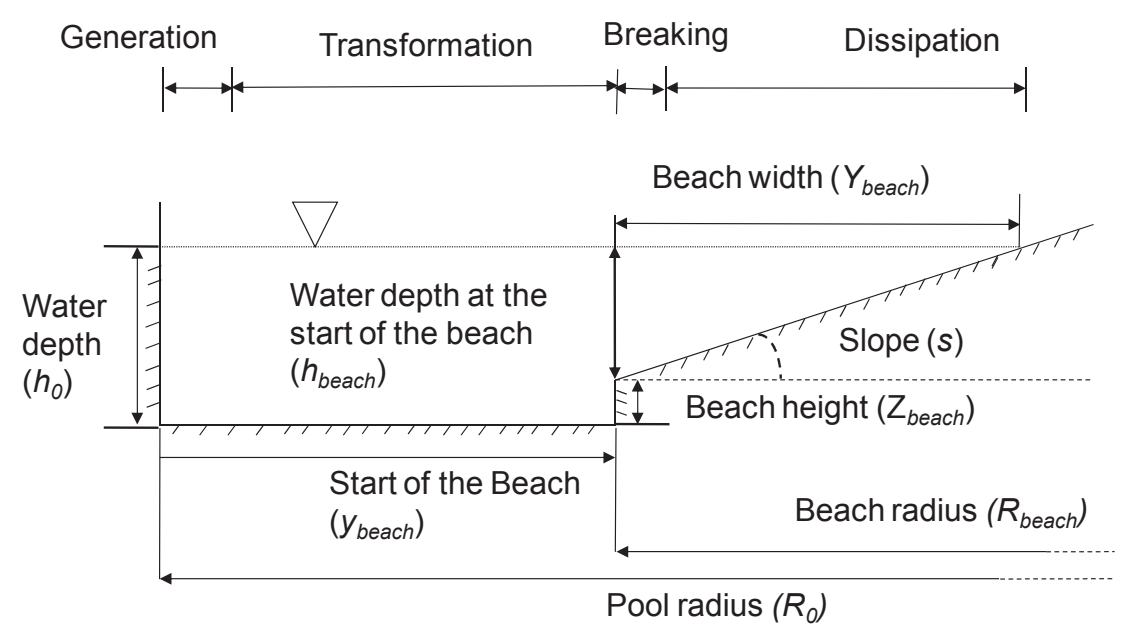

Figure 2-4. Circular track bathymetry parameters.

\subsubsection{Wave quality}

The next question surfers ask each other when checking the surf is: "how good is it". That is, for surfing, wave quality is as important, if not more important, than the wave height $\left(H_{\text {beach }}\right)$. This question is again subjective; however, the wave quality can be broken down into two elements:

a. The wave shape, including the breaking intensity and the width of the surfable wave wall.

b. The speed that the break point travels along the wave crest, which must be matched or exceeded for the surfer to stay on the unbroken part of the wave.

Further, even with the same swell hitting a stretch of coast, the wave quality will differ at different surf breaks due to each location's bathymetry, orientation to the swell, exposure to the wind and alike. Therefore, surfers will carefully weigh up the factors affecting the surf and often pick the surf break that they believe will offer the highest quality waves, even if it may mean surfing smaller waves. 
Finally, surfers may even trade wave quality for the opportunity to surf more waves in a session, by surfing lower quality, less crowded, waves. For the surfer, the wave quality may be as important, or more important, than the wave height, and the number of waves a surfer may surf in a given time period may be as important, or more important, than both the wave height and quality.

To meet all of the surfer's requirements, it was desirable to generate as many high quality, smooth waves of $H_{\text {beach }} \geq 2 \mathrm{~m}$ as possible in each pool.

\subsubsection{Wave shape}

The shape of the wave at the breakpoint is a critical element of the suitability of the wave for surfing. The shape of the wave is defined both in terms of the breaking intensity and wall width.

\section{Breaking intensity}

Galvin [54] and Battjes [55] found the wave break with different breaker shapes dependent on the beach slope $(s), H_{\text {beach }}$ and the wavelength where the wave crest is parallel with the beach slope $\left(\lambda_{s}\right)$. Battjes [55] used the inshore Iribarren number $(\xi)$, also called the "surf similarity parameter", to describe the breaker type on the basis of previous results of Galvin [54]:

$$
\xi=\frac{\tan (s)}{\sqrt{H_{\text {beach }} / \lambda_{s}}}
$$

with $\lambda_{s}$ being the wavelength [m] in deep water perpendicular to the orthogonal slope.

The types of breaker shapes defined by Galvin [54], and Battjes [55] found the range of values for $\xi$ for the different wave breaker types, as detailed in Table 2-1. The wave shape's suitability for surfing and examples of each wave shape generated in the circular scale model are shown in Figure 2-5 to Figure 2-8. 


\begin{tabular}{|l|l|}
\hline Breaker type & $\xi$ \\
\hline Spilling & $\xi<0.4$ \\
\hline Plunging & $0.4 \leq \xi \leq 2.0$ \\
\hline Surging / collapsing & $\xi>2.0$ \\
\hline
\end{tabular}

Table 2-1. Breaker type and $\xi$ (from Battjes [55]).

Spilling waves $(\xi<0.4)$ occur if the wave crest becomes unstable and flows down the front face of the wave producing a foamy water surface. Surfers would say a 'soft' or 'weak' wave. This regime was considered surfable; Figure 2-5.

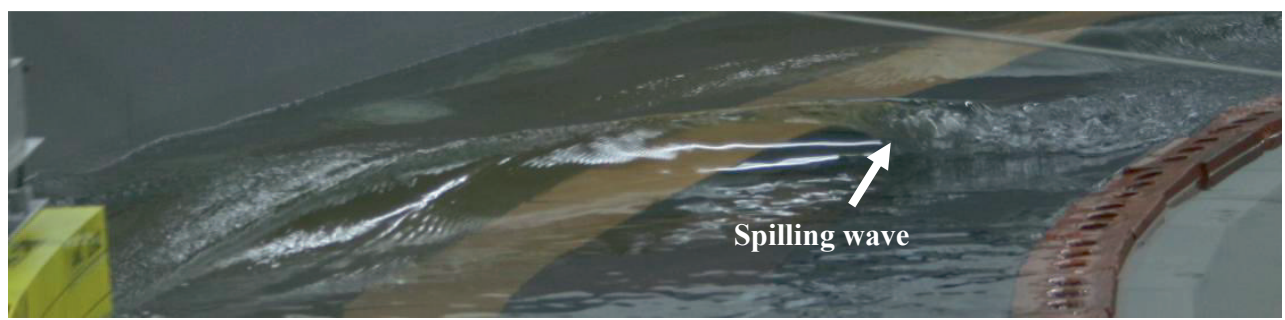

Figure 2-5. Spilling wave generated by condition 48 run 402 model $12-02$ with $\xi=0.4, d^{*}=0.2$ in $h_{0}=250 \mathrm{~mm}$ at $F r_{h 0}=0.95$ and $s=9^{\circ}$ and $y_{\text {beach }}{ }^{*}=1.4$. The pressure source was travelling towards the camera.

Plunging waves $(0.4 \leq \xi \leq 2.0)$ occur if the crest curls over the front face and falls into the base of the wave; surfers call this a barreling or tubing wave; Figure 2-6 with $\xi=0.95$. This regime is preferred by most surfers and the wave pool will be designed to create these types of plunging waves. 


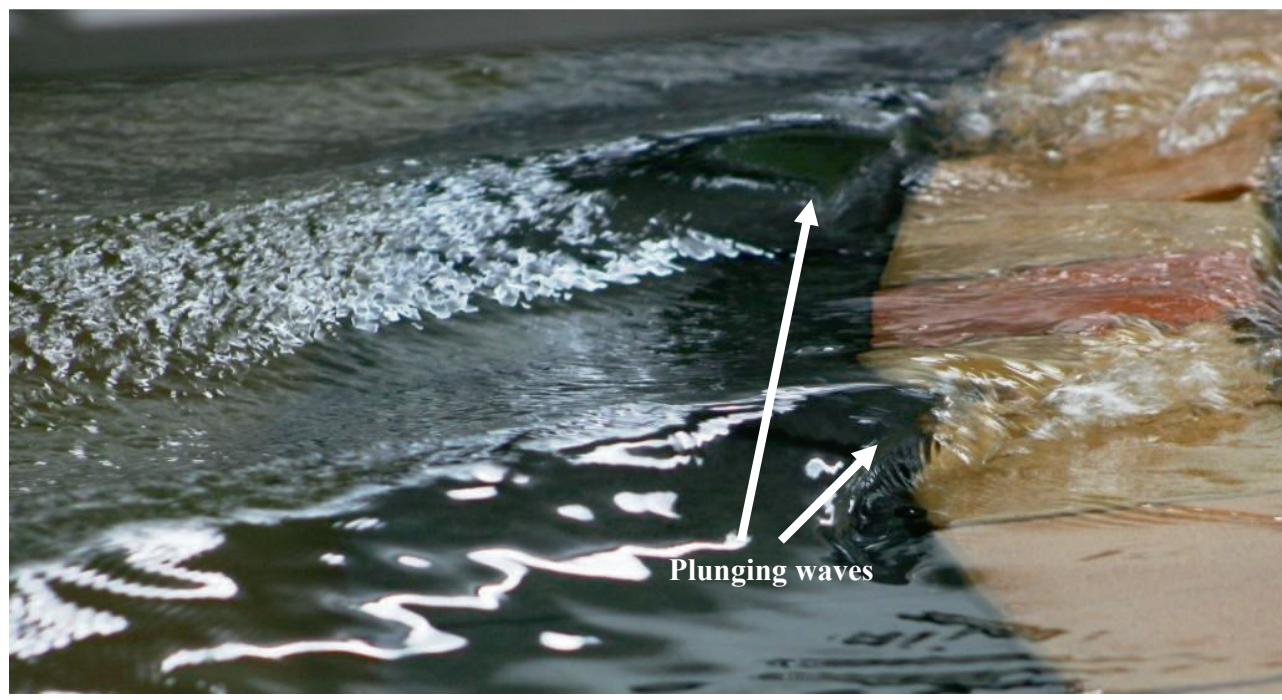

Figure 2-6. Plunging waves (first and second waves) generated by condition 56 model 12-02 with $\xi=1, d^{*}=0.2$ in $h_{0}=250 \mathrm{~mm}$ at $F r_{h 0}=0.95$ and $s=17^{0}$ and $y_{\text {beach }}{ }^{*}=1.9$.

Collapsing waves $(\xi>2.0)$ occur if the crest remains unbroken and the front face of the wave steepens and then falls, producing an irregular turbulent water surface; Figure 2-7. Surfers often encounter this regime at reef breaks when the tide is too low and the reef is not submerged enough to produce surfable waves. This is an unsurfable regime.

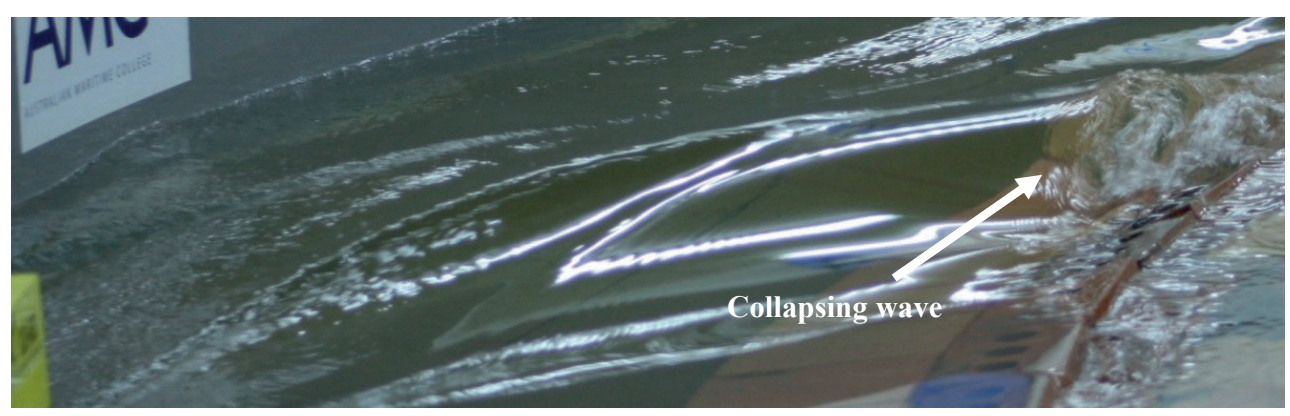

Figure 2-7. Collapsing breakers (first and second waves) generated by condition 52 model 12-02 with $\xi=2.3, d^{*}=0.2$ in $h_{0}=250 \mathrm{~mm}$ at $F r_{h 0}=0.95, s=23^{\circ}$ and $y_{\text {beach }}{ }^{*}=1.9$. 
Surging waves $(\xi>2.0)$ occur if the crest remains unbroken and the front face of the wave advances up the beach with minor breaking; Figure 2-7. This regime was considered unsurfable.

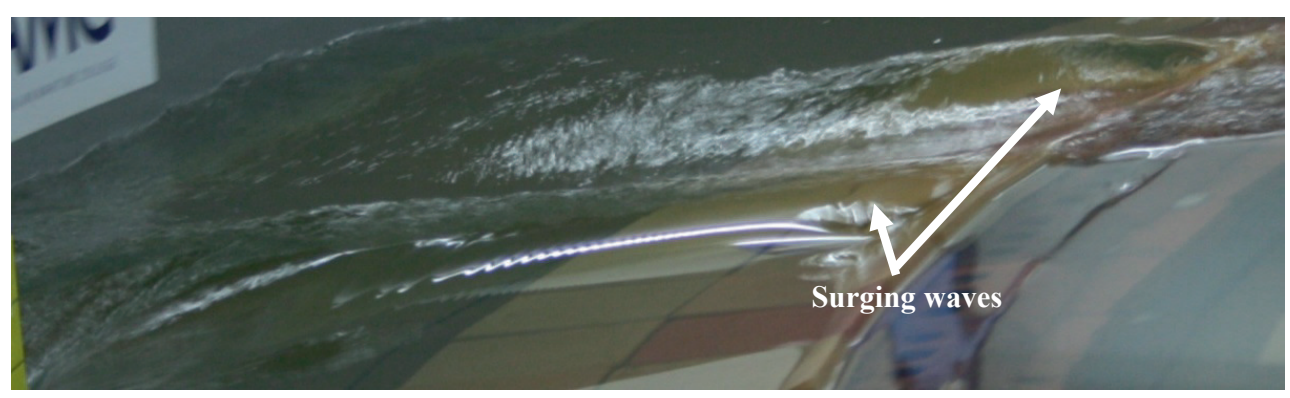

Figure 2-8. Surging waves generated by condition 50 model $12-02$ with $\xi=3.3, d^{*}=0.2$ in

$$
h_{0}=250 \mathrm{~mm} \text { at } F r_{h 0}=0.9, s=23^{\circ} \text { and } y_{\text {beach }}{ }^{*}=1.4 \text {. }
$$

Combined with $H_{\text {beach }} \geq 2 \mathrm{~m}$, the plunging wave shape allows the average height surfer to be able to stand "inside" the wave; Figure 2-9. Riding inside plunging, or "barrelling", waves is the most highly sought after experience in surfing, requires high quality waves and sufficient surfer skill. High quality plunging waves are naturally rare as not all surfing breaks generate plunging waves, and due to the distribution of $H_{\text {beach }}$ in a wave group (known in surfing as a "set" of waves), not every wave plunges. This rarity drives surfers to routinely travel all over the world in the search for high quality plunging waves. Therefore, to constantly generate high quality plunging waves is the ultimate aim of the wave pool.

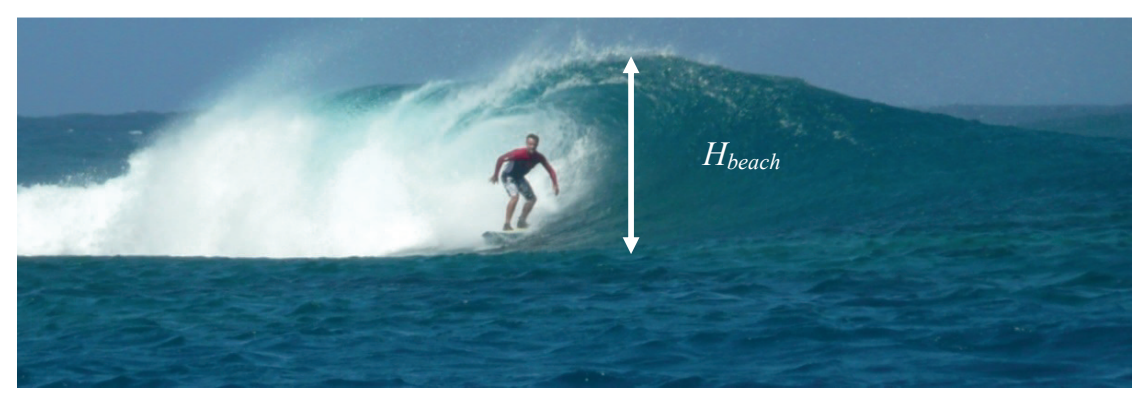

Figure 2-9. Surfer riding plunging "barrelling" wave of $H_{\text {beach }} \approx 2 \mathrm{~m}$. 


\section{Wall width}

The length of a smooth, unbroken wave crest was defined as the usable "wall" width. As defined by Hartley [39], a wide steep wall was required to provide surfers sufficient vertical and lateral space to perform typical manoeuvres. An example of such a high quality wave is shown in Figure 2-10.

Mead et. al. [34] further associates the different parts of the breaking wave with the different manoeuvres .The 'pocket' is just in front of the barrel (break point) and is where the majority of the wave's power is located. It forms the steepest part of the wave and thus is the section where surfers are able to generate the most speed. The 'shoulder' is where the wave is the less steep and generally surfers will struggle to generate speed whilst surfing on this section. Advanced surfers will often use a cutback manoeuvre to position themselves back in the pocket. The 'lip' is the uppermost point of the wave and is used for powerful top-turns or aerials. The 'white water' is the broken part of the wave in which is generally avoided by surfers of a reasonable skill level. The white water may be ridden by beginners while they are learning to stand up, but this is undesirable for experienced surfers.

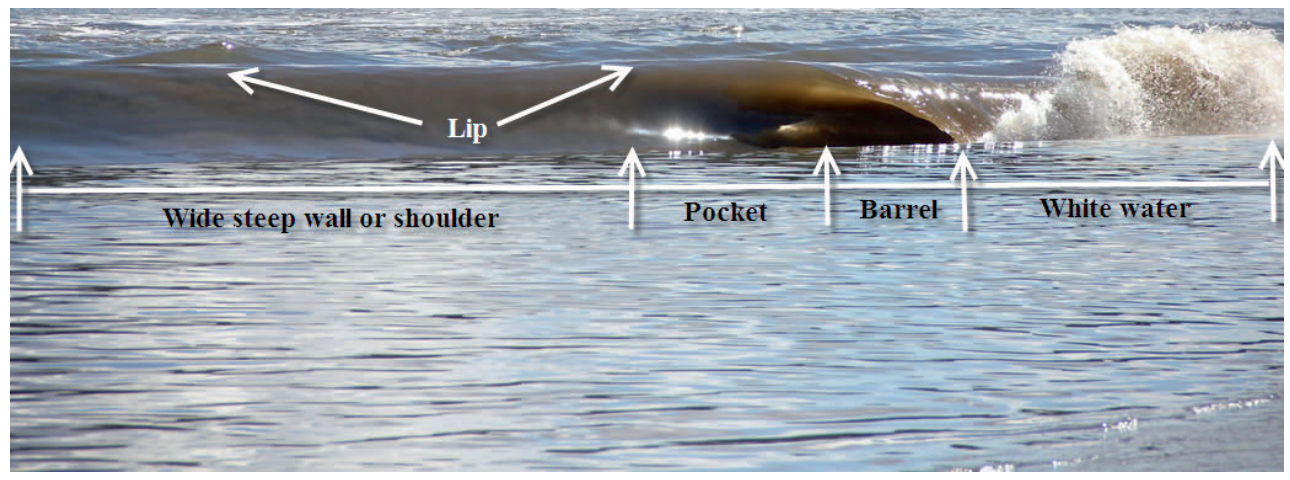

Figure 2-10. A high quality wave shape. The elements of the wave as described by Mead et. al. [34] are shown. 


\subsubsection{Surfer velocity components and wave celerity}

With the desired wave size and shape defined, the surfer velocity components and the wave phase speed or "celerity" $\left(c_{p}\right)$ needed to be determined.

Peel angle $\left(\theta_{\text {peel }}\right)$ was defined as the angle between the trail of the broken wave crest (white water) and the unbroken wave crest as it propagates shoreward; Figure 2-11 [56] [38] [34]. Peel angles range between $0^{\circ}$ and $90^{\circ}$, with low angles creating fast surfing waves and high angles creating slow waves [38]. The wave peel rate $\left(v_{\text {peel }}\right)$ described the speed that the breakpoint advances laterally along the wave crest, and was determined by the peel angle. The surfer must surf across the wave crest at least as fast as the wave peel rate in order to stay in front of the wave break point [33], with the surfer's speed ( $\left.c_{\text {surfer }}\right)$ or "board speed" [57] at the breakpoint, Figure 2-11, being:

$$
c_{\text {surfer }}=c_{p} / \sin \left(\theta_{\text {peel }}\right)
$$

and

$$
v_{\text {peel }}=c_{p} / \tan \left(\theta_{\text {peel }}\right)
$$

The physical limiting values for $\theta_{\text {peel }}$ and the impact on the wave quality were:

a. $\quad \theta_{\text {peel }}=0^{\mathrm{O}}, v_{\text {peel }} \rightarrow \infty$ and $c_{\text {surfer }} \rightarrow \infty$; Figure 2-12. In this case, the wave crests are parallel with the shoreline and the entire wave crest breaks simultaneously and the surfer is unable to stay on the unbroken wave face. This situation is termed a "closeout" [34].

b. $\quad \theta_{\text {peel }}=90^{\circ}, v_{\text {peel }}=0 \mathrm{~m} / \mathrm{s}$ and $c_{\text {surfer }}=c_{p}$; Figure 2-13. In this case, the wave crests are perpendicular to the shoreline. This wave is considered to be "slow" as the board speed is only equal to the wave celerity. 
The effect is that the surfer, and the wave breakpoint, travel parallel to the shoreline, but towards the shore, at the surfer speed $\left(c_{\text {surfer }}\right)$. To illustrate this, the wave velocity components are shown overlayed on the popular surf site at Lorne Point in Victoria, Australia [45]; Figure 2-14. This example closes matches the schematic shown in Figure 2-11. Lorne Point was considered a close analogue to waves to be generated in the wave pool, with $\theta_{\text {peel }} \approx 45^{\circ}$ and a plunging wave shape for even small waves of $h_{\text {beach }} \leq 1 \mathrm{~m}$.

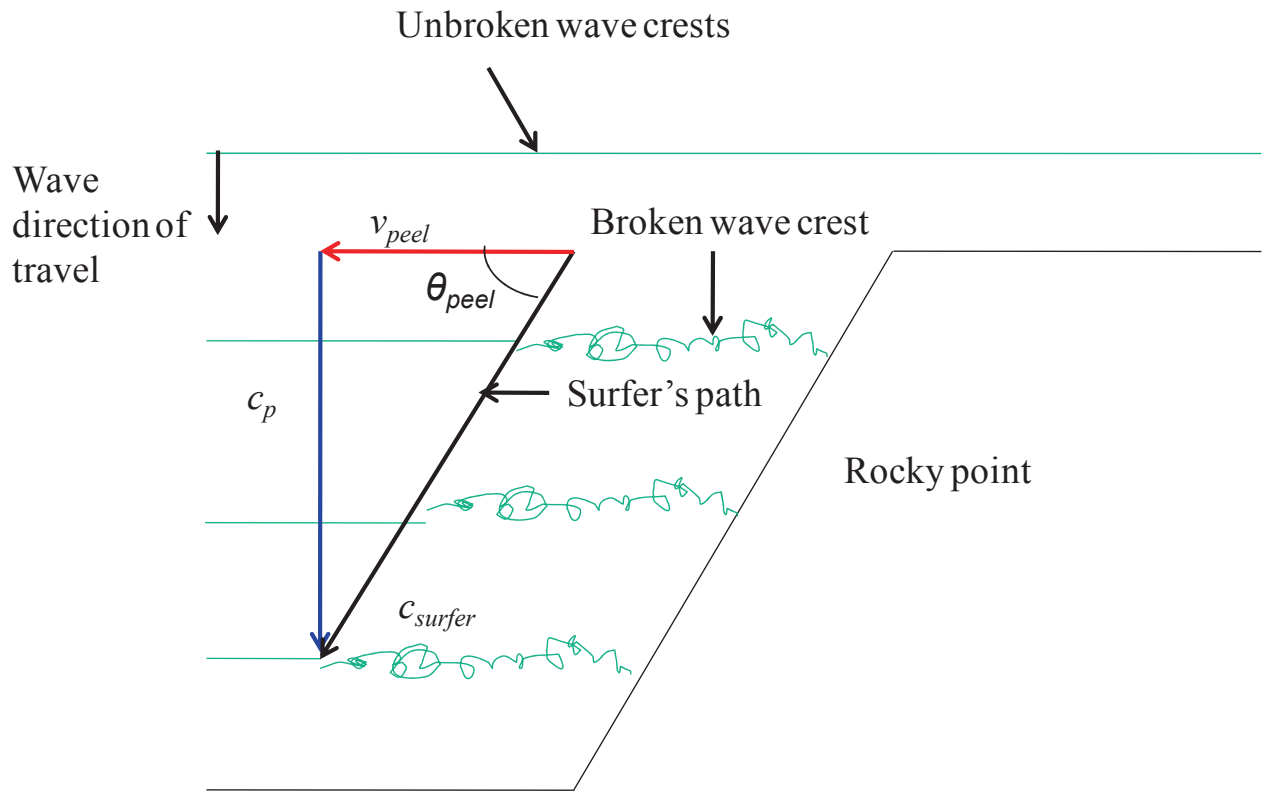

Sandy beach

Figure 2-11. Surfing speed components. 


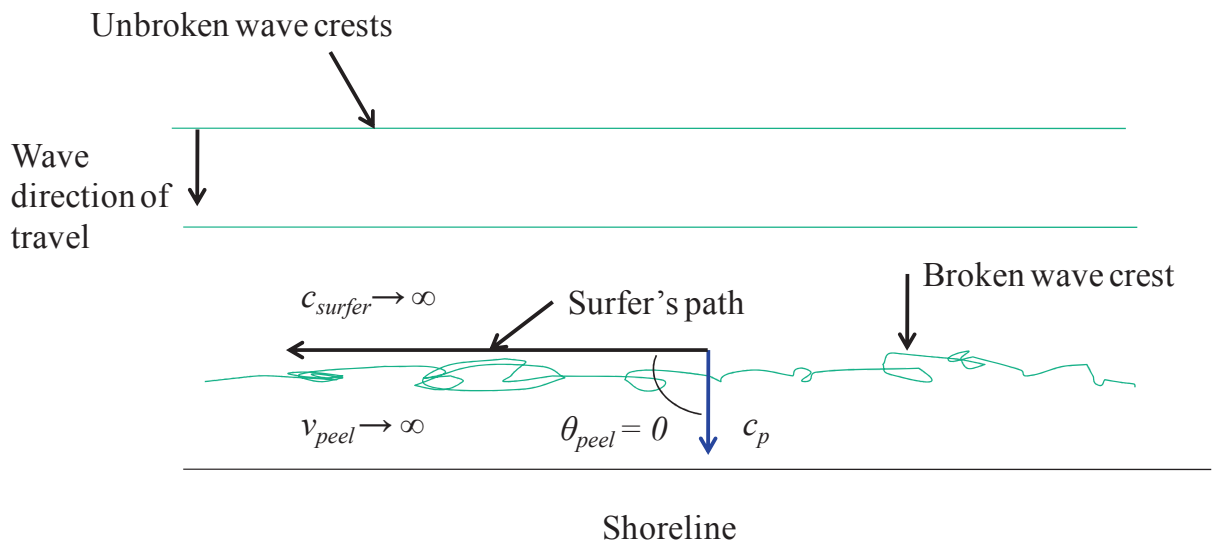

Figure 2-12. "Close-out" wave with $\theta_{\text {peel }}=0^{\mathrm{O}}$.

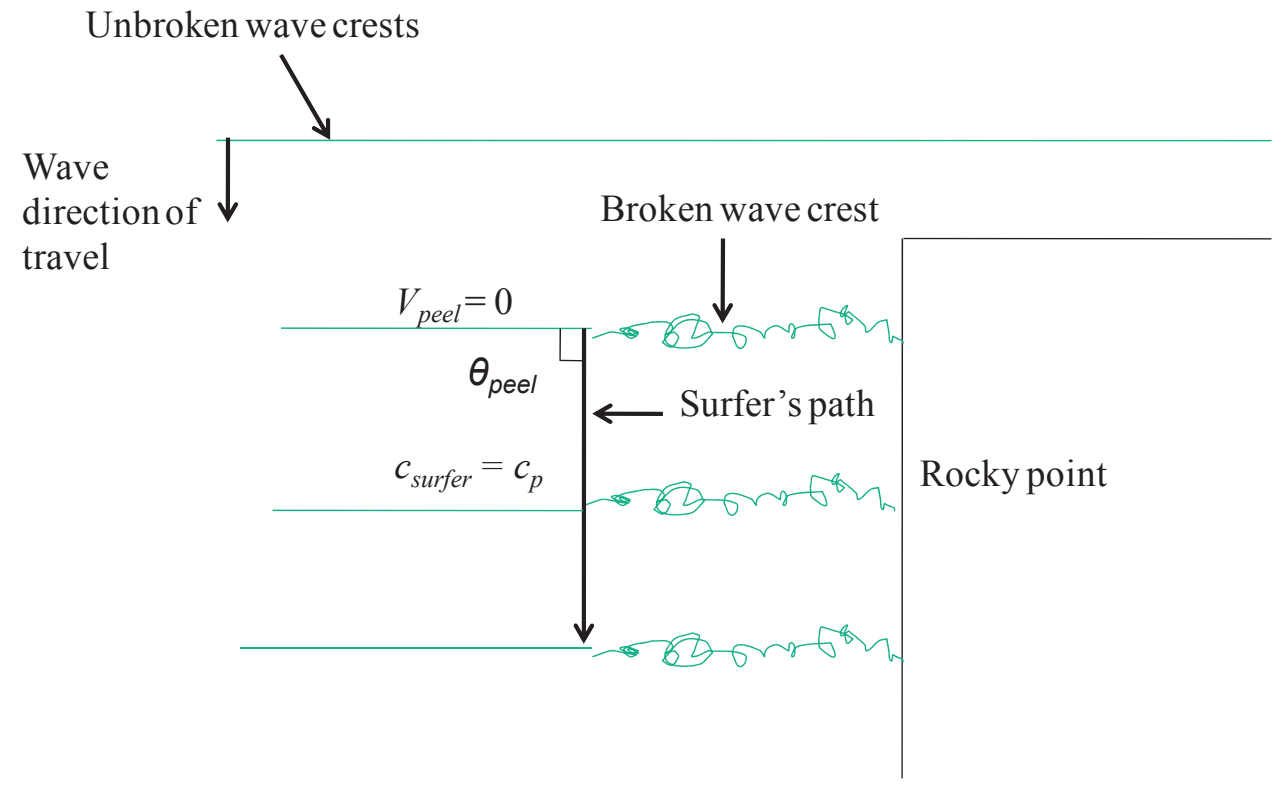

Figure 2-13. "Slow" wave with $\theta_{\text {peel }}=90^{\circ}$. 

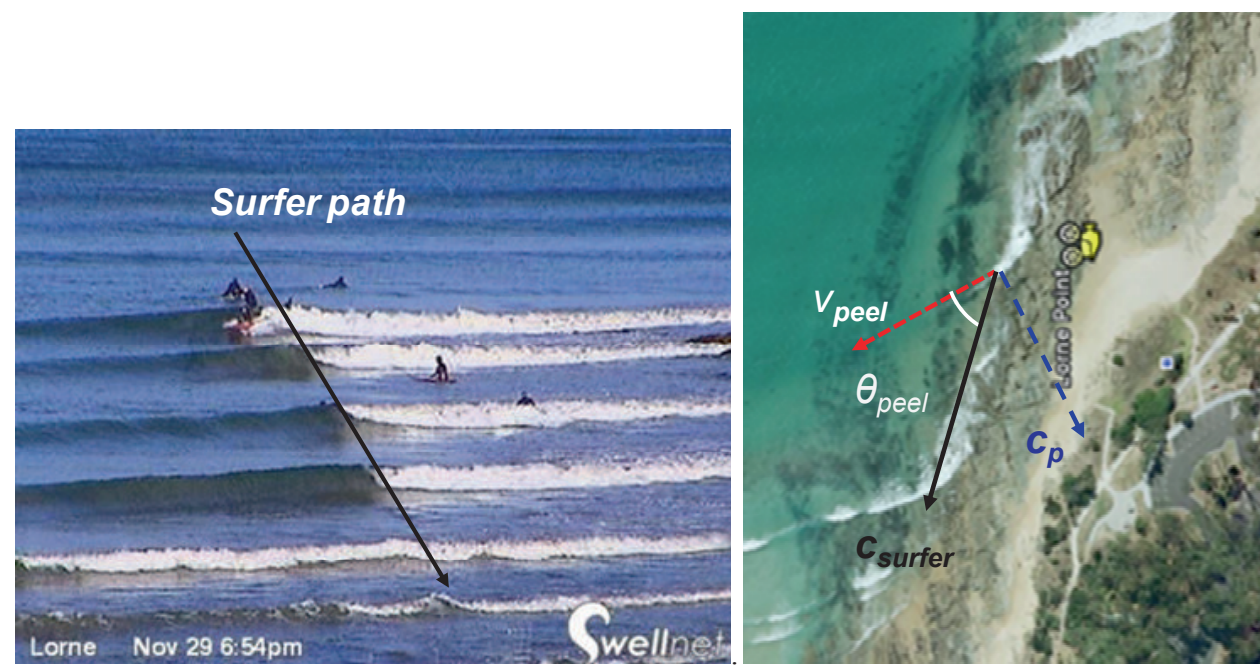

Figure 2-14. Lorne point with breaking waves (both elevation and plan view). The crest lines are indicated by the red lines, with the wave direction of travel perpendicular to the crest line (blue arrow). The black arrow indicates the surfer's and the breakpoint path, moving parallel to the shoreline at the “board speed" $\left(c_{\text {surfer }}\right)$. (Images captured from www.swellnet.com.au and GoogleMaps).

\section{Surfer skill}

Hutt et al. [38] defined the minimum surfer skill required to stay in the break point as a function of peel angle $\left(\theta_{\text {peel }}\right)$ and wave height $\left(H_{\text {beach }}\right)$, and thus wave peel rate $\left(v_{\text {peel }}\right)$; Figure 2-15:

a. 1-3 - beginner level of skill required;

b. 4-6 - intermediate level of skill required; and

c. $\quad$ 7-9 - expert level of skill required.

The assumption was the greater surfer skill is required to generate the higher $v_{\text {peel. }}$ Therefore, to allow the wave pool to be used by surfers with the broadest range of skill level, with the desire value of $H_{\text {beach }} \geq 2 \mathrm{~m}$, the range of peel angles possible was $27^{\circ}<\theta_{\text {peel }}<90^{\circ}$. 


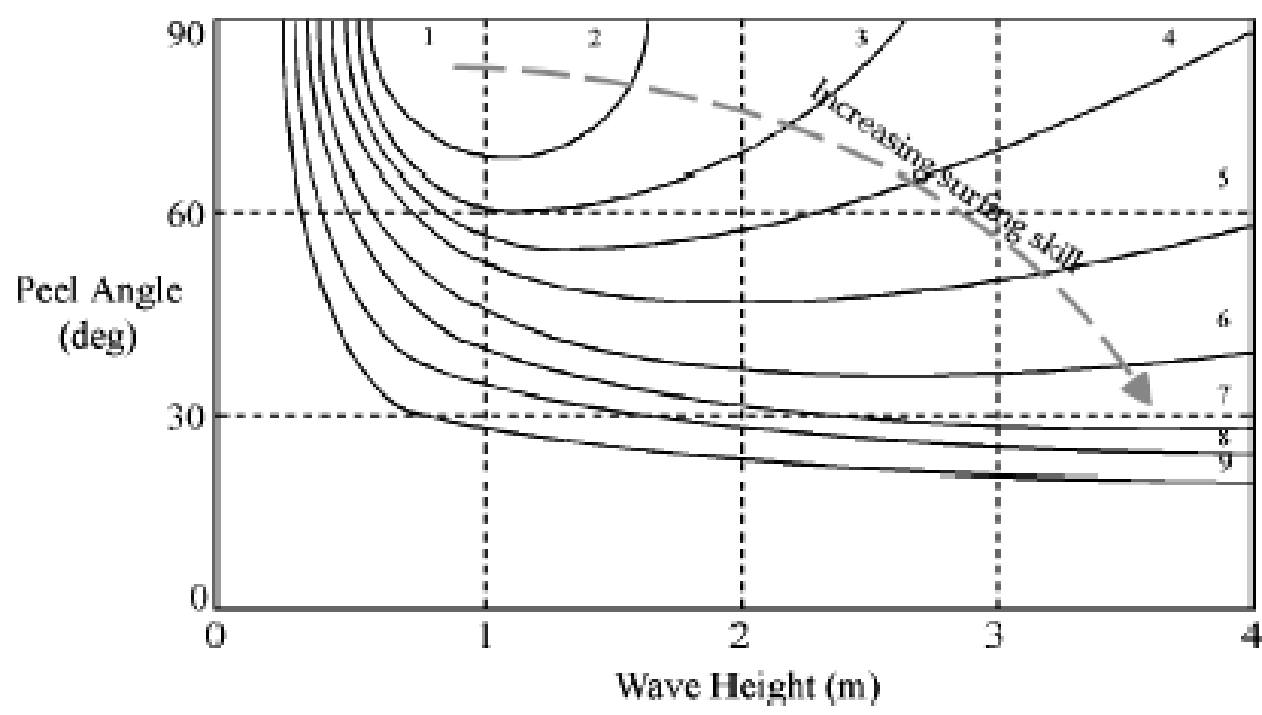

Figure 2-15. Surfer skill as a function of the peel angle $\left(\theta_{\text {peel }}\right)$ and wave height $\left(H_{\text {beach }}\right)$ (reproduced from Hutt et al. [38]).

\section{Surfer speed and wave celerity}

Whilst the surfer must generate a sufficient velocity across the wave ( $\left.v_{\text {peel }}\right)$ to stay ahead of the break point, to design the wave pool the pressure source velocity needed to be determined from the wave speed $\left(c_{p}\right)$.

The preferred $c_{p}$ range for surfing was determined by considering questions:

a. What is the design range of $\mathrm{cp}$ for a surfing wave?

b. What is the minimum cp for a wave to be surfable? 


\section{Design wave speed}

To determine the $c_{p}$ range for surfing, an initial analysis was conducted by a meta-analysis of existing surfing wave studies for mean $c_{p}$ for different surf breaks around the world by Dally [57] and Hutt et. al. [38]. The mean values of $c_{p}$ are plotted with the average; Figure 2-16.

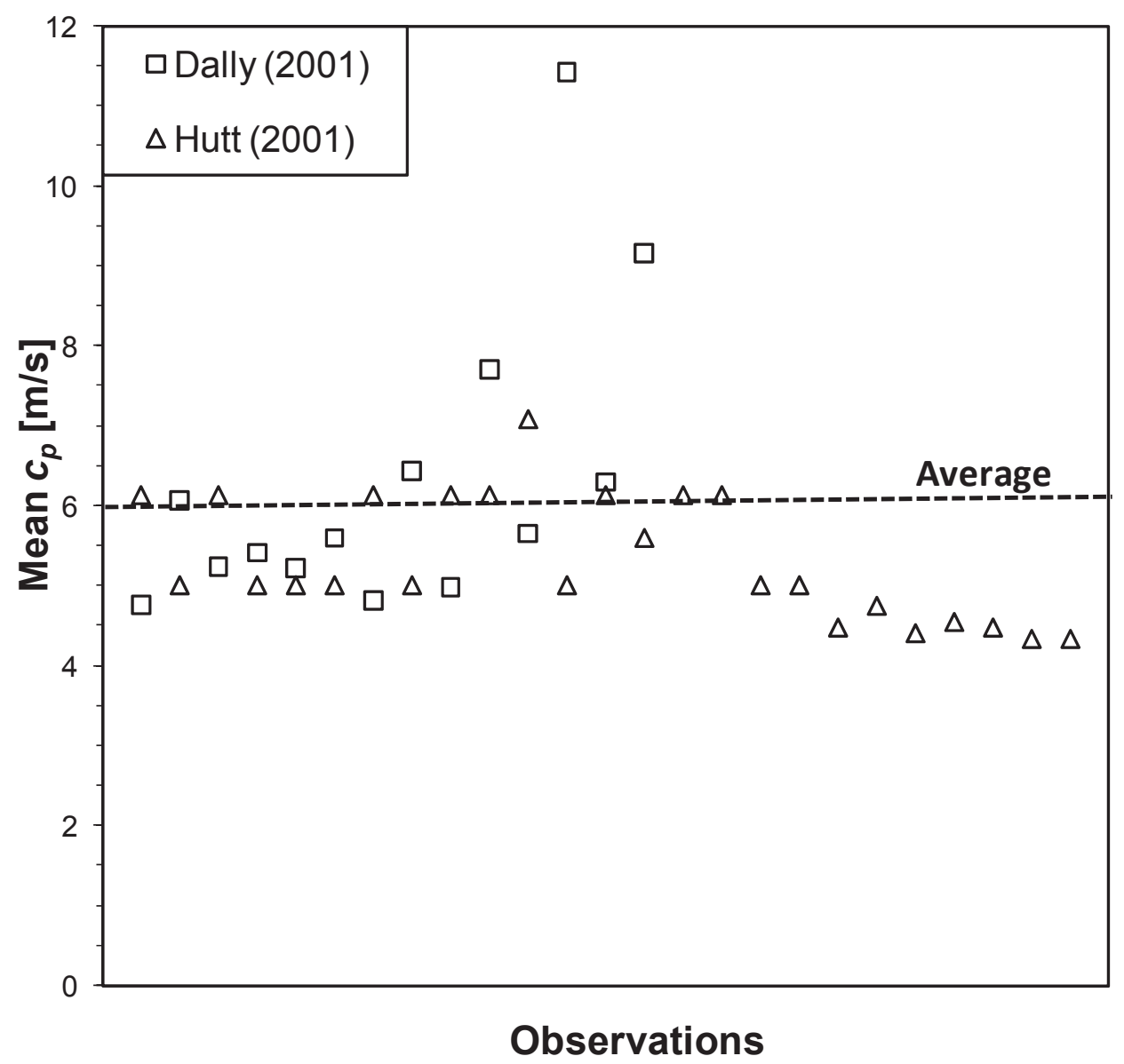

Figure 2-16. Dally [57] and Hutt et. al. [38] observed mean wave speed $\left(c_{p}\right)$ for surfing.

The average $c_{p}$ of all observations was $6 \mathrm{~m} / \mathrm{s}$, with this value was used as the initial design wave speed for the linear wave pool. 
An estimate of $c_{p}$ can be determined as a function of the water depth $(h)$ and wavelength $(\lambda)$ using the general wave dispersion relationship [58], where waves of different wavelengths travel at different speed:

$$
c_{p}^{2}=\frac{g \lambda}{2 \pi} \cdot \tanh ^{2} \frac{2 \pi h}{\lambda}
$$

For a given wavelength, waves in deeper water have a larger phase speed than in shallower water. Further, groups of waves move at a group velocity $\left(c_{g}\right)$, with waves continually created at the front of the group and destroyed at the back of the group [58]. A wave group in surfing is called a "set".

Deep water, where $c_{p}=\frac{c_{g}}{2}$, was defined as being where:

$$
\lambda<2 h
$$

For deep water, the general wave dispersion relationship, Eq. (2.4), reduces to:

$$
c_{p}=\sqrt{g \lambda / 2 \pi}
$$

Shallow water [58] was defined as being $c_{p}=c_{g}$ where

$$
\lambda>20 h
$$

For shallow water, the general wave dispersion relationship, Eq. (2.4), reduced to:

$$
c_{p}=\sqrt{g h}
$$

The full general dispersion relationship could be used for the empirical analysis undertaken in this study, however as wave breaking occurred on the beach, the use of the shallow water dispersion relationship, Eq. (2.8), was assumed to be reasonable to determine $c_{p}$. 


\section{Minimum wave speed}

For the surfing wave pool, it was desirable to be able to generate smaller waves, either for less skilled surfers and / or to scale the design for a smaller radius pool.

To determine the minimum $c_{p}$ that still produces surfable waves, the field observations were undertaken and analysed at Lorne Point. The smallest surfable waves were observed as having $h_{\text {beach }}=0.5 \mathrm{~m}$, and a wave period $(T)=3 \mathrm{~s}$. From these observations, the minimum $c_{p}$ was estimated as being $3 \mathrm{~m} / \mathrm{s}$, using the shallow water estimate from Anthoni [59]. This observation was supported by Dally [57] and Hutt et al. [38], who observed a minimum wave speed of $2 \mathrm{~m} / \mathrm{s}$.

\subsection{Ship waves}

\subsubsection{Linear Kelvin wave patterns}

Waves are generated by a pressure source moving through water (and other fluids) on or under the free surface. The wave pattern, Figure 2-17, formed by a pressure source (ship) in deep water $\left(F r_{h}<0.56\right)$ was derived first by Lord Kelvin [8]. The wave field, Figure 2-17, consists of diverging and transverse waves, with these waves intersecting on a line about $19^{\mathrm{O}}$ with the sailing line $\left(\theta_{\text {cusp }}\right)$, with the resulting locus cusps (featherlet waves) lying on the locus cusp line [60]; noting that only the port side is shown, with the wave pattern repeated on the starboard side.

The featherlet waves have an angle $\varnothing$ of approximately $55^{\circ}$ [61] with the sailing line for $F r_{h}<0.56$, with $\theta_{\text {cusp }}$ and $\varnothing$ increasing to $90^{\circ}$ as $F r_{h} \rightarrow 1$ [60]. Further, as $F r_{h}$ increases, a soliton [20] forms ahead of the pressure source and the transverse waves reduces with the wave energy concentrated in the divergent waves [60]; Figure 2-18. By operating the pressure source at $\mathrm{Fr}_{h} \rightarrow 1$, the divergent, surfing waves may be efficient generated. 
The wave speed, $c_{p}$, of the featherlet waves is related to the pressure source velocity $\left(u_{0}\right)$ :

$$
c_{p}=u_{0} \sin (\varnothing)
$$

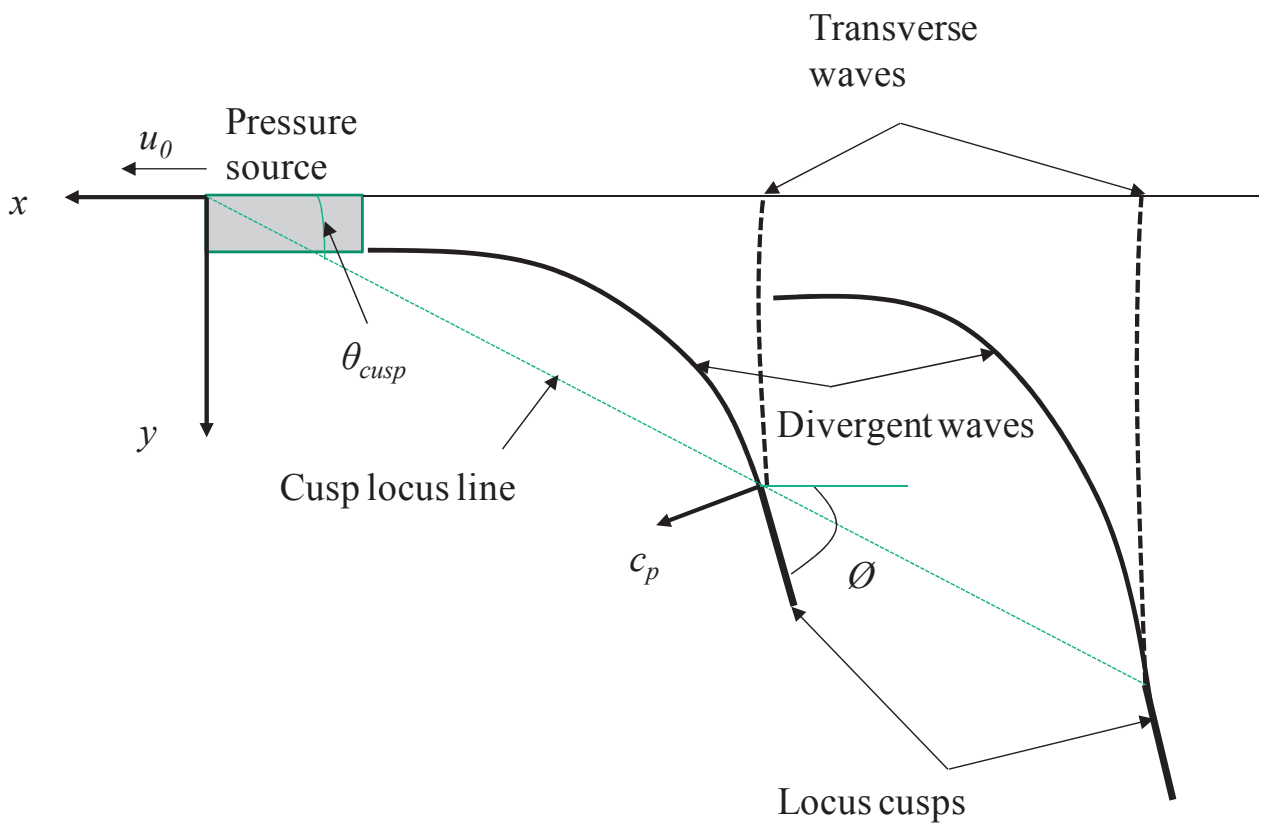

Figure 2-17. Deep water wave field. Locus cusps of the diverging and transverse waves lie on the Locus cusp line which encloses an angle $\theta_{\text {cusp }}=19^{\circ}$ with the sailing line. The angle between the sailing line and the propagation of the divergent ("featherlet") waves $(\varnothing) \approx 55^{\circ} \cdot u_{0}$ is the pressure source velocity and $c_{p}$ was wave phase speed. 


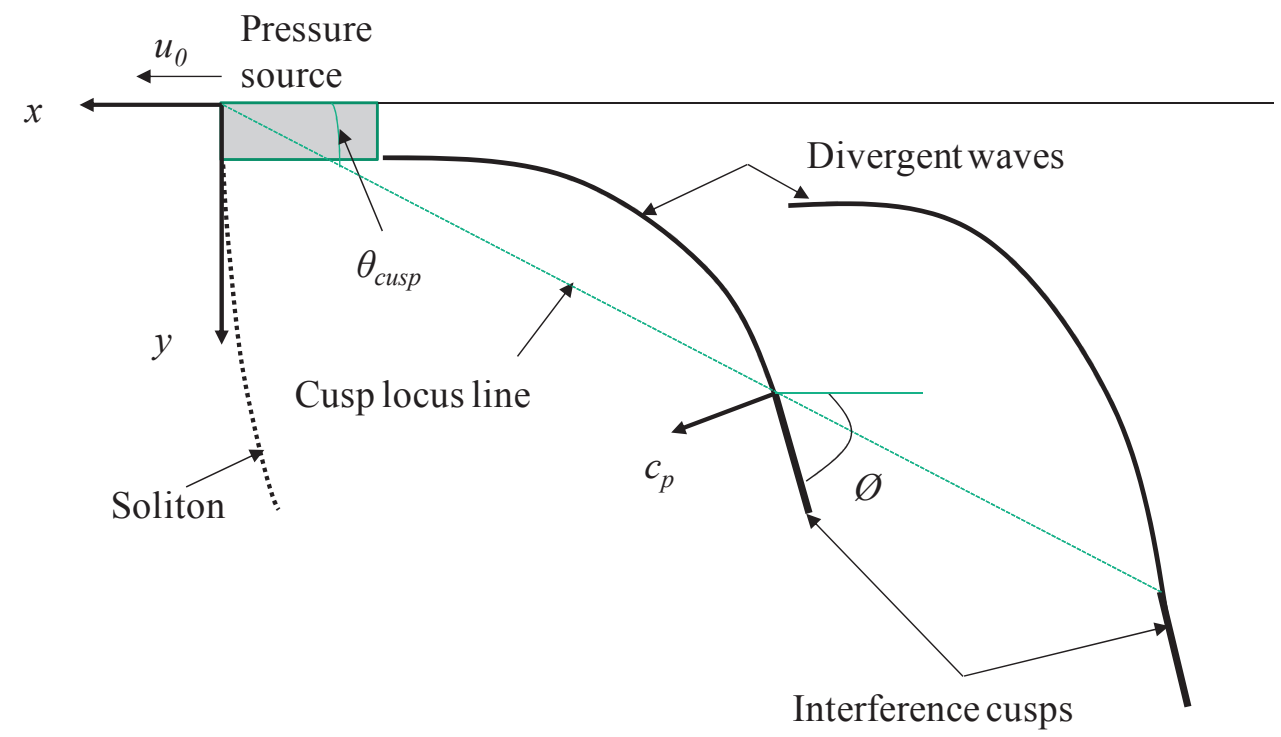

Figure 2-18. As $\mathrm{Fr}_{h} \rightarrow 1$, a soliton may form in front of the pressure source and the transverse waves reduce. $\theta_{\text {cusp }}$ increases as a function of $F r_{h}$.

\subsubsection{Circular Kelvin wave patterns}

For the wave pool under consideration, the pressure source travels in a circular track, rather than a linear track. This configuration allows the waves to constantly break without having to start and stop the pressure source.

The behaviour of a wave pattern generated by a pressure source travelling in a circular path is a less researched topic. Bhattacharya [62] approached the problem by superimposing wave cusp locus lines of $19^{\circ}$ around a circular path at 'varying positions of the instantaneous centre'; Figure 2-19. Bhattacharya [62] assumed that at finite points around a curved path the vessel will produce the same wave pattern as observed when travelling in a straight line. In Figure 2-19, this approach produces wave patterns that never converge on the centre of rotation, and Bhattacharya [62] predicted that the wave cusps will only disturb the outer 5\% of any given circular path, with this disturbed region termed the 'ring of influence'. 
A shortcoming of Bhattacharya [62] was that the $\theta_{\text {cusp }}=19^{\mathrm{O}}$ wave pattern is a time dependant phenomenon that requires the pressure source to travel through a straight line, and yielded errors. Soding [14] avoided this problem by changing the coordinate system from being fixed on the pressure source to fixed on the earth. In doing this he acknowledged that "later course changes of the ship are assumed to have no effect on the wave" [14]. With this in mind, the propagating wave system around a curved path producing the wave system in Figure 2-20, with a real life wave pattern of a pressure source (ship) moving in a circular pattern shown to support Soding's theory.

Soding assumed that this approach will only hold if the path radius is 'so large that the generated waves, described in a ship-fixed coordinate system at the ship's position, are the same as in the straight ahead motion' [14]. To determine whether Soding's theory may apply to the wave pool, the non-dimensional radius (tightness) $\left(R_{0}^{*}\right)$ of the circular track was defined as:

$$
R_{0}^{*}=\frac{R_{0}}{L W L}
$$

where $R_{0}$ is the radius of the circular track, and $L W L$ is the pressure source waterline length at $R_{0}$.

It was assumed that Soding's theory [14] may be valid for large radius tracks where $R_{0} \gg L W L$; with the linear track being where $R_{0}^{*} \rightarrow \infty$. To test this hypothesis, Doyle [43] numerically modelled two different radii circular tracks $\left(R_{0}^{*}=14\right.$ and 23) and concluded for $F r_{h 0}<1$ and $R_{0} \geq 14$, the wave pattern matched a rotated Kelvin wave. 


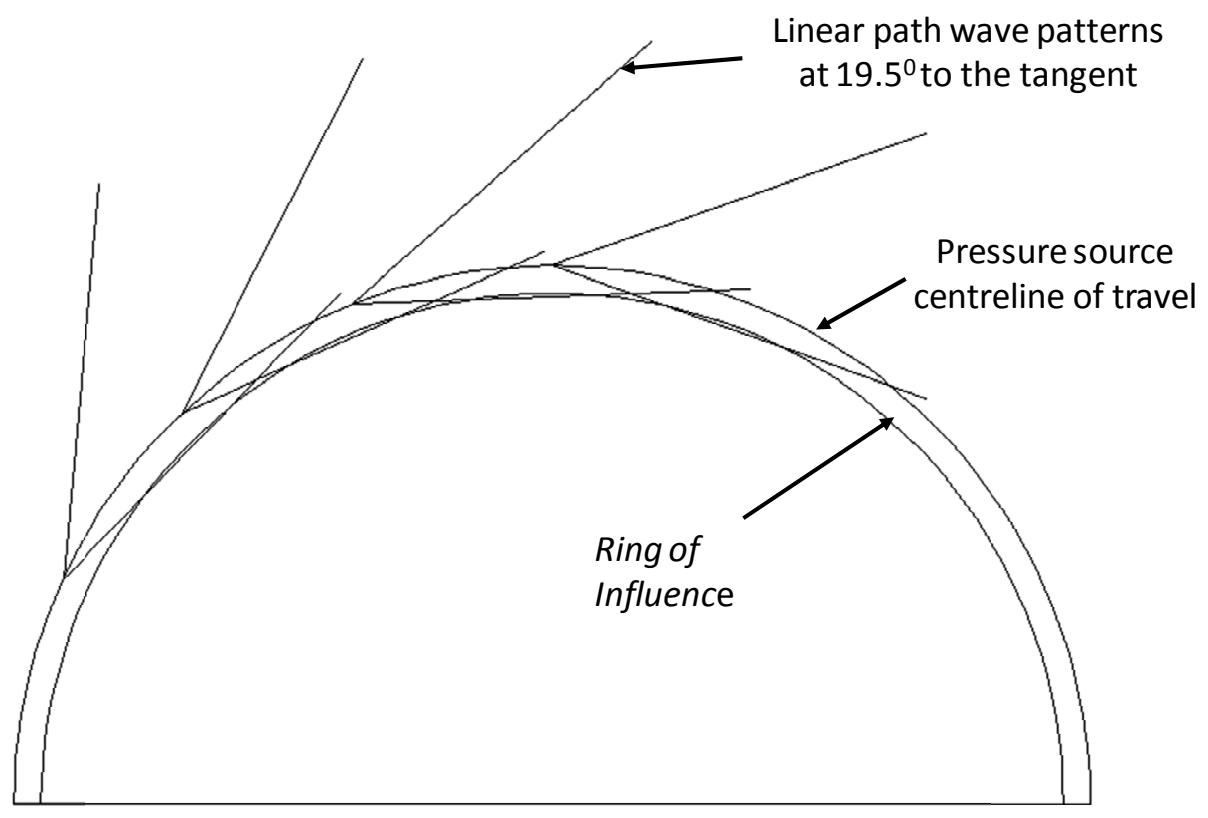

Figure 2-19. Bhattacharya's approach to the problem of curved path wave patterns, showing the empirical Ring of Influence [62] traced by the inner half of the normal linear Kelvin wave pattern. (Reproduced as presented in Doyle [43]).

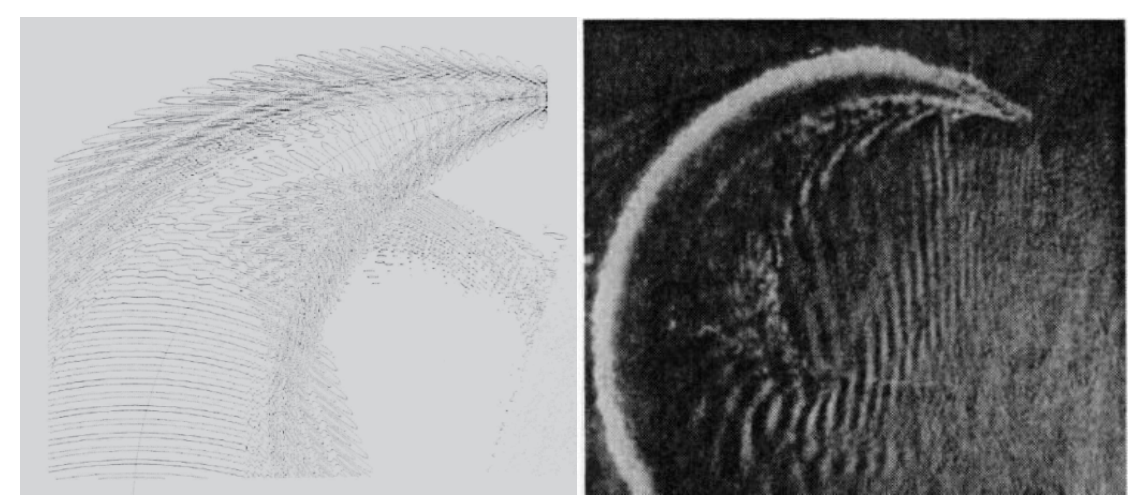

Figure 2-20: Soding's numerical prediction of a curved path wave pattern [14]. Photograph taken from Stoker [61] supporting Soding's work. (Reproduced as presented in Doyle [43]). 


\subsubsection{Surfing ship waves}

To confirm that divergent ship waves can be surfed, a series of trials were conducted using a fishing vessel travelling at a constant speed parallel to a linear shoaling beach within a river estuary. Under the right conditions, good quality, plunging waves (of approximately $1 \mathrm{~m}$ height) were generated and surfed; Figure 2-21. Figure 2-21 shows that one of the smaller waves generated by a moving pressure source can be consistently surfed. Table 2-2 details the boat configuration used during the trials.

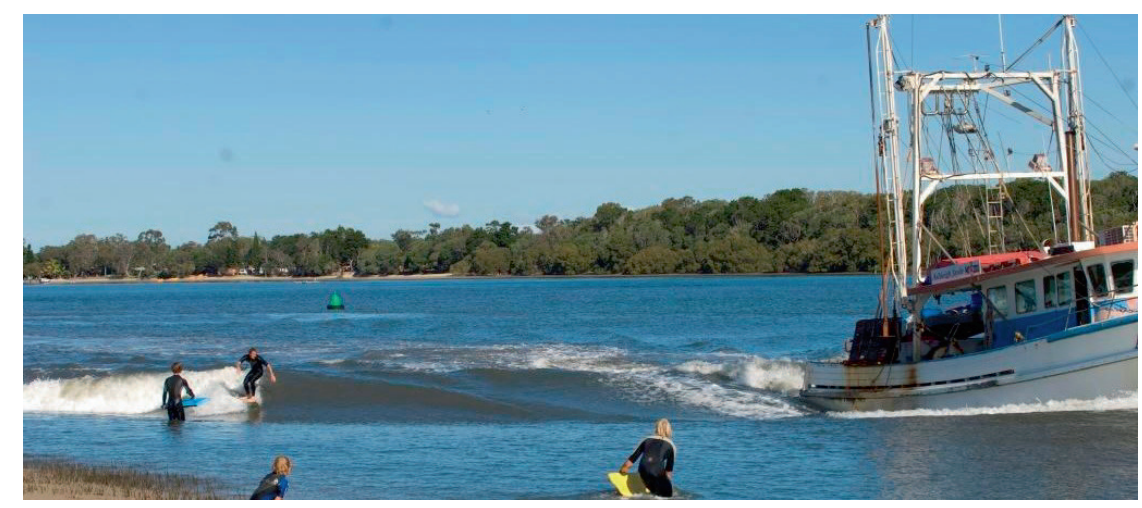

Figure 2-21. Trials using a fishing vessel on a river to generate surfable waves (reproduced with permission of Liquid Time Pty Ltd).

\begin{tabular}{|l|r|c|}
\hline Parameter & Value & Unit \\
\hline Waterline length $(L W L)$ & 15.8 & {$[\mathrm{~m}]$} \\
\hline Beam $(B)$ & 5.5 & {$[\mathrm{~m}]$} \\
\hline Draught $(d)$ & 2.7 & {$[\mathrm{~m}]$} \\
\hline Cross section area $\left(A_{s}\right)$ & 5.0 & {$\left[\mathrm{~m}^{2}\right]$} \\
\hline Displacement volume $(\nabla)$ & 157 & {$\left[\mathrm{~m}^{3}\right]$} \\
\hline Velocity $(u)$ & 5 & {$[\mathrm{~m} / \mathrm{s}]$} \\
\hline Depth Froude number $\left(\mathrm{Fr}_{h}\right)$ & 0.7 & {$[-]$} \\
\hline
\end{tabular}

Table 2-2. River testing boat configuration. 


\subsection{Wave pool design parameters}

To allow the circular pool to be designed for the requirements of breaking wave height $\left(H_{\text {beach }}\right)$, wave shape $(\xi)$, and pool radius $\left(R_{0}\right)$, a series of empirical relationships between the pressure source shape, operating conditions, and bathymetry parameters were developed. The limiting values for the parameters were subsequently determined experimentally through the scale model testing; refer Chapters 3, 4 and 5. In this section, each of the design parameters investigated are defined (including sign conventions).

\subsubsection{Pressure source shape parameters}

Experiments were conducted in both linear and circular tracks. For clarity, the relevant design parameters for each of these cases was dealt with separately, starting with the linear track case; Figure 2-22:

a. $\quad x$ was positive along direction of travel, $y$ was positive to port, and $z$ was positive upwards. The origin was on the static waterline at the bow.

b. The "bow", $x=0$, was defined as the forward extremity of the pressure source at the free surface for the static undisturbed water surface.

c. The centerline of the pressure source was the plane $y=0$.

d. The undisturbed water surface was the plane $z=0$.

e. The pressure source waterline length $(L W L)$ was defined as the distance between the forward and rear extremities of the pressure source at the free surface for the static undisturbed water surface.

f. The pressure source draught $(d)$ was defined as the distance between the free surface for the static undisturbed water surface and the keel (lowest extremity). 
g. The pressure source beam $(B)$ was defined as the width of the pressure source at the free surface for the static undisturbed water surface.

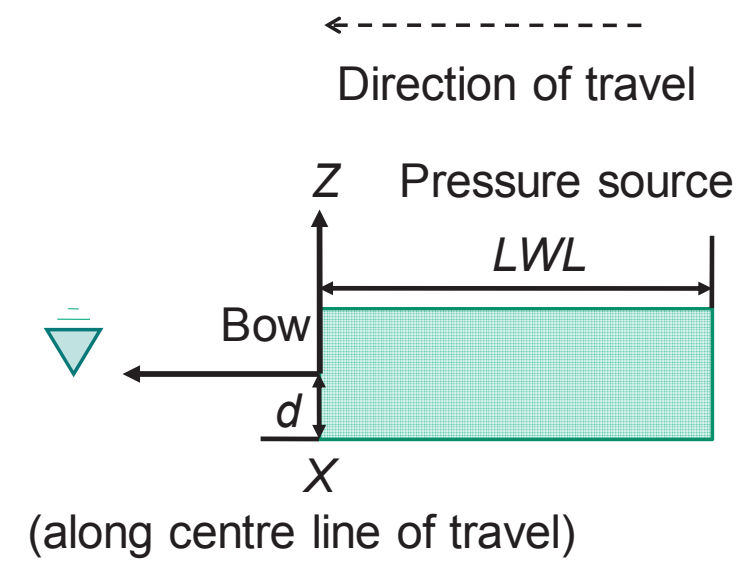

Figure 2-22: Pressure source parameters for a linear track.

The pressure source parameters for the circular track are shown in Figure 2-23, with the wavedozer shown in Figure 2-24. The parameters are the same as the linear track, with the following exceptions:

a. $y$ was positive radially inwards (to port in the anti-clockwise direction), and $z$ was positive upwards.

b. The outer wall of the pool was the plane $y=0$.

c. $\quad R$ was the radial position, positive outwards. The outer wall of the pool was $R_{0}$, where $y=0$.

d. For the wavedozer, $\alpha$ was the entry angle relative to the free surface. 
e. The undisturbed water surface was the plane $z=0$. The pressure source draught $(d)$ was measured at the outer wall $\left(R_{0}\right)$.

f. The pressure source beam $(B)$ was defined as the width of the pressure source at the free surface for the static undisturbed water surface.

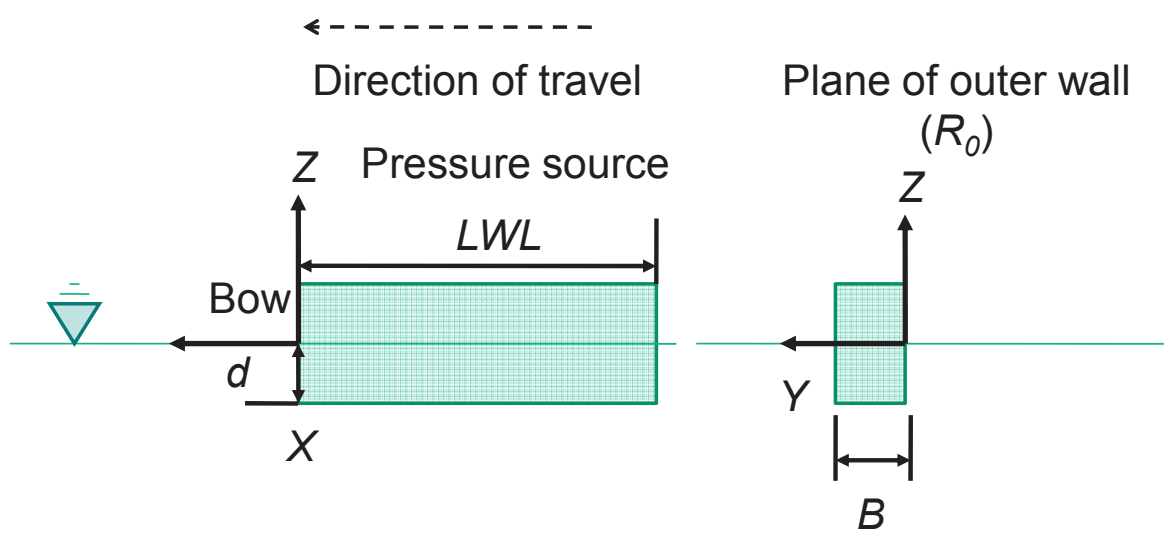

Figure 2-23: Circular track pressure source parameters.

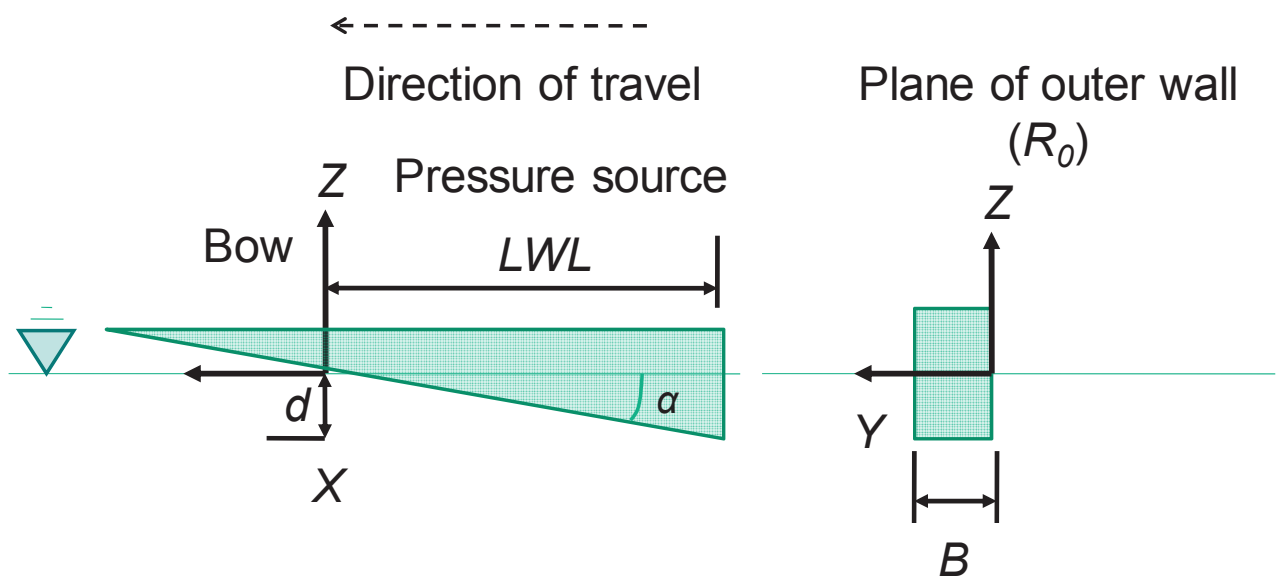

Figure 2-24: Circular track wavedozer pressure source parameters. 
The effect of the following pressure source parameters on the wave generation was investigated:

a. $\quad$ Beam $(\boldsymbol{B}) . B$ was non-dimensionalised by cubic root of the volume displacement $(\nabla)$ :

$$
B^{*}=\frac{B}{\sqrt[3]{\nabla}}
$$

The pressure source beam changed the volume displacement $(\nabla)$. To compare the linear and circular tracks, only the beam to port is considered for the linear track:

$$
\nabla=B \cdot d \cdot L W L
$$

For the wavedozer:

$$
\nabla=\frac{B \cdot d^{2}}{\tan (\alpha)}
$$

The limiting value was where the beam extends to the beach, or width of the channel for a rectangular cross-section. This configuration was first used by Standing [30], and later Renilson [32], to generate large transverse waves in a tow tank.

b. Waterline length $(\boldsymbol{L} \boldsymbol{W L})$ and entry angle $(\boldsymbol{\alpha})$. For the wavedozer, $L W L$ was related to the $d$ by $\alpha$ :

$$
\tan (\alpha)=\frac{d}{L W L}
$$

The physical limits were $\alpha \rightarrow 0$ and $\alpha=90^{\circ}$ (a vertical flat plate). $L W L$ was measured at the outer wall $\left(R_{0}\right)$ when the pressure source was stationary. 
c. Draught $(d) . d$ was normalised by:

$$
d^{*}=\frac{d}{h_{0}}
$$

The draught and beam were multiplied to determine pressure source cross-sectional area $\left(A_{s}\right)$ :

$$
A_{s}=B \cdot d
$$

\subsubsection{Bathymetry parameters}

The bathymetry parameters for the linear track are shown in Figure 2-25:

a. Channel width $(\boldsymbol{Y})$. The channel width for the linear track was determined by the UTAS AMC tow tank, with the pressure source placed in the center of the channel $(Y / 2)$.

b. Water depth (h). A constant water depth was used in the linear track. 


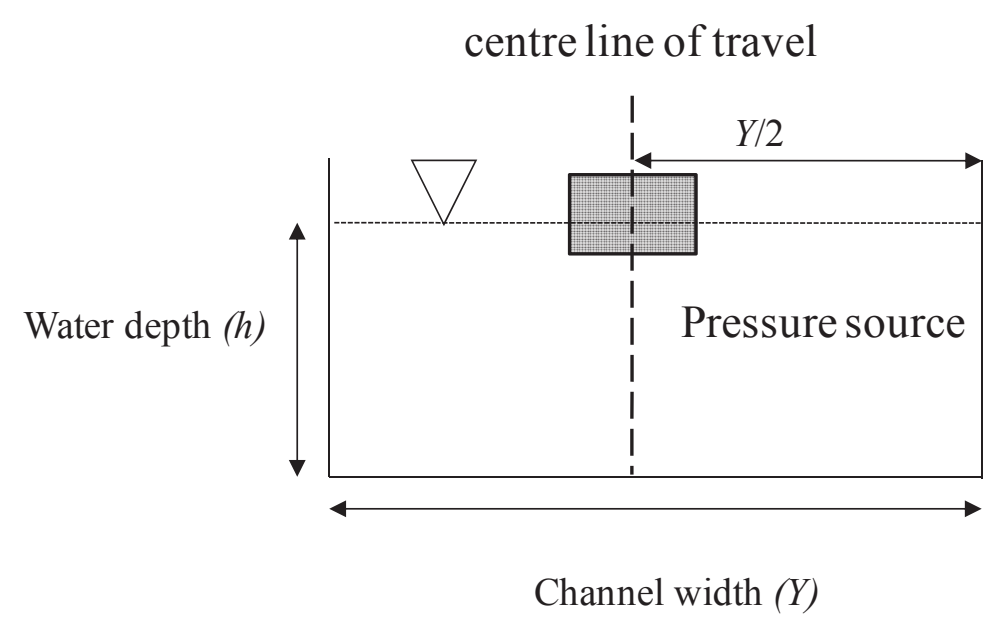

Figure 2-25: Bathymetry parameters for the linear track.

The bathymetry parameters for the circular track are shown in Figure 2-4 and analysed as follows:

a. Radius of the pool outer wall $\left(\boldsymbol{R}_{\boldsymbol{0}}\right)$. To define the tightness of the circular track, $R_{0}$ was non-dimensionalised by $L W L$; as per Eq. (2.10).

b. Radius of the start of the beach $\left(\boldsymbol{R}_{\text {beach }}\right)$. The start of the beach was defined as the start of the beach slope.

c. Lateral distance from the outer wall to the start of the beach $\left(y_{\text {beach }}\right)$. $y_{\text {beach }}$ was defined as distance between the outer wall and the start of the beach:

$$
y_{\text {beach }}=R_{0}-R_{\text {beach }}
$$


$y_{\text {beach }}$ was normalised by the pressure source waterline length:

$$
y_{\text {beach }}^{*}=\frac{y_{\text {beach }}}{L W L}
$$

d. Water depth at the pool outer wall $\left(\boldsymbol{h}_{0}\right)$. The water depth measured at $R_{0}$.

e. Vertical height of start of the beach $\left(\boldsymbol{Z}_{\text {beach }}\right)$. The start of the beach was raised by a step of height $Z_{\text {beach }}$ to allow $h_{\text {beach }}$ to be set at the start of the beach at $y_{\text {beach }}$.

f. Water depth at the start of the beach $\left(\boldsymbol{h}_{\text {beach }}\right)$. $h_{\text {beach }}$ was normalised by:

$$
h_{\text {beach }}^{*}=\frac{h_{\text {beach }}}{h_{0}}
$$

The physical limit was $h_{\text {beach }}=h_{0}$; i.e. the start of the beach started at the bottom of the channel without a step.

g. Beach width $\left(\boldsymbol{Y}_{\text {beach }}\right) . Y_{\text {beach }}$ was the distance from the start of the beach to the location where $h_{y}=0$ (dry land). The physical limit was:

$$
Y_{\text {beach }}=R_{0}-y_{\text {beach }}
$$

That is, no dry island exists as the channel was as wide as the pool radius.

h. Beach slope (s). The beach slope was defined:

$$
\tan (s)=\frac{Y_{\text {beach }}}{h_{\text {beach }}}
$$




\subsubsection{Wave parameters}

The key wave parameters are measured at the pressure source and at the start of the beach are shown in Figure 2-26:

a. Wave celerity $\left(\boldsymbol{c}_{\boldsymbol{p}}\right)$. The wave celerity was determined by the wave dispersion relationship. The shallow water dispersion relationship was assumed to apply, defined in Eq. (2.8). Substituting $h=h_{0}$ :

$$
c_{p}=\sqrt{g \cdot h_{0}}
$$

Note that $c_{p}$ is a function of $y$.

b. Velocity $\left(\boldsymbol{u}_{\boldsymbol{0}}\right) \cdot u$ was the velocity component parallel with the pressure source centerline of travel. $u_{0}$ was measured at the outer wall $\left(R_{0}\right)$, and was non-dimensionalised by the $h_{0}$ in terms of the depth Froude number $\left(F r_{h 0}\right)$ [9] and $L W L$ in terms of the length Froude number $\left(F r_{l}\right)$ :

$$
F r_{h o}=\frac{u_{0}}{\sqrt{\text { g. } h_{0}}}
$$

and

$$
F r_{l}=\frac{u_{0}}{\sqrt{\text { g. } L W L}}
$$


c. Wave velocity $\left(\boldsymbol{u}_{\text {beach }}\right)$. $u_{\text {beach }}$ was the breakpoint wave velocity component parallel with the pressure source centerline of travel at $R_{\text {beach }}$, with $u_{\text {beach }}=\operatorname{surfer}$ speed $\left(c_{\text {surfer }}\right)$, assuming the surfer is not moving across the wave crest. Substituting $u_{\text {beach }}$ into Eq. (2.2):

$$
u_{\text {beach }}=c_{p} / \sin \left(\theta_{\text {peel }}\right)
$$

d. Wave featherlet angle ( $\varnothing) . \varnothing=0$ corresponded to waves travelling perpendicular to the pressure source's track (x-axis), with positive angles $\varnothing$ correspond to waves being propagated to the left (portside) of the body. At the start of the beach, the wave featherlet angle was the wave peel angle; $\varnothing_{\text {beach }}=\theta_{\text {peel }}$ :

$$
\sin \left(\emptyset_{\text {beach }}\right)=\frac{c_{p}}{u_{\text {beach }}}
$$

e. Wave height $(\boldsymbol{H})$. Whilst the overall wave height $(H)$, Figure 2-2, was a design requirement, to allow the wave heights to be compared for pressure sources with different $B, d, \alpha$, and $L W L, H$ was non-dimensionalised by the cubic root of the volume displacement $(\nabla)$;

$$
H^{*}=\frac{H}{\sqrt[3]{\nabla}}
$$

f. Wavelength $(\lambda)$. The wavelength of the waves was the distance between one wave crest and the next, Figure 2-2.

g. Wave period $(\boldsymbol{T})$. The wave period was time between one wave crest and the next passing a fixed point; i.e. one wavelength to pass a fix point. 


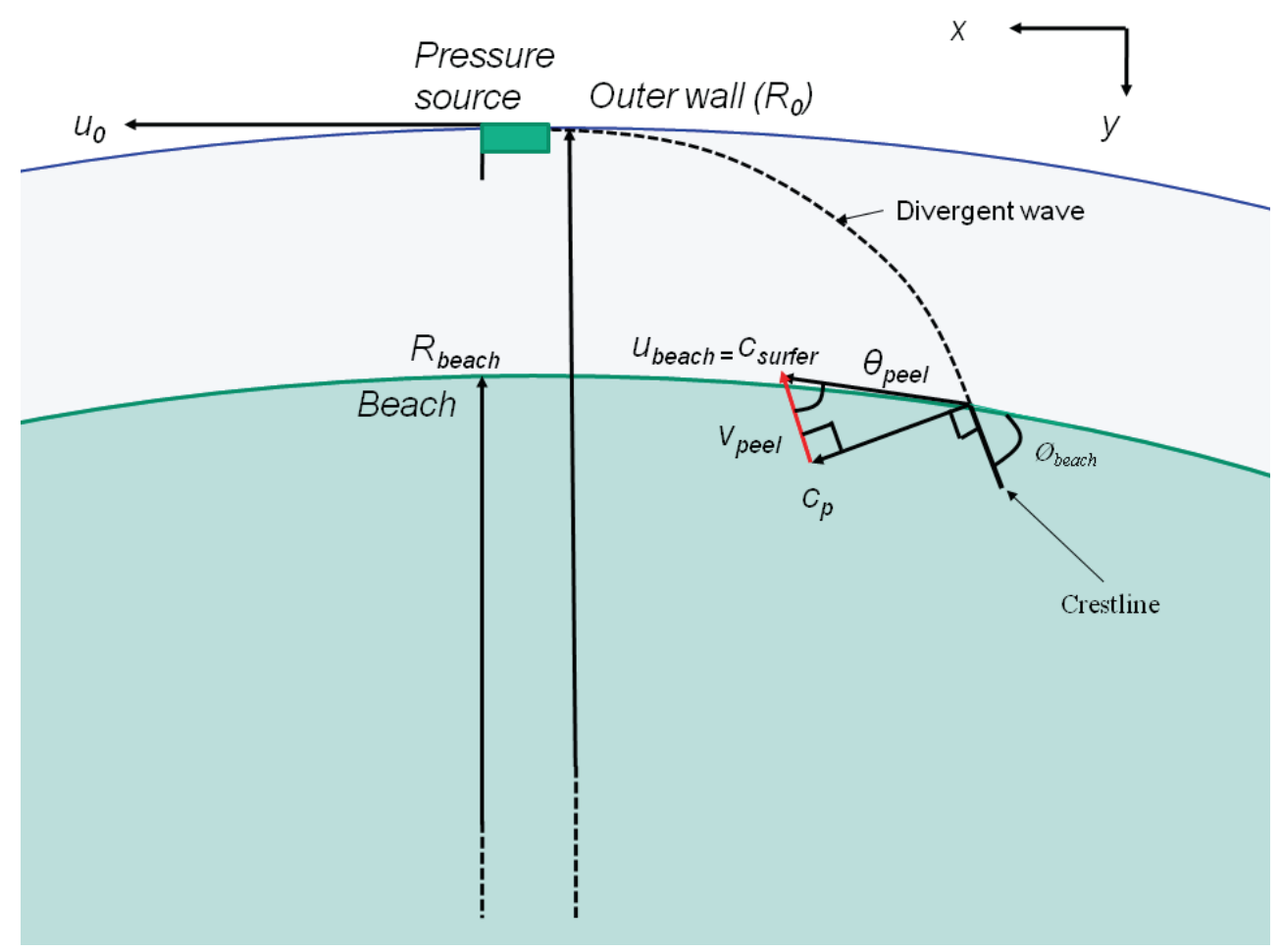

Figure 2-26. Pressure source and wave velocity components. The $\mathrm{x}$-axis was parallel with the pressure source centre-line of travel and the $y$ axis was perpendicular (radial) with the pressure source centreline of travel.

\subsubsection{Wave speed and pressure source velocity}

For a pressure source travelling in a circular track, the waves travelled with the pressure source; that is, the wave field was observed to have the same angular velocity $(\omega)$ as the pressure source. 
For the wave field to have the same $\omega$ as the pressure source at all radii, the tangential velocity component $(u)$ (parallel with the pressure source line of travel) must be proportional to the radial location $(R) . \omega$ was calculated at the pressure source centreline of travel $\left(R_{0}\right)$ :

$$
\omega=\frac{u_{0}}{R_{0}}
$$

The radius at $y\left(R_{y}\right)$ was defined as:

$$
R_{y}=R_{0}-y
$$

For the straight track:

$$
\lim _{R_{0} \rightarrow \infty}\left(\frac{R_{0}-y}{R_{0}}\right)=1
$$

To determine the wave velocity component parallel with the pressure source line of travel $\left(u_{y}\right)$ at $y$ as a function of $u_{0}$ and $R_{0}$, the angular velocity $(\omega)$ was assumed to be constant at all values of $y$, so Eq. (2.28) became:

$$
u_{y} / R_{y}=u_{0} / R_{0}
$$

To obtain $u_{y}$, Eq. (2.31) was rearranged to express $u_{y}$ as a function of $u_{y}$ and the radii:

$$
u_{y}=u_{0} \cdot R_{y} / R_{0}
$$

Again, to control the location of the wave break point, the bathymetry was designed to force the wave to break at the start of the beach $\left(y_{\text {beach }}\right)$. By forcing this condition, the certainty that the desired wave shape was able generated was increased. 
The tangential velocity at the start of the beach $\left(u_{\text {beach }}\right)$ was defined by substituting $u_{\text {beach }}$ for $u_{y}$ and $R_{\text {beach }}$ for $R_{y}$ in Eq. (2.32):

$$
u_{\text {beach }}=\left(\frac{R_{\text {beach }}}{R_{0}}\right) \cdot u_{0}
$$

By considering the channel section where $h_{0}$ was constant, Eq. (2.33) was rearranged:

$$
u_{0}=u_{\text {beach }} \cdot\left(\frac{R_{0}}{R_{\text {beach }}}\right)
$$

\subsubsection{Depth Froude number and water depth at the pool outer wall}

Eq (2.23) was rearranged for $u_{0}$ as a function of $F r_{h 0}$ and $h_{0}$ :

$$
u_{0}=F r_{h 0} \cdot \sqrt{g \cdot h_{0}}
$$

Further, $h_{0}$ was expressed as a function of $F r_{h 0}$ and $u_{0}$ :

$$
h_{0}=\frac{u_{0}^{2}}{F r_{h 0}{ }^{2} \cdot g}
$$

Again, considering the channel section where $h_{0}$ was constant, $u_{\text {beach }}$ was defined as a function of $F r_{h 0}$ and $h_{0}$ by combining Eq. (2.33) and Eq. (2.35), and rearranging:

$$
u_{\text {beach }}=F r_{h 0} \cdot \sqrt{g \cdot h_{0}} \cdot\left(\frac{R_{\text {beach }}}{R_{0}}\right)
$$


$h_{0}$ was defined a function of $F r_{h 0}$ and $u_{\text {beach }}$ by rearranging Eq. (2.37):

$$
h_{0}=\frac{R_{0}^{2} \cdot u_{\text {beach }}^{2}}{{R_{\text {beach }}}^{2} \cdot F r_{h 0}{ }^{2} \cdot g}
$$

With the water depth determined, the wave celerity $\left(c_{p}\right)$ was able to be calculated using general wave dispersion relationship; Eq. (2.8).

\subsubsection{Wave featherlet angle}

$\varnothing_{\text {beach }}$ was defined in Eq. (2.26). $\varnothing_{\text {beach }}$ was also determined in terms of $h_{0}$ by combining Eq. (2.26) with Eq. (2.8):

$$
u_{\text {beach }}=\frac{\sqrt{\text { g. } h_{0}}}{\sin \left(\varnothing_{\text {beach }}\right)}
$$

For the bathymetry used in the scale model testing, $h_{0}$ was constant from the outer wall to the start of the beach. $\varnothing_{\text {beach }}$ was determined as a function of $F r_{h 0}$ by substituting for $u_{\text {beach }}$ in Eq. (2.39) into Eq. (2.37):

$$
F r_{h 0 \cdot} \cdot \sqrt{g \cdot h_{0}} \cdot\left(\frac{R_{\text {beach }}}{R_{0}}\right)=\frac{\sqrt{\text { g. } h_{0}}}{\sin \left(\emptyset_{\text {beach }}\right)}
$$

Rearranging Eq. (2.40), $\varnothing_{\text {beach }}$ was expressed as a function of the pool and beach radii:

$$
\emptyset_{\text {beach }}=\sin ^{-1}\left(\frac{R_{0}}{R_{\text {beach }} \cdot F r_{h 0}}\right)
$$




\subsubsection{Lateral location of the start of the beach and wall width coefficient}

To determine the lateral location of the start of the beach $\left(y_{\text {beach }}\right)$, the wave quality was considered. As detailed in section 2.2.3, the length of smooth, unbroken wave crest was defined as the usable "wall" width. However, the wall width must be balanced against the phenomenon known as "lateral decay".

As the waves travel away from the pressure source, the wave height decreases as the wave energy is spread out across the lengthening wave crest. Havelock [60] showed the divergent wave height decreases exponentially with the lateral distance from the pressure source centre line of travel. He predicted that in sub-critical speed $\left(F r_{h}<0.7\right)$, the decay of divergent waves at the cusp has an exponent of $n=-0.33$, when measured tangential to a linear track:

$$
H_{y}=H_{0} \cdot y^{n}
$$

with $H_{0}$ being the wave height at the pressure source and determined for each pressure source.

For trans-critical speed $\left(0.7<F r_{h}<1.0\right)$, the exponent $n$ is less conclusive. Macfarlane [18] showed that $n$ changes with the pressure source speed and water depth, with the range of $1.3<n<-0.2$.

For the pool, the wall width was nominally the distance between the pressure source centreline of travel (being the outer wall in the circular pool) and the break point, minus the pressure source beam. Further, the area of turbulent water; termed the near-field region, Figure 2-27, is considered unsuitable for surfing and reduces the smooth surfable wall width; i.e. if the near-field region extended to the wave break point, there would be no surfable wall. A non-dimensional near-field region width, $Y_{N F}{ }^{*}$, was defined that was experimentally determined for each pressure source as a function of $F r_{h 0}$. 
Assuming the wave is triggered to break at the start of the beach $\left(y_{\text {beach }}\right)$, the usable wall width, $Y_{\text {wall }}$, was defined as a function of the distance to the breakpoint and the pressure source beam $(B)$ :

$$
Y_{\text {wall }}=y_{\text {beach }}-B . Y_{N F}^{*}
$$

The non-dimensionalised wall width $\left(Y_{\text {wall }}{ }^{*}\right)$ was defined in terms of the breaking wave height, $H_{\text {beach }}$ :

$$
Y_{\text {wall }}^{*}=\frac{\left(y_{\text {beach }}-B . Y_{N F}^{*}\right)}{H_{\text {beach }}}
$$

From the author's experience, to provide the surfer with sufficient lateral distance to perform the full range of surfing manoeuvres, as defined in Section 2.2.3, $Y_{\text {wall }} * \geq 1$ is required; i.e. the surfable wall needs to be at least as wide as the wave is high.

Therefore, the minimum distance to the start of the beach was determined as function of the surfable wall width and pressure source beam:

$$
y_{\text {beach }}=H_{\text {beach }} \cdot Y_{\text {wall }}^{*}+B \cdot Y_{N F}^{*}
$$

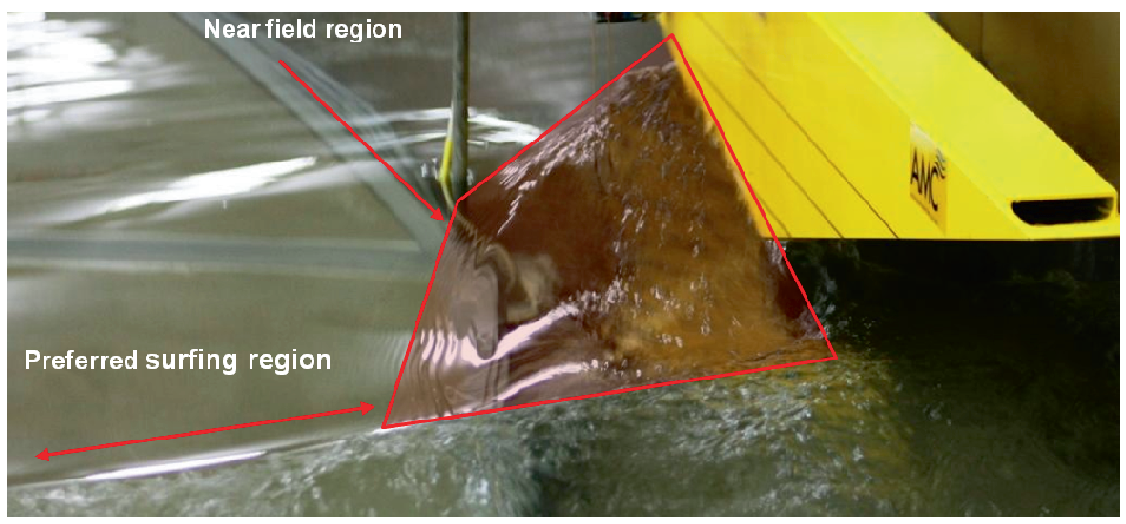

Figure 2-27. Near field and preferred surfing regions. 


\subsubsection{Wave breaking and water depth at the start of the beach}

Wave shoaling is the effect when a wave moves (y-axis in Figure 2-28) towards a shore with a sloping beach, the wave speed $\left(c_{p}\right)$ reduces with the reducing water depth $\left(h_{y}\right)$ in accordance with the wave dispersion relationship; Eq. (2.8).

The influence of shallowing water depth results in [63]:

a. Shortening of the wave length.

b. Increase in the wave height.

c. Increase in wave steepness. Wave steepness is defined as $H / \lambda$.

Should $h_{y}$ continue to decrease, the wave will reach a point where it comes too steep and breaks.

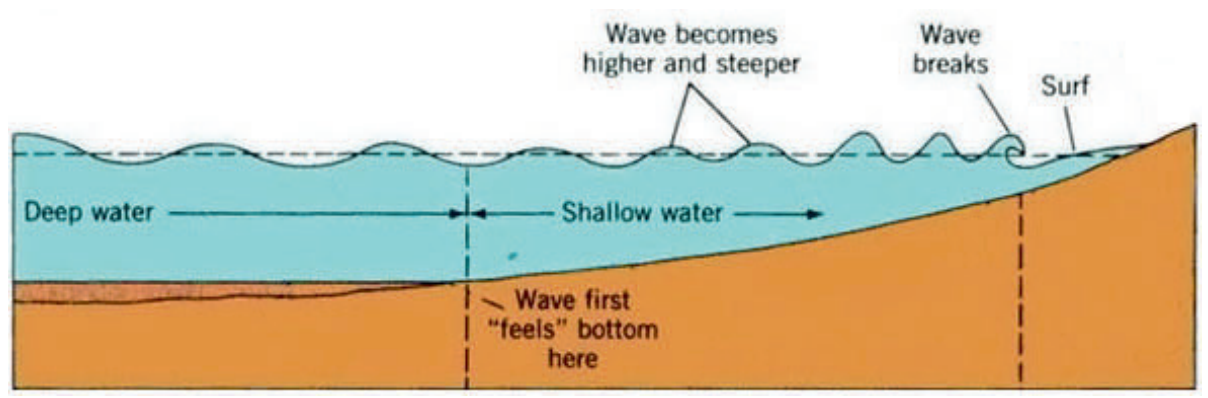

Figure 2-28. The wave steepness, $H / \lambda$, increases as a function of the water depth to a point where the wave breaks [63].

For the design of the wave pool, the waves will be forced to break at the start of the beach $\left(y_{\text {beach }}\right)$. This will allow the water depth at the start of the beach $\left(h_{\text {beach }}\right)$ to be set, and determined as a function of the design breaking wave height $\left(H_{\text {beach }}\right)$. The smaller waves for beginners will break in shallower water further up the beach slope; Figure 2-4. 
Miche [35] specified the wave height at the breakpoint $\left(H_{b r e a k}\right)$ as a function of $\lambda$ and $h$ :

$$
H_{\text {break }}=0.142 \lambda \tanh k h[\mathrm{~m}]
$$

Where wave number $(k)$ was:

$$
k=2 \pi / \lambda[\mathrm{rad} / \mathrm{m}]
$$

\section{Deep water}

In deep water, Eq. (2.46) reduces to a maximum wave steepness of:

$$
H_{\text {break }} / \lambda=0.142
$$

Or:

$$
\lambda / H_{\text {break }}=7
$$

\section{Shallow water}

In shallow water, Eq. (2.46) reduces to $H_{b r e a k}$ of:

$$
H_{\text {break }} / h=0.89
$$

Rearranging Eq. (2.50):

$$
h=1.12 . H_{\text {break }}
$$


For the pool, where the wave is assumed to be forced to break at the start of the beach, it was assumed $H_{\text {beach }}=H_{\text {break }}$ and the water depth was "shallow". Therefore, $h_{\text {beach }}$ was expressed as a function of $H_{\text {beach }}$ and a breaking water depth constant $(\gamma)$ :

$$
h_{\text {beach }}=\gamma \cdot H_{\text {beach }}
$$

where $\gamma=1.13$ from Eq.(2.51).

Finally, $h_{\text {beach }}$ was normalised by the water depth at the pool outer wall $\left(h_{0}\right)$ :

$$
h_{\text {beach }}^{*}=\frac{h_{\text {beach }}}{h_{0}}
$$

With the physical limit being $h_{\text {beach }}=h_{0}$.

\subsubsection{Length Froude number}

For a linear track, Soomere [58] states that the largest ship waves are developed when $F r_{l}=1 / \sqrt{\pi} \approx 0.56$ and $F r_{h} \approx 1$. Soomere [58] also recommends that ships should avoid operating in this condition as $L W L$ was half $\lambda$; the pressure source sits within the generated wave trough; Figure 2-29. Tuck et. al. [46] stated that a peak in wave making resistance observed at $F r_{l} \approx 0.6$ (in deep water).

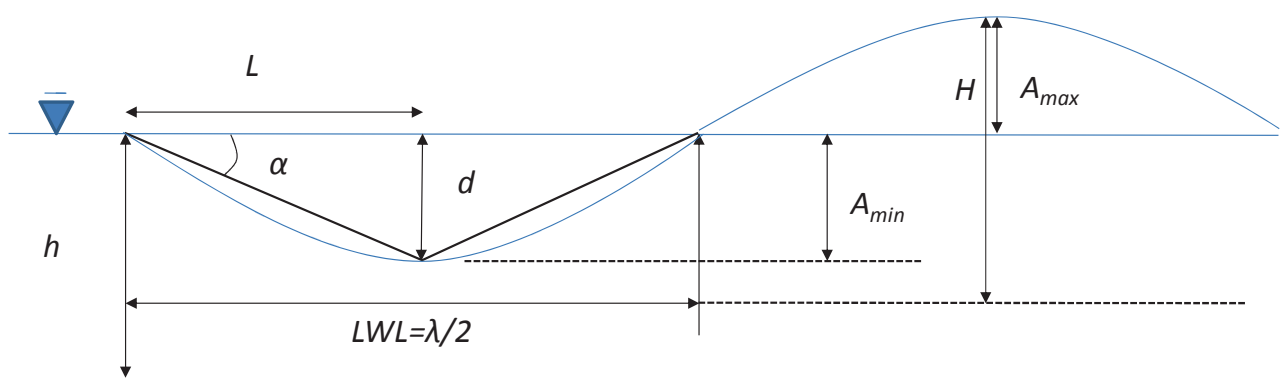

Figure 2-29. Pressure source to wave relationship at $F r_{l}=0.56$. 
For the wavedozer, $L W L$ and draught $(d)$ formed the entry angle $(\alpha)$, defined as:

$$
\tan (\alpha)=\frac{d}{L W L}
$$

For the wavedozer $F r_{l}$ was defined in terms of $d$ and $\alpha$, by substituting Eq. (2.54) into Eq. (2.24):

$$
F r_{l}=\frac{u_{o}}{\sqrt{g \cdot \frac{d}{\tan (\alpha)}}}
$$

\subsubsection{Inshore Iribarren number and beach slope}

To determine the wave breaking intensity, $\xi$, Eq. (2.1), the wavelength component parallel to the beach slope $\left(\lambda_{s}\right)$ was determined. For the experimental method, the wavelength component perpendicular to the slope, and parallel with the pressure source line of travel $\left(\lambda_{\text {beach }}\right)$, was measured; Figure 2-30. The wavelength parallel $\left(\lambda_{s}\right)$ to the slope was then determined as a function of $\lambda_{\text {beach }}$ and $\varnothing_{\text {beach }}$ :

$$
\lambda_{s}=\frac{\lambda_{\text {beach. }}}{\tan \left(\varnothing_{\text {beach }}\right)}
$$

$\xi$ as a function of $\lambda_{\text {beach }}$ was determined by substituting Eq. (2.56) into Eq. (2.1):

$$
\xi=\frac{\tan (s)}{\sqrt{\frac{H_{\text {beach }} \cdot \tan \left(\emptyset_{\text {beach }}\right)}{\lambda_{\text {beach }}}}}
$$


Finally, the beach slope $(s)$ was determined as a function of $H_{\text {beach }}$ by rearranging Eq. (2.57):

$$
s=\tan ^{-1}\left(\xi \cdot \sqrt{\frac{H_{\text {beach }} \cdot \tan \left(\emptyset_{\text {beach }}\right)}{\lambda_{\text {beach }}}}\right)
$$

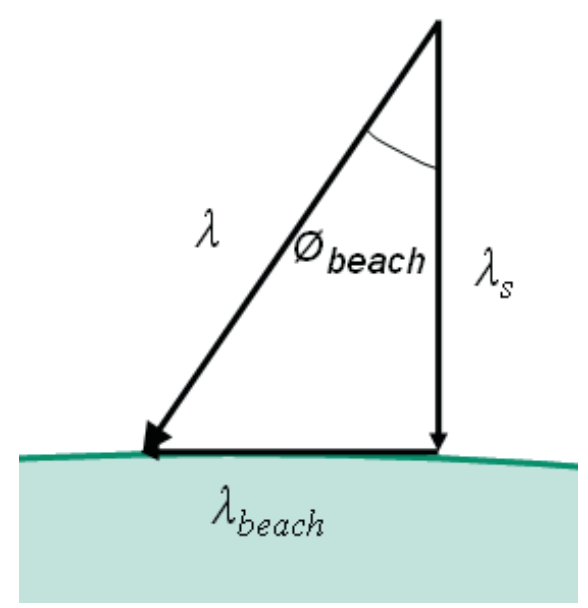

Figure 2-30. Wavelength components and featherlet angle $\left(\varnothing_{\text {beach }}\right)$.

\subsubsection{Blockage}

For a pressure source travelling in a constrained channel, the blockage $(\kappa)$, defined as the pressure source cross sectional area $\left(A_{s}\right)$ to channel cross-sectional area $\left(A_{c}\right)$ :

$$
\kappa=\frac{A_{s}}{A_{c}}
$$


For the pressure source:

$$
A_{s}=B . d
$$

For the circular track bathymetry, Figure 2-4, the width of the beach $\left(Y_{\text {beach }}\right)$ was defined as a function of $h_{\text {beach }}$ and $s$ :

$$
Y_{\text {beach }}=h_{\text {beach }} / \tan (s)
$$

For the channel with a beach of $s$ starting at $y_{\text {beach }}$.

$$
A_{c}=h_{0 .} y_{\text {beach }}+0.5 . h_{\text {beach }} . Y_{\text {beach }}
$$

Therefore, $A_{c}$ as a function of $h_{\text {beach }}$ and $s$ was determined by substituting Eq. (2.61) into Eq. (2.62):

$$
A_{c}=h_{0} \cdot y_{\text {beach }}+\frac{h_{\text {beach }}^{2}}{2 \tan (\mathrm{s})}
$$

Finally, $\kappa$ as a function of the pressure source shape and circular track bathymetry was determined by substituting Eq. (2.60) and Eq. (2.63) into Eq. (2.59):

$$
\kappa=\frac{B \cdot d_{0}}{h_{0} \cdot y_{\text {beach }}+\frac{h_{\text {beach }}{ }^{2}}{2 \tan (\mathrm{s})}}
$$




\subsubsection{Draught and waterline length}

The non-dimensionalised draught, $d^{*}$, was determined as a function of $\kappa$ and $B$, by rearranging Eq. (2.64) and substituting into Eq. (2.15):

$$
d^{*}=\frac{\kappa \cdot\left(h_{0} \cdot y_{\text {beach }}+\frac{h_{\text {beach }^{2}}}{2 \tan (\mathrm{s})}\right)}{B \cdot h_{0}}
$$

For the wavedozer, the waterline length $(L W L)$ was determined by rearranging Eq. (2.54) to have $L W L$ as a function of $d$ :

$$
L W L=\frac{d}{\tan (\alpha)}
$$

$L W L$ as a function of $\kappa$ and $B$ was detemined by substituting in Eq. (2.65) into Eq. (2.66):

$$
L W L=\frac{\kappa \cdot\left(h_{0} \cdot y_{\text {beach }}+\frac{h_{\text {beach }}{ }^{2}}{2 \tan (\mathrm{s})}\right)}{B \cdot \tan (\alpha)}
$$

\subsubsection{Beam}

Finally, in designing the pressure source, the beam was a major design parameter. The beam $(B)$ directly contributes to the blockage, Eq. (2.60), and the surfable wall width Eq. (2.43). The beam as function of blockage was determined by rearranging, Eq. (2.65):

$$
B=\frac{\kappa \cdot\left(h_{0} \cdot y_{\text {beach }}+\frac{h_{\text {beach }}{ }^{2}}{2 \cdot \tan (s)}\right)}{d^{*} \cdot h_{0}}
$$


For $B$ as a function of $H_{\text {beach }}$, the lateral distance relationship, Eq. (2.45), was substituted into Eq. (2.68):

$$
B \cdot \frac{d^{*} \cdot h_{0}}{\kappa}=h_{0} \cdot\left(H_{\text {beach }} \cdot Y_{\text {wall }}^{*}+B \cdot Y_{\text {wash }}^{*}\right)+\frac{h_{\text {beach }}{ }^{2}}{2 \cdot \tan (s)}
$$

Rearranged to group $B$ :

$$
\begin{gathered}
B \cdot \frac{d^{*} \cdot h_{0}}{\kappa}-B \cdot h_{0} \cdot Y_{\text {wash }}^{*}=h_{0} \cdot H_{\text {beach }} \cdot Y_{\text {wall }}^{*}+\frac{h_{\text {beach }}{ }^{2}}{2 \cdot \tan (s)} \\
B \cdot h_{0} \cdot\left(\frac{d^{*}}{\kappa}-Y_{N F}^{*}\right)=h_{0} \cdot H_{\text {beach }} \cdot Y_{\text {wall }}^{*}+\frac{h_{\text {beach }}^{2}}{2 \cdot \tan (s)} \\
B=\frac{\left(H_{\text {beach }} \cdot Y_{\text {wall }}^{*}+\frac{h_{\text {beach }}^{2}}{2 \cdot \tan (s) \cdot h_{0}}\right)}{\left(\frac{d^{*}}{\kappa}-Y_{N F}^{*}\right)}
\end{gathered}
$$

\subsection{Discussion}

The empirical relationships defined in this chapter allowed the pressure source shape, operating conditions, and bathymetry to be based on the design parameters of breaking wave height $\left(H_{\text {beach }}\right)$, wave breaking intensity $(\xi)$, and pool radius $\left(R_{0}\right)$. That is, for the commercial pool, the set of empirical relationships between the design parameters were determined to allow a pool of a given radius (determined by the available land area) to be designed for a combination of the desired height of the largest waves at the break point, and a plunging wave shape.

The limiting values for the pressure source shape, operating conditions, and bathymetry parameters were determined experimentally. The experiments and the results are discussed in the following chapters. 


\section{Chapter 3 Experimental approach}

\subsection{Chapter introduction}

This chapter, and annex A, detail the test program, model setup, instrumentation, testing procedure, treatment of the results and the error analysis. 639 test runs (159 tow tank and 480 scale model) over 81 conditions (18 tow tank and 63 scale model) were conducted, as detailed in Annex B.

The results were used to determine the design parameter limiting values for input to the empirical analysis, and to validate the author's Michlet linear potential flow predictions, Essen's RAPID non-linear potential flow predictions [42], and Doyle [43] and Javanmardi's FVM models [44].

\subsection{Aims}

The focus of the experimental approach was first to determine the effect of the pressure source shape, operating conditions, and bathymetry on the wave generation, with the results presented in Chapter 4. The effects of the bathymetry on the wave breaking were tested, with the results presented in Chapter 5 .

\subsection{Facilities}

In order to achieve these objectives, linear and circular track scale models were built and tested at the University of Tasmania (UTAS) Australian Maritime College (AMC). The linear testing was conducted in the $100 \mathrm{~m}$ tow tank, with the circular scale model built in the Model Test Basin. The design for each of the bathymetries for the linear and circular track test series are detailed in Annex A. The instrumentation used to capture the wave shape and currents are

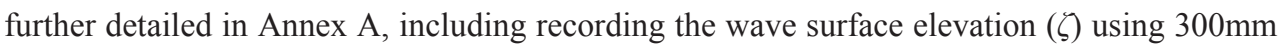
long capacitance type wave probes $(W P)$. 


\subsubsection{Linear track scale model}

The linear tow tank had a rectangular cross-section with a width of $3.55 \mathrm{~m}$, with a flat bottom; Figure 3-1 and Figure 3-2. The model scale was chosen based on the tow tank carriage maximum speed of $4 \mathrm{~m} / \mathrm{s}$ and maximum water depth of $1.5 \mathrm{~m}$.

The pressure sources were attached to the model carriage with a fixed heave and trim. The pressure sources were symmetrical about the centre line of track, with the pressure source travelling down the centre of the tank. Measurements were only taken on the port side.

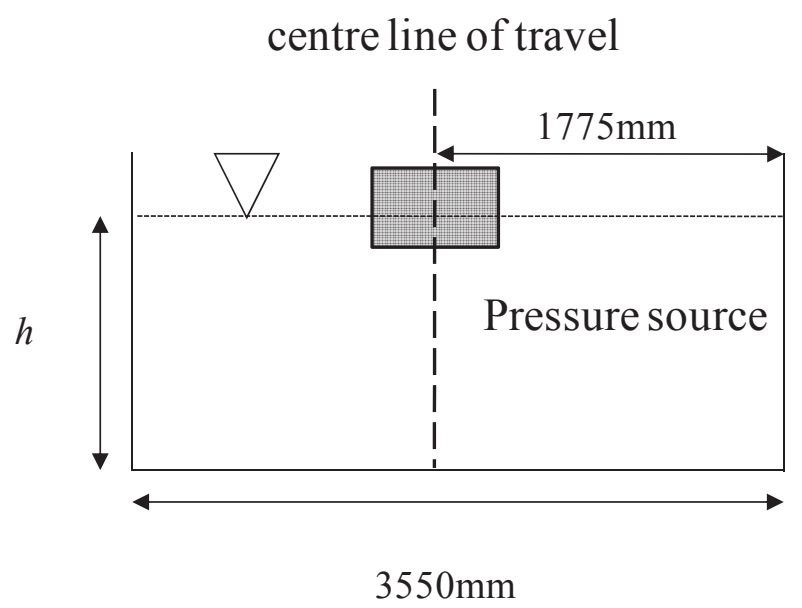

Figure 3-1: Linear track tow tank channel cross-section. 


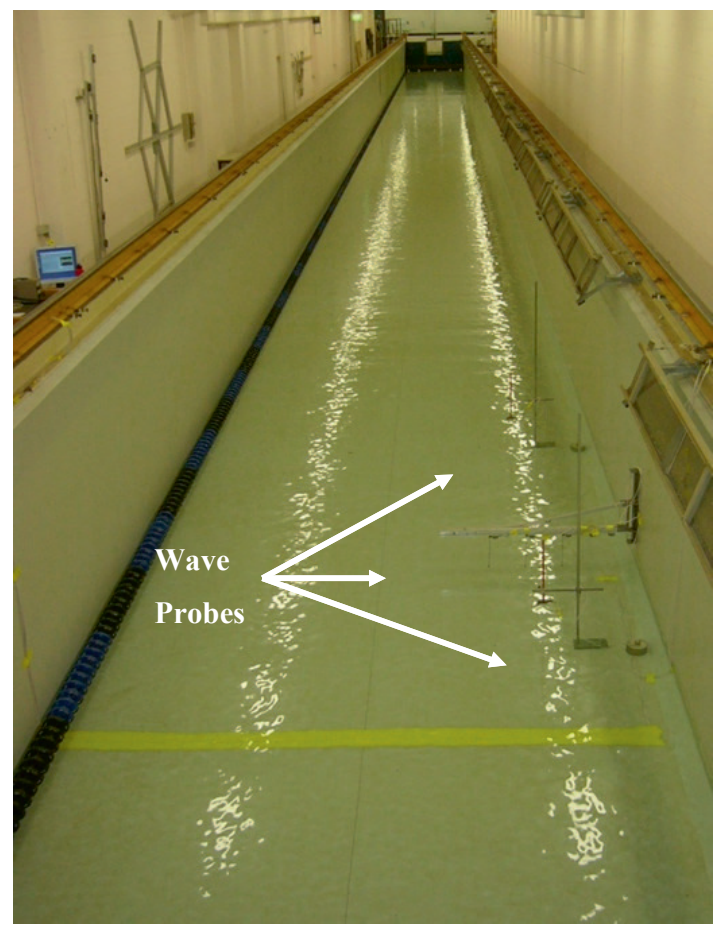

Figure 3-2. Linear track tow tank setup. The wave probe array is shown.

\subsubsection{Circular track scale model}

The Model Test Basin is $35 \mathrm{~m}$ long, $12 \mathrm{~m}$ wide and has a water depth range of 0 to $1.0 \mathrm{~m}$. The bottom of the basin was flat, $+/-3 \mathrm{~mm}$, providing the ability to conduct experiments in very shallow water depths.

The radius of the circular track scale model was the maximum that could be installed in the basin, allowing for $1 \mathrm{~m}$ access around the model; Figure 3-3. The motor and gearbox were installed permanently into the ceiling, and controlled using the existing winch controller. The scale model design drawings are detailed in Figure A-3 to Figure A-5. 
The pressure sources were attached to the drive arms and were fixed in heave and trim. The bathymetry was built from a combination of fibre reinforced concrete sheets, bricks, pavers and concrete blocks.

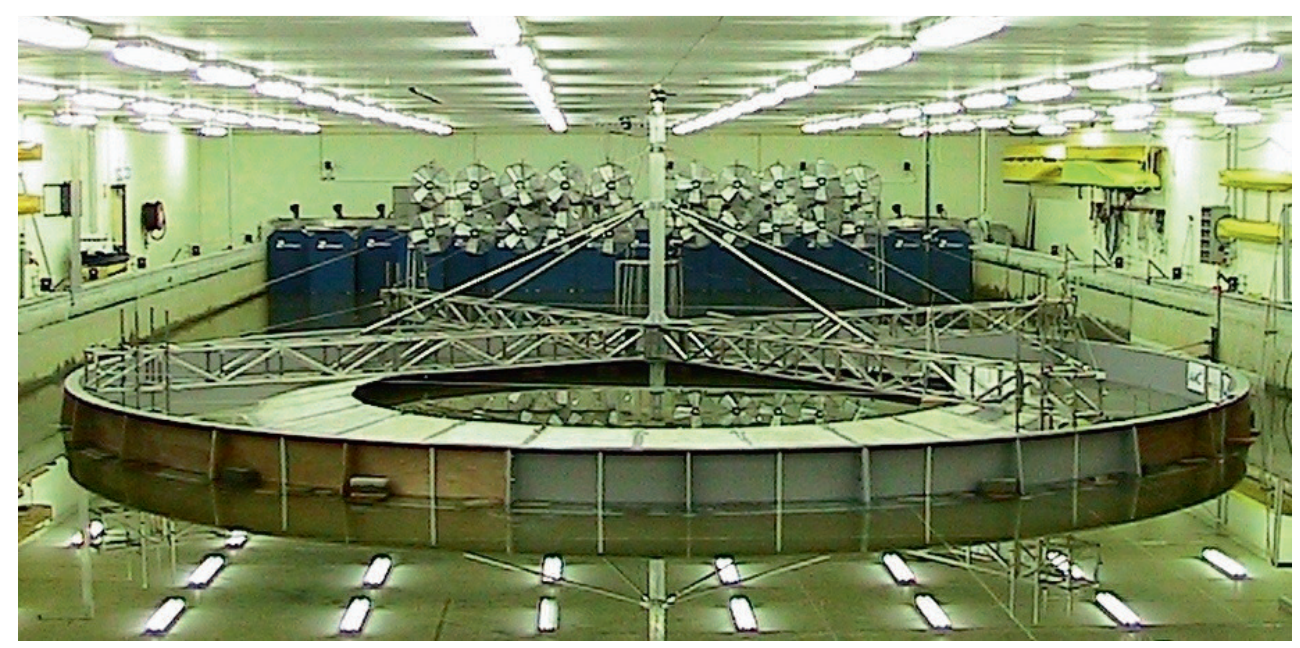

Figure 3-3. Circular track scale model installed in the UTAS AMC Model Test Basin.

\subsection{Pressure source models}

Two different types of pressure source shapes were investigated: parabolic and wavedozer. Examples are shown in Figure 3-4 for a parabolic pressure source, Figure 3-5 a linear track wavedozer and Figure 3-6 a circular track wavedozer. The wavedozer was investigated by Standing [30], and further developed by Driscoll [31] and Renilson [32]. The wavedozer was also a very simple structure to form, essentially simply being an inclined flat plate. The wavedozers used differed from those previously tested by Standing [30], Driscoll [31] and Renilson [32], that spanned the channel, where the wavedozer tested by the author had a limited beam. Renilson [32] used entry angle $(\alpha)$ of $14^{\mathrm{O}}$ and this was initially used by the author. The pressure sources tested in each series are detailed in Table 3-1 and shown in Annex A. 


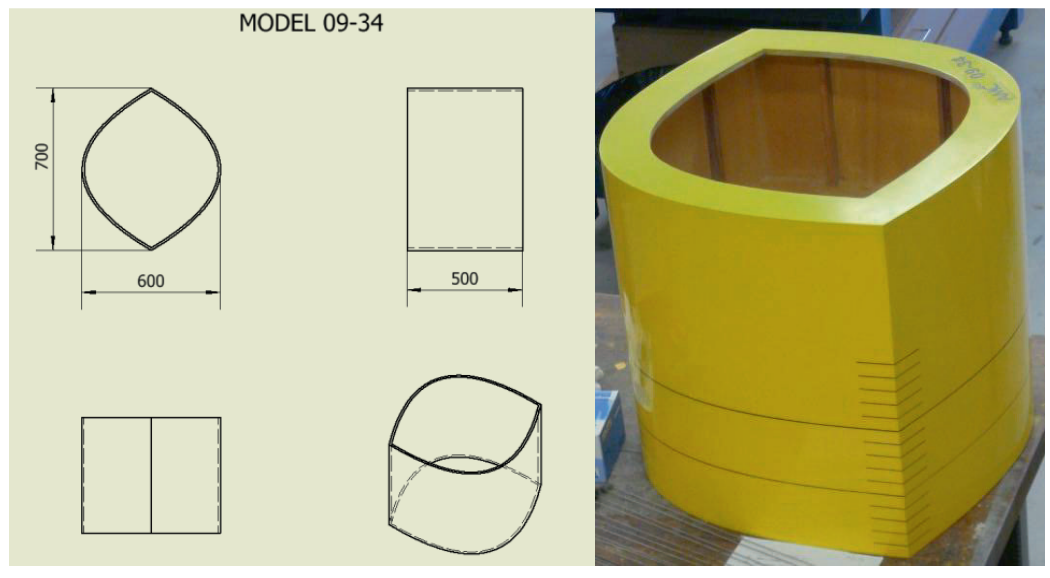

Figure 3-4: Linear track scale model 09-34 parabolic pressure source with 700mm length, $600 \mathrm{~mm}$ beam and, $500 \mathrm{~mm}$ height.

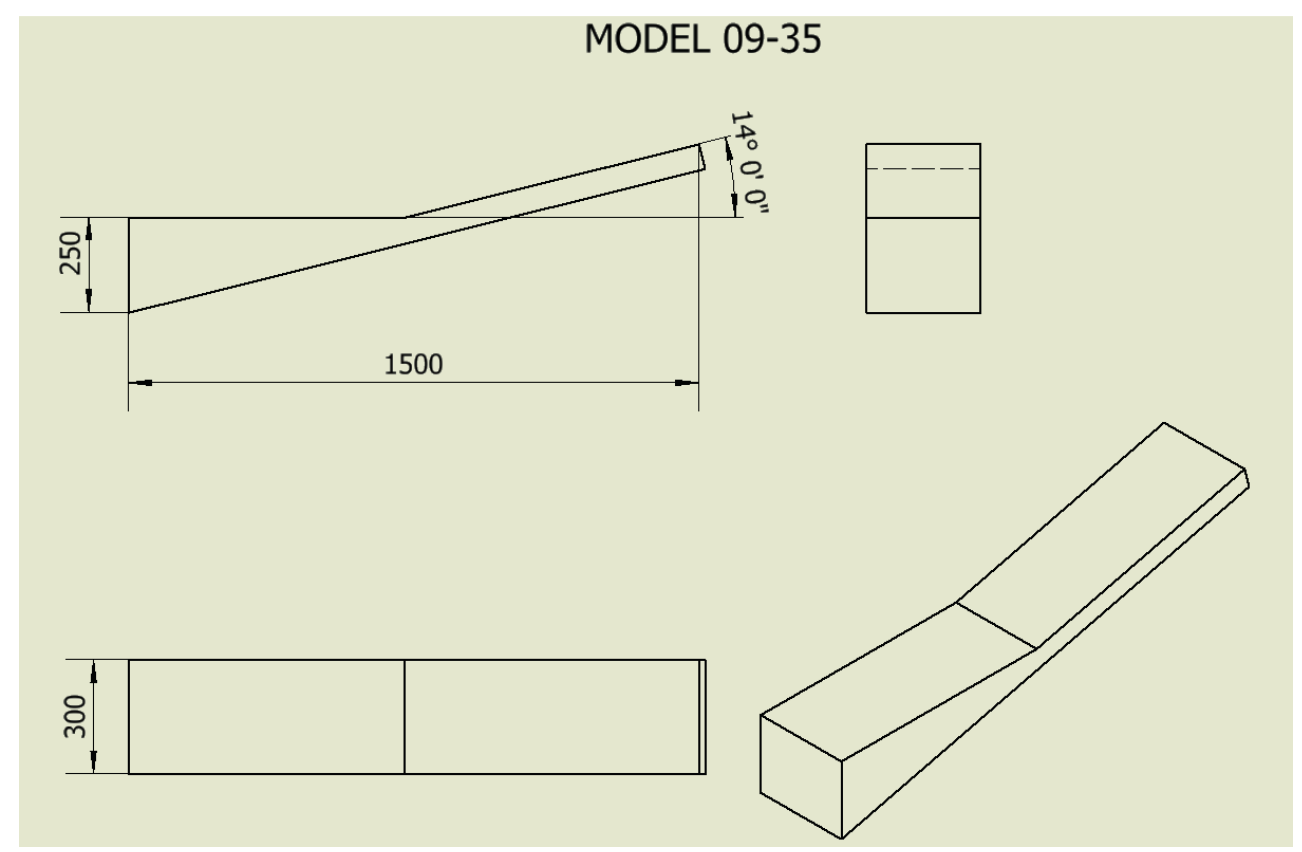

Figure 3-5: Linear track scale model 09-35 wavedozer with $1500 \mathrm{~mm}$ length, $300 \mathrm{~mm}$ beam and $\alpha=14^{\mathrm{O}}$. 


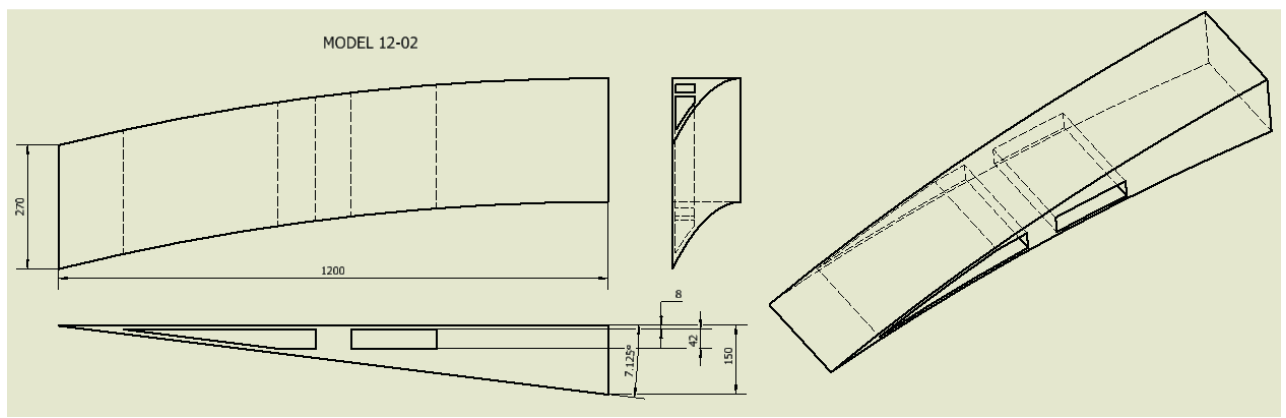

Figure 3-6: Circular track series 3 model 12-02 wavedozer with $1200 \mathrm{~mm}$ length, $275 \mathrm{~mm}$ beam and $\alpha=7^{\mathrm{O}}$.

\begin{tabular}{|l|l|l|c|c|}
\hline Serial & $\begin{array}{l}\text { Model } \\
\text { Number }\end{array}$ & $\begin{array}{l}\text { Pressure } \\
\text { Source Type. }\end{array}$ & $\begin{array}{l}\text { Beam } \\
{[\mathbf{m m}]}\end{array}$ & $\alpha$ [deg] \\
\hline \multicolumn{5}{|c|}{ Linear } \\
\hline 1 & Model 09-33 & Parabolic & 300 & N/A \\
\hline 2 & Model 09-34 & Parabolic & 600 & N/A \\
\hline 3 & Model 09-35 & Wavedozer & 300 & 14 \\
\hline \multicolumn{5}{|c|}{ Circular Series 1 } \\
\hline 4 & Model 10-24 & Wavedozer & 176 & 14 \\
\hline 5 & Model 10-25 & Wavedozer & 251 & 14 \\
\hline 6 & Model 10-26 & Wavedozer & 176 & 14 \\
\hline 7 & Model 10-27 & Wavedozer & 251 & 14 \\
\hline \multicolumn{7}{|c|}{ Circular Series 2 } \\
\hline 8 & Model 11-10 & Wavedozer & 75 & $4-18$ \\
\hline 9 & Model 11-11 & Wavedozer & 175 & 14 \\
\hline 10 & Model 11-12 & Wavedozer & 275 & 14 \\
\hline 11 & Model 11-13 & Wavedozer & 150 & 14 \\
\hline & & Circular Series 3 & 7 \\
\hline 12 & Model 12-02 & Wavedozer & 275 & 7 \\
\hline 13 & Model 12-03 & Wavedozer & 550 & 7 \\
\hline
\end{tabular}

Table 3-1. Pressure sources. 


\subsection{Error analysis}

Error analysis (uncertainty analysis) was important in establishing a baseline of confidence for all data sets.

\subsubsection{Wave height reproducibility}

The repeatability of the wave heights measured by the wave probes was assessed for multiple configurations, with a $95 \%$ confidence level error within $5 \%$ found to be appropriate for all conditions. It was believed that this error incorporates allowances for the speed variation, wave probe calibration (assumed to be $+/-0.5 \mathrm{~mm}$ ), stability and repeatability. Thus this error of $+/-5 \%$ was used for all wave height plots.

\subsubsection{Ramp rate}

To determine the point at which the pressure source speed reached the steady state test speed, different ramp rates,

Table 3-2, were tested for $F r_{h 0} .=0.975$; with an example of the time trace of the pressure source speed shown in Figure 3-7. It was desirable to measure the waves on the first pass to ensure a sufficiently calm water surface.

As shown in Figure 3-7, the speed was found to oscillate for approximately 25 - 30 seconds for a ramp rate of $5 \%$ per second, with a $95 \%$ confidence for the error of the speed from 20 - 40 seconds at $F r_{h 0}=0.975$ was $F r_{h 0}=+/-0.018=+/-2 \%$. It was concluded that a ramp rate of $5 \%$ per second allowed a sufficiently steady state speed to be achieved at the first pass, with any variation in wave height within the $5 \%$ repeatability error. 


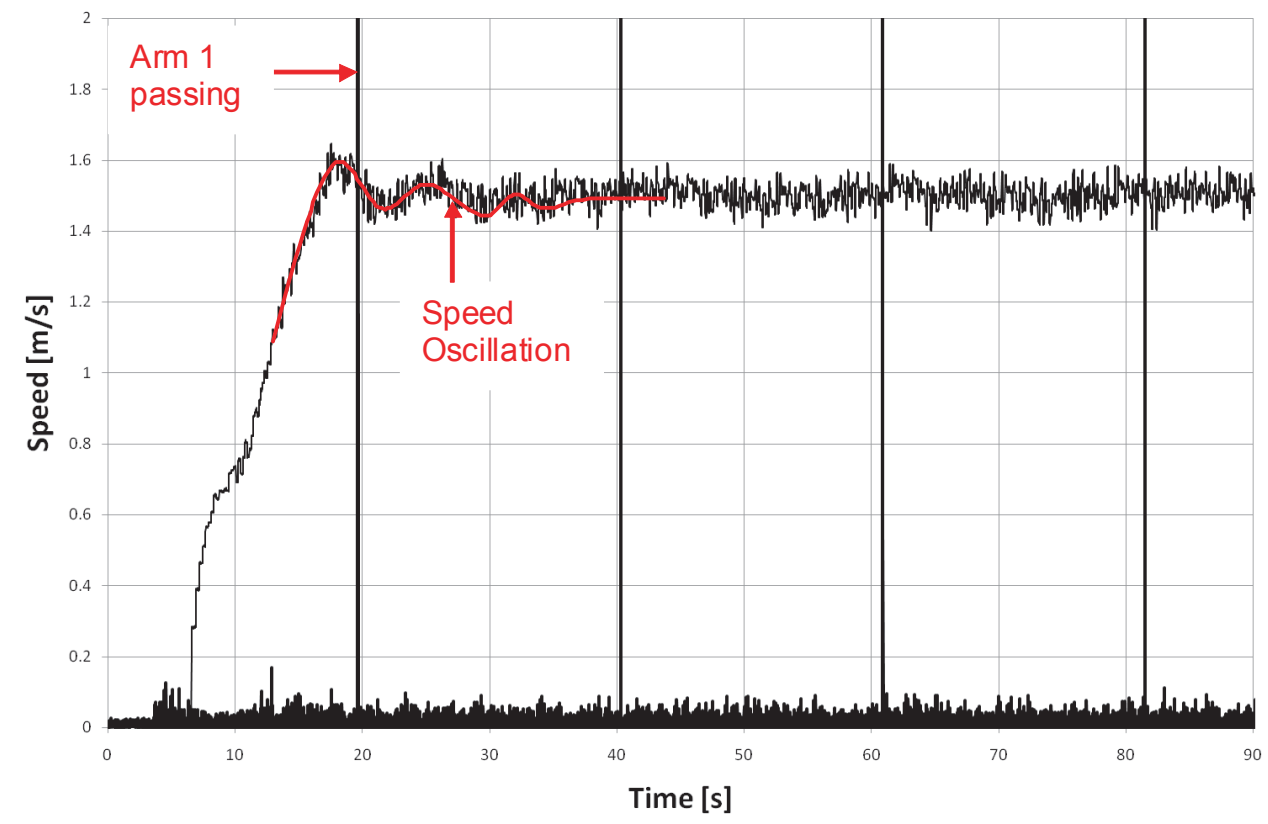

Figure 3-7: Example of time trace of $u_{0}$ for condition 6 model 2 with $d^{*}=0.2$ in $h_{0}=250 \mathrm{~mm}$ at $F r_{h 0}=0.975$ with a ramp rate of $5 \%$ per second. The passing of arm number 1 recorded by the laser is shown.

\begin{tabular}{|c|c|}
\hline $\begin{array}{c}\text { Ramp up value } \\
{[\% / \mathbf{s e c}]}\end{array}$ & $\begin{array}{c}\text { Time to steady speed } \\
{[\mathbf{s}]}\end{array}$ \\
\hline 2.5 & 20 \\
\hline 5 & 25 \\
\hline 7.5 & 40 \\
\hline 10 & 60 \\
\hline
\end{tabular}

Table 3-2. Time for $u_{0}$ to reach a steady state for different ramp rates. 


\subsection{Analysed results}

As detailed in section 2.4, to allow the wave heights to be compared for pressure sources with different non-dimensionalised and normalised design parameters, the wave height was normalised by the cubic root of the pressure source volume displacement $(\nabla)$ :

$$
H^{*}=\frac{H}{\sqrt[3]{\nabla}}
$$

Stive [64] states that scale effects on wave height, and wave induced velocities, in the range $0.1 \mathrm{~m}$ to $1.5 \mathrm{~m}$ are negligible. Therefore, it was assumed that the generated wave heights were able to be scaled geometrically with the length scale, and velocities scaled by the Froude velocity scale; being the square root of the length scale.

\subsubsection{Qualitative assessment - wave score}

For determining the suitability of the waves for surfing, the wave quality was as important as the maximum wave height at the break point. To support the qualitative assessment of the wave quality, the wave scoring system developed by Hartley [39], based on the Association of Surfing Professions scale [65], was used, Table 3-3. The judging criteria were clarified to allow for the steady state nature of the waves generated in the pool. An example of a wave in each score range are shown in Figure 3-8 to Figure 3-12 respectively. The wave scores for the first and second waves for each run for Conditions 47 to 64 are detailed in Annex C.

\begin{tabular}{|l|l|l|}
\hline Score & Description & Requirements \\
\hline 0 & No wave. & Unrideable. \\
\hline $0.0-1.9$ & Barely surfable. & No turns. Spilling wave. \\
\hline $2.0-3.9$ & Fair. & Simple turns. Spilling wave. \\
\hline $4.0-5.9$ & Average. & Turns, smooth wave. Spilling wave. \\
\hline $6.0-7.9$ & Good. & Plunging wave with smooth, steep wall. \\
\hline $8.0-10.0$ & Excellent. & Plunging wave with long, smooth, steep wall. \\
\hline
\end{tabular}

Table 3-3. Wave scores (Hartley [39]). 


\section{Barely surfable}

Figure 3-8 is an example of a barely surfable wave, with a score of 1 . This wave may be ridden on large displacement board (longboard) with no significant turns possible.

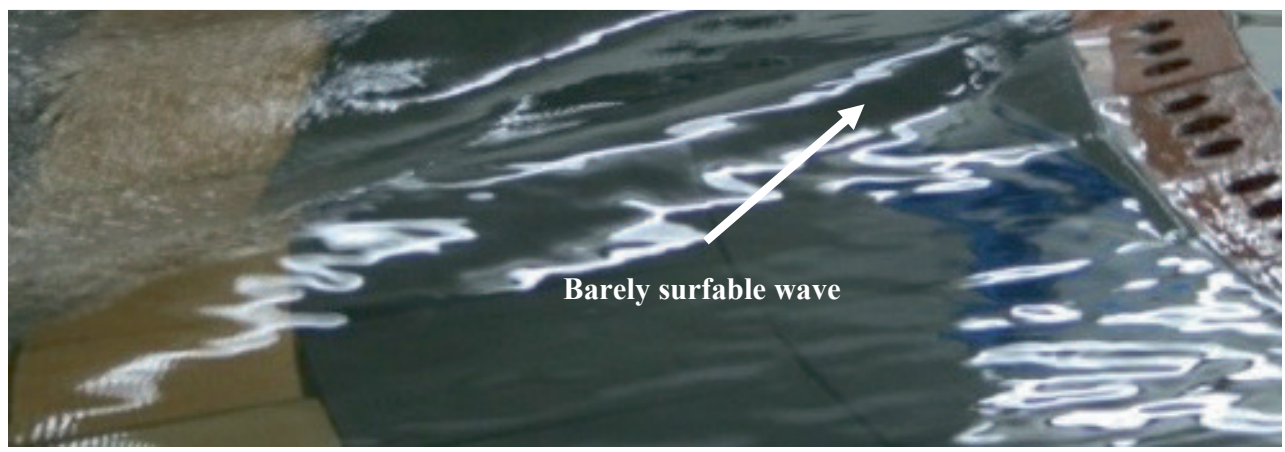

Figure 3-8. Example of barely surfable quality waves for condition 48 model $12-02$ with $d^{*}=0.2$ in $h_{0}=250 \mathrm{~mm}$ at $F r_{h 0}=0.95, \kappa=0.07, s=17^{\circ}$, and $y_{\text {beach }}{ }^{*}=1.4$. The pressure source was travelling towards the camera.

\section{Fair}

Figure 3-9 is an example of fair quality waves, with scores of 4 and 3 for the first and second wave respectively. These spilling waves had clean wave faces. They would allow only noncritical turns as the waves were not quite steep enough to support high performance manoeuvres.

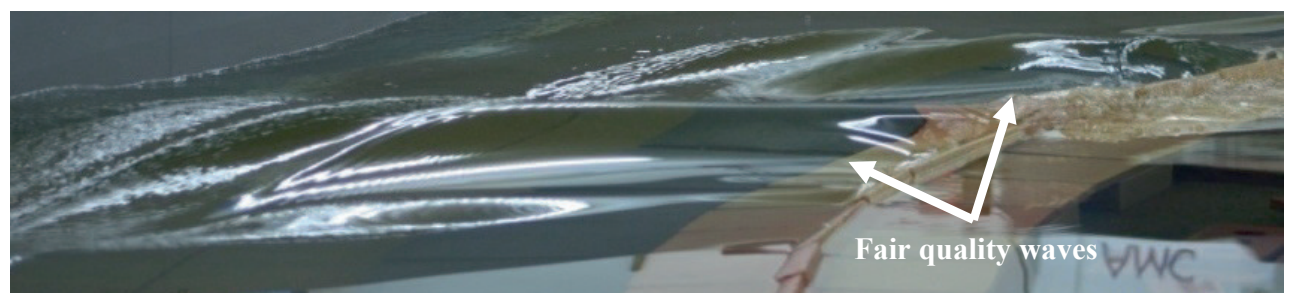

Figure 3-9. Example of fair quality waves for condition 57 model $12-02$ with $d^{*}=0.2$ in $h_{0}=250 \mathrm{~mm}$ at $F r_{h 0}=0.95, \kappa=0.06, s=17^{\circ}$, and $y_{\text {beach }} *=1.9$. 


\section{Average}

Figure 3-10 is an example of an average quality wave, with a score of 5. These spilling waves had a clean wave face. They would allow only non-critical turns as the wave was not quite steep enough to allow high performance manoeuvres.

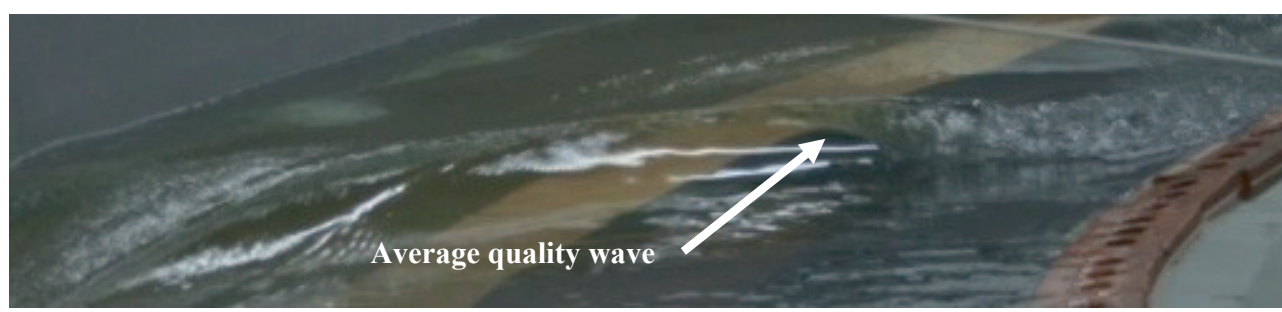

Figure 3-10. Example of an average quality wave for condition 48 model $12-02$ with $d^{*}=0.2$ in $h_{0}=250 \mathrm{~mm}$ at $F r_{h 0}=0.95, \kappa=0.07, s=17^{\circ}$ and $y_{\text {beach }} *=1.4$.

\section{Good}

Figure 3-11 is an example of a good quality wave, with a score of 8 . This spilling wave had a long steep clean wave face that was starting to plunge. The wave would allow high performance manoeuvres.

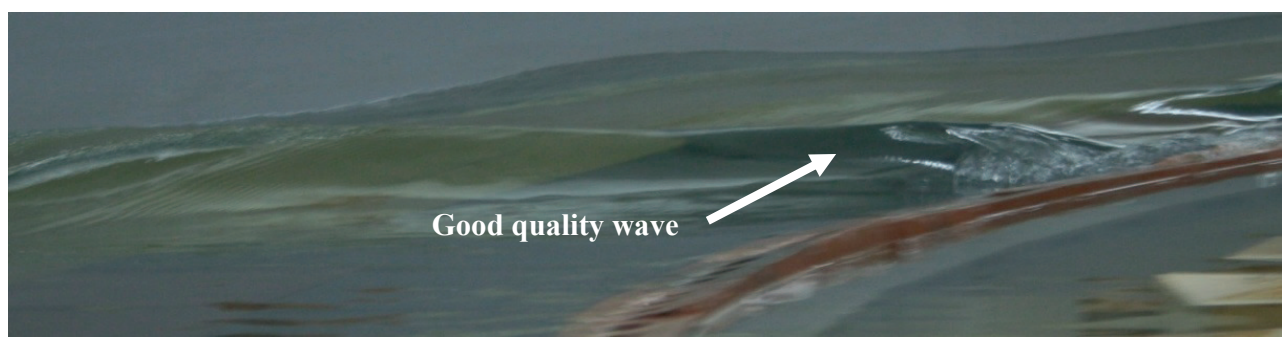

Figure 3-11. Example of a good quality wave for condition 55 model $12-02$ with $d^{*}=0.2$ in $h_{0}=250 \mathrm{~mm}$ at $F r_{h 0}=0.95, \kappa=0.07, s=17^{\circ}$ and $y_{\text {beach }} *=1.4$. 


\section{Excellent}

Figure 3-12 is an example of excellent quality waves, with scores of 10 . These plunging waves had long steep clean wave faces, and plunging shape creating a round (hollow) barrel. The wave would allow high performance manoeuvres as well as allowing for barrel rides.

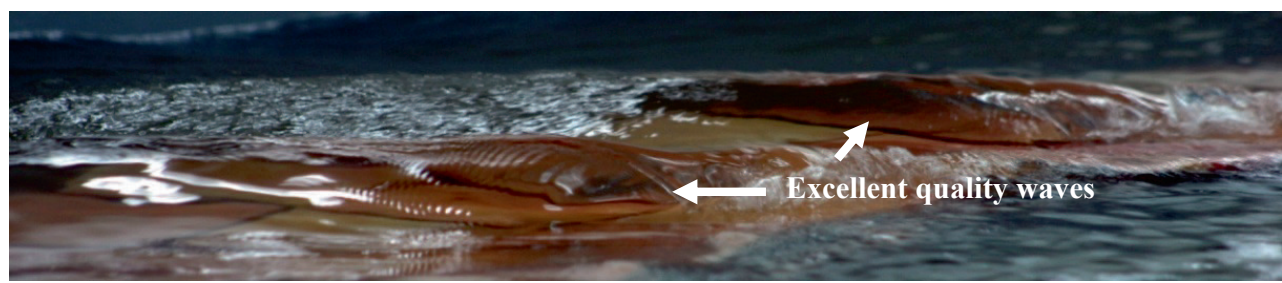

Figure 3-12. Example of excellent quality waves for condition 45 model $11-12$ with $d^{*}=0.2$ in $h_{0}=250 \mathrm{~mm}$ at $F r_{h 0}=0.975, \kappa=0.06, s=17^{\circ}$ and $y_{\text {beach }} *=1.9$.

\subsubsection{Wave shape analysis}

To assist in the analysis of the wave shapes, the wave probe time traces were combined to form a surface elevation plot of the free surface. Wave breaking was not (easily) captured by the wave probes, with photographs used to analyse the breaking wave shape. 


\section{Chapter 4 Pressure sources and wave generation}

\subsection{Chapter introduction}

This chapter details the experimental results to determine the effect of the pressure source shape, operating conditions, and bathymetry on the wave generation, with the focus to generate the highest practical, smooth waves.

The design parameters tested included:

a. Pressure source shape: parabolic and wavedozer. The pressure source shape effect on the near field effect was tested.

b. Velocity $\left(\boldsymbol{u}_{\boldsymbol{0}}\right)$ and Blockage $(\boldsymbol{\kappa})$. The limiting values for the pressure source parameters of entry angle, waterline length, beam and draught and operating condition (velocity) were determined, by initially considering blockage $(\kappa)$ and depth Froude number $\left(F r_{h}\right)$.

c. Wavedozer entry angle $(\alpha)$ and waterline length $(\boldsymbol{L} \boldsymbol{W} \boldsymbol{L})$. The effect of entry angle on the wave height and quality was tested.

d. Beam $(\boldsymbol{B})$. The limiting value of beam to generate the maximum the wave height was determined.

e. Draught $(\boldsymbol{d})$. The limiting value of draught to generate the maximum the wave height was determined.

f. Pressure source symmetry. For the wave pool, it is desirable to use a symmetrical, pressure source, as it allowed the pressure source to generate both left and right hand breaking waves without the need to change the pressure source, simply by being driven in clockwise and anti-clockwise directions respectively. The waves generated by symmetrical and asymmetrical pressure sources were compared. 
g. Linear and circular tracks. The effect of the pool radius $\left(R_{0}\right)$ on wave generation was determined. Physically, $R_{0}$ determines the overall size of the pool, the land area required, and the maximum number of pressure sources that may be used with the pool without degrading the wave quality, and thus the maximum number of surfing waves generated.

h. Multiple pressure source interaction. In order to generate the maximum number of surfable waves, the commercial wave pool requires multiple pressure sources, without adverse wave interaction; that is, the water surface needs to calm sufficiently after the passing of one pressure source, prior to the second pressure source travelling through the same water so as not to affect the wave quality of the waves generated by second and subsequent pressure sources. The wave interaction between multiple pressure sources was investigated.

The design parameters were normalised or non-dimensionalised as detailed in section 2.4.1. 


\subsection{Pressure source shape}

Michell [10] stated, and reiterated in Lazauskas [66], that the ship waves are created by a pressure source where there is a change in the cross-sectional area. Therefore, the initial focus of this study was on pressure source designs that had continually changing cross-sectional area to efficiently generate waves. Initial tests were conducted by Schipper [41] and Vries [40] using hyperbolic tangent waterline pressure sources in a linear track, with $B^{*}=0.6$ and 0.8. These initial tests lead to the investigation of the parabolic and wavedozer pressure sources, detailed in Section 3.4 and annex A.

To determine the pressure source design parameters for generating the highest waves, models were initially tested in a linear track. $H^{*}$ as a function of $F r_{h}$ measured close the pressure source for $\mathrm{Fr}_{h}<1.0$ were compared, with model $09-34600 \mathrm{~mm}$ beam parabolic pressure source generating the highest waves.

\subsection{Near-field region}

The near-field width $\left(Y_{N F}{ }^{*}\right)$ was determined for pressure sources by reviewing photos of the waves. For all the speeds of most interest $\left(\mathrm{Fr}_{h}>0.75\right)$, the parabolic models had a wide $\left(Y_{N F} *>5\right)$ near-field region, whilst the wave dozer (with $\alpha=14^{\circ}$ ) had a narrower near-field region $\left(Y_{N F} *<3\right)$. The wavedozer was chosen as the design pressure source as it produced the smoothest waves with the widest surfable wall.

In the circular track, for model 12-02 with $\alpha=7^{\circ}$, Figure 4-1, $Y_{N F} *$ was plotted as a function of $F r_{h 0}$, with $Y_{N F} * \leq 2$; Figure 4-2. 


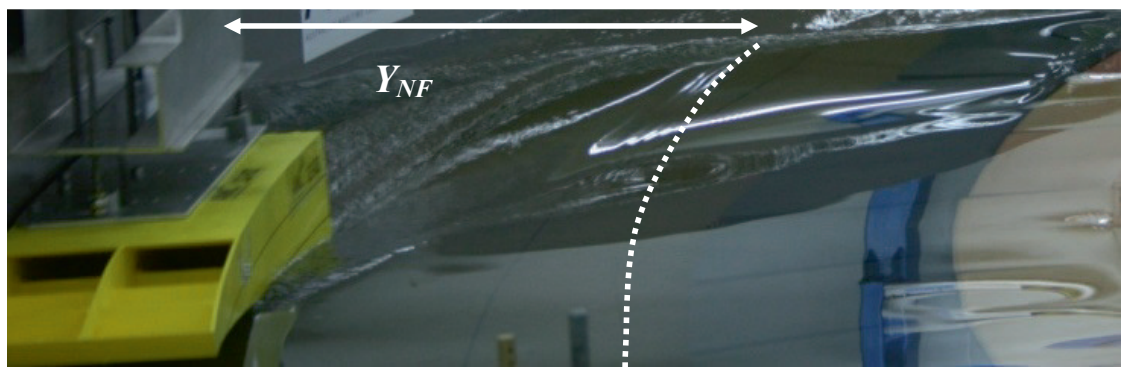

Figure 4-1. $Y_{N F} *=2$ for condition 56 model $12-02$ with $d^{*}=0.2$ in $h_{0}=250 \mathrm{~mm}$ at $F r_{h 0}=0.95$.

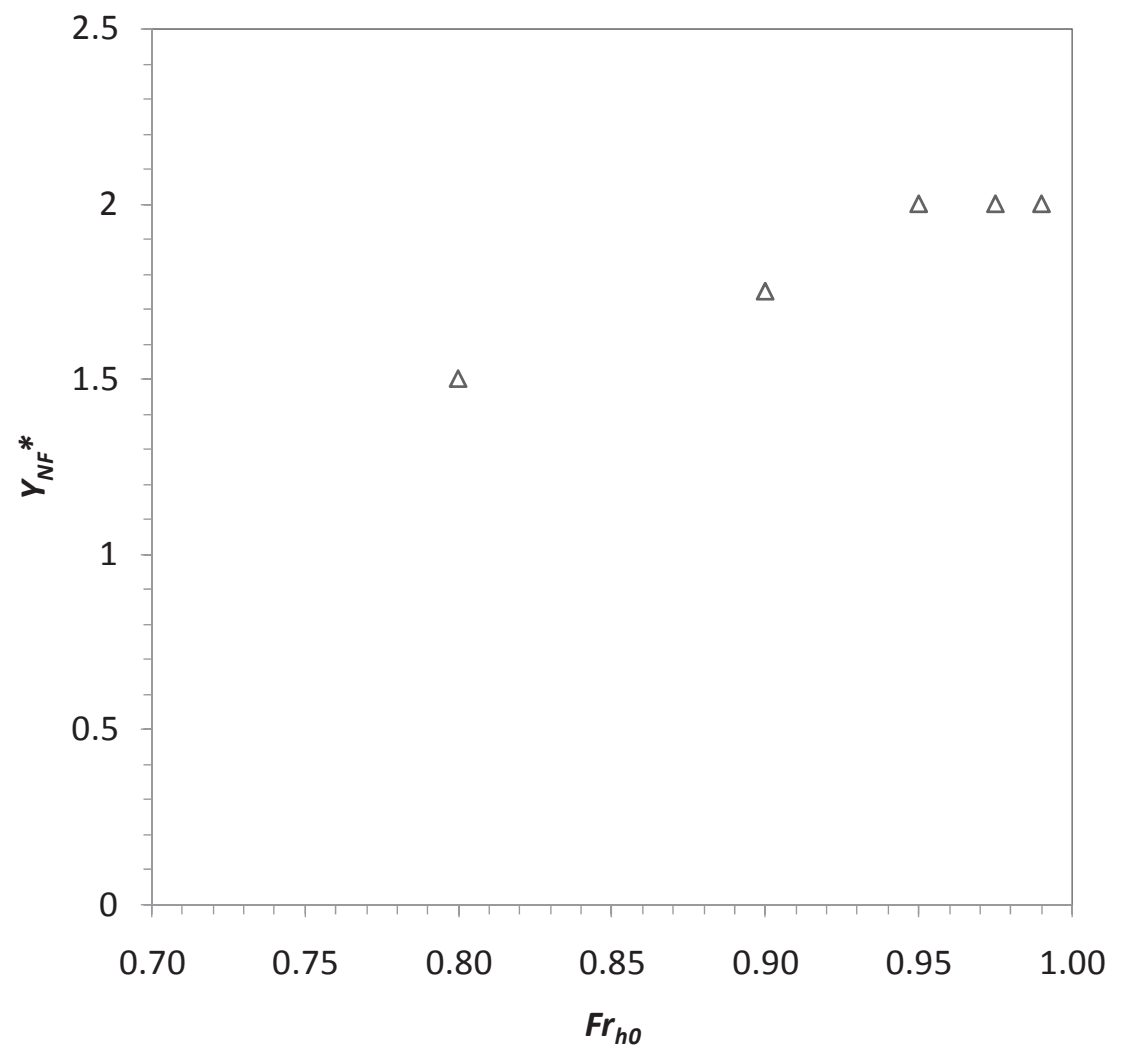

Figure 4-2. $Y_{N F} *$ as a function of $F r_{h 0}$ for condition 62 model 12-02 with $d^{*}=0.2$ in $h_{0}=250 \mathrm{~mm}$ and $\kappa \approx 0$. 


\subsection{Blockage and Depth Froude Number}

Once the wavedozer was determined as the design pressure source, the limiting values for the pressure source parameters of entry angle, waterline length, beam and draught and operating condition (velocity) were determined, by initially considering blockage $(\kappa)$ and depth Froude number $\left(F r_{h 0}\right)$.

\subsubsection{Critical zone}

Lyakhovitsky [23] described various zones, where solitons may be generated in a constrained channel, as functions of $\kappa$ and $F r_{h 0}$, as shown in Figure 4-3. Each zone is defined as follows and separated by "critical boundaries":

a. Sub-critical zone with limited soliton formation and a divergent wave field.

b. Critical zone with significant soliton formation.

c. Super-critical zone with limited soliton formation and super-critical wave field.

Lyakhovitsky [23] observed that the soliton forming critical zone expanded with increased $\kappa$; Figure 4-3. 


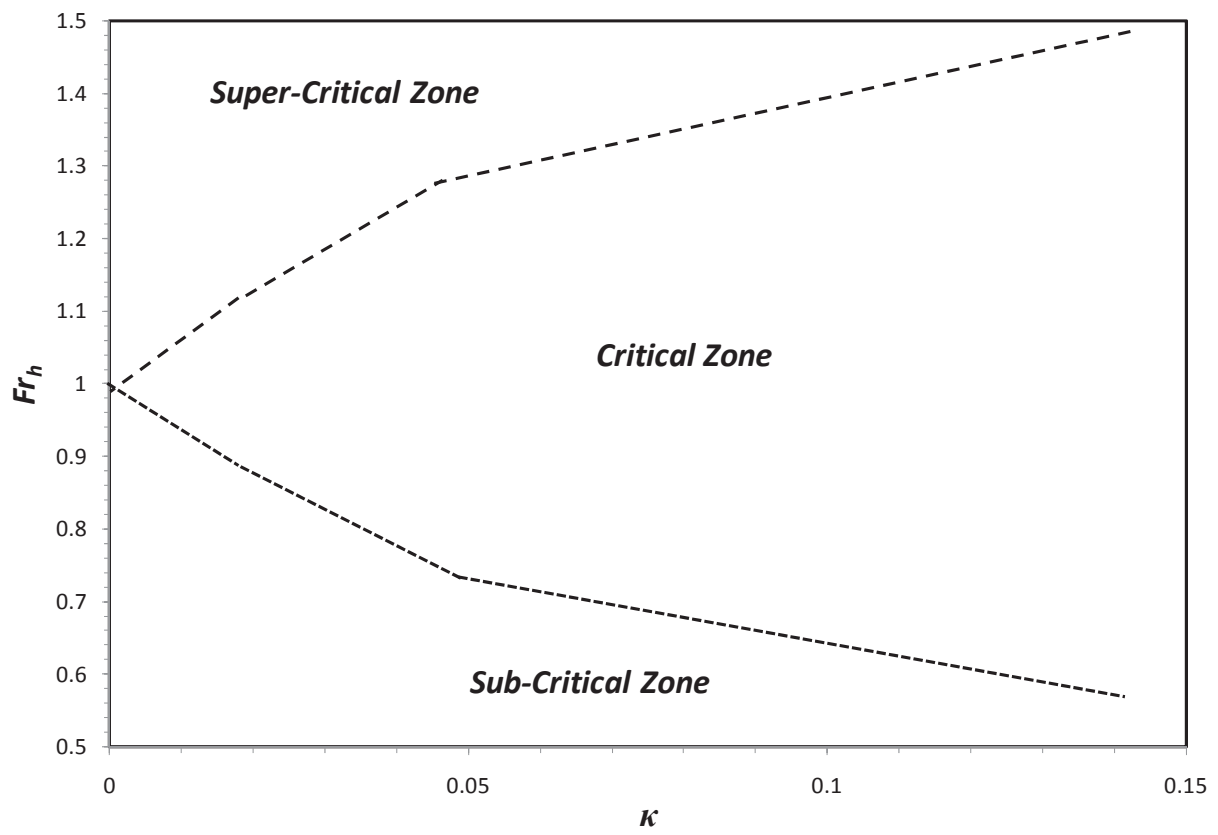

Figure 4-3. $\kappa$ as a function of $F r_{h}$ (Lyakhovitsky [23]).

\subsubsection{Criticality effect on wave height}

The circular scale model series 3 results with and without a beach in place are plotted against the Lyakhovitsky [23] critical boundaries in Figure 4-4. The conditions were determined to be in the critical zone when the wave height, $H^{*}$, as a function of lateral distance, $y^{*}$, was less than generated by condition $62 \kappa \approx 0$ at the same $F r_{h 0}$. An example to determine the where condition $56 \kappa=0.07$ at $F r_{h 0}=0.95$ was "sub-critical" or "critical", is shown in Figure 4-6:

a. The wave traces were analysed to determine the wave height for both conditions 56 and 62 at different lateral distances, $y^{*}$.

b. $\quad H^{*}$ as a function of $y^{*}$ were plotted for both conditions and compared; Figure $4-5$. The wave heights for condition 56 are less than condition 62, thus condition 56 determined to be "critical". 
c. Condition $56 \kappa=0.07$ at $F r_{h 0}=0.95$ was plotted as a "critical" (solid diamond) against Lyakovitsky's critical boundary.

Of the combinations of $\kappa$ and $F r_{h 0}$, only a few conditions were found to be "sub-critical" within Lyakovitsky's critical zone, with the furthest point being condition $49 y_{\text {beach }} *=1.9$ and $\kappa=0.06$ at $F r_{h 0}=0.95$. These results highlighted that the sensitivity of the wave generation is very complex when the parameters place the condition within the critical zone; extremely small changes in the design values may mean the difference between the waves being acceptable or unacceptable. In fact, the best possible waves are clearly generated in this zone. However, it was shown that within this critical zone, wave height may alter dramatically with small changes in any of the many design parameters, thus careful consideration must be given to each parameter value.

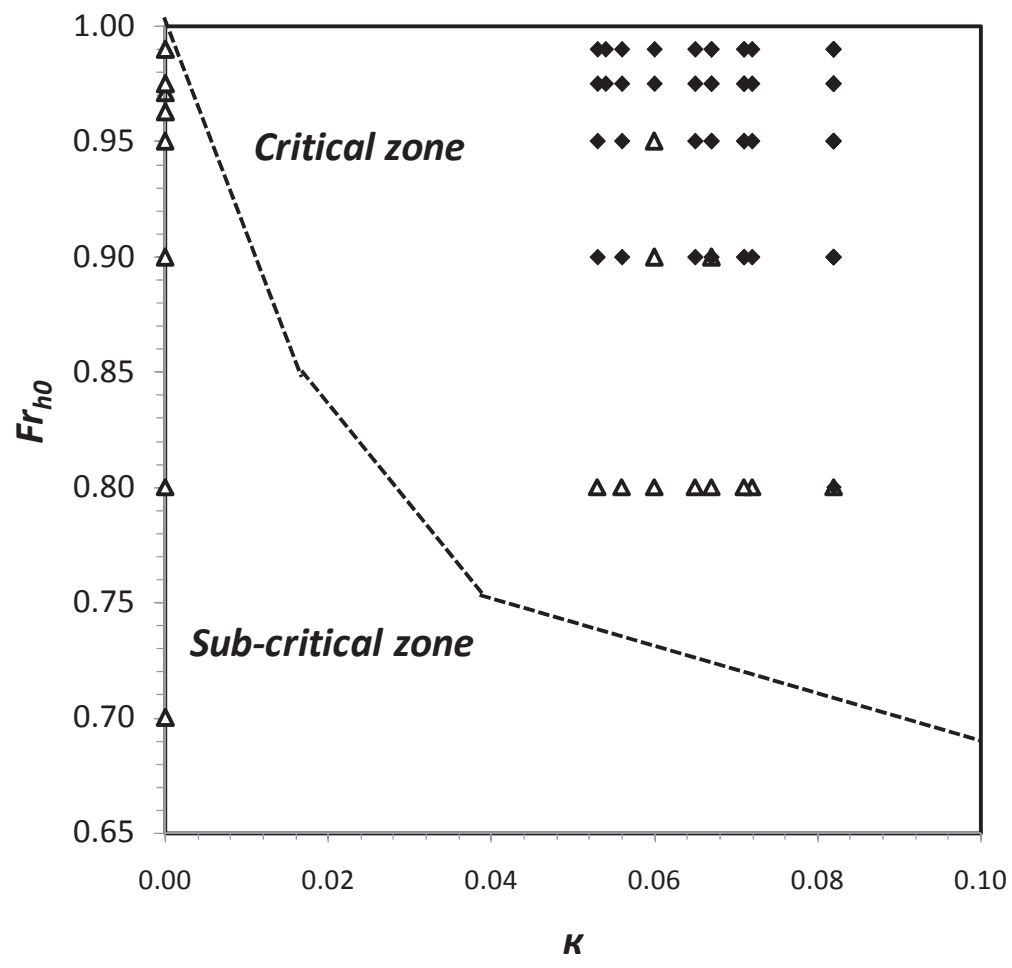

Figure 4-4. Sub-critical (open triangles) and critical (solid diamonds) configurations plotted against Lyakhovitsky [23] critical boundary. 


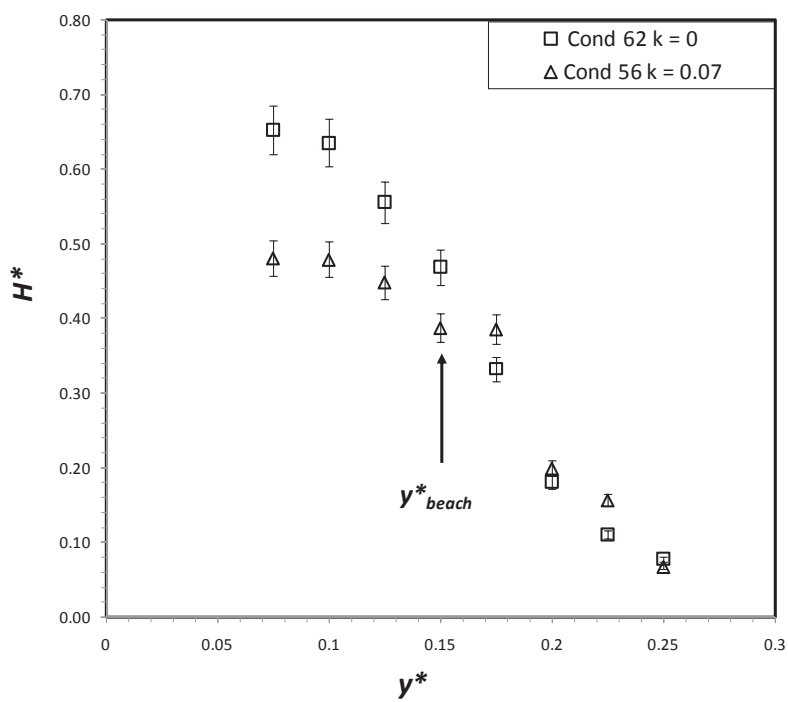

Figure 4-5. $H^{*}$ as a function of $y^{*}$ for different values of $\kappa$ for model $12-02$ with $d^{*}=0.2$ in $h_{0}=250 \mathrm{~mm}$ at $F r_{h 0}=0.95$; condition $62 \kappa \approx 0$ and condition $56 \kappa=0.07$ and $y_{\text {beach }}{ }^{*} .=1.9$.

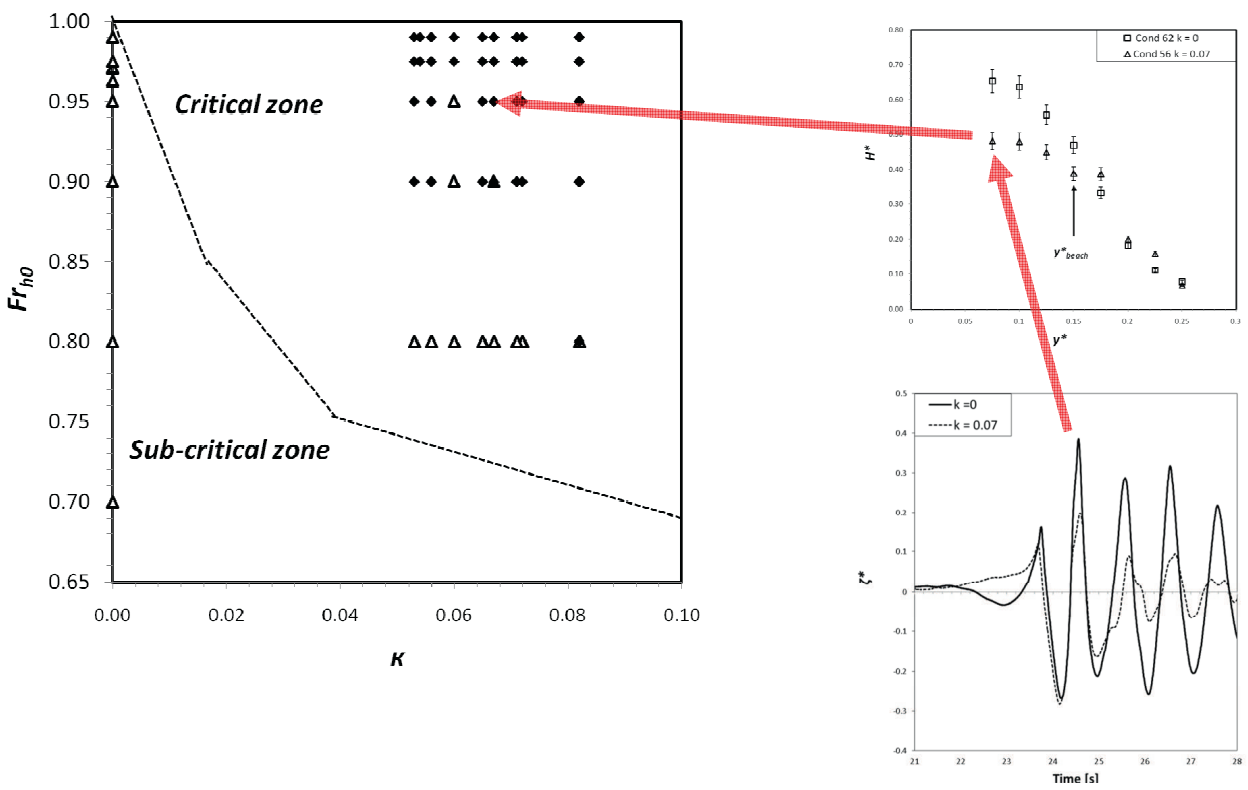

Figure 4-6. Determining whether the test point was "sub-critical" or "critical" for condition 56 model $12-02$ at $F r_{h 0}=0.95$ with $\kappa=0.07$ and $d^{*}=0.2$ in $h_{0}=250 \mathrm{~mm}$. 


\subsubsection{Depth Froude number}

The wave height as a function of the depth Froude Number $\left(F r_{h 0}\right)$ for each configuration was determined from the raw experimental data. For the unconstrained (no beach) conditions, $\kappa \approx 0, H^{*}$ increased as $F_{h 0} . \rightarrow 1$, however as blockage increased with a beach in place, the maximum $H^{*}$ was generated at $F r_{h 0}<1$; Figure 4-7.

For all conditions, a bow wave was generated in front of the pressure source, including for $\kappa \approx 0$; Figure 4-8. The bow wave was believed to be due to a combination of the two phenomena: a primary wave or surge; and / or a soliton. The bow wave was generally not steep enough to break, and therefore was not able to be used for surfing. Therefore, the formation of the bow wave was a limitation on the generation of the surfable divergent waves, and was sought to be minimised.

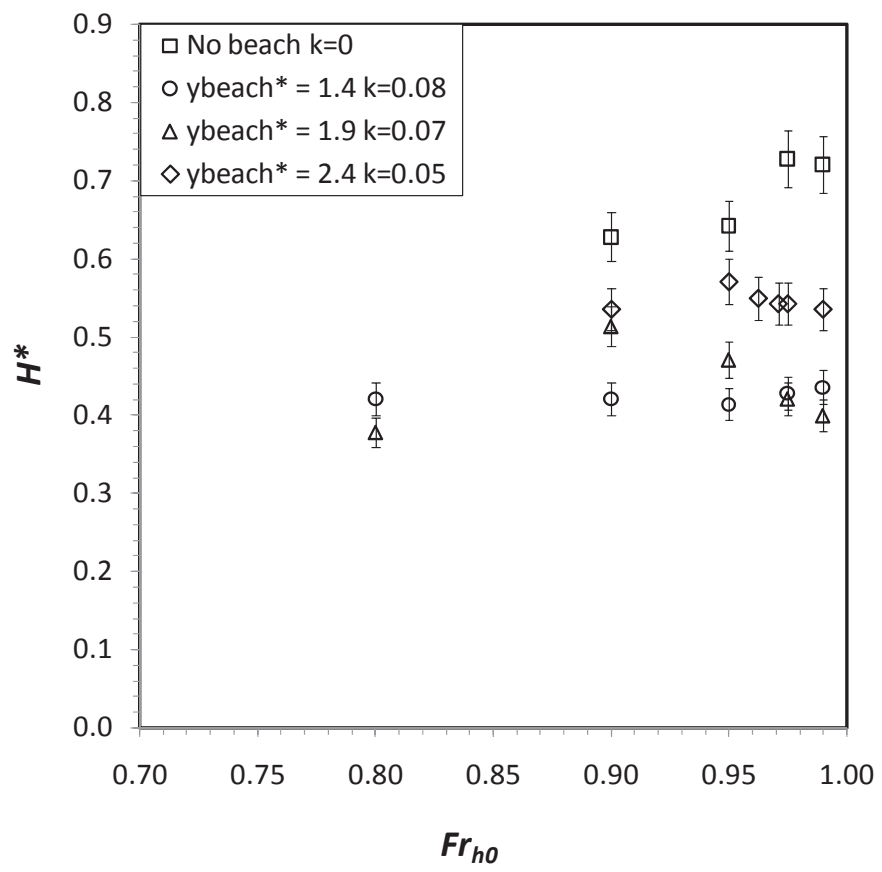

Figure 4-7. $H^{*}$ as a function of $F r_{h 0}$ at $y^{*}=0.9$ for model $12-02$ with $d^{*}=0.2$ in $h_{0}=250 \mathrm{~mm}$ with different $\kappa$ and $y_{\text {beach }} *$. 


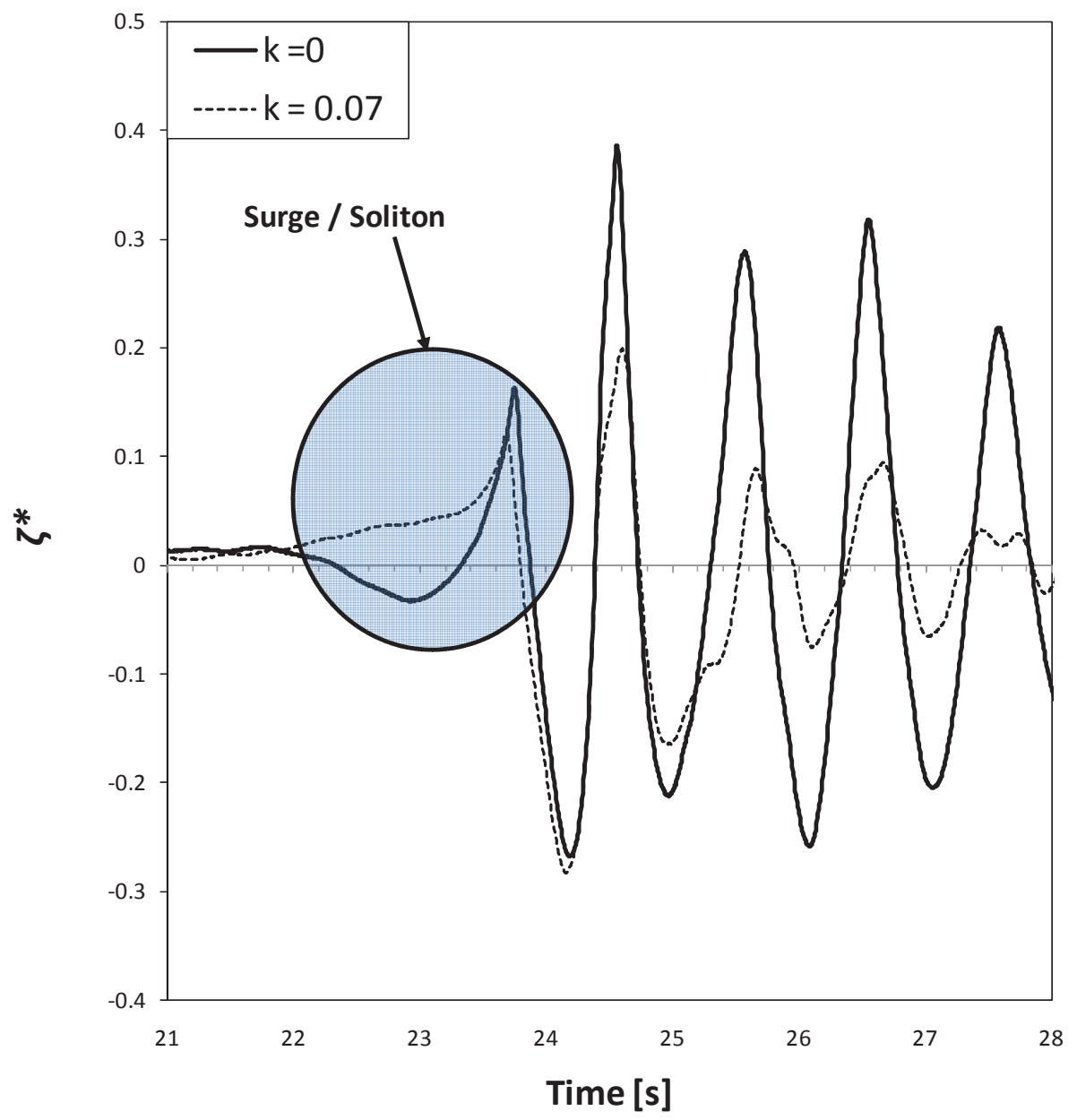

Figure 4-8. Time traces of $\zeta^{*}$ at $y^{*}=0.9(W P 1)$ for model $12-02$ with condition $62 \kappa \approx 0$ and condition $56 s=17^{\mathrm{O}}$ and $\kappa=0.07$ at $F r_{h 0}=0.95$ with $d^{*}=0.2$ in $h_{0}=250 \mathrm{~mm}$. Model 11-12 was time shifted to align with model 12-02. The pressure source bow passed the wave probe at time $=24.5$ seconds. 


\subsection{Entry angle and waterline length}

For the wavedozer, an initial entry angle $(\alpha)$ of $14^{\mathrm{O}}$ was used, based on the configuration tested by Driscoll and Renilson [31]. To determine the effect of $\alpha$ on the wave height, $H^{*}$ was plotted as a function of $F r_{h 0}$ for different values of $\alpha$ for two different beam wavedozers; Figure 4-9 and Figure 4-10. From Figure 4-9 and Figure 4-10, $H^{*}$ increasing with $\alpha$ for both models, as the pressure source volume displacement changed with $\alpha$, as detailed in section 2.4.1. This is highlighted by plotting $H^{*}$ as a function of $\alpha$ for $F r_{h 0}=0.99$; Figure 4-11.

As the waterline length $(L W L)$ of the pressure source, and thus the displacement, changed with the entry angle, $H^{*}$ was plotted as a function of $F r_{l}$; Figure 4-12 and Figure 4-13. As the waterline length increases with decreasing entry angle for a given draught, the improved wave quality is likely to be due to the increased $\mathrm{Fr}_{l}$. A shallow entry angle pressure source generating smoother waves than a shorter pressure source with a steeper entry angle.

The surface elevation $(\zeta)$ time traces close to the pressure source $(y=375 \mathrm{~mm}$ at $W P 1)$ were compared, Figure 4-14, noting that the dimensional surface elevation was used to allow direct comparison. From Figure 4-14, similar wave shapes were observed for the variation in $\alpha$. The wave generated by $\alpha=14^{\mathrm{O}}$ was steep enough to break close to the pressure source; Figure 4-15. The local wave breaking did not occur for $\alpha \leq 7^{\mathrm{O}}$; Figure 4-16. As wave breaking was undesirable prior to the start of the beach, it was concluded that $\alpha<14^{\mathrm{O}}$ was required to generate a smooth wave(s). 


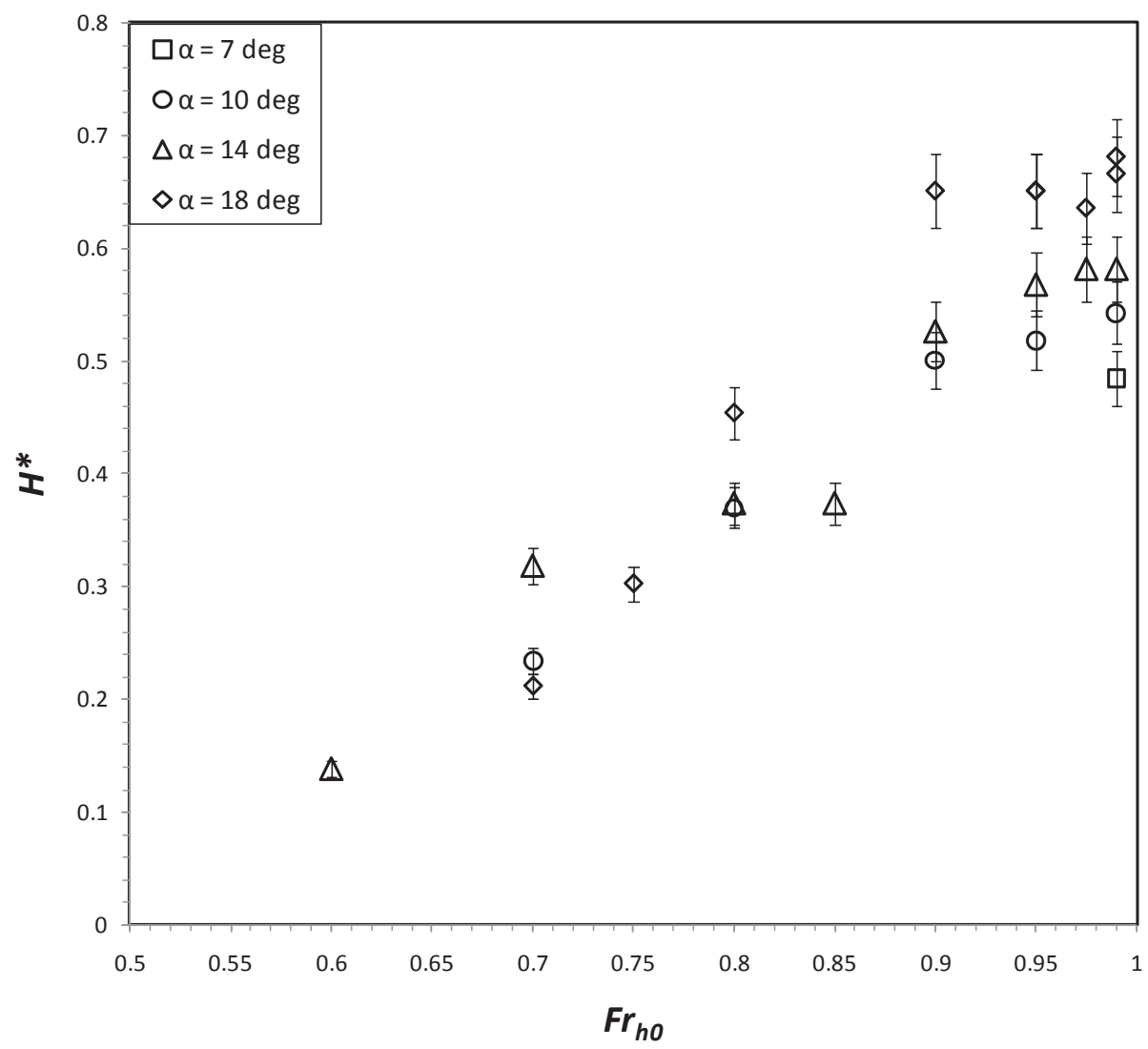

Figure 4-9. $H^{*}$ as a function of $F r_{h 0}$ at $y=375 \mathrm{~mm}(W P I)$ with different values of $\alpha$ for model 11-10 $B=75 \mathrm{~mm}$ (left) with $d^{*}=0.2$ in $h_{0}=250 \mathrm{~mm}$ and $\kappa \approx 0$. 


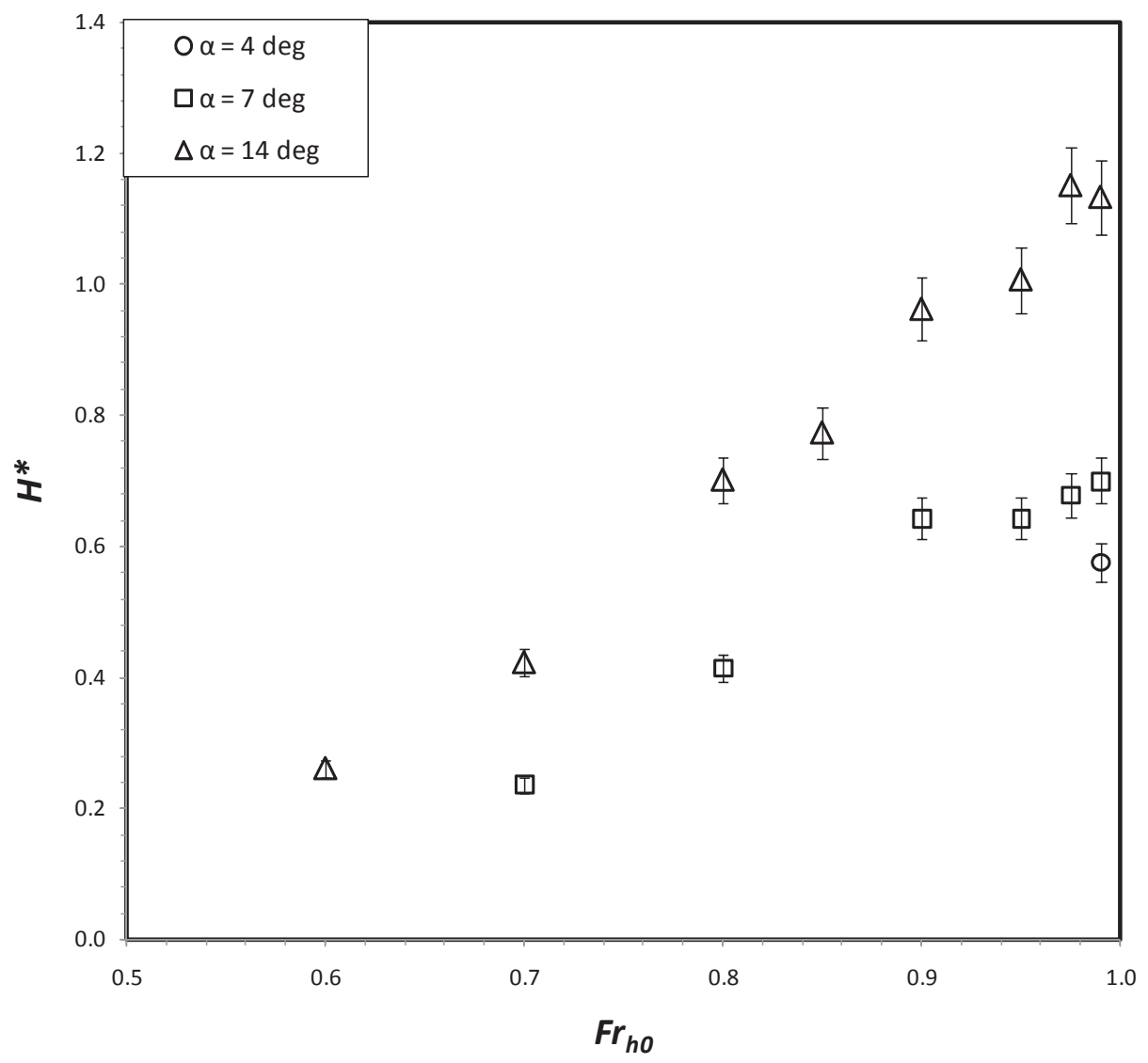

Figure 4-10. $H^{*}$ as a function of $F r_{h 0}$ at $y=375 \mathrm{~mm}(W P I)$ with different values of $\alpha$ for model 11-12 $B=275 \mathrm{~mm}$ (right) with $d^{*}=0.2$ in $h_{0}=250 \mathrm{~mm}$ and $\kappa \approx 0$. 


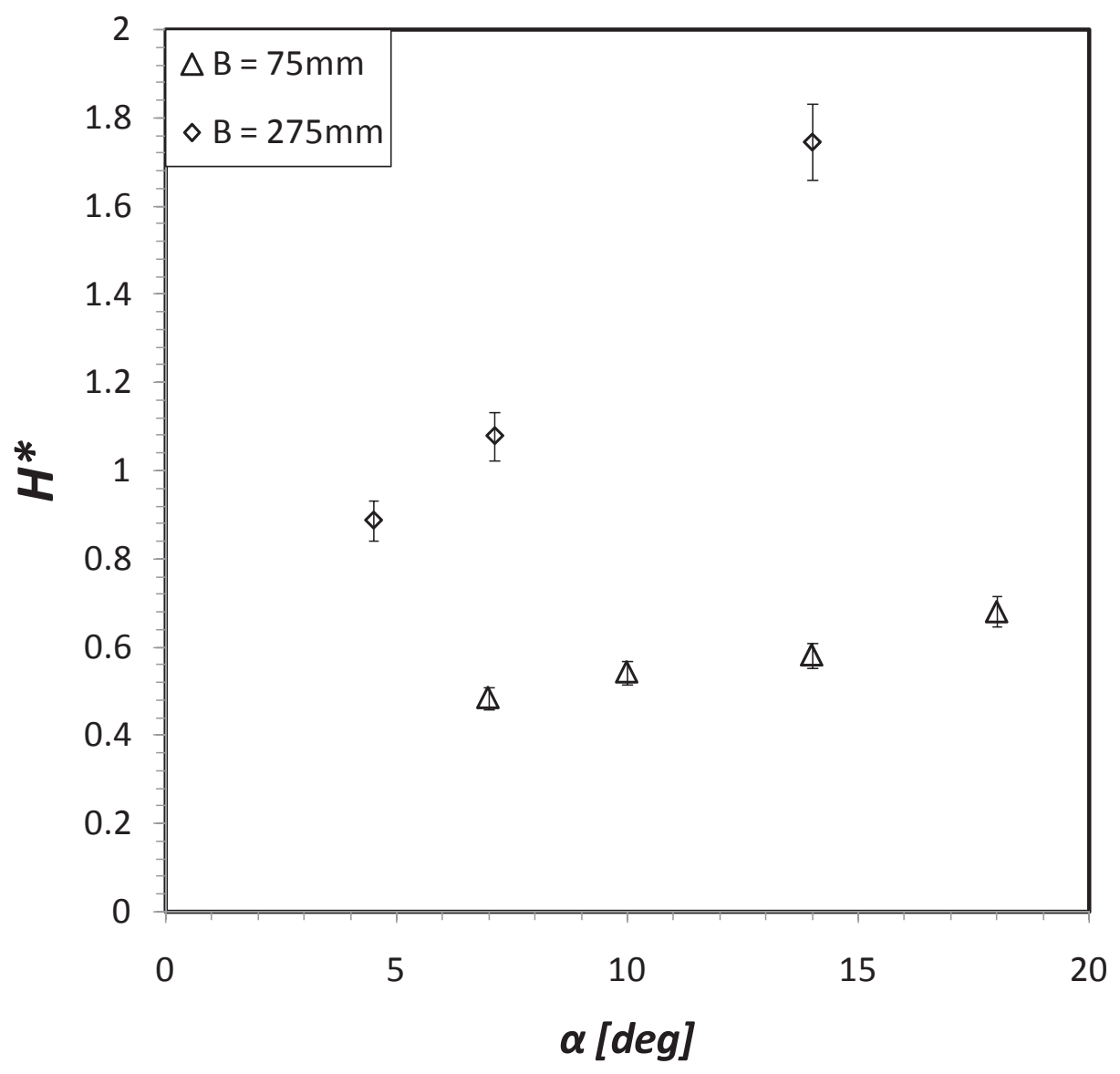

Figure 4-11. $H^{*}$ as a function of $\alpha$ at $y=375 \mathrm{~mm}(W P I)$ for models $11-10 B=75 \mathrm{~mm}$ and model $11-12 B=275 \mathrm{~mm}$ with $d^{*}=0.2$ in $h_{0}=250 \mathrm{~mm}$ at $F r_{h 0}=0.99$ and $\kappa \approx 0$. 


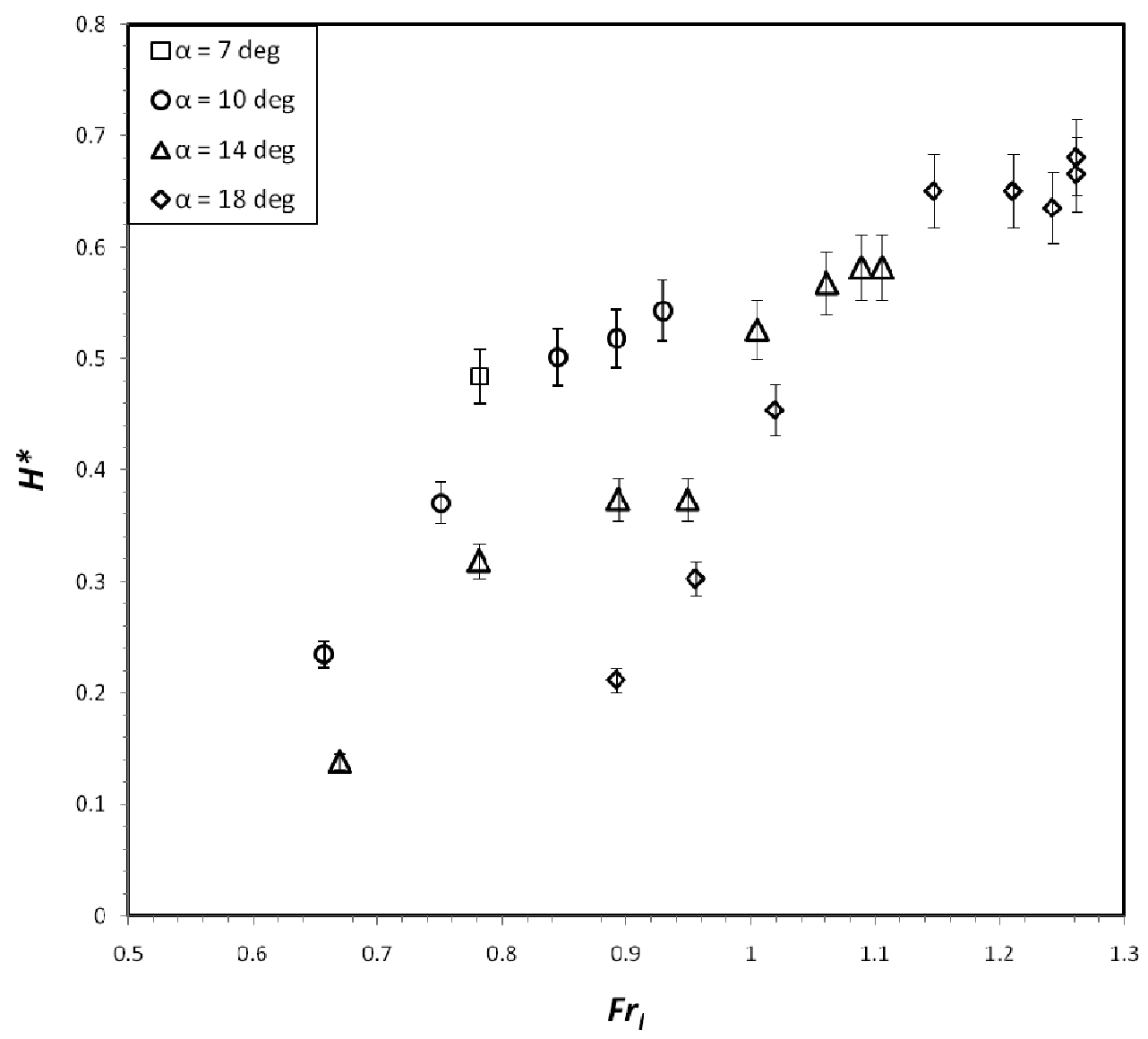

Figure 4-12. $H^{*}$ as a function of $F r_{l}$ at $y=375 \mathrm{~mm}(W P 1)$ with different values of $\alpha$ for model 11-10 $B=75 \mathrm{~mm}$ with $d^{*}=0.2$ in $h_{0}=250 \mathrm{~mm}$ and $\kappa \approx 0$. 


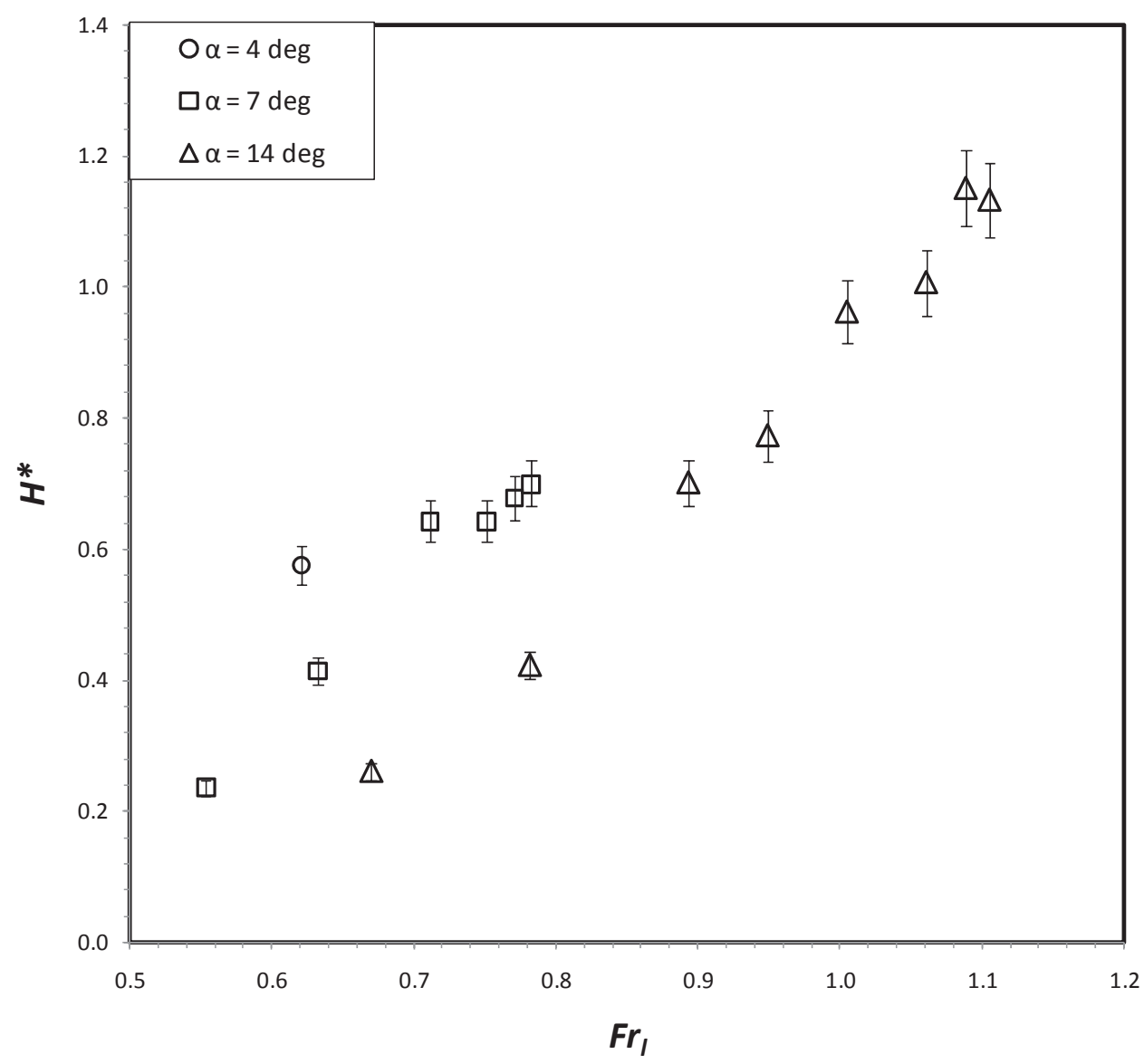

Figure 4-13. $H^{*}$ as a function of $F r_{l}$ at $y=375 \mathrm{~mm}(W P 1)$ with different values of $\alpha$ for model 11-12 $B=275 \mathrm{~mm}$ with $d^{*}=0.2$ in $h_{0}=250 \mathrm{~mm}$ at $F r_{h 0}=0.99$ and $\kappa \approx 0$. 


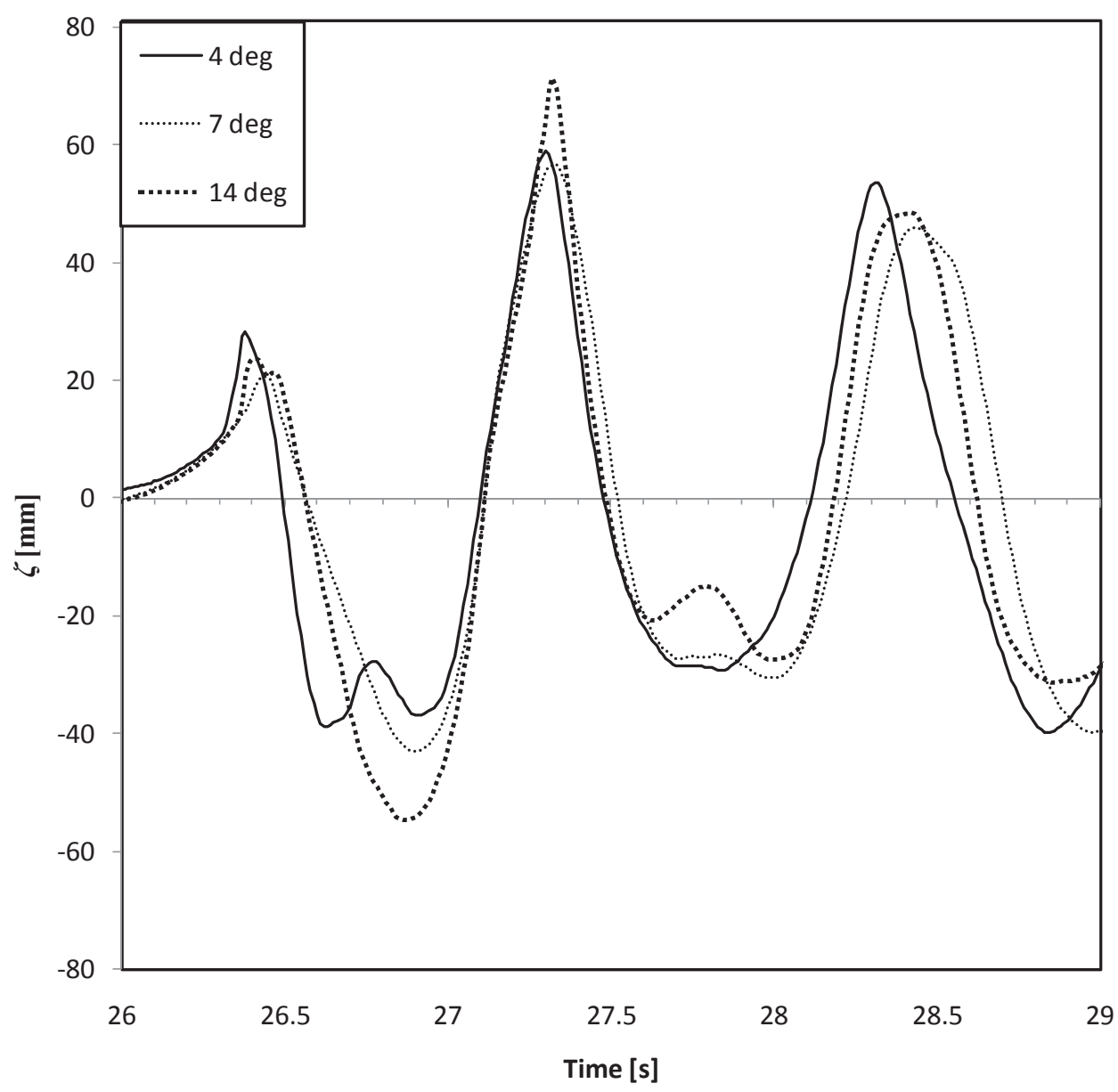

Figure 4-14. Time traces of $\zeta$ for model $11-12 B=275 \mathrm{~mm}$ at $y=375 \mathrm{~mm}(W P 1)$ with different values of $\alpha$ with $d^{*}=0.2$ in $h_{0}=250 \mathrm{~mm}$ at $F r_{h 0}=0.99$ and $\kappa \approx 0$. For comparison $\alpha=4^{0}$ and $7^{0}$ were time shifted to align with $\alpha=14^{\circ}$. 


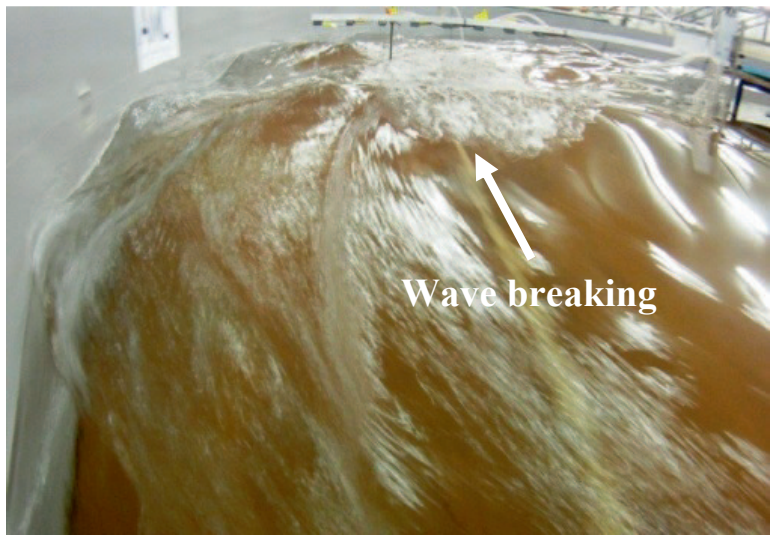

Figure 4-15. Wave quality for model $11-12 B=275 \mathrm{~mm}$ with $d^{*}=0.2$ in $h_{0}=250 \mathrm{~mm}$ and $\kappa \approx 0$ at $F r_{h 0}=0.99$ at with $\alpha=14^{\mathrm{O}}$ rear view at water level. The arrow indicates local wave breaking.
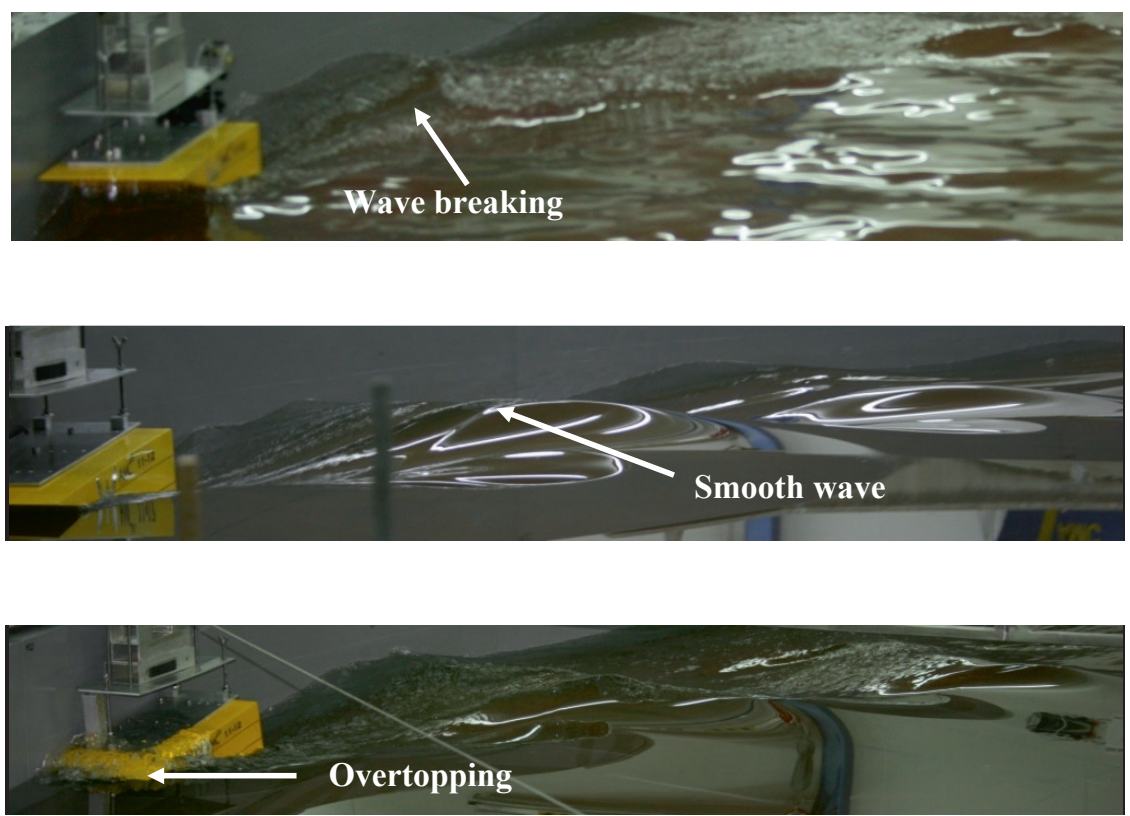

Figure 4-16. Waves generated by model $11-12 B=275 \mathrm{~mm}$ with $d=50 \mathrm{~mm}$ in $h_{0}=250 \mathrm{~mm}$ and $\kappa \approx 0$ at $F r_{h}=0.99$ with $\alpha$ of $14^{\mathrm{O}}$ (top), $7^{\mathrm{O}}$ (middle) and $4^{\mathrm{O}}$ (bottom). Note for $\alpha=4^{\circ}$, the bow was slightly submerged. 


\subsection{Beam}

The next parameter limiting value to be determined was the pressure source beam, in terms of the beam $(B)$. The effect of changing the beam includes:

a. $\quad \kappa$ increases proportional to $B$; Eq. (2.60).

b. $\quad \nabla$ increases proportional to $B$; Eq. (2.12).

c. The surfable wall width, $Y_{\text {wall }}$ *, is reduced by the beam and near field effects; Eq. (2.43).

$H^{*}$ was plotted as a function of $B^{*}$ close to the pressure source $\left(y^{*}=0.9\right)$ for different values of $\mathrm{Fr}_{h 0}$; Figure 4-17. From Figure 4-17, $H^{*}$ increased proportional to $B^{*}$, however it is unknown if this relationship would continue for $B^{*}>1$.4. Further, as Figure 4-17 was limited to $\kappa \approx 0$, the linear relationship between $H^{*}$ and $B^{*}$ may not be valid for $\kappa>0$. It is recommended to test $B^{*}>1.4$ with $\kappa>0$; i.e. with a beach in place. 


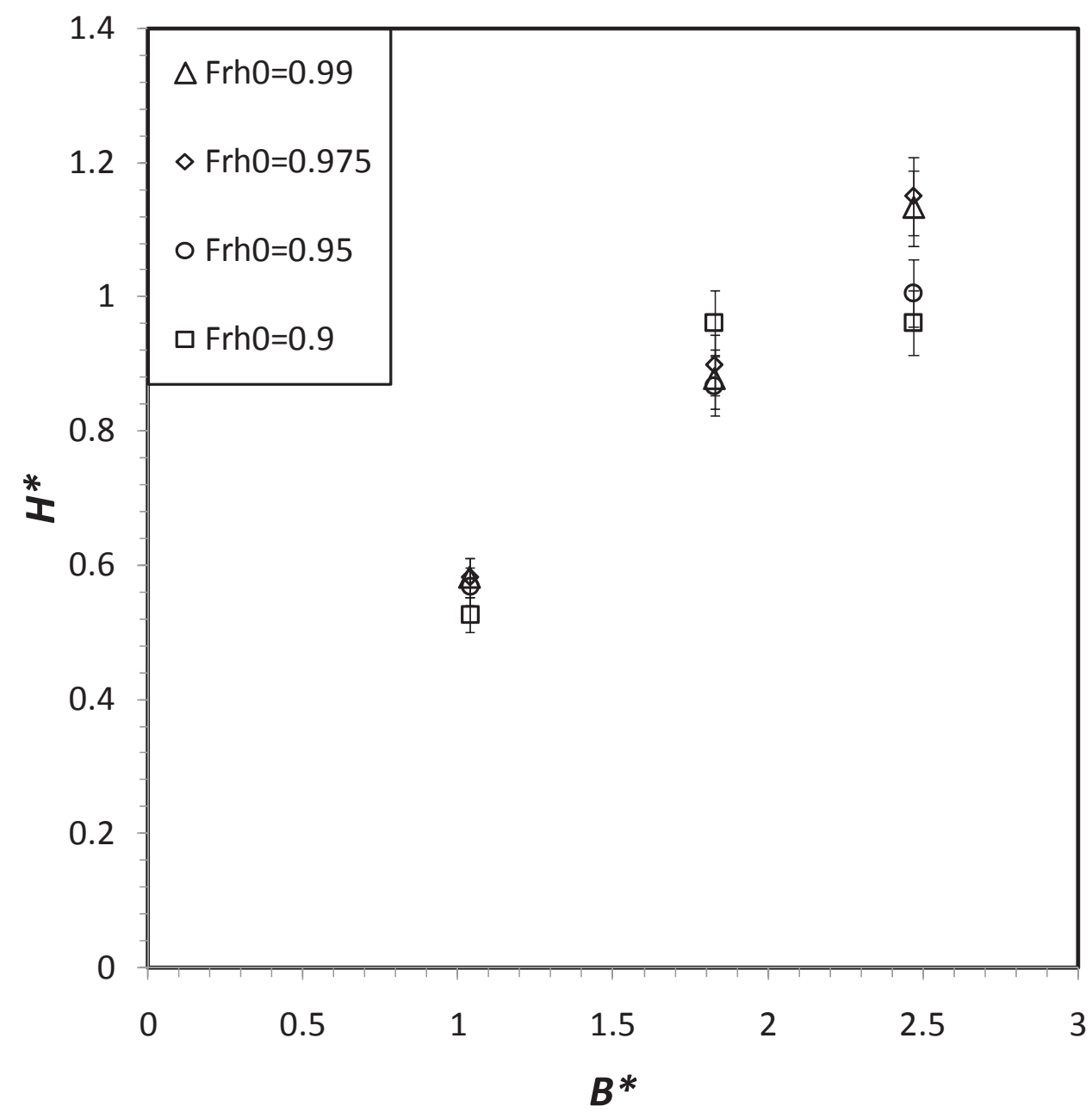

Figure 4-17. $H^{*}$ as a function of $B^{*}$ (models $11-10,11-11$ and 11-12) at $y^{*}=0.9$ at different values of $F r_{h 0}$ with $d^{*}=0.2$ in $h_{0}=250 \mathrm{~mm}$ and $\kappa \approx 0$. 


\subsection{Draught}

The next parameter limiting value to be determined was the pressure source draught, in terms of the draught $(d)$. The effect of changing the draught include:

a. $\quad \kappa$ increases proportional to $d$; Eq. (2.64).

b. $\quad \nabla$ increases proportional to $d$; Eq. (2.12).

c. $\quad \alpha$ and $L W L$ increases proportional to $d$; Eq.(2.66).

With the beach in place at $y_{\text {beach }}=950 \mathrm{~mm}, H^{*}$ was plotted as a function of $d^{*}$ close to the pressure source $(y=375 \mathrm{~mm})$ at $F r_{h 0}=0.975$; Figure 4-18. From Figure 4-18, the wave height increased with draught to a limiting value of $d^{*} \leq 0.32$; with $\kappa=0.08$.

For the same conditions Figure 4-18, the wave height $H^{*}$ was plotted as a function of $\mathrm{Fr}_{\text {; }}$; Figure 4-19. The maximum wave height was generated at $F r_{l}=0.6$; close to the value stated by Soomere [58] of $F r_{l} \approx 0.56$ for the development of the largest ship wave; section 2.4.9. A peak in wave making resistance observed in Tuck et. al. [46] at $F r_{l} \approx 0.6$ (in deep water). 


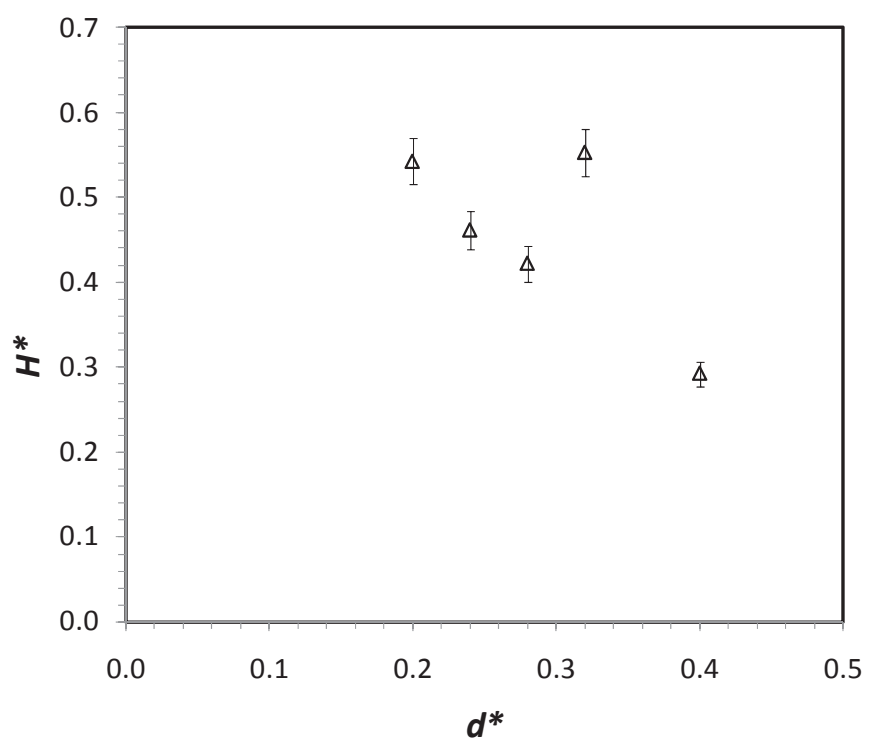

Figure 4-18. $H^{*}$ as a function of $d^{*}$ at $y=375 \mathrm{~mm}(W P 1)$ for conditions 59 and 60 model $12-02 \alpha=7^{\circ}$ in $h_{0}=250 \mathrm{~mm}$ at $F r_{h 0}=0.975$ and $y_{\text {beach }}=950 \mathrm{~mm}$.

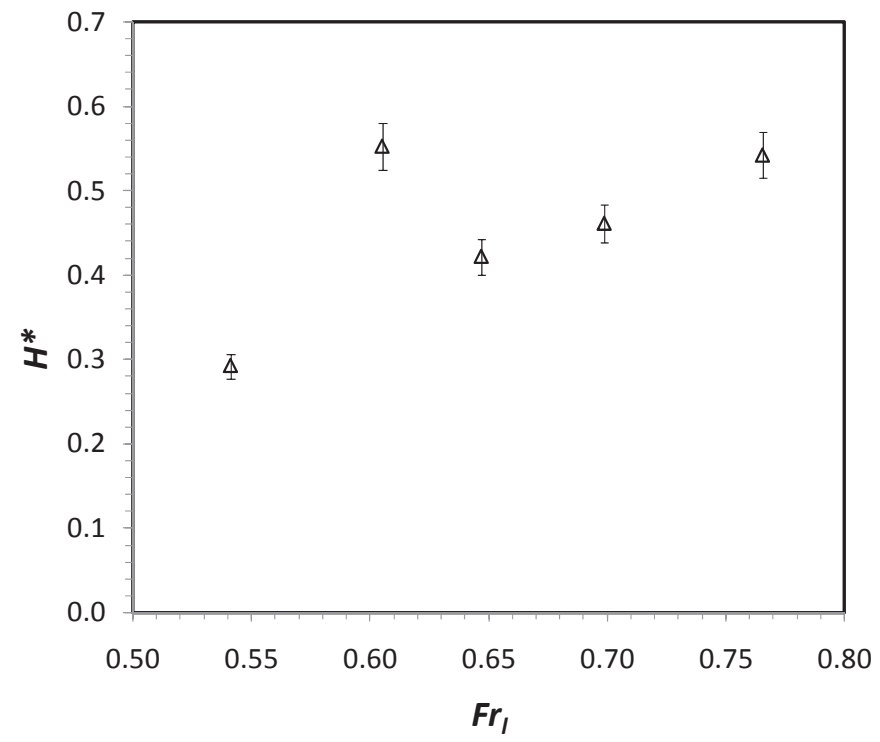

Figure 4-19. $H^{*}$ as a function of $F r_{l}$ at $y=375 \mathrm{~mm}(W P 1)$ for conditions 59 and 60 model 12-02 in $h_{0}=250 \mathrm{~mm}$ at $F r_{h 0}=0.975$ and $y_{\text {beach }}=950 \mathrm{~mm}$. 


\subsection{Pressure source symmetry}

Modern high speed ships are often fitted with a cut-off or transom stern. Two distinct flow regimes may be observed near a transom, depending on its design and the forward speed of the ship: wetted and unwetted [67]. At sufficient high forward speeds the water flow leaves the transom smoothly, cleanly separating from the base of the transom, leaving the transom fully unwetted [67], with a dead water region behind. The unwetted case is also known as the dry-transom regime.

The presence of the free surface immediately behind the transom causes the pressure to drop to atmospheric pressure at the transom lower edge, whereas if the hull would continue smoothly at the transom the pressure would be significantly different and probably higher, dependent on the features of the hull design [68]. The pressure reduction towards the transom edge results in an upwards curved flow behind the transom, resulting in a wave crest behind the transom hollow. This pressure reduction and resultant wave crest increases with the draught eventually resulting in a breaking wave behind the transom [67], also known as the 'rooster tail'. The wave crest behind the transom edge was observed for the models with $\alpha=14^{\mathrm{O}}$, and the rooster tail was observed in condition 46; Figure 4-20.

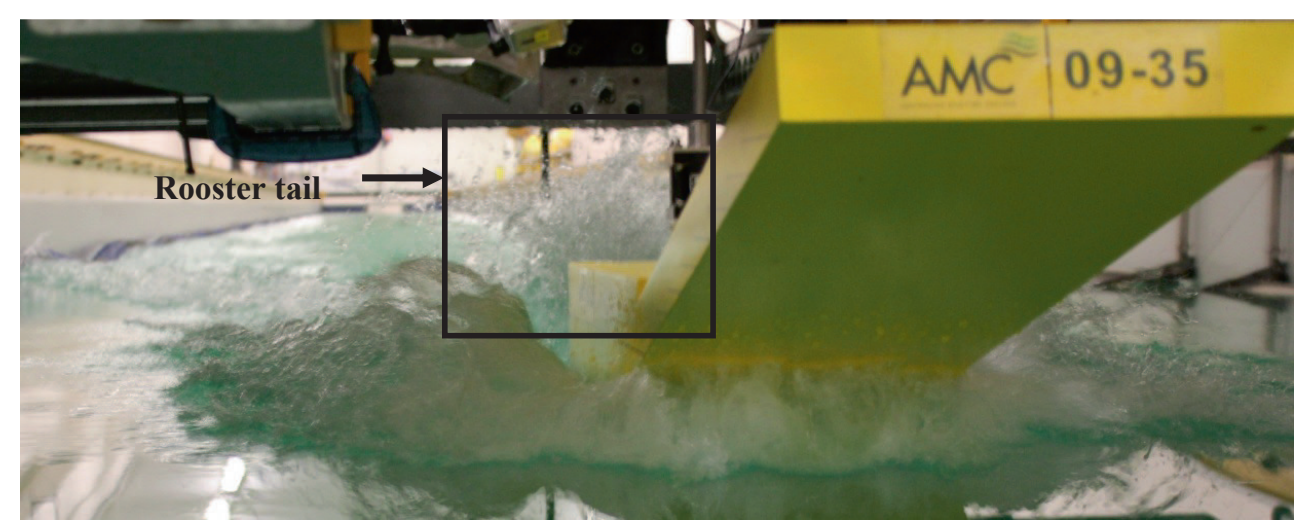

Figure 4-20. "Rooster tail" generated by condition 46 model 09-35 dry transom with $\alpha=14^{\mathrm{O}}$ with $d^{*}=0.07$ in $h_{0}=1500 \mathrm{~mm}$ at $F r_{h 0}=0.95\left(u_{0}=3.6 \mathrm{~m} / \mathrm{s}\right)$. 
However, for the circular wave pool, it is desirable to use a symmetrical pressure source (about $x=\frac{L W L}{2}$ ), as it allows the pressure source to generate both left and right hand breaking waves without the need to change the pressure source, simply by being driven in clockwise and anti-clockwise directions respectively.

Symmetrical pressure sources with $\alpha=14^{\mathrm{O}}$ were tested, with the near field wave breaking occurring close to the pressure source at the higher speeds of $F r_{h 0}>0.8$. For this condition, the asymmetrical pressure source generated higher waves than the symmetrical pressure source for $F r_{h 0}>0.8$, Figure 4-21, likely due to the pressure reduction detailed above and the larger displacement of the symmetrical pressure source. However, the symmetrical pressure source generated higher waves as a function of $\mathrm{Fr}_{l}$; Figure 4-22

To allow a comparison of the wave shape, the surface elevation (ל) was compared for both pressure source forms at $F r_{h 0}=0.95$; Figure 4-23. The wave shapes were similar, except the maximum wave crest was truncated for the symmetrical pressure source. As these investigations were conducted with pressure sources with $\alpha=14^{\mathrm{O}}$, future testing is required to compare asymmetrical and symmetrical pressure sources with $\alpha=7^{\mathrm{O}}$. 


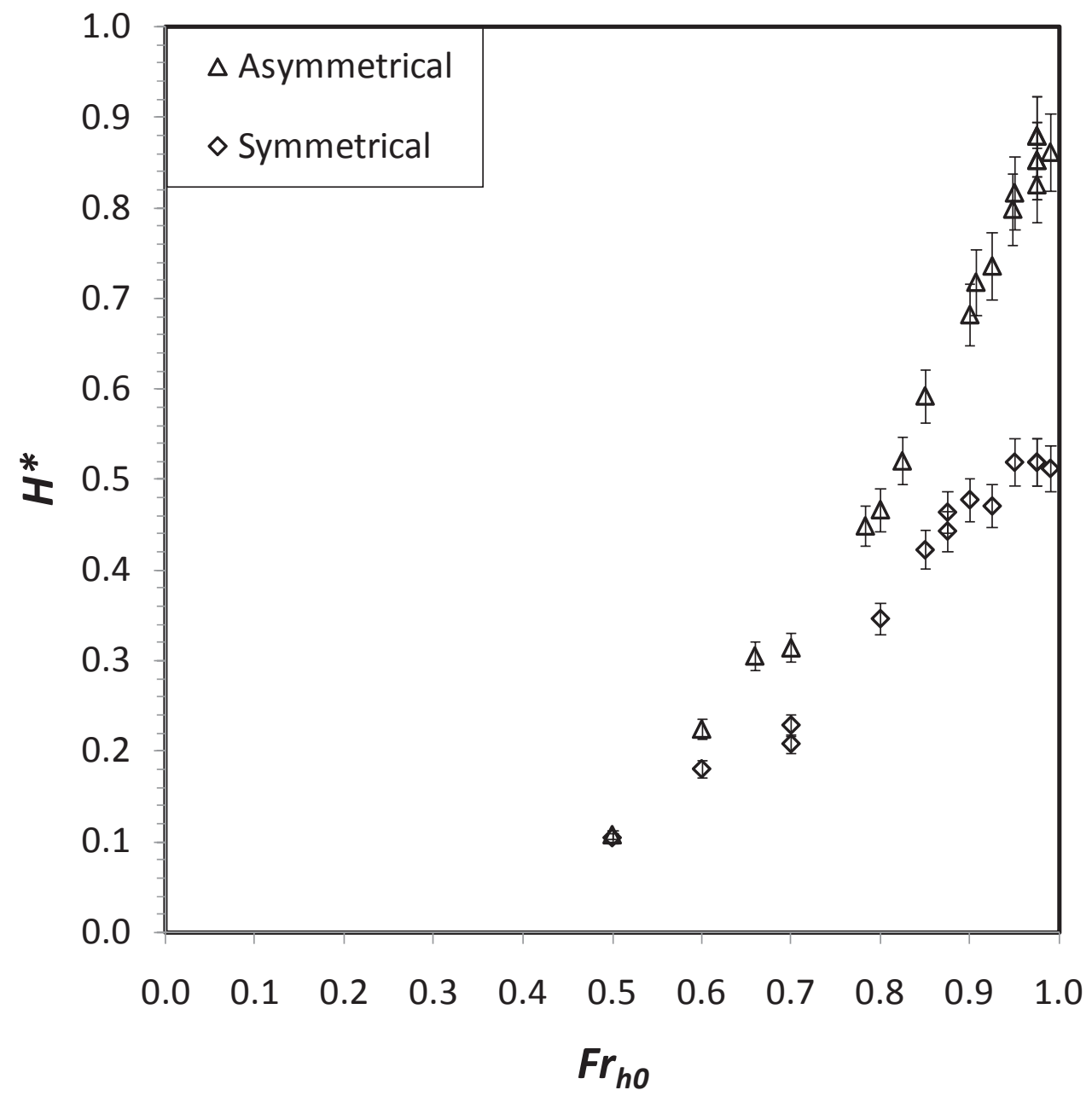

Figure 4-21. $H^{*}$ as a function of $F r_{h 0}$ at $y=375 \mathrm{~mm}(W P 1)$ for model 10-25 asymmetrical and model 10-27 symmetrical with $d^{*}=0.2$ in $h_{0}=250 \mathrm{~mm}$ and $\kappa \approx 0$. 


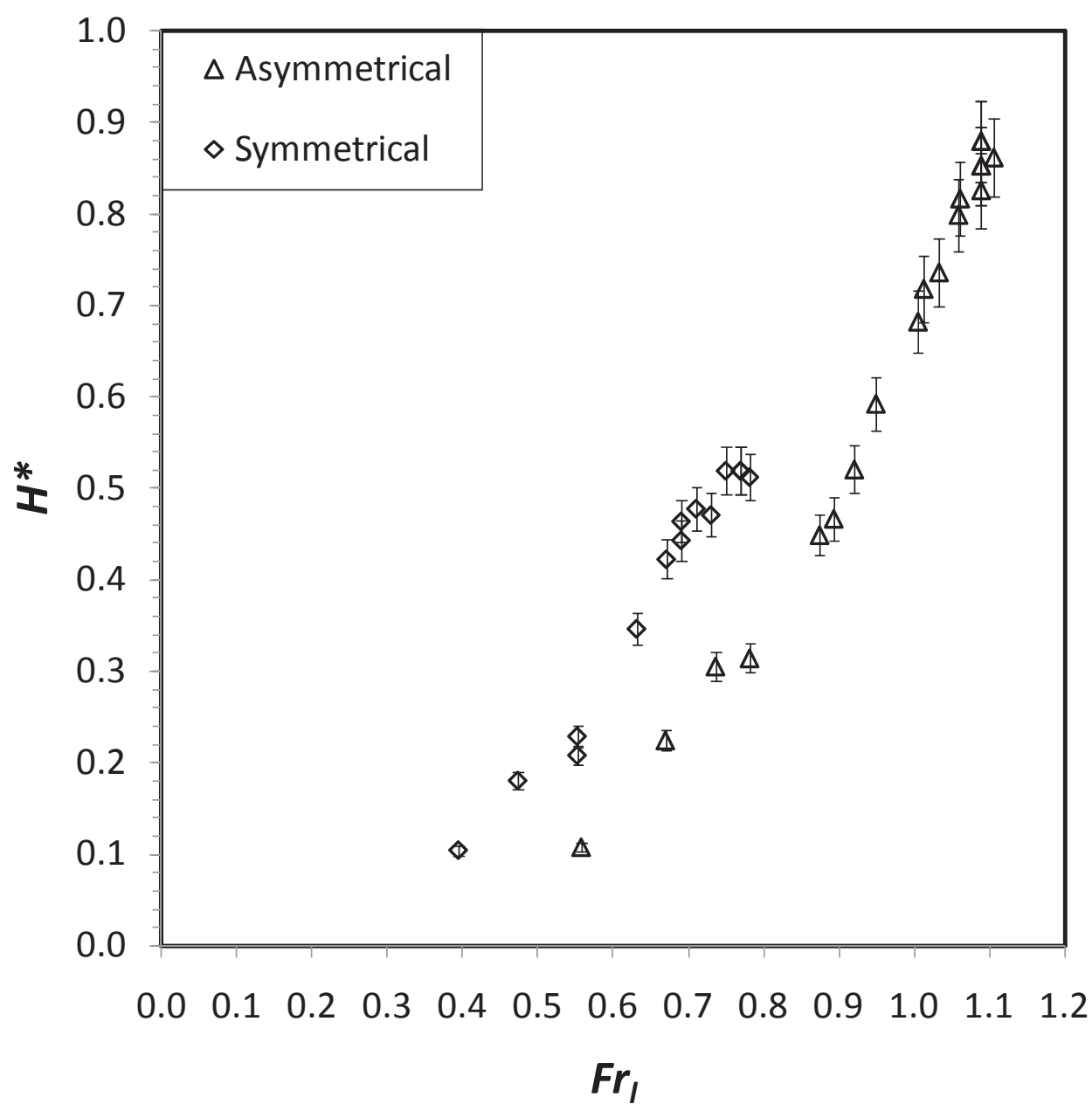

Figure 4-22. $H^{*}$ as a function of $F r_{l}$ at $y=375 \mathrm{~mm}(W P 1)$ for model 10-25 asymmetrical and model 10-27 symmetrical with $d^{*}=0.2$ in $h_{0}=250 \mathrm{~mm}$ and $\kappa \approx 0$. 


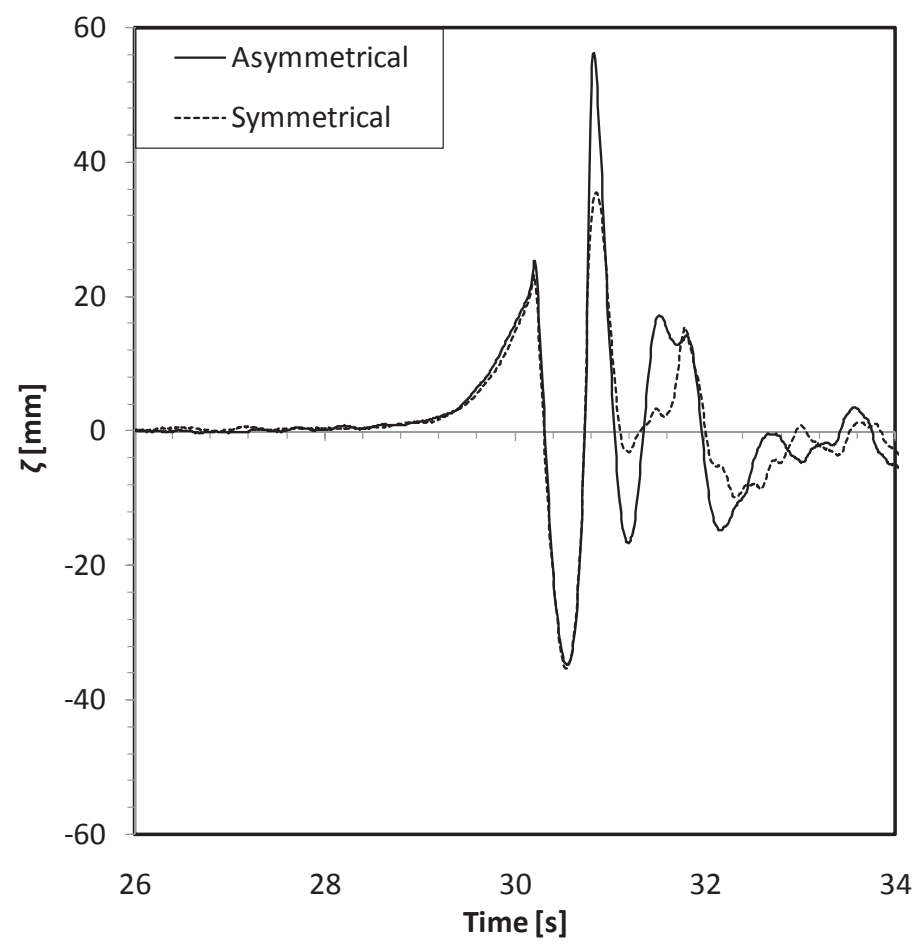

Figure 4-23. Time traces of $\zeta$ at $F r_{h 0}=0.95$ at $y=375 \mathrm{~mm}(W P I)$ for model $10-25$ asymmetrical and model 10-27 symmetrical with $d^{*}=0.2$ in $h_{0}=250 \mathrm{~mm}$ and $\kappa \approx 0$. For comparison, model 10-27 was time shifted to align with model 10-25.

\subsection{Linear and circular tracks}

The effect of the pool radius $\left(R_{0}^{*}=\frac{R_{0}}{L W L}\right)$ on wave generation was investigated. The comparison was made between the waves generated by the pressure source in a straight line $\left(R_{0} * \rightarrow \infty\right)$, and circular tracks $(\kappa \leq 0.01)$ with two different non-dimensional radii: $R_{0} *=12$ (model 11-13) and $R_{0} *=25$ (model 11-10); Figure 4-24. From Figure 4-24, the wave height, $H^{*}$, close to the pressure source was similar for the different values of $R_{0} *$ for $0.7 \leq F r_{h 0} \leq 0.99$.

The reason for the difference at $F r_{h 0}=0.5$ to 0.6 is unknown. This may be due to interactions of the divergent and transverse wave components. Further, these peaks in wave height 
occurred at $F r_{l}=0.6$, with a peak in wave making resistance observed in Tuck et. al. [46] at $F r_{l} \approx 0.6$ (in deep water).

The wave trace of the surface elevation, $\zeta^{*}$, were compared for different values of $R_{0} *$ close to the pressure source $\left(y^{*}=5.2\right)$ for $F r_{h 0}=0.9$; Figure 4-25. Whilst the wave height $\left(H^{*}\right)$ was similar for all radii, the wave trough $\left(\zeta_{\min } *\right)$ was shallower and the wave crest higher $\left(\zeta_{\max } *\right)$ for smaller values of $R_{0} *$; Figure 4-26.

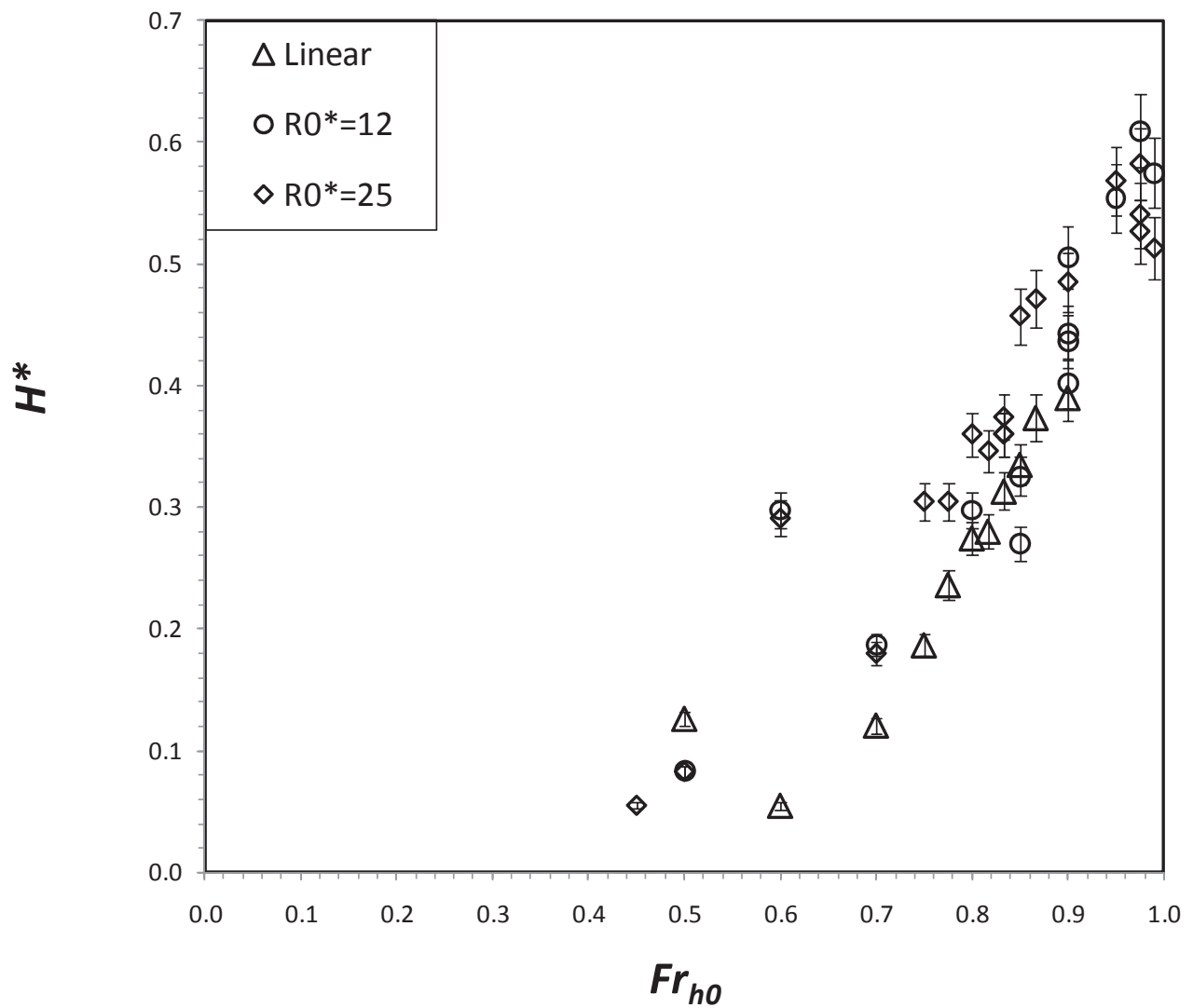

Figure 4-24. $H^{*}$ as a function of $F r_{h 0}$ at $y^{*}=5.2$ and $\kappa=0.01$ for linear track model 09-35 $R_{0}{ }^{*} \rightarrow \infty$ with $d^{*}=0.2$ in $h_{0}=500 \mathrm{~mm}$ and compared to circular track model $11-10 R_{0} *=25$ with $d^{*}=0.2$ in $h_{0}=250 \mathrm{~mm}$ and model $11-13 R_{0} *=12$ with $d^{*}=0.2$ in $h_{0}=500 \mathrm{~mm}$. 


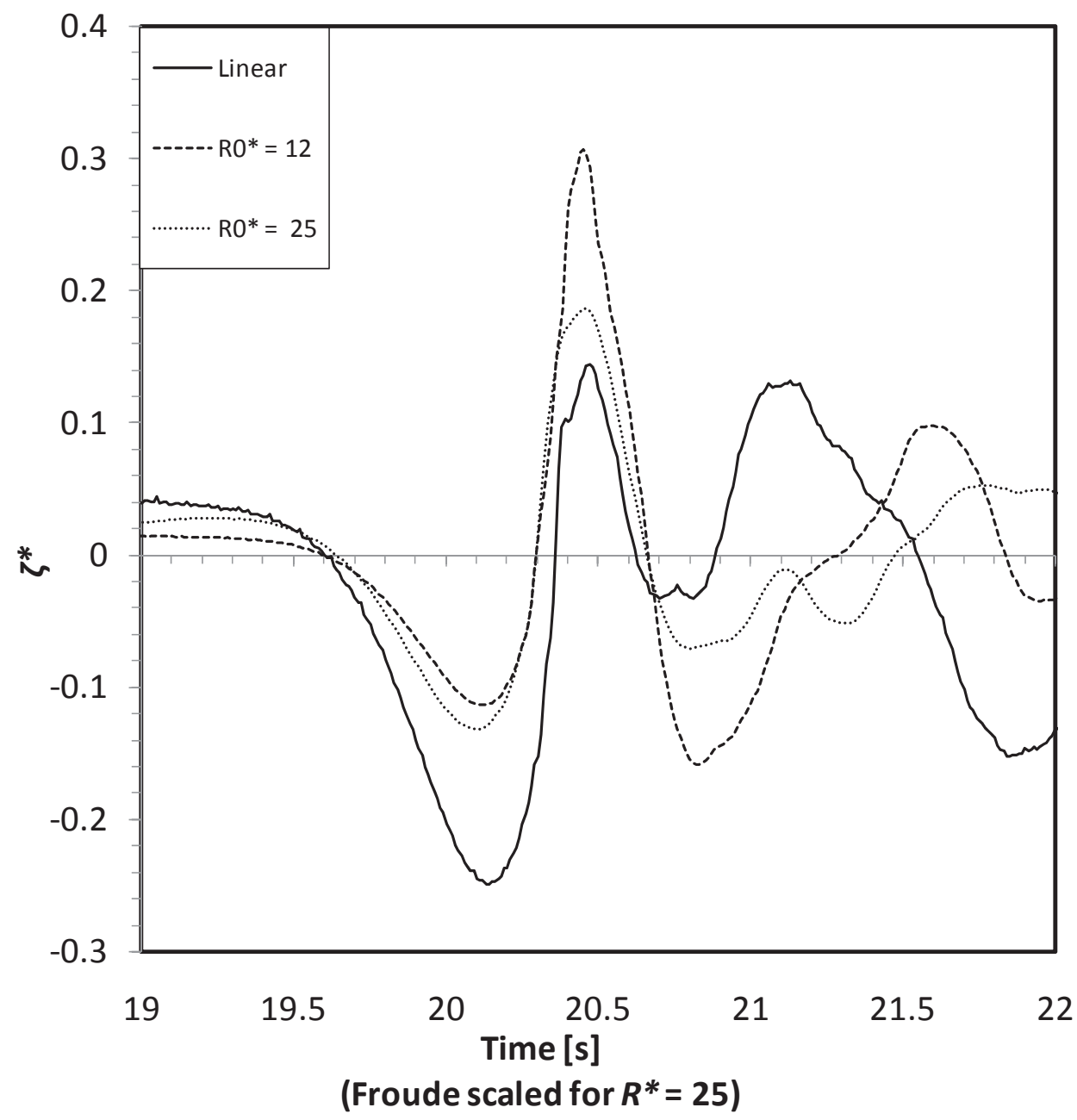

Figure 4-25. Time trace of the surface elevation $\zeta^{*}$ at $y^{*}=5.2$ and $F r_{h 0}=0.9$ with $\kappa=0.01$ and $\alpha=14^{\circ}$ for linear track model $09-35 R_{0} * \rightarrow \infty$ with $d^{*}=0.2$ in $h_{0}=500 \mathrm{~mm}$ and compared to circular track model 11-10 $R_{0} *=25$ with $d^{*}=0.2$ in $h_{0}=250 \mathrm{~mm}$ and model $11-13 R_{0} *=12$ with $d^{*}=0.2$ in $h_{0}=500 \mathrm{~mm}$. Model 09-35 and model 11-13 were time shifted and Froude scaled to align with model 11-10. 


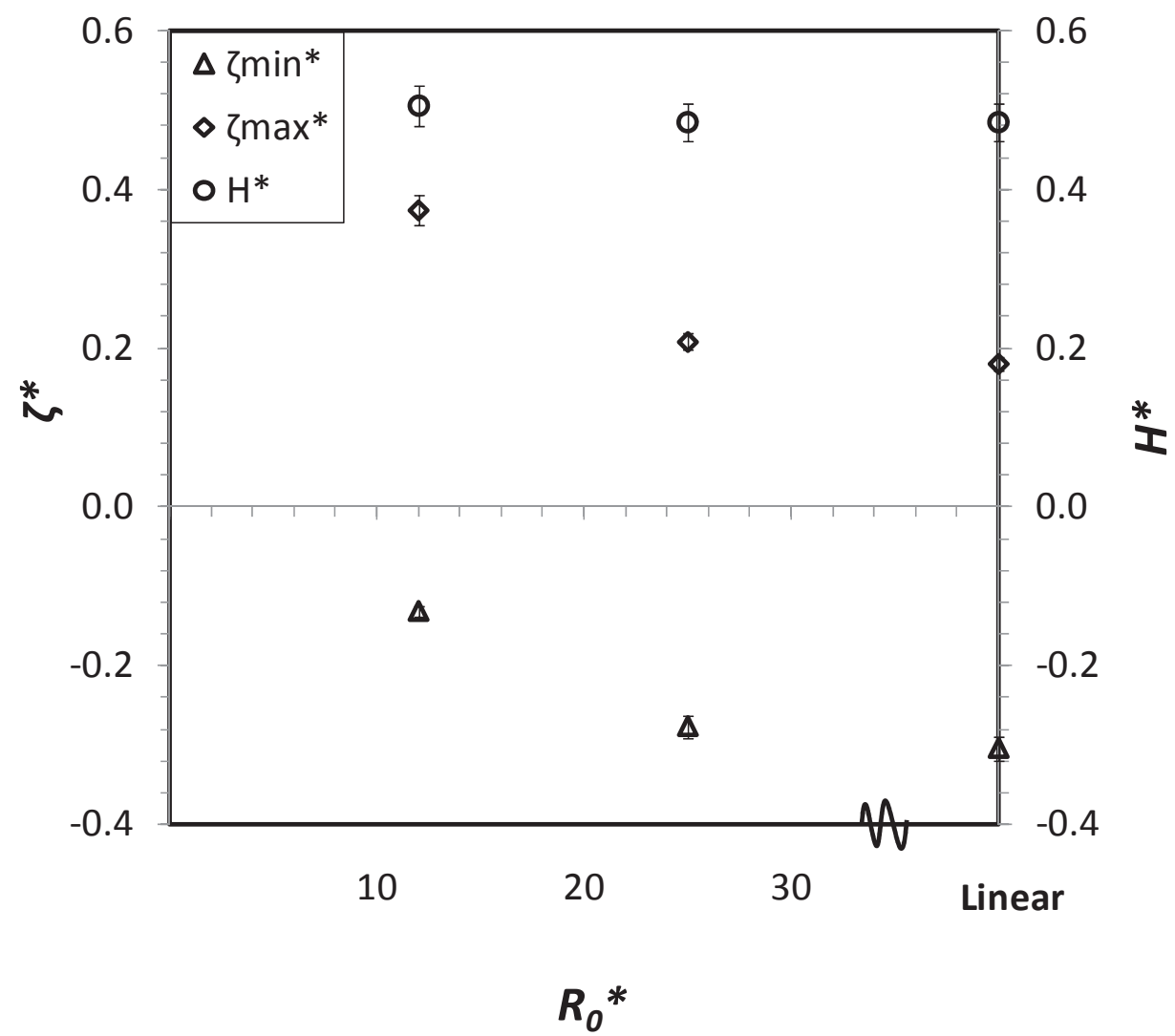

Figure 4-26. Minimum and maximum surface elevation $\zeta^{*}$ and wave height $H^{*}$ at $y^{*}=5.2$ and $F r_{h 0}=0.9$ with $\kappa=0.01$ for linear track model $09-35 R_{0}{ }^{*} \rightarrow \infty$ with $d^{*}=0.2$ in $h_{0}=500 \mathrm{~mm}$ compared to circular track model 11-10 $R_{0}^{*}=25$ with $d^{*}=0.2$ in $h_{0}=250 \mathrm{~mm}$ and model $11-13 R_{0}^{*}=12$ with $d^{*}=0.2$ in $h_{0}=500 \mathrm{~mm}$.

\subsection{Multiple pressure source interaction}

In order to generate the maximum number of surfable waves, the commercial wave pool requires multiple pressure sources, without adverse wave interaction. The water surface needs to calm sufficiently after the passing of one pressure source, prior to the second pressure source travelling through the same water. 
To determine the time required to allow the water surface to calm, by observation, non-adverse residual waves interaction was defined being when surface elevation, $\zeta_{w p l}$, measured close to the pressure source $\left(y^{*}=0.9\right)$, was less than $10 \%$ of the maximum $\zeta_{\max }$ of the first wave generated. As an example, Figure 4-27, for the first pressure source (top left figure), $\zeta_{w p l}$ of the first wave was $56 \mathrm{~mm}$ at time $=30 \mathrm{~s}$. Therefore, the water was defined as being calm enough for the second pressure source to pass when $\zeta_{w p l}<5.6 \mathrm{~mm}$; which occurs by time $=38 \mathrm{~s}$. With the second pressure source passing at time $=50 \mathrm{~s}$, the pressure sources could be placed closer together.

To determine an initial estimation of the time interval required between the pressure sources, the time traces of $\zeta_{w p l}$ with 1, 2 and 4 pressures sources were compared; Figure 4-28. The four pressure sources used were not the same geometry (different displacement volumes), so the dimensional surface elevations are shown. From Figure 4-28, it appears that at least four pressure sources may be equally spaced around the perimeter of the circular wave pool.

As an example, for condition 56 model 12-02 at $F r_{h 0}=0.95$, the pressure source passes at $30 \mathrm{~s}$, with the water calmed sufficiently by $34 \mathrm{~s}$; an interval of $4 \mathrm{~s}$. By calculating the time interval between successive pressures sources for differing numbers of pressure sources, Table 4-1, it may be possible to use up to 5 pressure sources. 


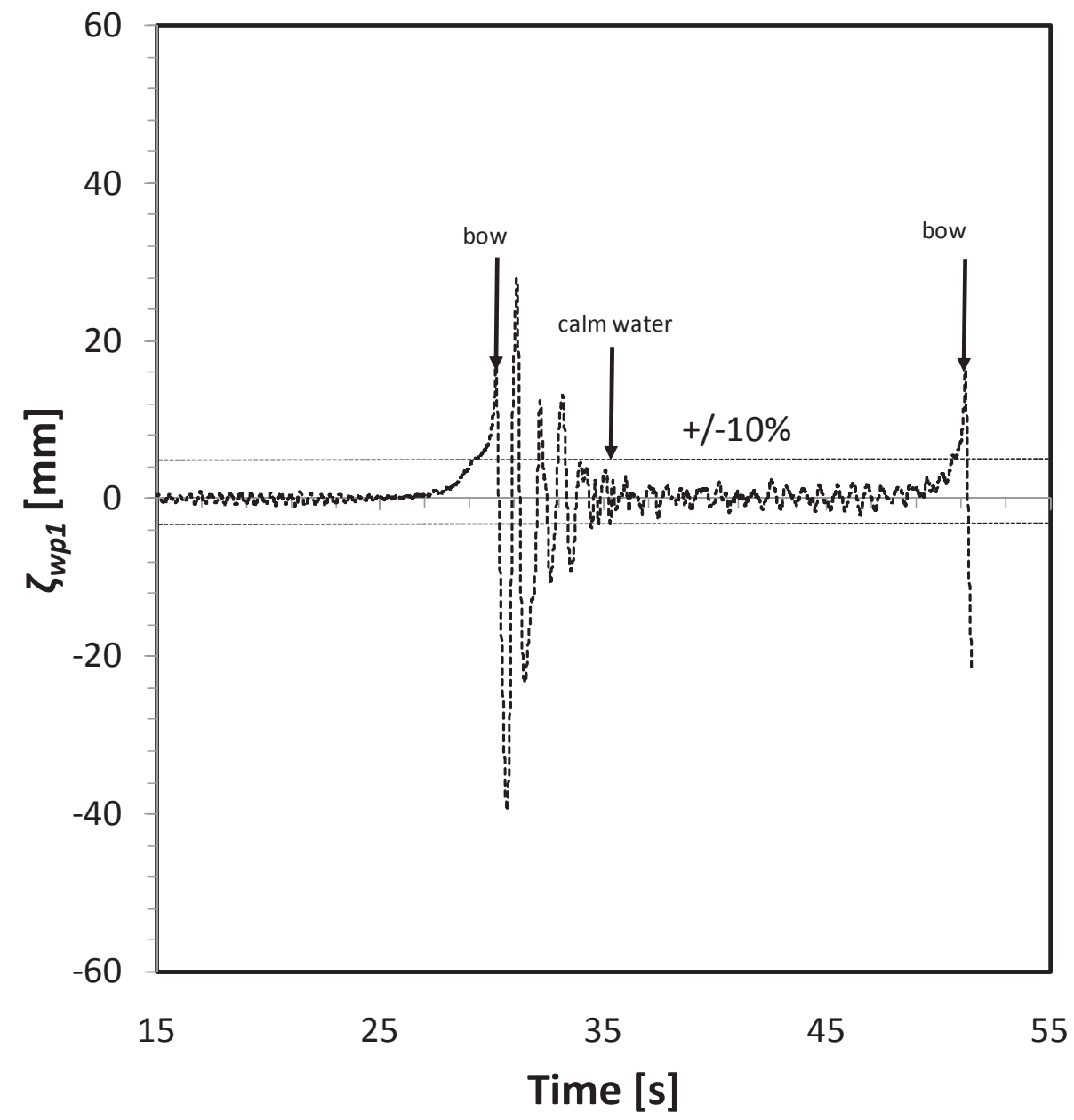

Figure 4-27. Time trace of $\zeta_{w p l}$ at $y^{*}=0.9(W P I)$ for condition 56 model 12-02 with $d^{*}=0.2$ in $h_{0}=250 \mathrm{~mm}$ and $\kappa=0.06$ at $F r_{h 0}=0.95$. 

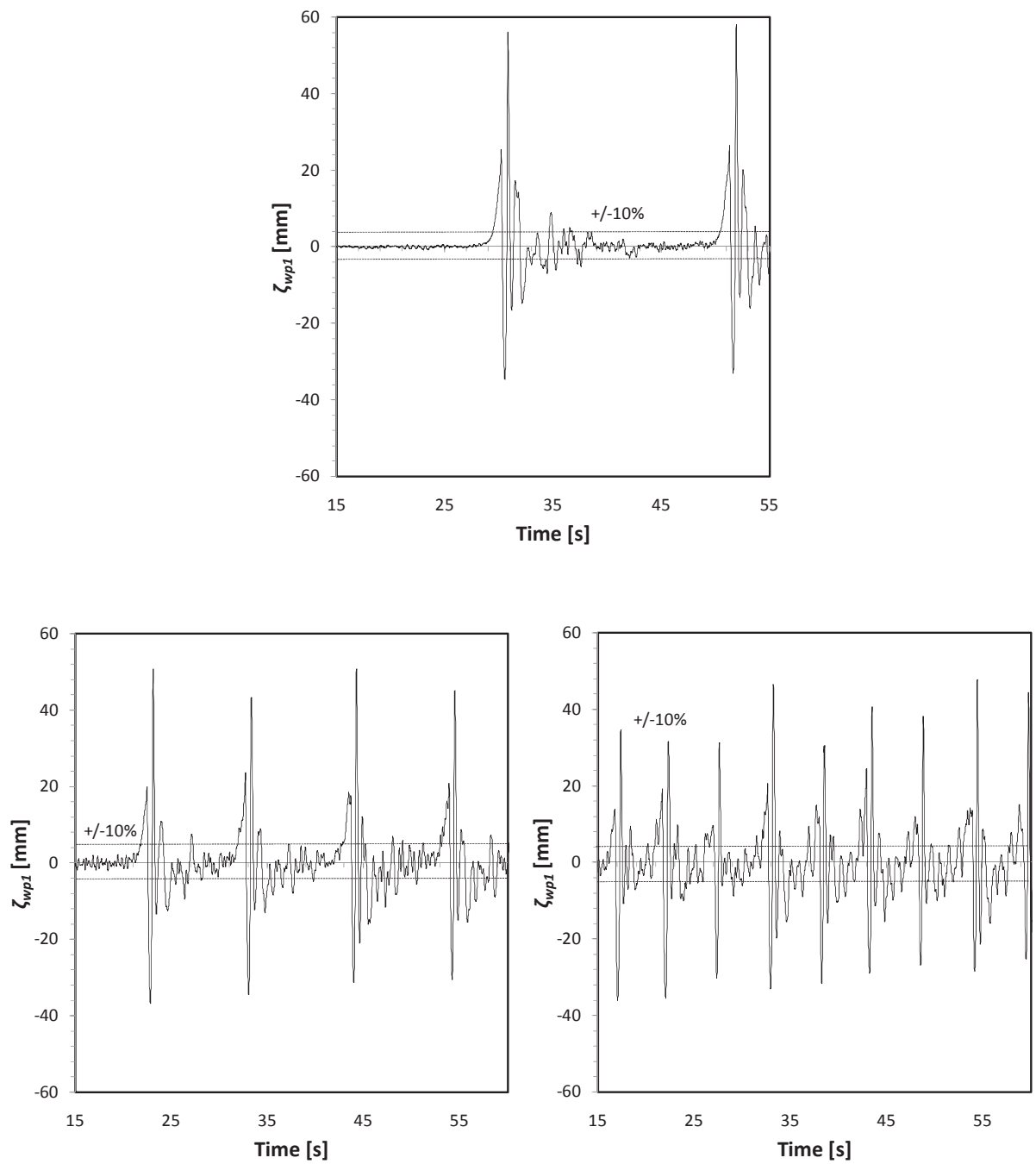

Figure 4-28. Time traces of $\zeta_{\text {wpl }}$ at $y^{*}=0.9(W P l)$ for $d^{*}=0.2$ in $h_{0}=250 \mathrm{~mm}$ and $\kappa \approx 0$ at $F r_{h 0}=0.95$ for condition 6 model 10-25 (left), condition 14 models 10-25 and 10-27 (centre), and condition 15 models 10-24, 10-25, 10-26 and 10-27. 


\begin{tabular}{|c|c|}
\hline Number of pressure sources & Time interval \\
\hline 1 & 21.1 \\
\hline 2 & 10.6 \\
\hline 3 & 7.0 \\
\hline 4 & 5.3 \\
\hline 5 & 4.2 \\
\hline 6 & 3.5 \\
\hline
\end{tabular}

Table 4-1. Time between consecutive pressure sources for $h_{0}=250 \mathrm{~mm}$, and $F r_{h 0}=0.95$.

\subsection{Discussion}

A key finding was that in order to generate high, smooth waves in the constrained channel the pressure source shape, operating conditions, and bathymetry could not be considered in isolation, with a balance needed between the competing requirements. Of the combinations of $\kappa$ and $F r_{h o}$, only a few conditions were found to be "sub-critical" within Lyakovitsky's [23] critical zone. These results highlighted that the sensitivity of the wave generation is very complex when the parameters place the condition within the critical zone. The best possible waves are clearly generated in this critical zone, extremely small changes in the many design parameters may mean the difference between the waves being acceptable or unacceptable. Thus careful consideration must be given to each parameter value.

$\mathrm{Fr}_{l}$ was found to affect the generated wave height and quality. The wavedozer pressure source shape developed the smoother waves with a narrower near-field region than the parabolic pressure sources. For the wavedozer, the entry angle proved critical to the design, with a limiting value of $\alpha \leq 7^{\circ}$ appearing to provide the best balance of wave height and quality. Further, a symmetrical pressure source was desirable as it will allow the pressure source to generate both left and right hand breaking waves by being driven in clockwise and anticlockwise directions respectively without the need to change the pressure source.

Lastly, it was concluded the water calmed sufficiently (to less than $10 \%$ of the maximum wave height) to allow multiple pressure sources to be used in a pool whilst maintaining sufficient wave quality for surfing. 


\section{Chapter 5 Bathymetry and wave breaking}

\subsection{Chapter introduction}

This chapter details the experimental results for the bathymetry design parameters with respect to the breaking wave shape and quality. A qualitative assessment of the breaking waves was conducted using the wave scoring method defined in Section 3.6.1. For each run, the wave scores for the first and second waves were determined.

The design parameters investigated included:

a. Pool radius. The effect of the pool radius $\left(R_{0} * \frac{R_{0}}{L W L}\right)$ on wave generation and breaking was determined. Physically, $R_{0}$ determines the overall size of the pool, the land area required, and the maximum number of pressure sources that may be used with the pool without degrading the wave quality and thus the maximum number of surfing waves generated.

b. Blockage ( $\boldsymbol{\kappa})$ and depth Froude depth $\left(\boldsymbol{F r} \boldsymbol{r}_{\boldsymbol{h}}\right)$. The quality of the breaking waves was determined blockage $(\kappa)$ and depth Froude depth $\left(F r_{h 0}\right)$.

c. Lateral distance to the start of the beach $\left(y_{\text {beach }} *\right)$. The effect of $y_{\text {beach }} *$, on the lateral wave decay and wave quality was tested.

d. Beach slope (s). The beach slope was a key parameter in determining the wave breaking intensity. To determine the slope required to generate the desired plunging wave, slopes of 9, 17 and 23 degrees were tested.

e. Water depth at the start of the beach $\left(h_{\text {beach }}\right)$ and at the outer wall $\left(h_{0}\right)$. By continuing the constant water depth in the channel $\left(h_{0}\right)$ to the start of the beach, the aim was to delay wave breaking until triggered by the beach. 
The parameters were normalised or non-dimensionalised as detailed in Section 2.4.1.

The currents generated in the channel were also measured and discussed. Finally, the methods of maximising wave dissipation post breaking and improving wave quality at the breakpoint by carefully shaping the beach are discussed.

\subsection{Pool radius}

The effect of the pool radius $\left(R_{0} *\right)$ on wave breaking was determined. $H^{*}$ was plotted as a function of $F r_{h 0}$ for $y_{\text {beach }} *=1.9$ and $\kappa=0.07$ with $R_{0} *=6$ and $R_{0} *=12$; Figure 5-1. The wave heights at the beach were less for $R_{0} *=12$ than for the tighter radius pool of $R_{0} *=6$.

$H^{*}$ was plotted as a function of $y^{*}$ at $F r_{h 0}=0.95$; Figure 5-2, with the greater wave heights for the tighter radius pool extended to the beach $\left(y_{\text {beach }} *=1.9\right)$, after which the wave heights appear similar (post-breaking).

The wave trace of the surface elevation, $\zeta^{*}$, were compared for different values of $R_{0} *$ for $F r_{h 0}$ $=0.95$ at the start of the beach $\left(y_{\text {beach }} *=1.9\right)$, Figure 5-3 and Figure 5-4. Both pool radii appeared to generate a similar depth of wave trough $\left(\zeta_{\min } *\right)$, however the crest height $\left(\zeta_{\max } *\right)$ was greater for $R_{0} *=6$.

The first and second wave scores were plotted as functions of $F r_{h 0}$ for $R_{0} *=12$ and $R_{0} *=6$, Figure 5-5 and Figure 5-6 respectively. When observing the wave quality at the nominal design pressure source velocity $\left(F r_{h 0}=0.95\right)$, the less tight track, $R_{0} *=12$, produced a plunging wave (score of 9.5), whilst the tighter radius track produced a spilling wave (score of 6); Figure 5-7 and Figure 5-8 respectively. The loss of wave breaking intensity may have been due to the shortening of the wavelength and change in the peel angle at the beach for the tighter track. This suggests that a trade-off between wave height and quality may be required when selecting the pool radius. 


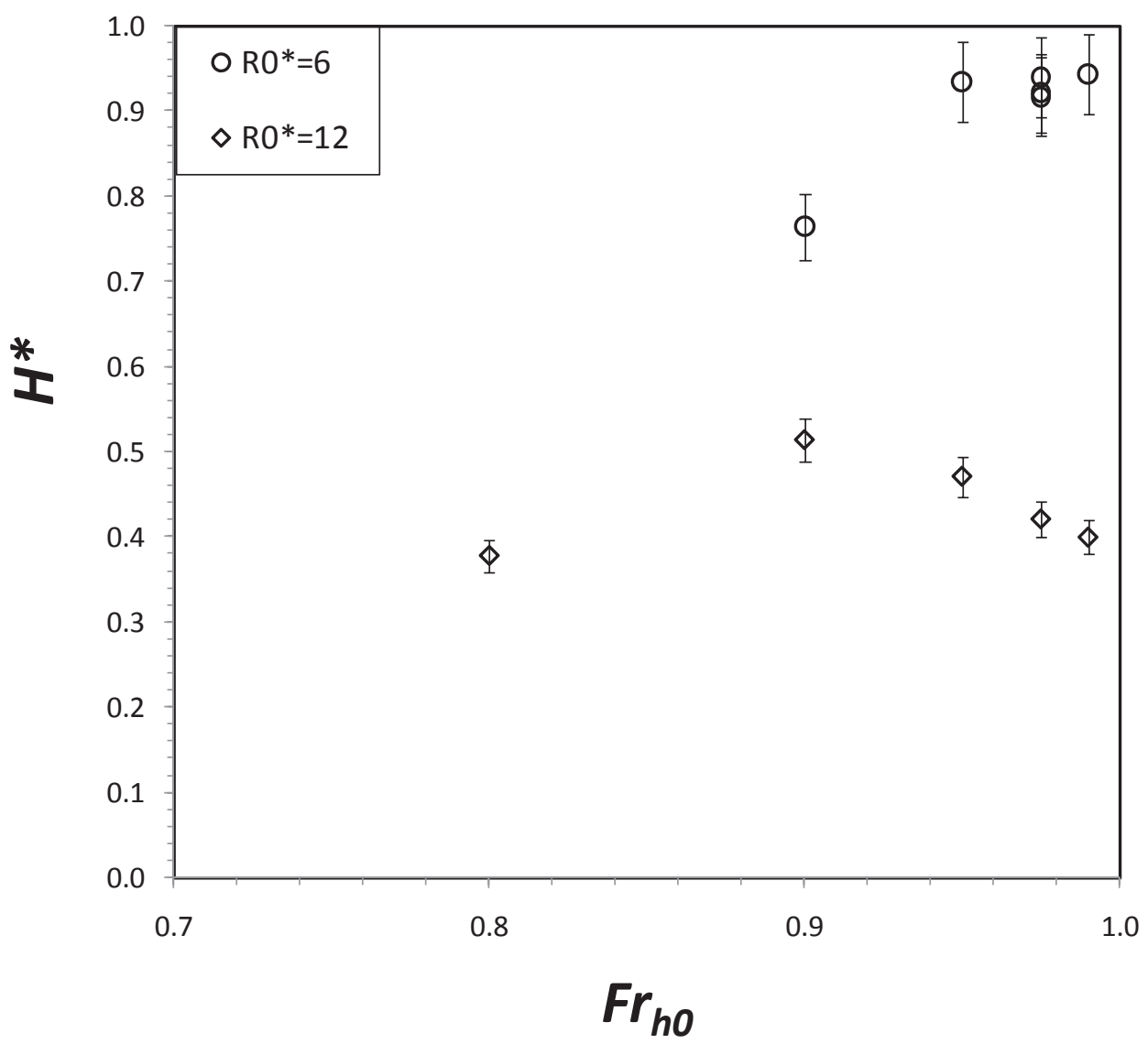

Figure 5-1. $H^{*}$ as a function of $F r_{h 0}$ at $y_{\text {beach }}{ }^{*}=1.9$ with $\kappa=0.07$ for condition 56 model 12-02 $R_{0}{ }^{*}=12$ with $d^{*}=0.2$ in $h_{0}=250 \mathrm{~mm}$ and condition 63 model $12-03 R_{0} *=6$ with $d^{*}=0.2$ in $h_{0}=500 \mathrm{~mm}$. 


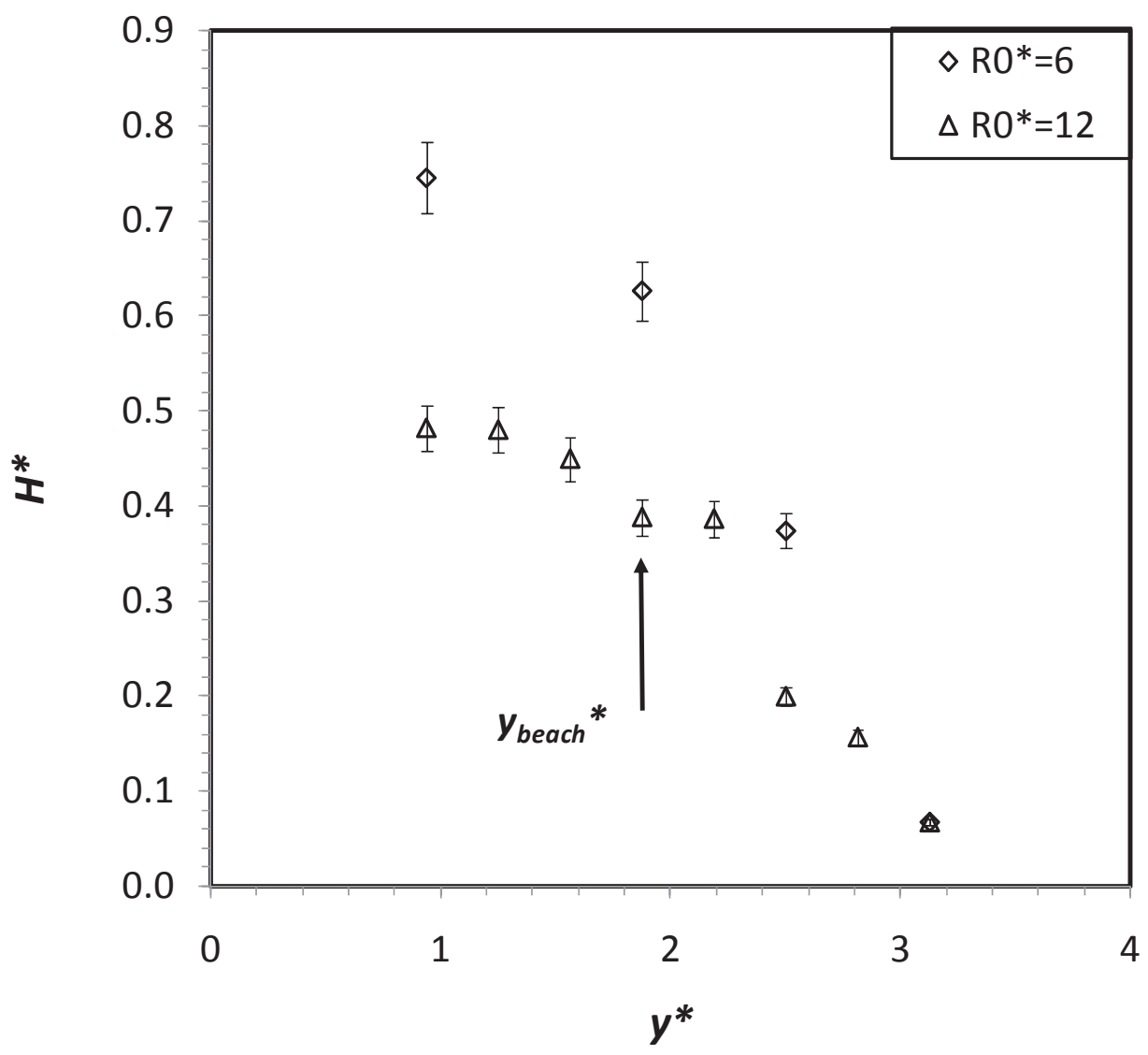

Figure 5-2. $H^{*}$ as a function of $y^{*}$ for $F r_{h 0}=0.95, \kappa=0.07$ and $y_{\text {beach }} *=1.9$ for condition 56 model 12-02 $R_{0}^{*}=12$ with $d^{*}=0.2$ in $h_{0}=250 \mathrm{~mm}$ and condition 63 model $12-03 R_{0}^{*}=6$ with $d^{*}=0.2$ in $h_{0}=500 \mathrm{~mm}$. 


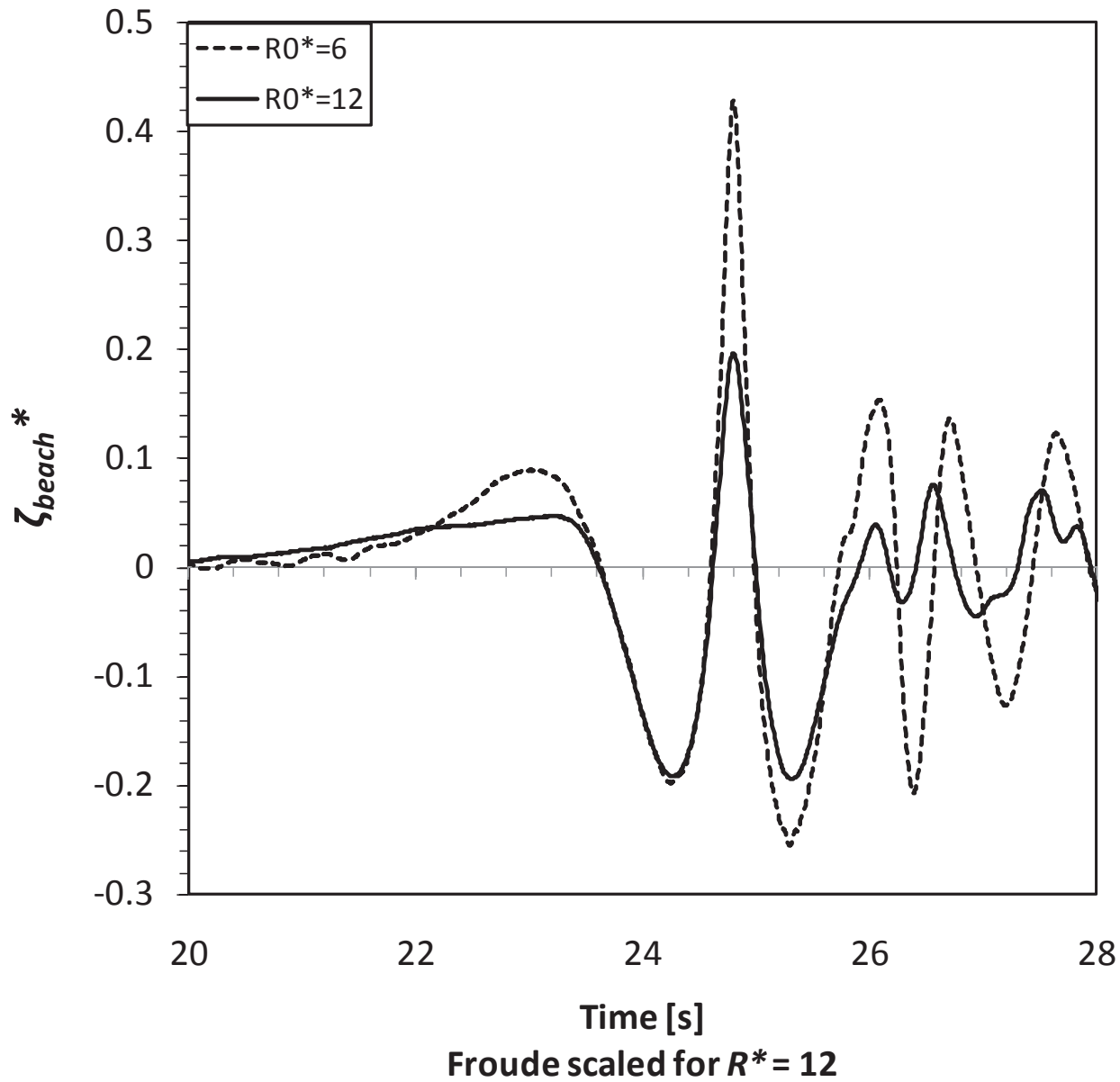

Figure 5-3. Time trace of the surface elevation $\zeta_{\text {beach }} *$ at $y_{\text {beach }} *=1.9$ for $F r_{h 0}=0.95$ and $\kappa=0.07$ for condition 56 model 12-02 $R_{0}{ }^{*}=12$ with $d^{*}=0.2$ in $h_{0}=250 \mathrm{~mm}$ and condition 63 model 12-03 $R_{0}^{*}=6$ with $d^{*}=0.2$ in $h_{0}=500 \mathrm{~mm}$. Model $12-02$ was time shifted and Froude scaled to align with model 12-03. 


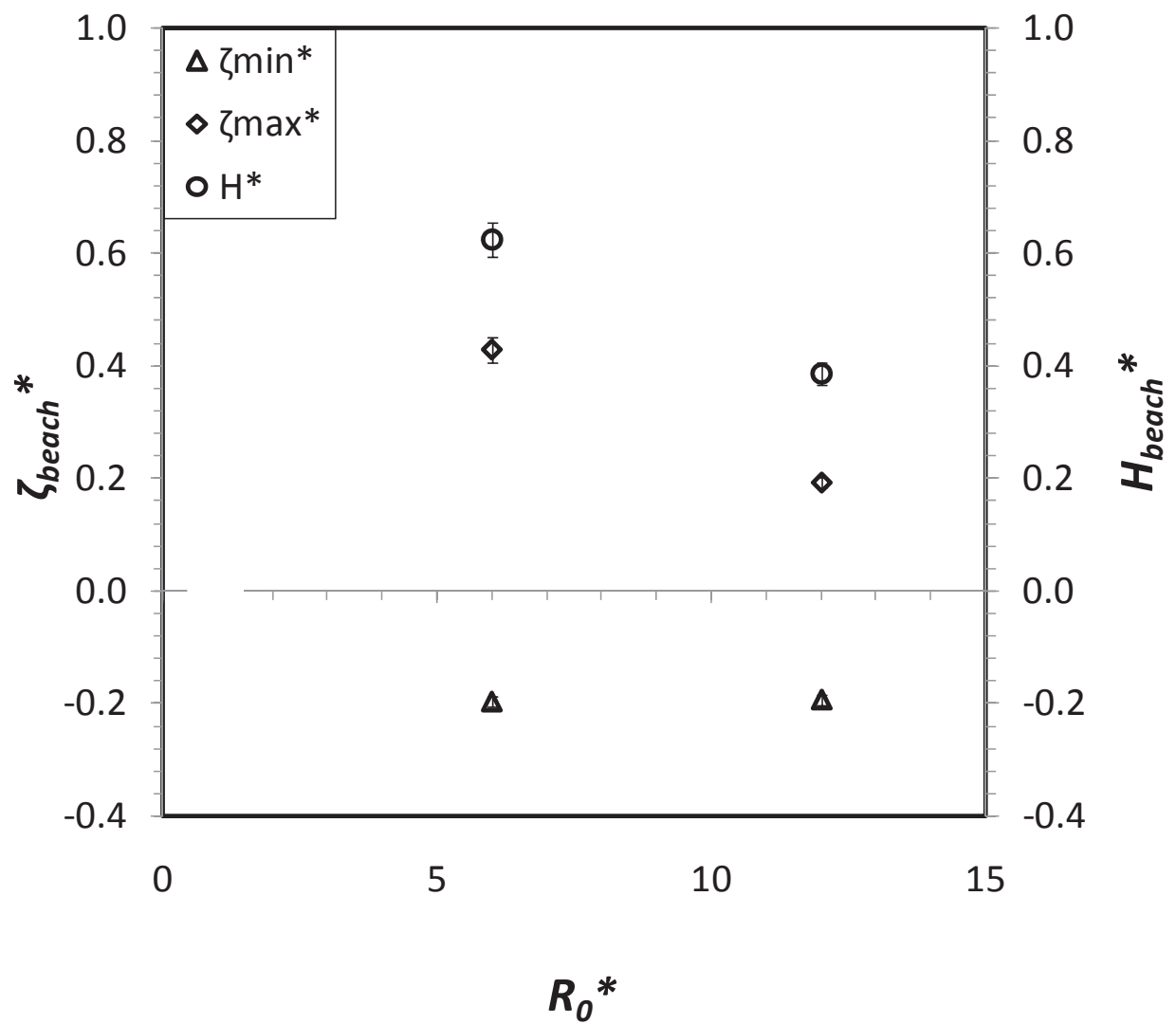

Figure 5-4. Minimum and maximum surface elevation $\zeta_{\text {beach }} *$ and wave height $H_{\text {beach }} *$ at $y_{\text {beach }} *=1.9$ for $F r_{h 0}=0.95$ and $\kappa=0.07$ for condition 56 model $12-02 R_{0}^{*}=12$ with $d^{*}=0.2$ in $h_{0}=250 \mathrm{~mm}$ and condition 63 model 12-03 $R_{0}{ }^{*}=6$ with $d^{*}=0.2$ in $h_{0}=500 \mathrm{~mm}$. 


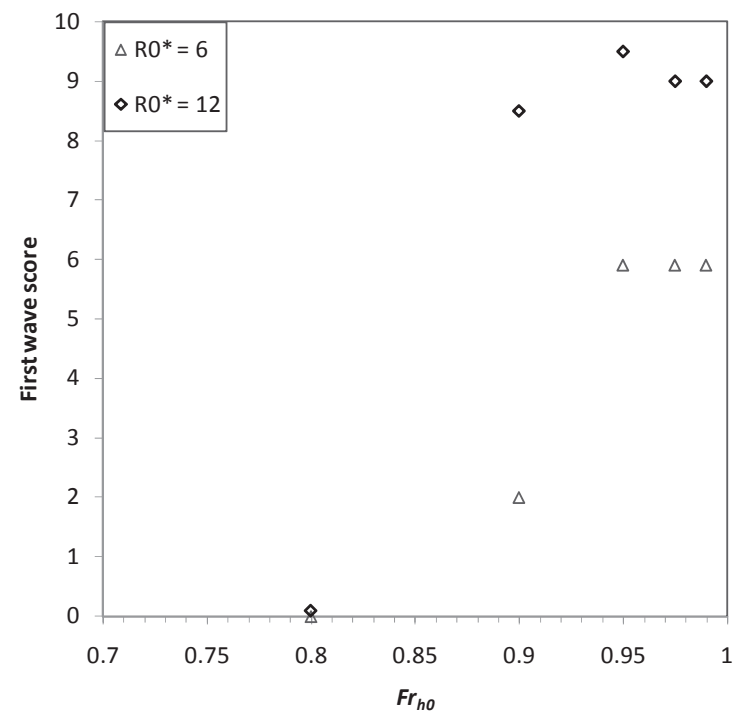

Figure 5-5. First wave score as a function of $F r_{h 0}$ for condition 56 model $12-02 R_{0} *=6$ compared to condition 56 model 12-03 $R_{0} *=12$.

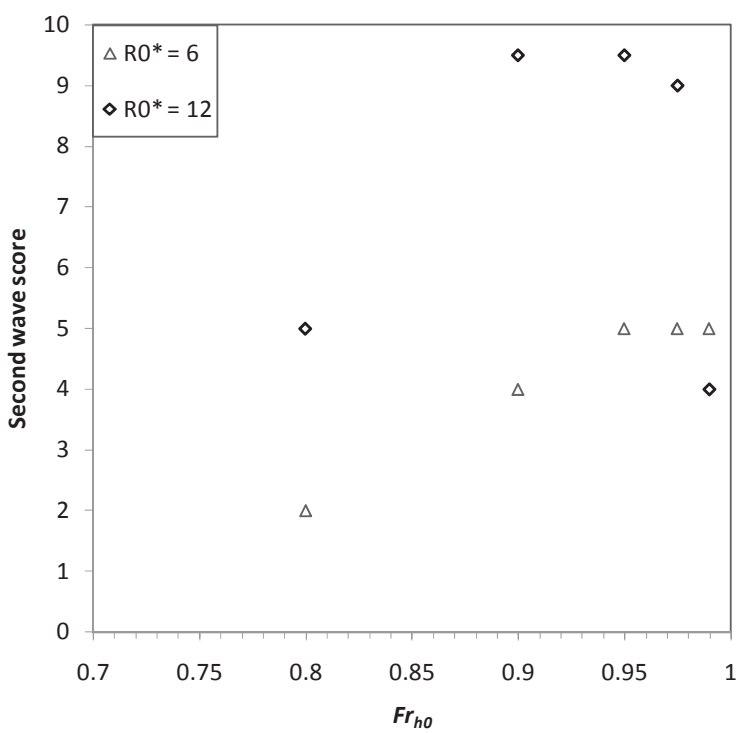

Figure 5-6. Second wave score as a function of $F r_{h 0}$ for condition 56 model 12-02 $R_{0} *=6$ compared to condition 56 model $12-03 R_{0} *=12$. 


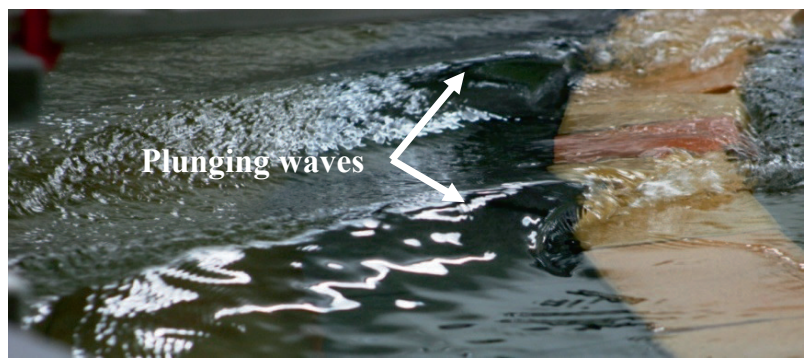

Figure 5-7. Plunging waves generated by condition 56 model $12-02 R_{0}^{*}=12$ and $\kappa=0.07$ with $d^{*}=0.2$ in $h_{0}=250 \mathrm{~mm}$ water depth, $y_{\text {beach }} *=1.9$ at $F r_{h 0}=0.95$.

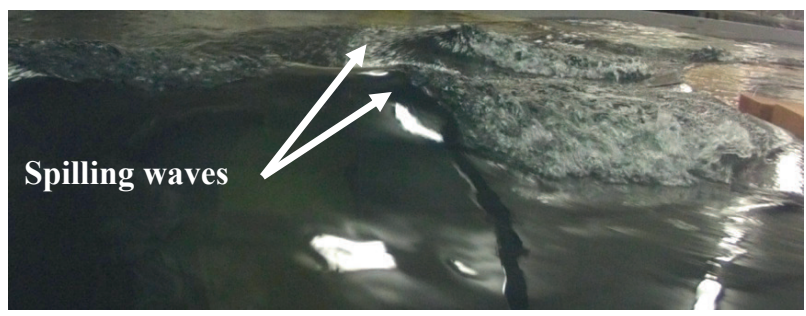

Figure 5-8. Spilling waves generated by condition 63 model $12-03 R_{0} *=6$ and $\kappa=0.07$ with $d^{*}=0.2$ in $h_{0}=500 \mathrm{~mm}$ water depth, $y_{\text {beach }}{ }^{*}=1.9$ at $F r_{h 0}=0.95$. 


\subsection{Lateral distance to the start of the beach}

Different lateral distances to the start of the beach $\left(y_{\text {beach }}{ }^{*}\right)$ were tested, and the effect on the wave height and quality were determined. A beach is required to trigger wave breaking.

$H^{*}$ was plotted as a function of $y^{*}$ for different values of $y_{\text {beach }}{ }^{*}$ at $F r_{h 0}=0.95$; Figure 5-9. $H_{\text {beach }} *$ was similar for $y_{\text {beach }} *=1.4$ and $y_{\text {beach }} *=1.9$, but was significantly lower for $y_{\text {beach }} *=2.4$. The reduction in wave height at the start of the beach is likely due to lateral decay, as detailed in section 2.4.7.

To determine the quality of the waves at the break point, the wave scores for the first and second waves were plotted as functions of $\mathrm{Fr}_{h 0}$; Figure 5-10 and Figure 5-11 respectively. The highest quality waves were created with $y_{\text {beach }}{ }^{*}=1.9$ at $F r_{h 0}=0.95$, however similar quality waves were developed at $F r_{h 0}=0.9$. Further similar quality waves were also produced for $y_{\text {beach }} *=2.4$ at $F r_{h 0} \geq 0.95$, noting that with the surfable wall width $\left(Y_{\text {wall }} *\right)$ proportional to $y_{\text {beach }}{ }^{*}$, as detailed in section 2.4.7,

To provide the optimum trade-off between wave height and quality at the break point, the limiting values were determined to be $y_{\text {beach }} *=1.9$ and $F r_{h 0}=0.9$. 


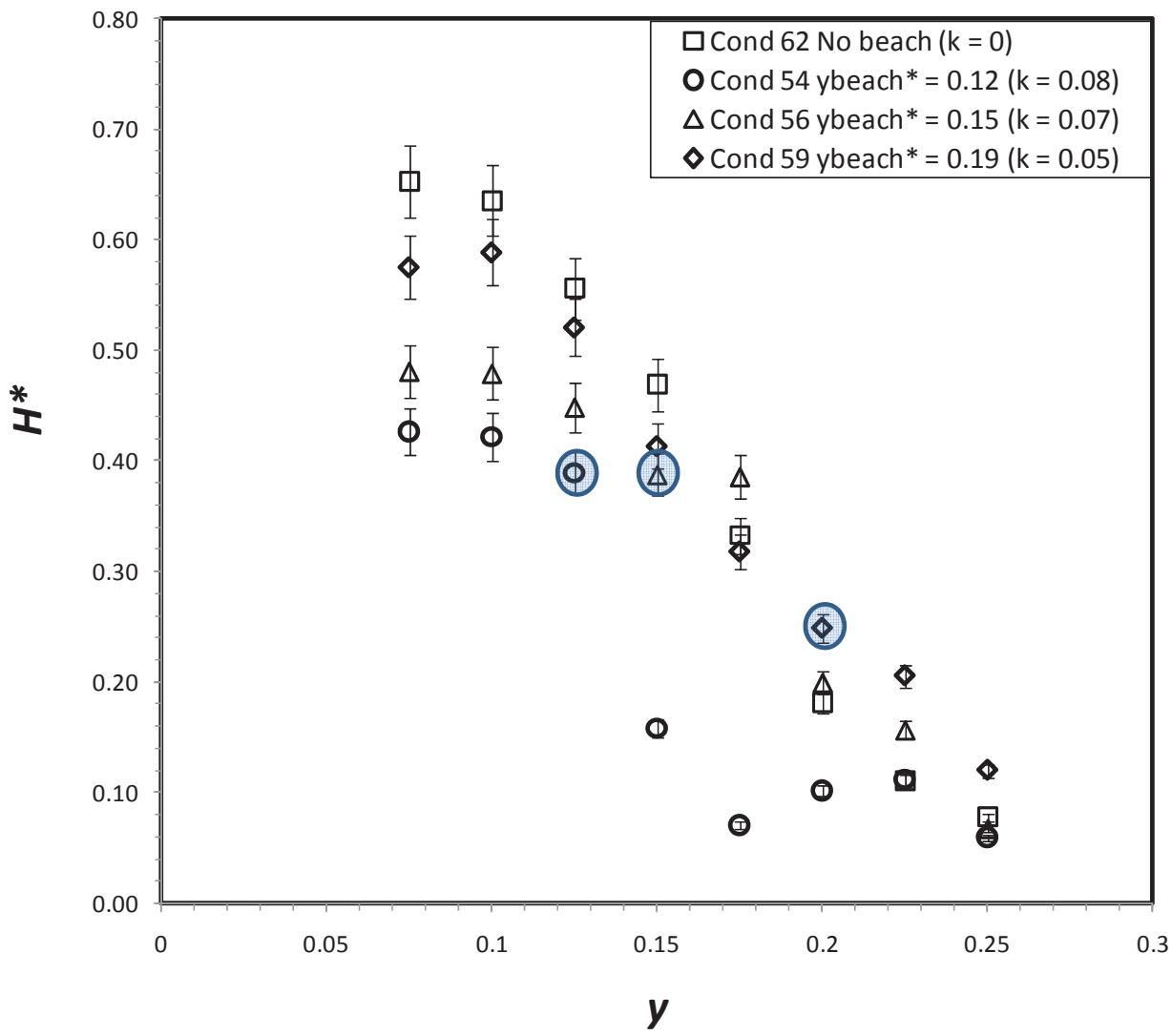

Figure 5-9. $H^{*}$ as a function of $y^{*}$ for different values of $y_{\text {beach }} *$ for model $12-02$ with $d^{*}=0.2$ in $h_{0}=250 \mathrm{~mm}$ at $F r_{h 0}=0.95 . H_{\text {beach }} *$ for each condition is circled. 


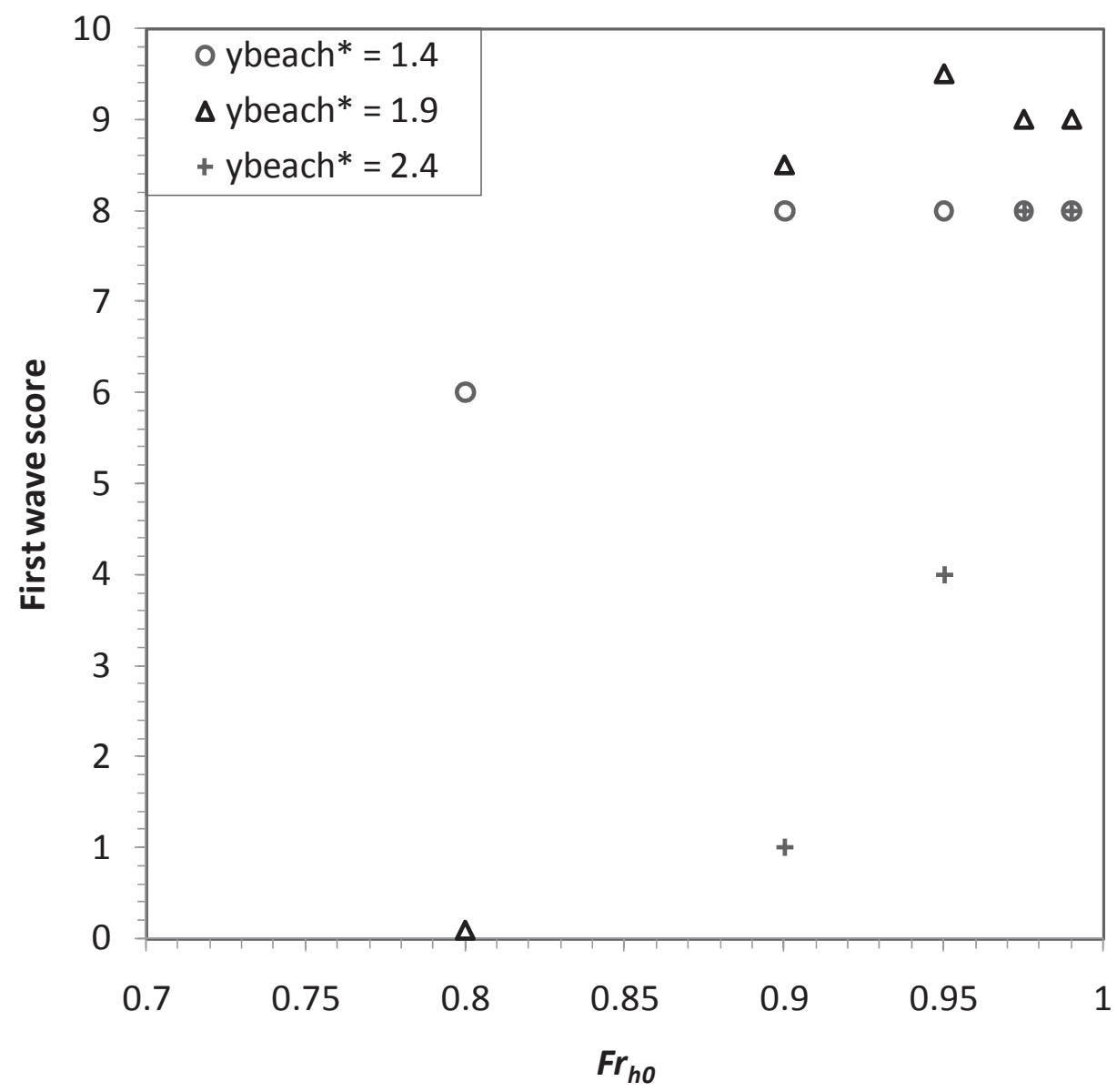

Figure 5-10. First wave scores as a function of $F r_{h 0}$ for different values of $y_{\text {beach }} *$ for model 12-02 with $d^{*}=0.2$ in $h_{0}=250 \mathrm{~mm}$. 


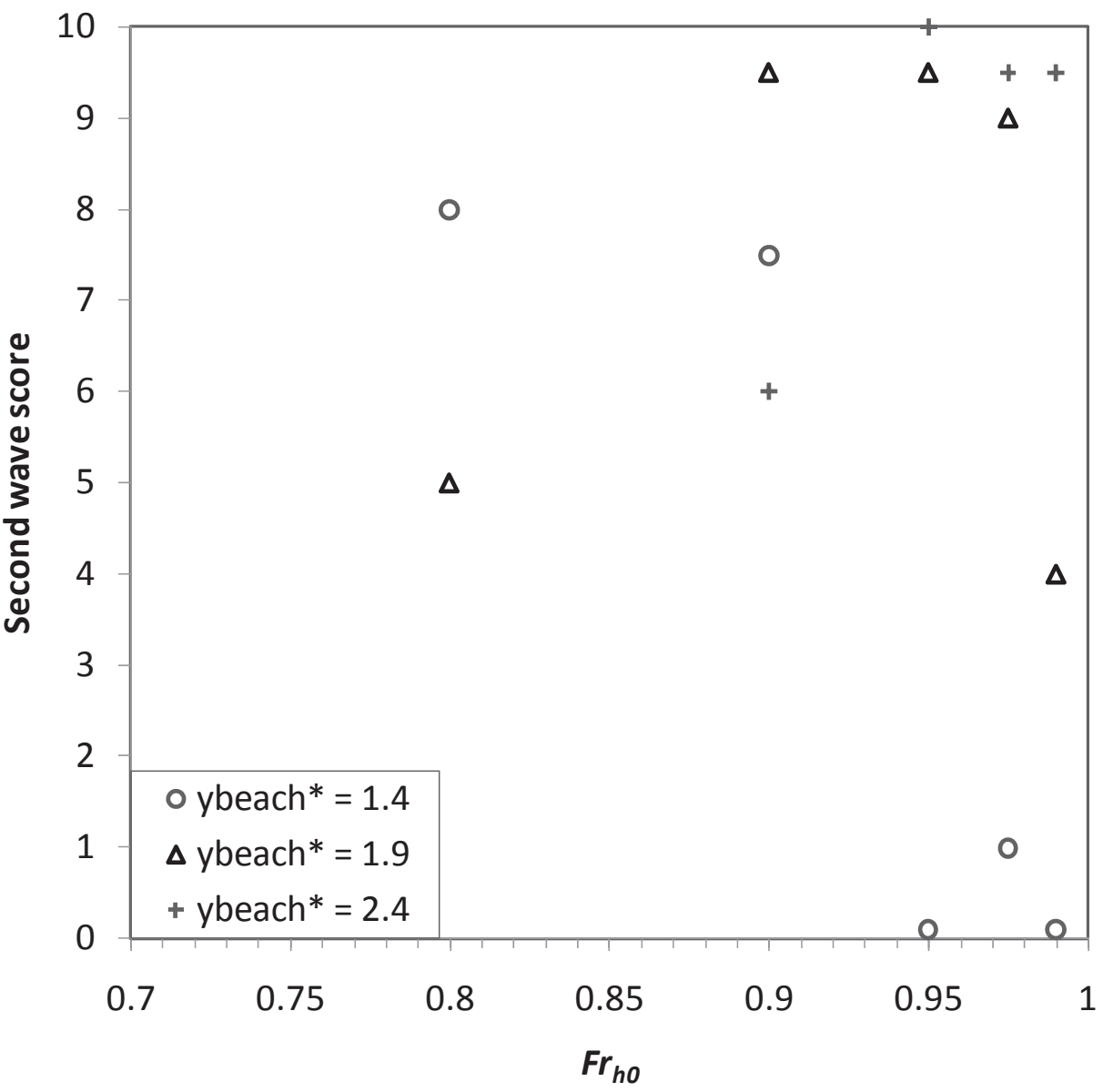

Figure 5-11. Second wave scores as a function of $F r_{h 0}$ for different values of $y_{\text {beach }} *$ for model 12-02 with $d^{*}=0.2$ in $h_{0}=250 \mathrm{~mm}$. 


\subsection{Beach slope}

To determine the slope required to generate the desired plunging wave, slopes of 9,17 and 23 degrees were tested. $H^{*}$ was plotted as a function of $y^{*}$ for different values of $s$; Figure 5-12. The wave heights at the beach were similar.

The wave scores for the first and second waves were plotted as functions of $F r_{h 0}$; Figure 5-13 and Figure 5-14 respectively. The highest quality waves were generated with $s=17^{\mathrm{O}}$ at $F r_{h 0}=0.95$.

The beach slope $(s)$ was a key parameter in determining the wave breaking intensity, with:

a. $\quad s=9^{\mathrm{O}}$ produced surfable waves with a spilling shape.

b. $s=17^{\mathrm{O}}$ produced surfable waves with a plunging shape.

c. $\quad s=23^{\mathrm{O}}$ produced barely surfable surging waves.

The soliton formation was hypothesised to be proportional to the beach slope, $s$, however the soliton and / surge was similar for different beach slopes; Figure 5-15. 


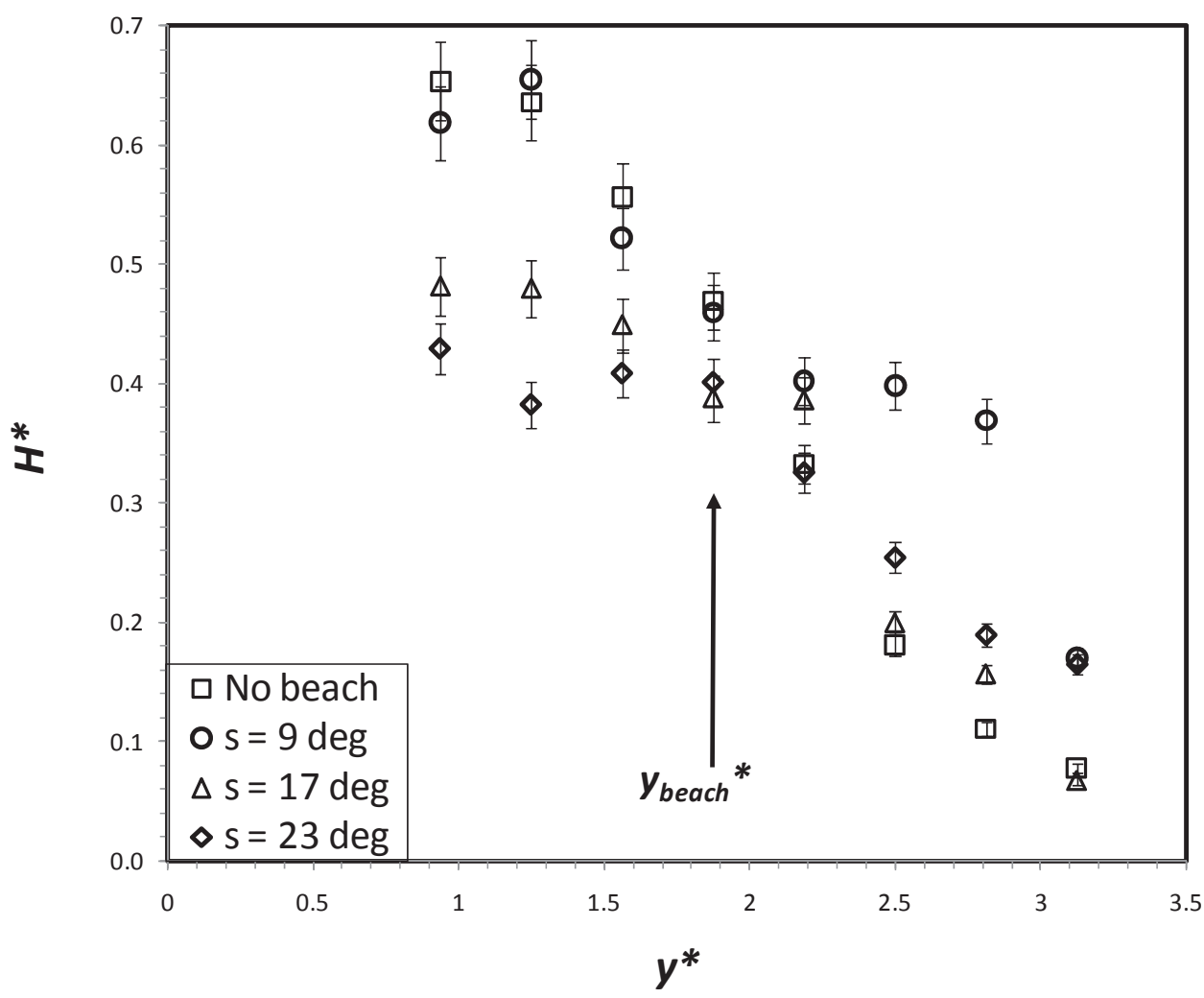

Figure 5-12. $H^{*}$ as a function of $y^{*}$ at for different values of $s$ for model $12-02$ with $d^{*}=0.2$ in $h_{0}=250 \mathrm{~mm}$. 


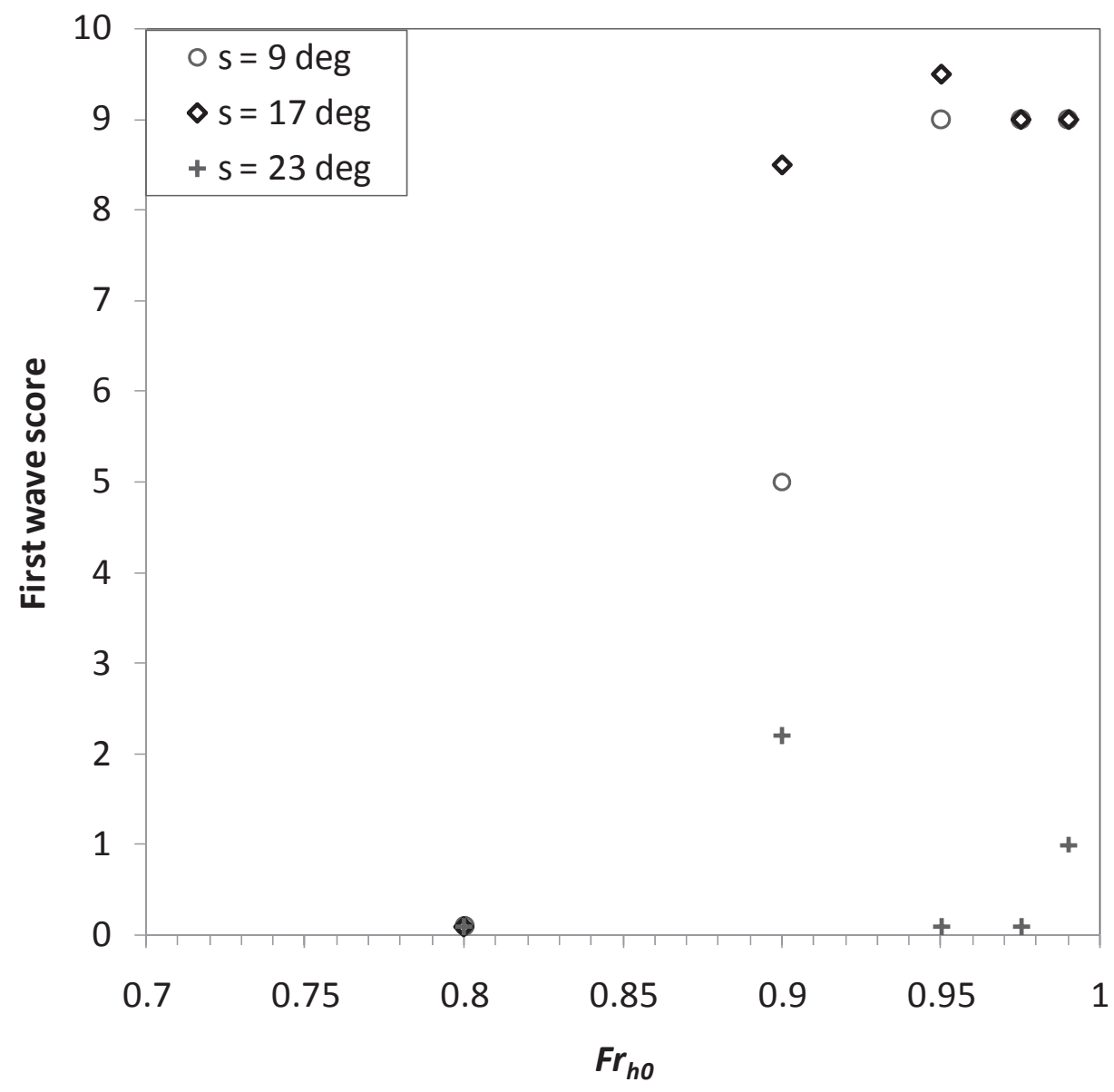

Figure 5-13. First wave scores as a function of $F r_{h 0}$ for different values of $s$ for model 12-02 with $d^{*}=0.2$ and $y_{\text {beach }} *=2.4$. 


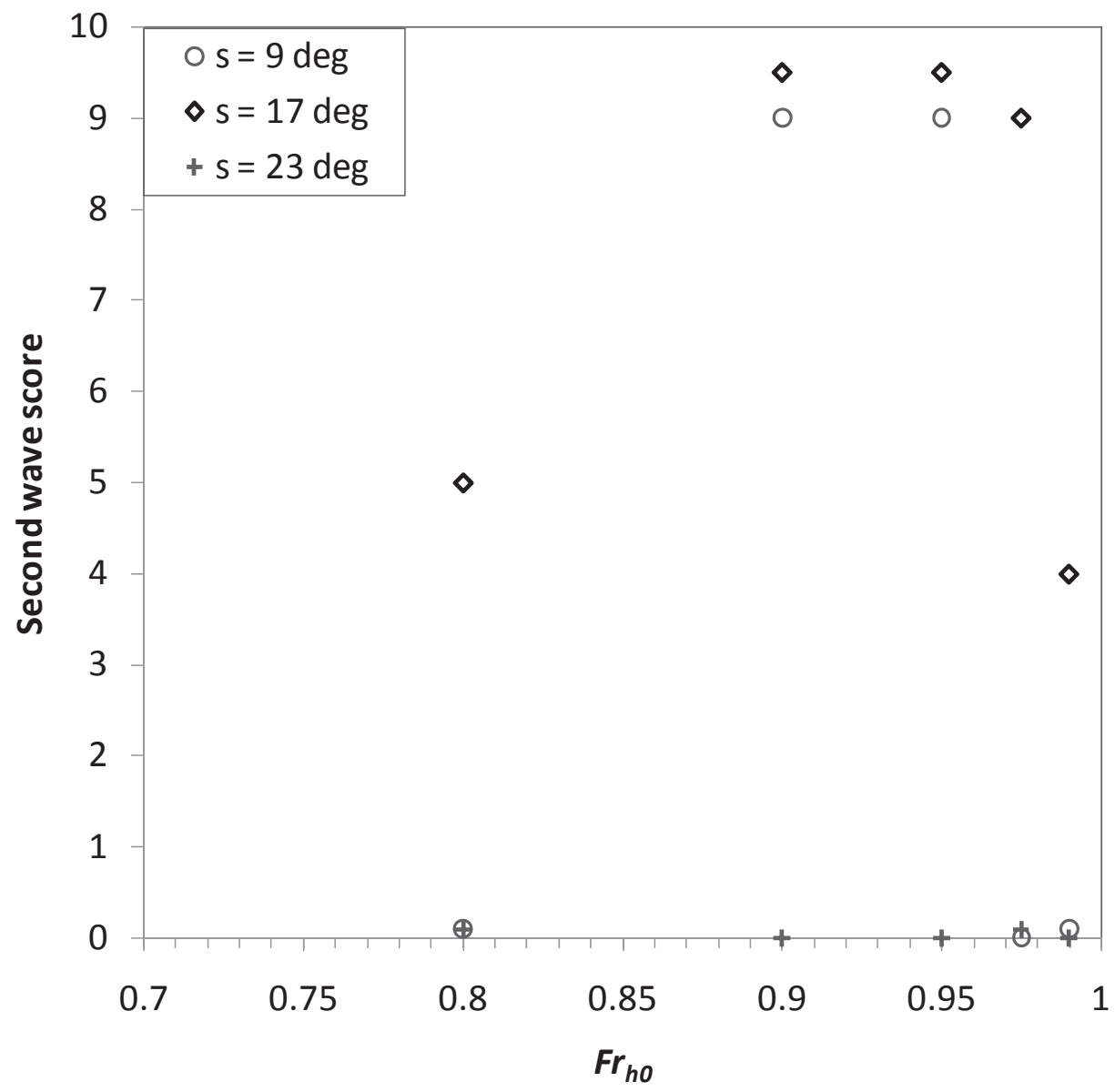

Figure 5-14. Second wave scores as a function of $F r_{h 0}$ for different values of $s$ for model 12-02 with $d^{*}=0.2$ and $y_{\text {beach }} *=2.4$. 


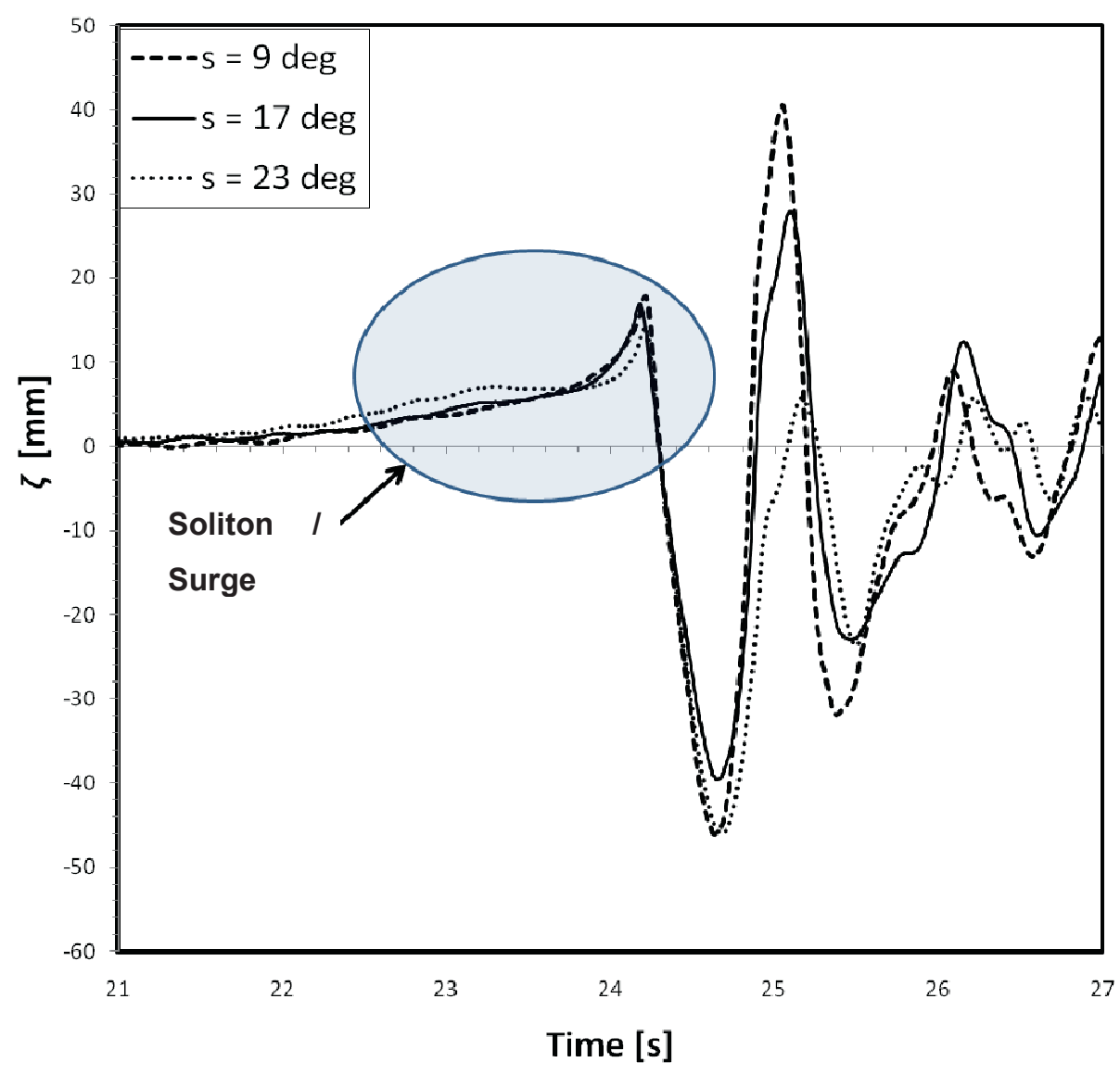

Figure 5-15. Time traces of $\zeta^{*}$ at $y^{*}=0.9$ showing the solitons and / or surge generated by model 12-02 with $d^{*}=0.2$ in $h_{0}=250 \mathrm{~mm}$ at $F r_{h 0}=0.95$ for condition $49 s=9^{\circ}$, condition $56 s=17^{\circ}$, and condition $52 s=23^{\circ}$. Conditions 52 and 56 were time shifted to align with Condition 49 . 


\subsection{Water depth at the start of the beach and the outer wall}

For the design of the pool, the water depth at:

a. The start of the beach $\left(h_{\text {beach }}\right)$ was determined by the breaking wave height $\left(H_{\text {beach }}\right)$, as defined by Eq. (2.52), where the breaking water depth constant $\gamma=1.13$ assuming for shallow water.

b. The outer wall $\left(h_{0}\right)$ was determined by the pressure source velocity $\left(u_{0}\right)$ and the design $F r_{h 0}$ as defined by Eq. (2.36), with $u_{0}$ determined from the surfer speed $\left(u_{0}\right)$ and radii of the beach $\left(R_{\text {beach }}\right)$ and pool $\left(R_{0}\right)$ as defined in Eq. (2.34).

By continuing the constant water depth in the channel $\left(h_{0}\right)$ to the start of the beach, wave breaking was delayed until triggered by reduction of the water depth to $h_{\text {beach }}$ at the start of the beach. Many surf breaks include a step at the start of the beach, referred to as a "ledge" in Mead et. al.[34], with the ledge believed to help trigger the wave to break with the desired plunging shape. 


\subsection{Wave dissipation}

Once the wave has broken, the waves were required to be rapidly dissipated to prevent the broken wave reflecting off the beach and adversely interacting with the following waves. The rapid wave dissipation was demonstrated as a rapid lateral decrease in $H^{*}$; Figure 5-16 and Figure 5-17.

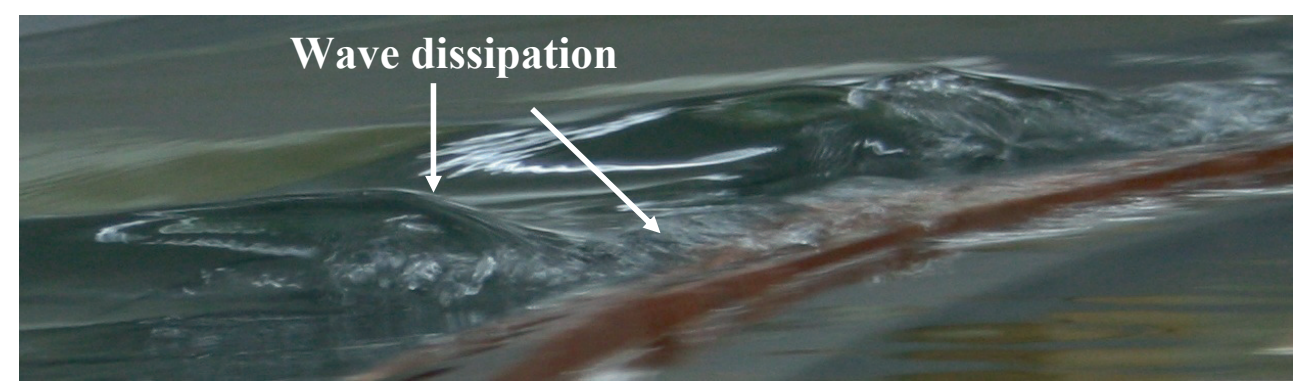

Figure 5-16. Rapid wave dissipation post breaking for condition 49 model 12-02 with $d^{*}=0.2$ in $h_{0}=250 \mathrm{~mm}$ and $y_{\text {beach }}{ }^{*}=0.15$ at $F r_{h 0}=0.95$. 


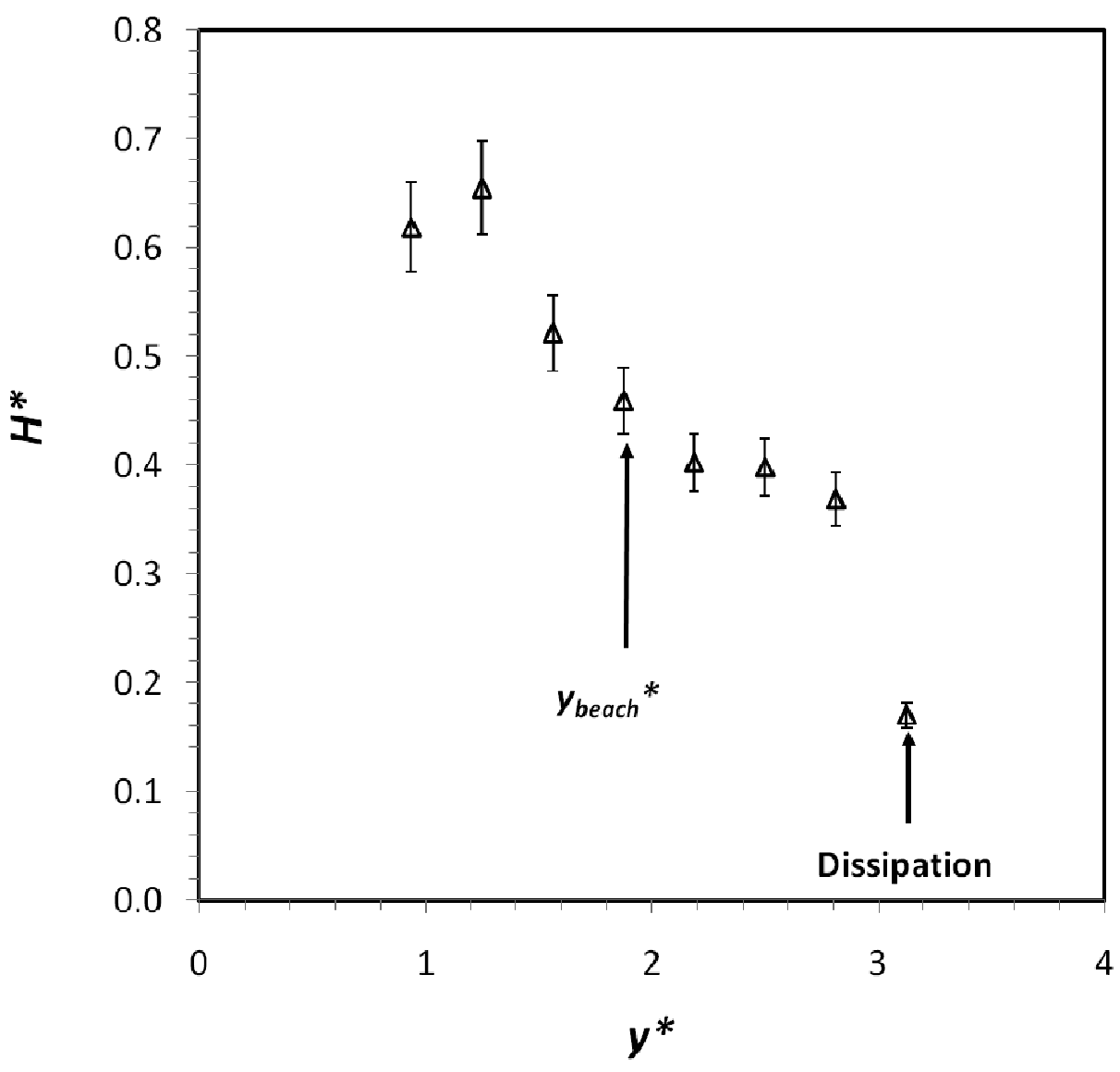

Figure 5-17. $H^{*}$ as a function of $y^{*}$ for condition 49 model $12-02$ with $d^{*}=0.2$ in $h_{0}=250 \mathrm{~mm}$ and $y_{\text {beach }} *=1.9$ at $F r_{h 0}=0.95$.

\subsection{Currents}

As the pressure source travels, a current was generated in the pool. The current was found to reach a steady state. In the circular track scale model, an Acoustic Doppler Velocimeter (ADV) was used to measure the current velocity parallel with the pressure direction of travel $\left(u_{c}\right)$. In the circular track series 1 , to measure $u_{c}$ at the surface at different values of $y$, a measured grid (each $250 \mathrm{~mm}$ apart) was spaced circumferentially, with floats placed on the 
surface at different radial positions. A camera was used to automatically take photographs every two seconds of the float locations, with the surface current velocity calculated from the results; refer to Annex A for further details.

The effect of the velocity of the current, $u_{c}$, effectively reduces $u_{0}$ to $u_{0}$ ':

$$
u_{0}^{\prime}=u_{0}-u_{c}
$$

The current velocity was normalised by the pressure source velocity:

$$
u_{c}^{*}=\frac{u_{c}}{u_{0}}
$$

\subsubsection{Current velocity as a function of $\boldsymbol{F r}_{\boldsymbol{h} 0}$}

For all conditions, $u_{c}{ }^{*}$ decreased as $F r_{h 0} \rightarrow 1$; Figure 5-18. For design case of condition 56 at $F r_{h 0}=0.9, u_{c}^{*}=0.06$ was considered acceptable as it did not appear to adversely affect the wave height or shape. 


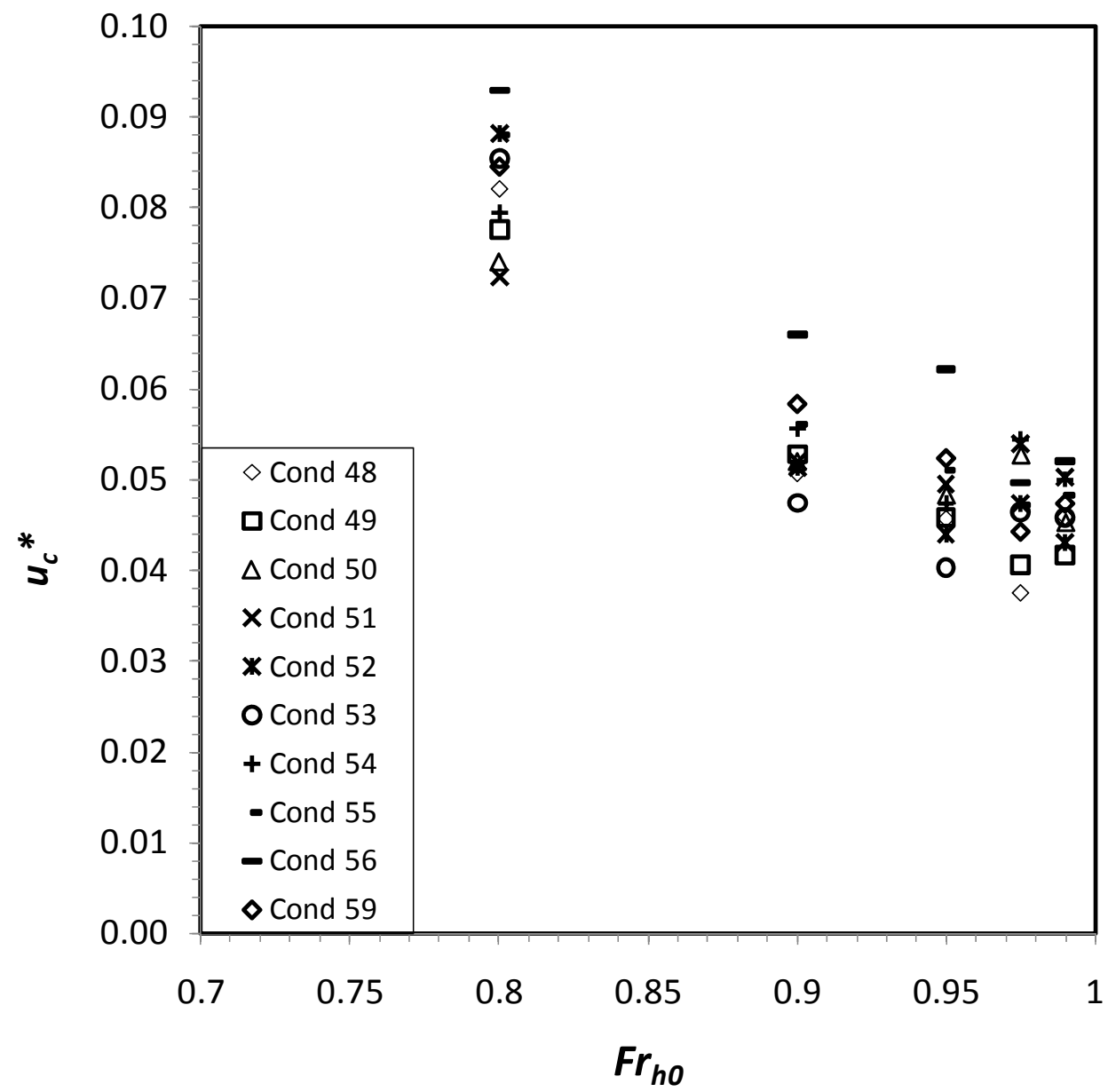

Figure 5-18. $u_{c}{ }^{*}$ as a function of $F r_{h 0}$ measured by the $\mathrm{ADV}$ at $y^{*}=0.9$ and $Z^{*}=0.28$ for conditions 48 to 56 and 59 model $12-02$ with $d^{*}=0.2$ in $h_{0}=250 \mathrm{~mm}$.

\subsubsection{Current velocity with multiple pressure sources}

$u_{c}{ }^{*}$ with multiple pressures sources were tested:

a. Condition 6, 1 pressure source, model 10-25.

b. Condition 15, 2 pressure sources, models 10-25 and 10-27. 
c. Condition 16, 4 pressure sources, models 10-24 to 10-27.

$u_{c}{ }^{*}$ and the ratio of the current speed with multiple pressure sources to the current speed with only one pressure source are detailed in Table 5-1. $u_{c}{ }^{*}$ was approximately proportional to the number of pressure sources, with the deviation from a linear relationship likely due to crosssectional areas of the pressure sources.

\begin{tabular}{|c|c|c|c|}
\hline Condition & $\begin{array}{c}\text { Number of pressure } \\
\text { sources }\end{array}$ & Models & $\boldsymbol{u}_{\boldsymbol{c}}^{*}$ \\
\hline 6 & 1 & $10-25$ & 0.04 \\
\hline 14 & 2 & $10-25$ and $10-27$ & 0.09 \\
\hline 15 & 4 & $10-24,10-25,10-26$ and $10-27$ & 0.13 \\
\hline
\end{tabular}

Table 5-1: Current measured by the ADV for $F r_{h 0}=0.975$ with $1(\kappa=0.05), 2(\kappa=0.06)$ and $4(\kappa=0.07)$ pressure sources.

\subsubsection{Current velocity to lateral and vertical location in the channel}

To determine how the current velocity, $u_{c} *$ through the channel cross-section, $u_{c}{ }^{*}$ was plotted as a function of $y^{*}$ for different heights above the channel bottom, $Z^{*}$, for condition 60 model 12-02 with $F r_{h 0}=0.975$ and $\kappa=0.07$; Figure 5-19. For all vertical locations, the current decreased with distance from the pressure source centre line of travel $\left(y^{*}=0\right)$. A plot of the $u_{c}{ }^{*}$ as a function of $y^{*}$ at the surface condition 6 model $10-25$ at $F r_{h 0}=0.975$ and $\kappa=$ 0.07 shows a similar relationship; Figure 5-20. To allow a direct comparison with the current speed measured by the ADV (at $Z^{*}=0.2$ ), Table 5-2 lists the current velocity at the surface and measured at the ADV.

$u_{c} *=0.02$ at the beach was considered insignificant, and was unlikely to affect the wave quality. However, $u_{c}{ }^{*}$ at $y_{\text {beach }}{ }^{*}$ will need to be investigated with multiple pressure sources operating. 


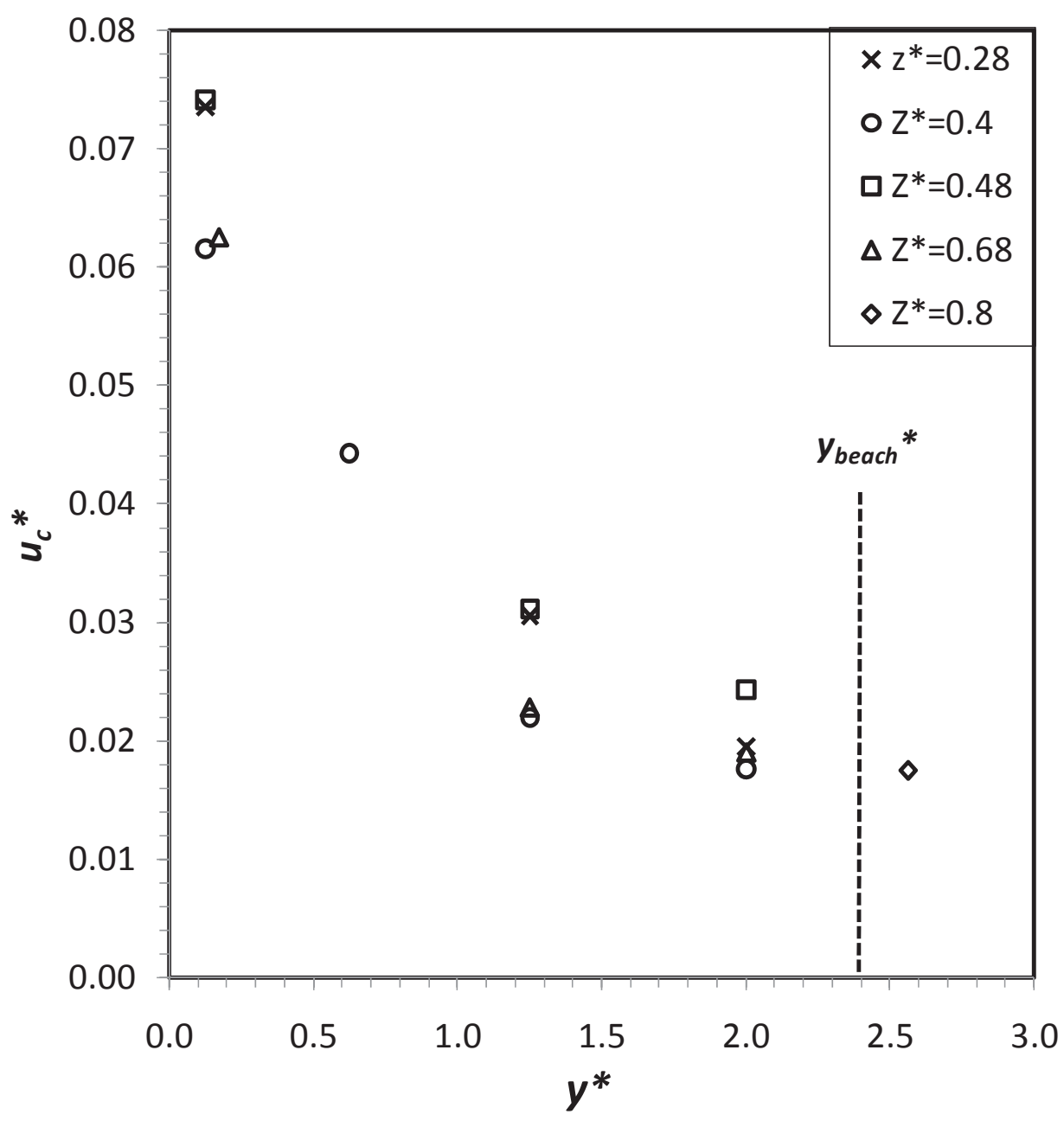

Figure 5-19. $u_{c} *$ as a function of $y *$ measured by the ADV for different $Z *$ for condition 59 model 12-02 with $d^{*}=0.2$ and $y_{\text {beach }}{ }^{*}=2.4$ in $h_{0}=250 \mathrm{~mm}$ at $F r_{h 0}=0.975$ and $\kappa=0.05$. 


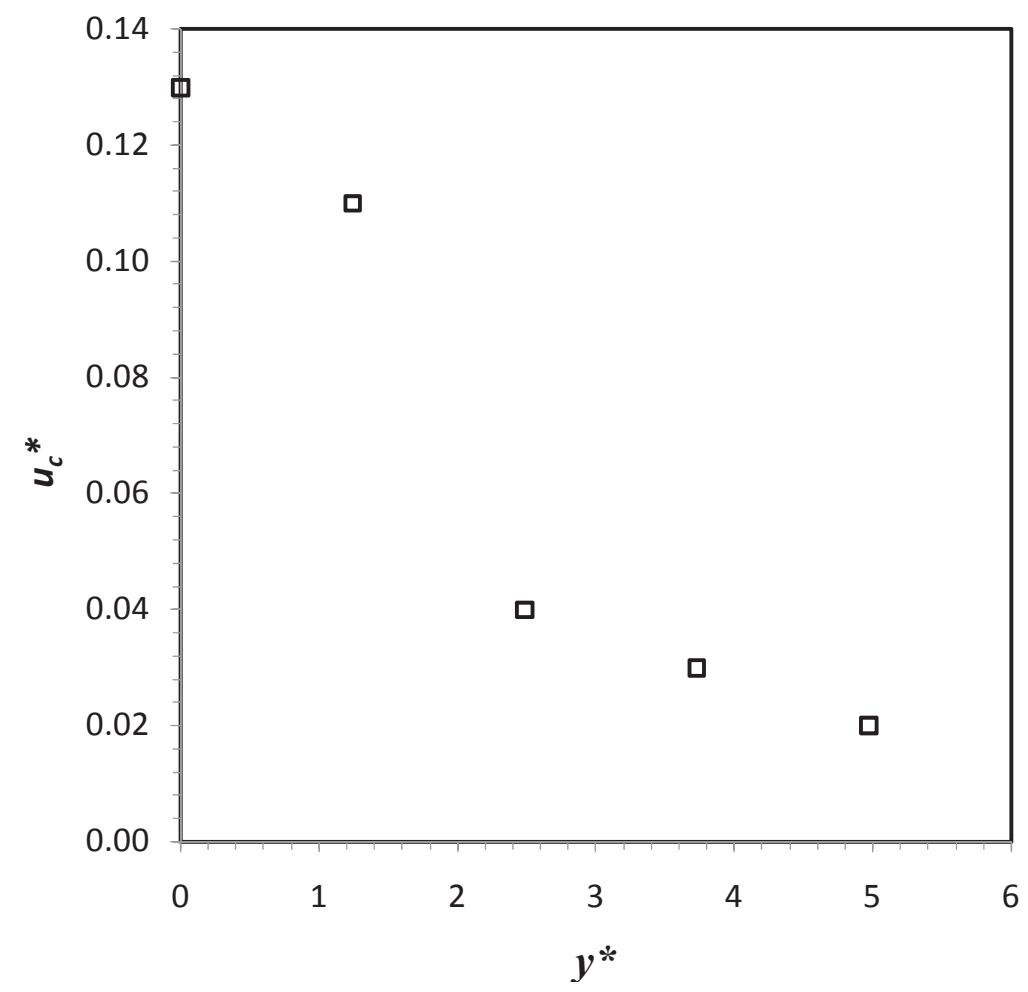

Figure 5-20. $u_{c} *$ on the surface observed with the surface floats as a function of $y^{*}$ for condition 6 model $10-25$ at $F r_{h 0}=0.975, y_{\text {beach }} *=1.4$ and $\kappa=0.07$.

\begin{tabular}{|c|c|}
\hline $\boldsymbol{y}^{*}$ & $\boldsymbol{u}_{\boldsymbol{c}}{ }^{*}$ \\
\hline \multicolumn{2}{|c|}{ ADV } \\
\hline 1.9 & 0.04 \\
\hline \multicolumn{2}{|c|}{ Surface (using floats) } \\
\hline 0.0 & 0.13 \\
\hline 1.2 & 0.11 \\
\hline 2.5 & 0.04 \\
\hline 3.7 & 0.03 \\
\hline 5.0 & 0.02 \\
\hline
\end{tabular}

Table 5-2: $u_{c} *$ as a function of $y^{*}$ for condition 6 model 10-25 at $F r_{h 0}=0.975, y_{\text {beach }} *=1.4$ and $\kappa=0.07$. 


\subsubsection{Current velocity as a function of blockage}

$u_{c}^{*}$ was plotted as a function of $\kappa$ for each condition with $d^{*}=0.2$ at $F r_{h 0}=0.95$; Figure 5-21. From Figure 5-21, blockage was not a major determinant of the current velocity. However, when $u_{c}{ }^{*}$ was plotted as a function of the draught $\left(d^{*}\right), u_{c}{ }^{*}$ was proportional to $d^{*}$; Figure 5-22.

As the final design of the wave pool will potentially use multiple pressure sources, in the event the current adversely affects the wave quality, it is recommended that either less pressure sources, or reduced blockage should be used. Alternatively, anti-current devices (either passive or active) may be considered, including:

a. Passive systems, such as anti-drift curtains or baffles. These systems require no additional energy requirements and are technologically simple. Anti-drift currents are used in tow tanks to suppress currents and allow shorter times between runs [29]. However, possible surfer entanglement is an issue, and so they should be placed in deep water away from the beach.

b. Active system based on return from any water treatment system. However this introduces a mixing issue, and may not be effective.

c. Regular reversal of the pressure source direction of travel. 


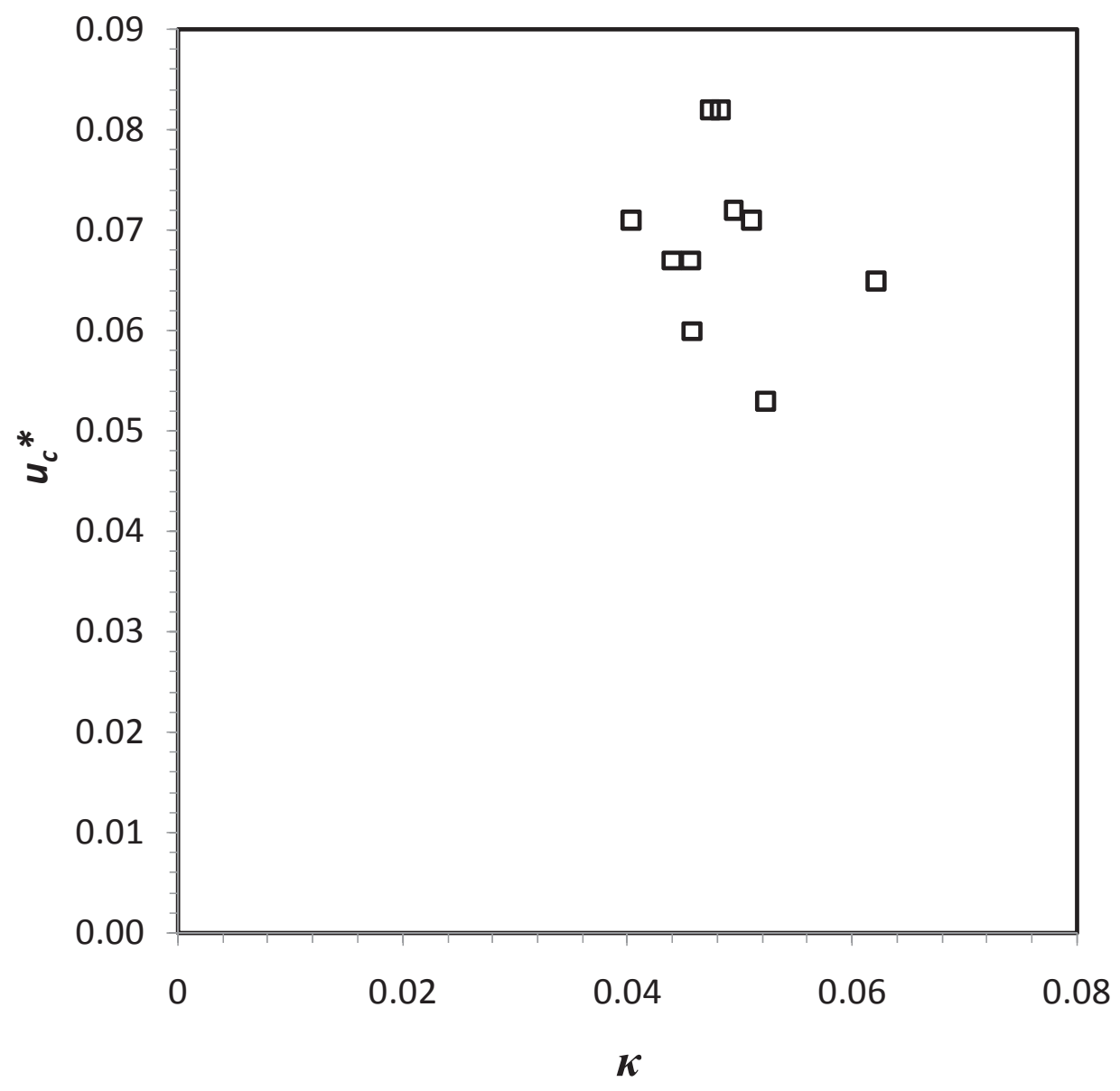

Figure 5-21. $u_{c}{ }^{*}$ as a function of $\kappa$ measured by the ADV at $y^{*}=0.9$ and $Z^{*}=0.28$ for conditions 48 to 60 model $12-02$ with $d^{*}=0.2$ in $h_{0}=250 \mathrm{~mm}$ at $F r_{h 0}=0.95$. 


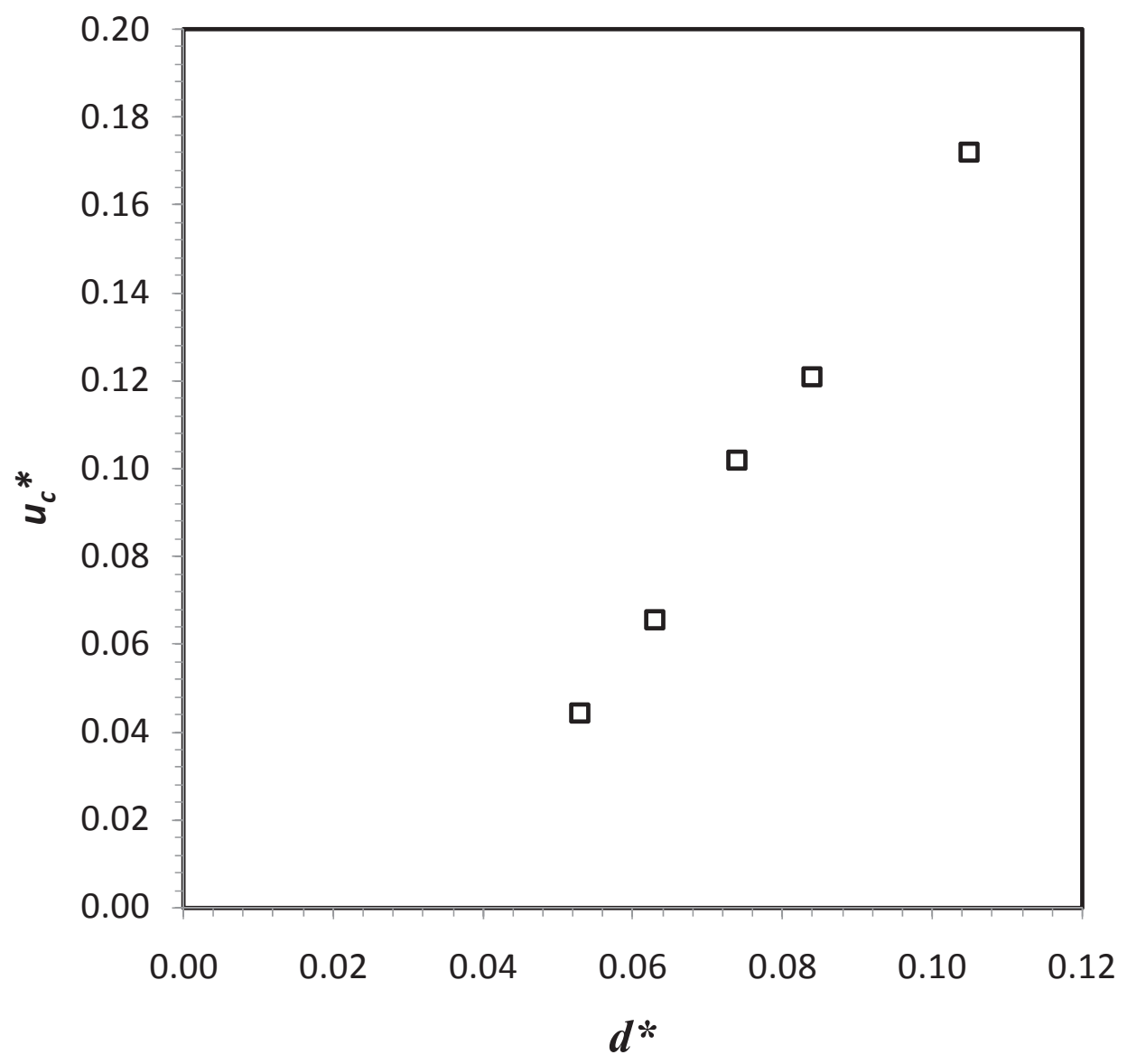

Figure 5-22. $u_{c}^{*}$ as a function of $d^{*}$ measured by the $\mathrm{ADV}$ at $y^{*}=0.9$ and $Z^{*}=0.28$ for condition 60 model 12-02 with different values of $d^{*}$ in $h_{0}=250 \mathrm{~mm}$ at $F r_{h 0}=0.975$. 


\subsection{Discussion}

\subsubsection{Wave quality}

In this chapter, the effect of the bathymetry on the wave quality was investigated. The wave scoring method, detailed in Section 3.6.1, allowed a qualitative assessment of the waves from the surfer's perceptive to be conducted. The wave quality for surfing shown to be extremely sensitive to changes in the pressure source shape, operating conditions and bathymetry. It was determined that a satisfactory balance of high quality plunging waves and breaking wave height was combination of $F r_{h 0}=0.9$ and $\kappa=0.07$ for condition 56. However, this combination was "critical" within the Lyakhovitsky [23] critical zone. An alternative trade-off was to create larger, spilling waves by either reducing the beach slope (condition 49) or increasing the pool radius (condition 63) for $F r_{h 0}=0.95$, that are both "sub-critical" within the Lyakhovitsky [23] critical zone.

\subsubsection{Pool design steps}

To design a full size pool, it is recommended to use the empirical relationships and design parameter values chosen from the experimental results:

a. Set the pool radius $\left(R_{0}\right)$. This will be determined from the available land area.

b. Assuming a wavedozer is used, select the entry angle $(\alpha)$ to maximise the wave quality and set the waterline length. It was concluded that an entry angle of $\alpha=7^{\circ}$ generated the highest quality waves.

c. Select the depth Froude number $\left(F r_{h 0}\right)$ and increase the pressure source beam $(B)$ and draught $(d)$ as high as possible without losing wave height due to soliton formation, with a combination of blockage $(\kappa)$ and $F r_{h 0}$ that is "sub-critical" within the Lyakhovitsky [23] critical zone. From $F r_{h 0}$ and $u_{0}$, set the water depth at the outer wall $\left(h_{0}\right)$. 
d. Select the desired surfer speed $\left(c_{\text {surfer }}=u_{\text {beach }}\right)$ and lateral distance to the start of beach $\left(y_{\text {beach }}\right)$, to set the pressure source velocity $\left(u_{0}\right)$. As an example, for a commercial $200 \mathrm{~m}$ diameter pool, based on condition 56 with $F r_{h 0}=0.9$, the surfer speed would be $5.4 \mathrm{~m} / \mathrm{s}$, close to the mean value of $6 \mathrm{~m} / \mathrm{s}$ observed by Dally [57] and Hutt et al. [38]; Section 2.2.4.

e. Select the desired wave height $\left(H_{\text {beach }}\right)$ and wave breaking intensity $(\xi)$ at the beach. This will set the water depth at the beach $\left(h_{\text {beach }}\right)$ and slope angle $(s)$.

f. To increase the number of surfable waves in the pool, increase the number of pressure sources until any adverse effects to the wave quality (smoothness) becomes unacceptable. 


\section{Chapter 6 Summary, concluding remarks and further work}

\subsection{Summary}

The primary aim of the research was to investigate the novel idea to produce continuous breaking waves, by rotating a pressure source around the outer perimeter wall of an annular wave pool.

In the early stages of the study it was found that a pressure source operating in a constrained waterway, travelling in a circular track at high depth Froude numbers exhibits highly nonlinear behaviour. This invalidated the use of linear and simple non-linear potential flow numerical analysis tools such as Michlet, DELKELV and RAPID. Even considering simplified configurations, such as linear track, no blockage $(\kappa \approx 0)$, and no beach, the predicted wave height and shape generally did not correlate well with experimental results. Thus, a predominantly experimental approach was undertaken.

A method of qualitative scoring wave shape from the surfer's perspective was developed and proved valuable for focusing the research effort. At the end of the testing, high quality continuous breaking waves of adequate height with the desired plunging shape were able to be generated, with these waves being desirable for surfing.

\subsection{Concluding remarks}

A set of empirical relationships between the design parameters were determined to allow a pool to be designed for a combination of the desired height of the largest waves at the break point, and a plunging wave shape in a given pool radius. A small change in any one of the many variables can change the waves generated from being "highly desirable by surfers" to being "unsurfable".

Each of these relationships is briefly described: 
a. Track. The radius of the pressure source track, when combined with the blockage, affected the height and shape of the waves, both close to the pressure source and at the break point. The circular tracks appeared to generate similar height waves to a linear track in a rectangular channel $(\kappa>0.01)$, however the shape differed, with a shallower trough $\left(\zeta_{\min }{ }^{*}\right)$ and higher crest $\left(\zeta_{\max }{ }^{*}\right)$ as the tightness of the track increased; i.e. $R_{0}{ }^{*}$ decreased. For an unconstrained channel $(\kappa \approx 0)$, the wave height and shape were similar for different values of $R_{0} *$. With a beach in place $(\kappa \approx 0.07)$, the wave height $\left(H^{*}\right)$ and crest surface elevation $\left(\zeta_{\max }{ }^{*}\right)$ increased $R_{0} *$ decreased. The breaking wave shapes were also compared, with $R_{0} *=12$ produced a plunging wave, whilst $R_{0} *=6$ produced a spilling wave. This reduction in the wave quality for the tighter radius track determined that a trade-off between wave height and shape was required when selecting $R_{0} *$.

b. Velocity, depth Froude number and blockage. For the unconstrained channel $(\kappa \approx 0)$, the height of the wave increased as $F r_{h 0} \rightarrow 1$. However with the beach in place $(\kappa>0)$, the maximum wave height was reached at $F r_{h 0}<1$. The limiting values were $F r_{h 0}=0.9$ and $\kappa=0.07$ to provide a balance of wave height and quality.

c. Beam and draught. The volume displacement of the pressure source and the blockage were proportional to the pressure source beam and draught. The design values needed to be sufficient to generate adequate height waves.

d. Entry angle and waterline length. The entry angle did not have an effect on wave height, but did affect the wave quality. The pressure source entry angle $(\alpha)$ was initially set to $14^{\mathrm{O}}$, as used by Driscoll and Renilson [31] [32], caused local wave breaking close to the pressure source. $\alpha=7^{\mathrm{O}}$ was found to produce higher quality waves, eliminating the local wave breaking. As the waterline length increased with decreasing entry angle for a given draught, the improved wave quality was due to the increased length Froude number, with a longer, shallow pressure source generating high quality waves compared to a shorter, steeper pressure source. 
e. Beach. The design of the beach was critical to the wave quality produced. The key trade-offs were having the start of the beach close enough to the pressure source to minimise wave height decay, whilst not being so close as to limit the surfable wave wall width or suffer blockage effects. The beach slope was also critical to generating the desired wave shape, with a beach of $s=17^{\mathrm{O}}$ generating the preferred plunging wave shape.

\subsection{Further work}

Further work that may be conducted to optimise of the pressure source and bathymetry, including investigating the use of concave and convex bottom wavedozer pressure sources. Support to the commercialisation of the wave pools may also be required.

This work may also be applicable to waterway civil engineering applications, such as port and channel design, including ship - ship interaction in harbours and shipping channels. The experimental methods used in this research may also allow the further investigation into wave making resistance, thus drag and fuel consumption of ships, and reduction of the impact of the waves on the shoreline in environmentally sensitive areas. 


\section{Bibliography}

1. Farley, O.R., N.K. Harris, and A.E. Kilding, Physiological demands of competitive surfing. J Strength Cond Res, 2012: p. 1887-96.

2. Weight, D. Economics of surf reefs. in 3rd International Surfing Reef Symposium. 2003. Raglan, New Zealand.

3. Wicker, C. Everything you need to know about wave pools. 200731 December 2009]; Available from:

http://www.surfshot.com/In+A+Minute/Everything+you+need+to+know+about+Wav e+Pools+-141833.html.

4. Aquatic_Development_Group. Real surfing: custom designed wave pools for the ultimate surfing experience. 200530 December 2009]; Available from: www.aquaticgroup.com.

5. Waveloch. Flowrider Single. 200929 December 2009]; Available from: http://www.waveloch.com/attraction/flowrider-single.

6. Waveloch. Flying Reef and Moving Reef. 200929 December 2009]; Available from: http://www.waveloch.com/attraction/flying-reef-and-moving-reef.

7. Webber, G.M., Wave Generating Apparatus, I.P. Australia, Editor. 2004: Australia.

8. Kelvin, L., Ship Waves, in Trans. Institution of Mechanical Engineers. 1887: London.

9. $\quad$ Froude, W., Law of Comparison. 1868.

10. Michell, J.H., The wave resistance of a ship, in Philosophical Magazine. 1898. p. 106123. 
11. Lamb, H., Hydrodynamics. 1879: Cambridge University Press.

12. Wehausen, J.V. and E.V. Laitone, Surface Waves, in Encyclopaedia of Physics. 1960, Springer Verlag.

13. Bhattacharya, R.N., Wave Resistance of a Ship Moving in a Circular Path. 1957, Department of Mathematics, Jadavpur University. Calcutta

14. Soding, H., Far-Field Ship Waves. Ship Technology Research, 2006. 53: p. 138-147.

15. Havelock, T.H. The Forces On Submerged Spheroid Moving In A Circular Path. in Royal Society. 1950. London.

16. Macfarlane, G.J. and M.R. Renilson, Wave Wake - A Rational Method For Assessment, in International Conference on Coastal Ships and Inland Waterways. 1999, Royal Institution of Naval Architects (RINA): London. p. 14.

17. Macfarlane, G.J. and M.R. Renilson, When is low wash low wash-an investigation using a wave wake database, in International Conference on Hydrodynamics for High Speed Craft-Wake Wash and Motions Control. 2000, Royal Institution of Naval Architects (RINA): London. p. 14.

18. Macfarlane, G., Marine Vessel Wave Wake: Focus on Vessel Operations within Sheltered Waterways, in Australian Maritime College 2012, University of Tasmania.

19. Verheij, H.P. and M.P. Bogaerts, Ship Waves and the Stability of Armour Layers Protecting Slopes. 1989.

20. Russell, J.S., Report on waves. 1844, Fourteenth meeting of the British Association for the Advancement of Science. 
21. Lap, A.J.W., Fundamentals of ship building and propulsion, in International shipbuilding progress. 1954: Rotterdam.

22. Zakharov, S. and A. Kryukov, Ship-induced solitons as a manifestation of critical phenomena. 2008, Lebedev Physical Institute, Russian Academy of Sciences, Moscow: Moscow.

23. Lyakhovitsky, A., Shallow Water and Supercritical Ships. 2007, New Jersey: S\&H SOHO Inc.

24. Robbins, A., G.A. Thomas, M.R. Renilson, and G.J. Macfarlane, Subcritical Wave Wake Unsteadiness. International Journal of Maritime Engineering, 2011(153): p. pp. 153-161.

25. Tuck, E.O., D.C. Scullen, and L. Lazauskas, Wave Patterns and Minimum Wave Resistance for High-Speed Vessels, in 24th Symposium on Naval Hydrodynamics. 2002: Fukuoka, JAPAN.

26. Koushan, K., Automatic Hull Form Optimisation Towards Lower Resistance And Wash Using Artificial Intelligence, in FAST2003 Conference. 2003: Ischia Italy.

27. Ertekin, R.C., W.C. Webster, and J.V. Wehausen, Waves Caused by a Moving Disturbance in a Shallow Channel of Finite Width. J. Fluid Mechanics, 1986. 169: p. 275-292.

28. Dam, T.K., K.Tanimoto, B.H.Nguyen, and Y. Akagawa, Numerical study of propagation of ship waves on a sloping coast, in Ocean Engineering 33. 2005. p. 350364. 
29. Whittaker, T.J.T., R. Doyle, and B. Elsaesser, An experimental investigation of the physical characteristics of fast ferry wash, in 2. Int. Conf. on High-Performance Marine Vehicles HIPER. 2001, P, HSVA,: Hamburg.

30. Standing, R.G., Proving Trials of the Wavedozer, a Travelling Beam Wavemaker. 1976, National Physical Laboratory, Ship Division.

31. Driscoll, A. and M.R. Renilson, The Wavedozer. A System of Generating Stationary Waves in a Circulating Water Channel AMTE(H) TM80013, 1980.

32. Renilson, M.R., Wavedozer. 1981, University of Glasgow: Glasgow.

33. Scarfe, B.E., M.H.S. Elwany, S.T. Mead, and K.P. Black, The Science of Surfing Waves and Surfing Breaks - A Review. 2003, ASR Ltd and Coastal Environments.

34. Mead, S.T. and K.P. Black, Field studies leading to the bathymetric classification of world-class surfing breaks. Natural and Artificial Reefs for Surfing and Coastal Protection. Journal of Coastal Research, 2001(Special Issue No. 29): p. 5-20.

35. Miche, M., Le Pouvoir Reflechissant des Ouvrages Maritimes Exposes a l'Action de laHoule". Annals des Ponts et Chaussess, 1951(121e Annee): p. 285-319.

36. Iribarren, C.R. and C. Nogales. Protection des Ports. in XVIIth Int. Nav. Congress. 1949. Lisbon.

37. Eldeberky, Y. and J.A. Battjes. Parameterization of triad interactions in wave energy models. in Proc. Coastal Dynamics Conf. '95. 1995. Gdansk, Poland.

38. Hutt, J.A., K.A. Black, and S.T. Mead, Classification Of Surf Breaks In Relation To Surfing Skill Journal of Coastal Research., 2001(Special Issue Number 29): p. 66-81. 
39. Hartley, A., Quantifying wave face quality for surf craft riding, in National Centre for Maritime Engineering and Hydrodynamics. 2012, University of Tasmania Australian Maritime College.

40. Vries, S.D., On the Generation of Surfable Ship Waves in a Circular Pool, part II, in Faculty of Civil Engineering and Geosciences. 2007, Delft University of Technology.

41. Schipper, M.A.D., On the generation of surfable ship waves in a circular pool: Part I Physical background \& Wave pool design, in Faculty of Civil Engineering and Geosciences. 2007, Delft University of Technology.

42. Van Essen, S., Wave Pool Project; RAPID Non-linear Potential Flow Wave Height Predictions. 2011, Technical University (TU) Delft and Australian Maritime College.

43. Doyle, N., The Circular Wave Pool - Predicting Curved Path Wave Patterns, in National Centre for Maritime Engineering and Hydrodynamics. 2010, Australian Maritime College, University of Tasmania.

44. Javaramadi, M., J. Binns, S.A. Schmied, M.R. Renilson, G. Thomas, G. Macfarlane, and R. Huijsmans, The formation of surfable waves in a circular wave pool comparison of numerical and experimental approaches, in 31 st International Conference on Ocean Offshore and Arctic Engineering 2012: Rio de Janeiro, Brazil.

45. Schmied, S.A., J. Binns, M.R. Renilson, G. Thomas, G. Macfarlane, and R.H.M. Huijsmans, A Novel Method for Generating Continuously Surfable Waves. Marine Technology Society Journal, 2010. Volume 44, Number 2(March/April 2010): p. 7-12.

46. Tuck, E.O., L. Lazauskas, and D.C. Scullen, Sea Wave Pattern Evaluation, Part 1 Report: Primary Code And Test Results (Surface Vessels). 1999, Applied Mathematics Department, the University of Adelaide. p. 10. 
47. Schmied, S.A. and M. Meir, Surfin' In Circles, in Engine. 2007.

48. Schmied, S.A., J. Binns, M.R. Renilson, G. Thomas, G. Macfarlane, and R.H.M. Huijsmans, A Novel Method for Generating Continuously Surfable WavesComparison of Predictions With Experimental Results. Journal of Ocean Offshore and Arctic Engineering (JOMAE), 2013. Vol. 135 (Issue 3).

49. Schmied, S.A., J. Binns, M.R. Renilson, G. Thomas, G. Macfarlane, and R.H.M. Huijsmans, A Novel Method for Generating Continuously Surfable Waves, in Offshore, Maritime and Artic Engineering. 2011: Rotterdam, the Netherlands.

50. Binns, J., S.A. Schmied, M.R. Renilson, G. Thomas, G. Macfarlane, and R. Huijsmans, Novel Method For Generating Continuously Surfable Waves, in Pacific 2012. 2012: Sydney, Australia.

51. Schmied, S.A., J. Binns, M.R. Renilson, G. Thomas, G. Macfarlane, and R.H.M. Huijsmans, A Novel Method For Generating Continuously Surfable Waves, in 32th International Conference on Ocean, Offshore and Arctic Engineering. 2013: Nantes, France.

52. Etcheverry, O. The Stalled Evolution of Wave Pools. 201310 Sep 2013]; Available from: http://www.theextremescene.com/blog/stalled-evolution-wave-pools.

53. Bascom, W., Waves and Beaches. 1964, Garden City, New York: Anchor Books, Doubleday and Company Inc.

54. Galvin, C.J.J., Breaker Type Classification on Three Laboratory Beaches. J. Geoph. Res., 1968(73): p. 3651-3659.

55. Battjes, J.A. Surf Similarity. in Proc 14th International Conference on Coastal Engineering. 1974. 
56. Walker, J.R., Recreational Surf Parameters. 1974, University of Hawaii, Department of Ocean Engineering: Honolulu, Hawaii.

57. Dally, W.R., The maximum speed of surfers. Journal of Coastal Research., 2001(Special issue 29 Natural): p. 33-40.

58. Soomere, T., Long Ship Waves In Shallow Water Bodies. Applied Wave Mathematics: Selected Topics In Solids, Fluids and Mathematical Methods, ed. E.a.S. Quak, T. (Ed.). 2009, Heidelberg: Springer.

59. Anthoni, F. Oceanography: waves theory and principles of waves, how they work and what causes them. 200030 December 2009]; Available from: http://www.seafriends.org.nz/oceano/waves.htm.

60. Havelock, T.H., The propagation of groups of waves in dispersive media, with application to waves on water produced by a traveling disturbance. 1908, Proceedings of the Royal Society of London. p. pp. 398-430.

61. Stoker, J.J., Water waves; The mathematical theory with applications. 1957, New York: Interscience Publishers.

62. Bhattacharya, R.N., Wave in deep water due to the arbitrary motion of a pressurearea along any curved path on the undisturbed free-surface. International Shipbuilding Progress, 1969. Vol. 16(no. 177): p. 155-165.

63. Ucar, M.E. Near Shore Wave Models. 2012 [cited Retrieved May 2012; Available from:

https://www.meted.ucar.edu/sign_in.php?go_back_to=http\%253A\%252F\%252Fwww. meted.ucar.edu\%252Foceans\%252Fnearshore_wave_models\%252Fprint.htm. 
64. Stive, M.J.F., A scale comparison of waves breaking on a beach. Coastal Engineering, Elsevier Science Publishers B.V.; Amsterdam., 1984(9): p. 151-158.

65. Association_of_Surfing_Professions. Judging Criteria. 12 Apr 2012]; Available from: www.aspworldtour.com/press-room/judging-criteria/.

66. Lazauskas, L., Resistance, Wave-Making and Wave-Decay of Thin Ships, with Emphasis on the Effects of Viscosity, in Applied Mathematics Department. 2009, The University of Adelaide.

67. Starke, B., H.C. Raven, and A.V.D. Ploeg, Computation of transom-stern flows using a steady free-surface fitting RANS method. 2007, In Proceedings of the 9th International Conference on Numerical Ship Hydromechanics: Ann Arbor, Michigan.

68. De Jong, P., Seakeeping Behaviour Of High Speed Ships; An Experimental And Numerical Study. 2011, Technische Universiteit Delft. 


\section{Annexes}

A. Scale model experiments

B. Scale model experiments run sheet summary

C. Circular track series 3 results summary 


\section{Annex A Scale model experiments}

Scale model experiments were conducted in both a linear and circular track.

The linear track series tests were conducted in the UTAS AMC 100m tow tank; shown with the wave probes installed; Figure A- 1. The pressure sources were attached to the model carriage and driven down the tow tank.

The circular scale model was a custom built model installed into the UTAS AMC model test basin; Figure A-2. The scale model design drawings are detailed in Figure A-3 to Figure A-5. The scale model also provides UTAS AMC with a facility to conduct further research into wave mechanics and ship waves.

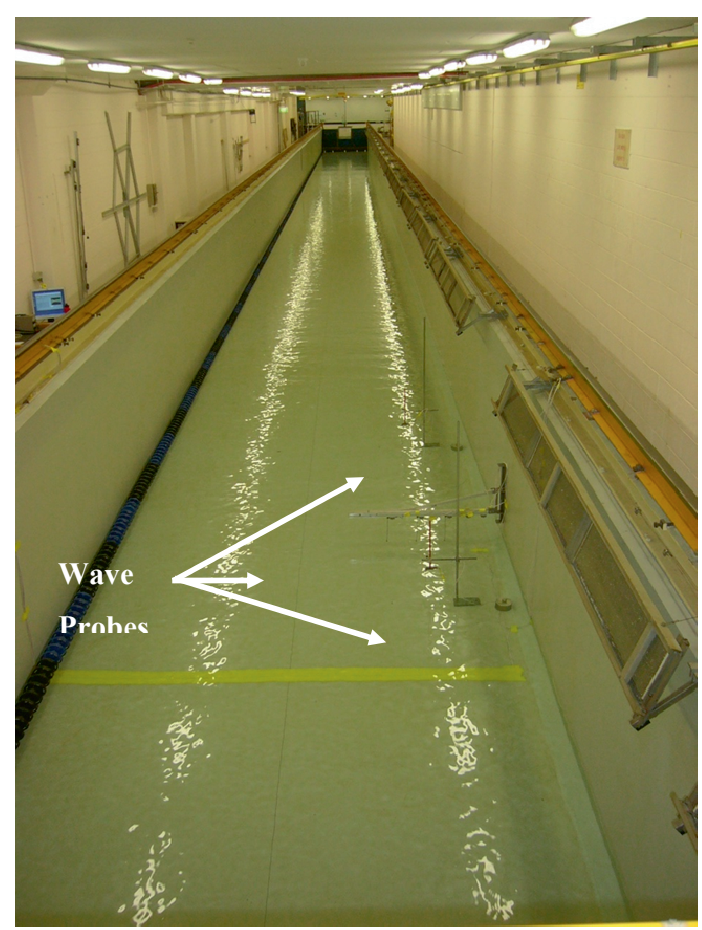

Figure A- 1. Linear Tow tank setup. The wave probe array is shown. 


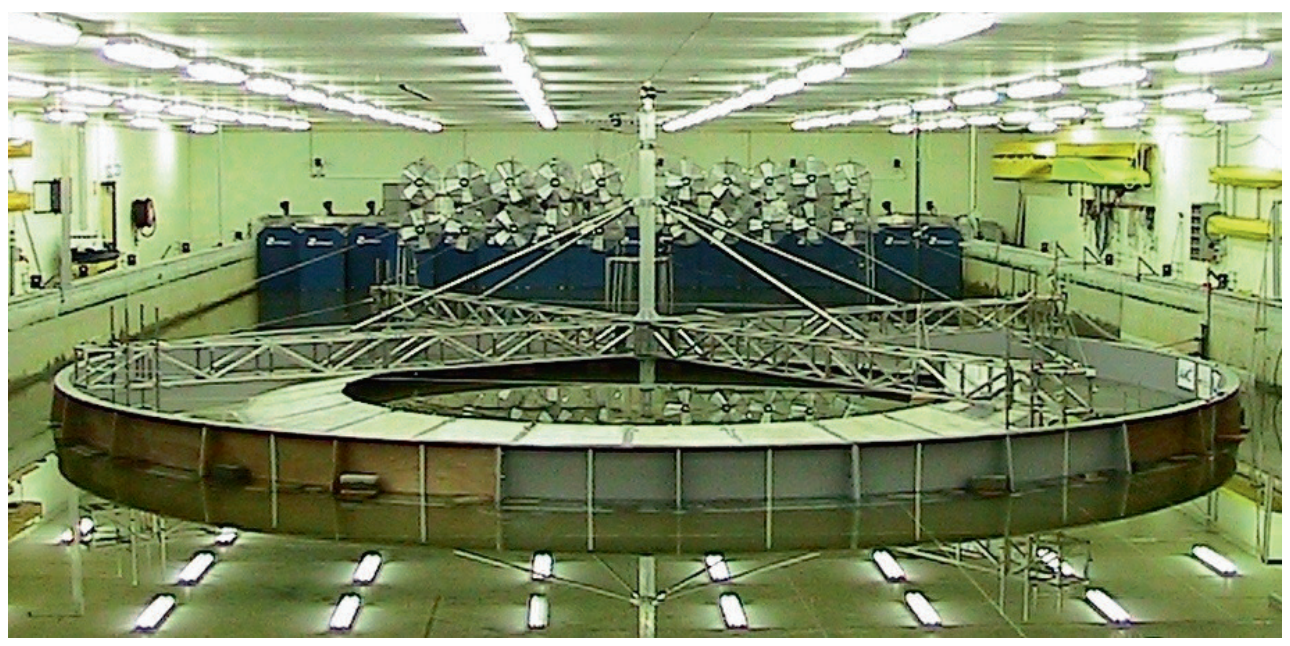

Figure A-2. Scale model.
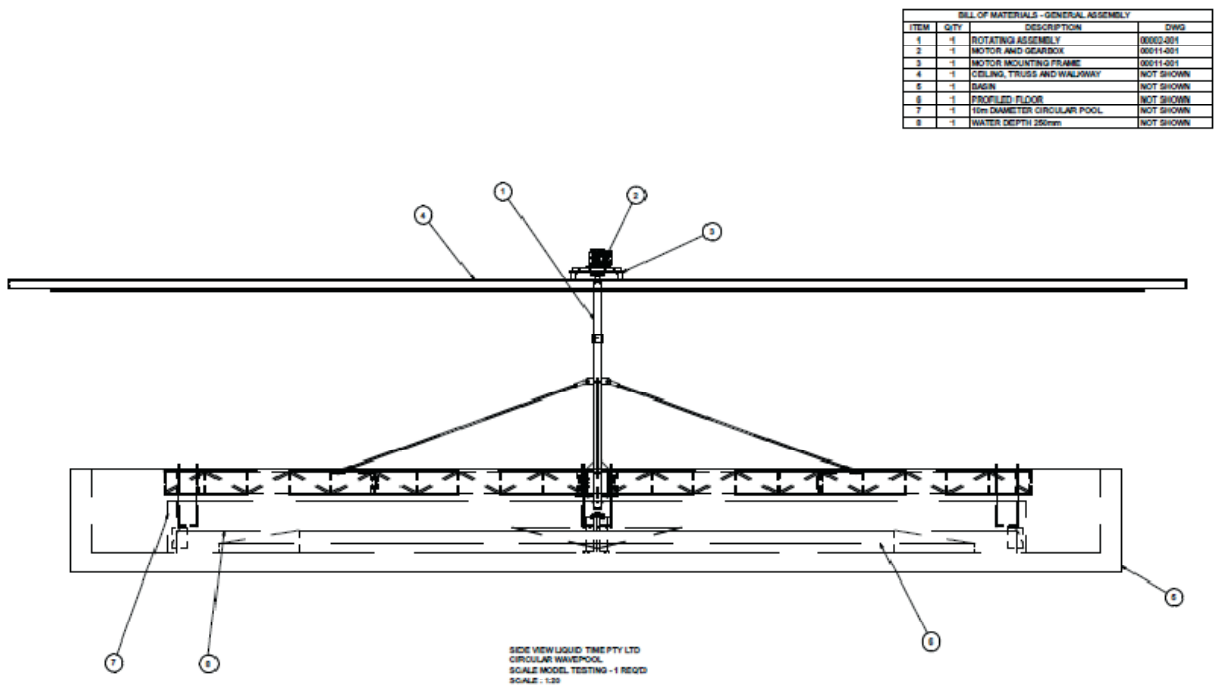

Figure A-3. Circular track scale model installation into UTAS AMC model test basin. 


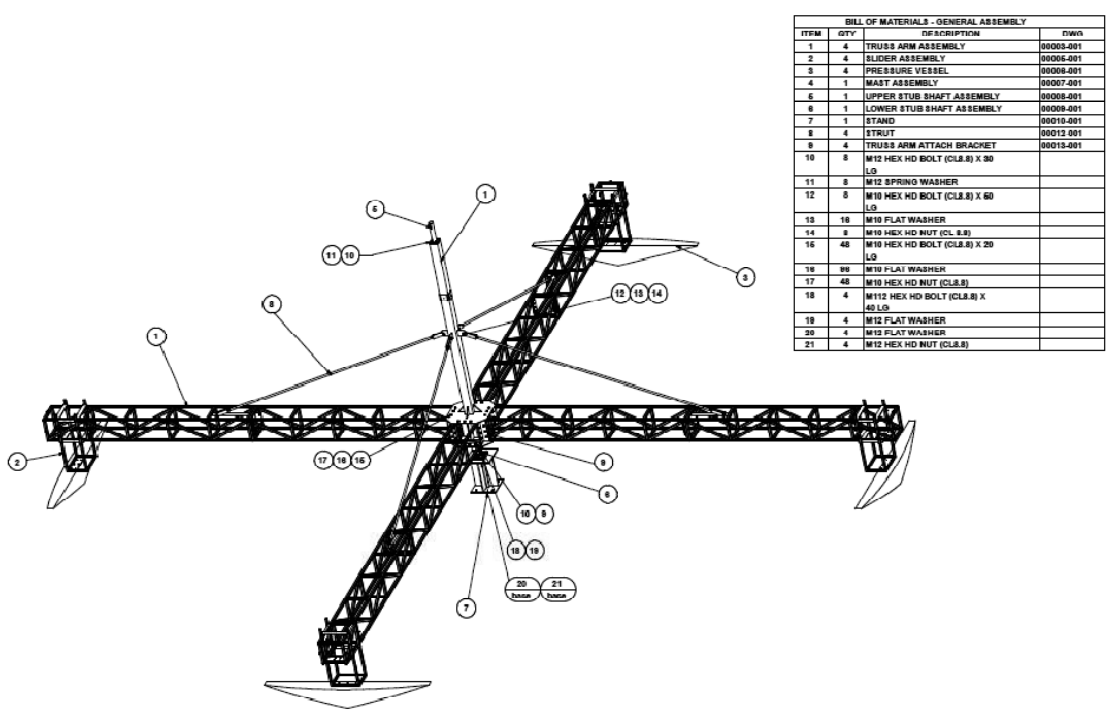

Figure A-4. Circular track scale model rotating assembly.
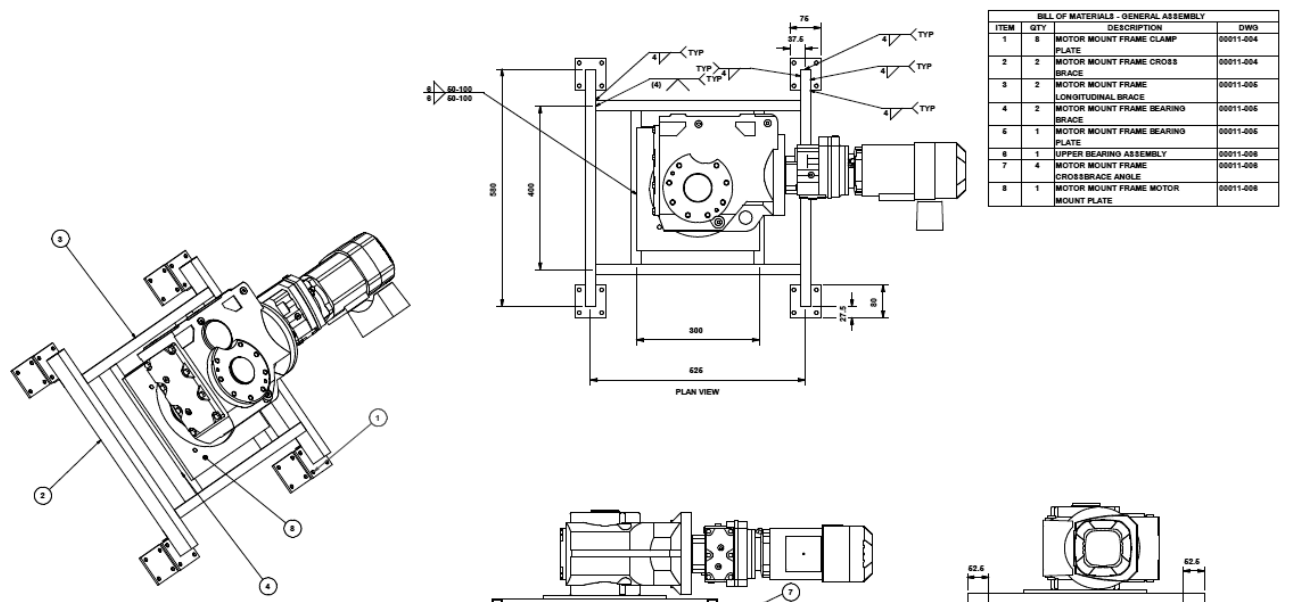

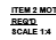
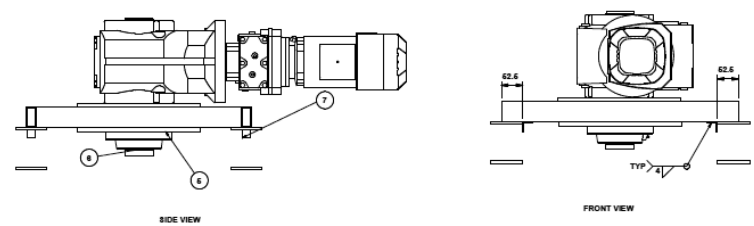

Figure A-5. Circular track scale model motor and 90 degree gearbox. 


\section{Bathymetry}

\section{Linear track}

The linear tow tank had a rectangular cross-section with a width of $3550 \mathrm{~mm}$, Figure A-6, with slight chamfered lower corners. The pressure sources were symmetrical about the centre line of travel, with the pressure source travelling down the centre of the tank. The measurements were only taken on the port side.

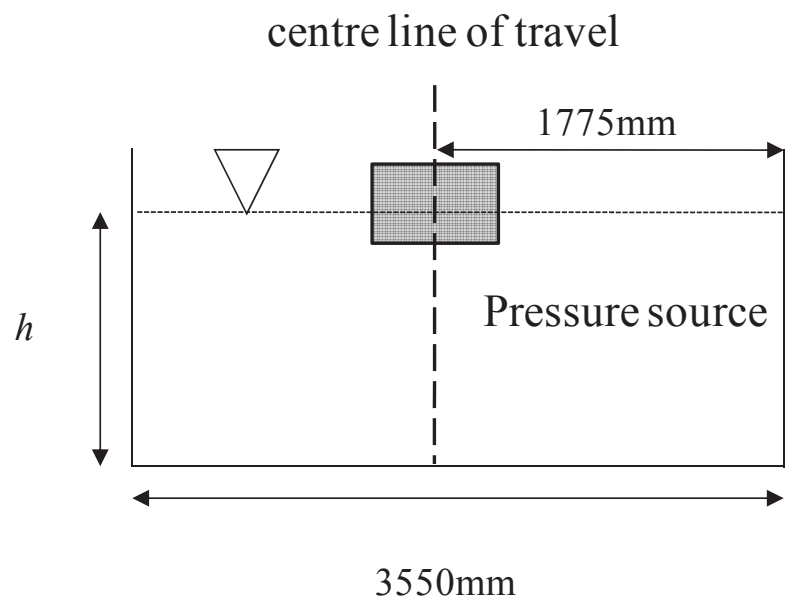

Figure A-6. Linear track tow tank channel cross-section.

\section{Circular track series 1}

For the circular track series 1 , a beach of $s=9^{\mathrm{O}}$ was built out of fibre reinforced concrete sheets; Figure A-7 and Figure A-8. 


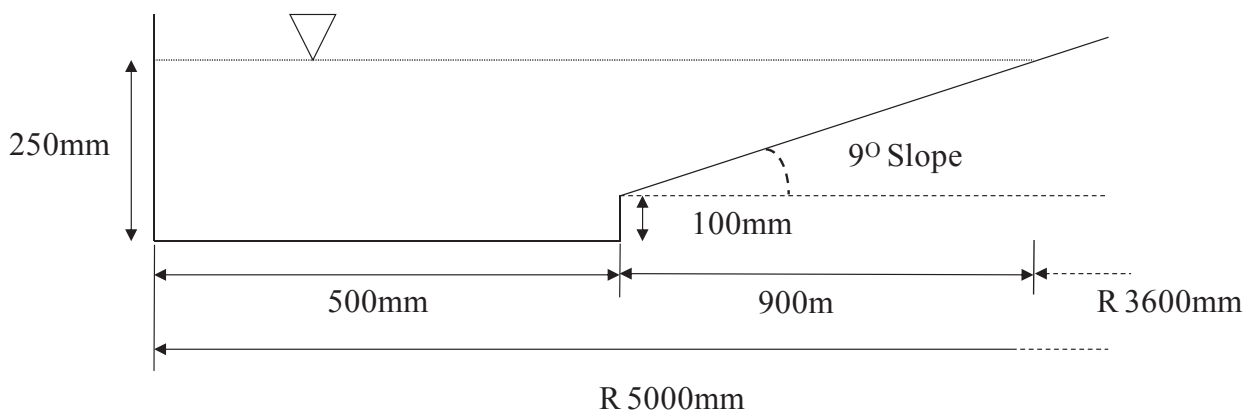

Figure A-7. Circular track series 1 scale model channel cross-section.

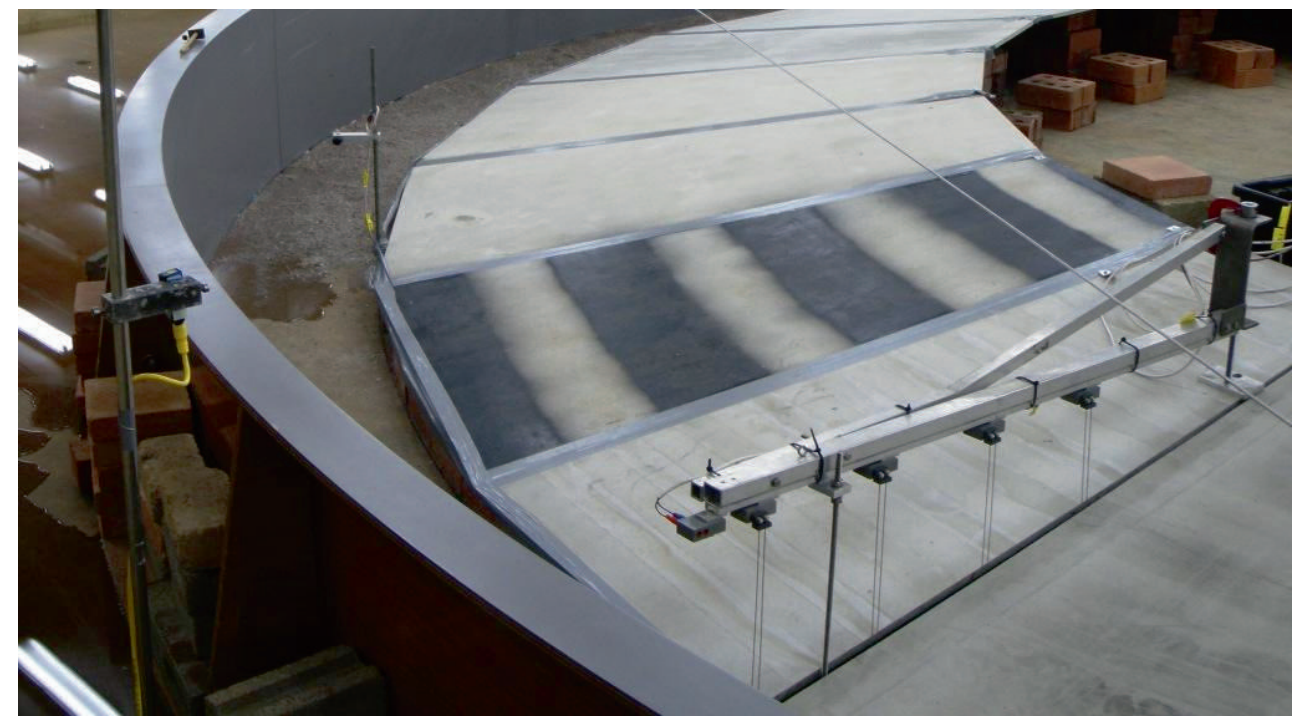

Figure A-8. Circular track series 1 beach. 


\section{Tow tank comparison}

The linear track tow tank cross-section was modeled as a curved track in half scale with the centerline $(y=888 \mathrm{~mm})$; Figure A-9 and Figure A-10. This test was used to compare the linear and circular tracks.

\section{Pressure source}

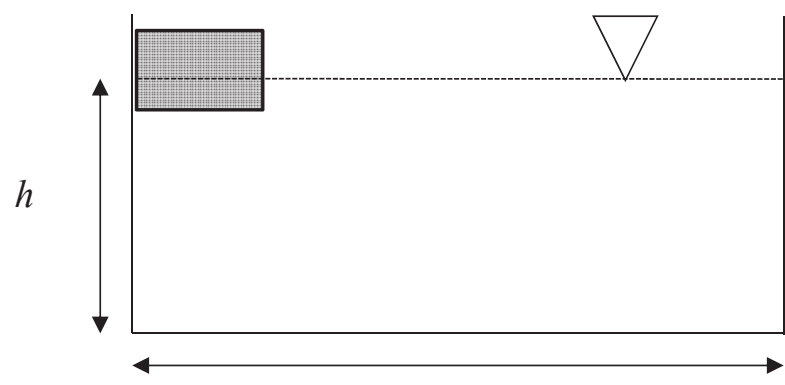

$888 \mathrm{~mm}$

Figure A-9. Circular track scale model channel cross-section with wall.

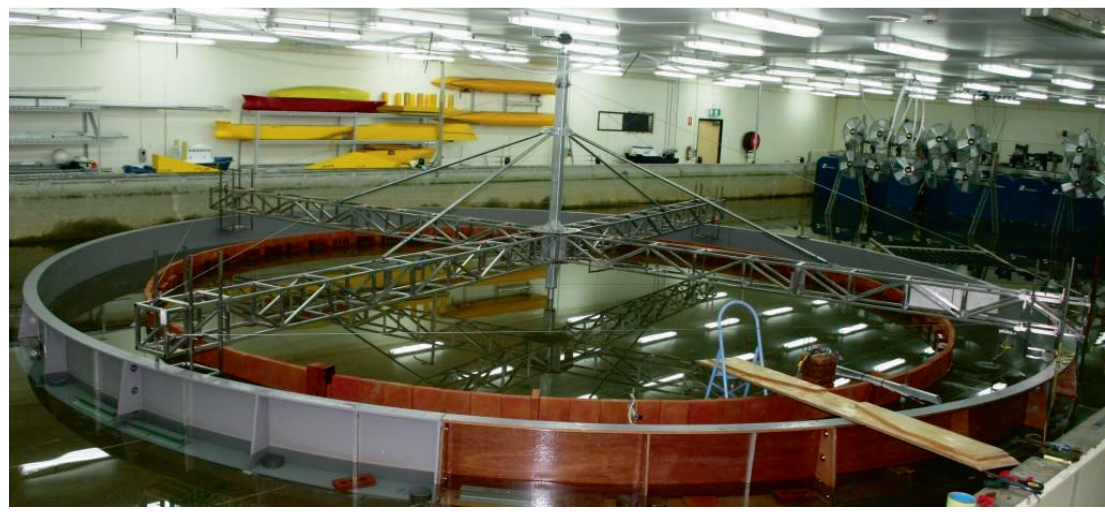

Figure A-10. Circular track scale model with wall at $y=888 \mathrm{~mm}$ 
Finally, the wall was removed to measure any wall effects; Figure A-11. The wall away from the wave probes was retained to minimise wave interaction across the pool.

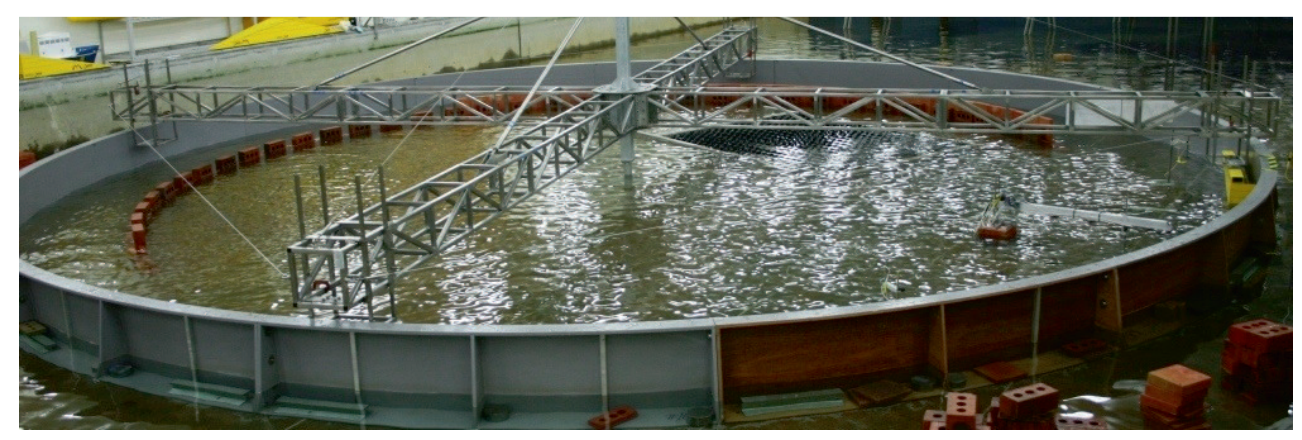

Figure A-11. Circular track scale model with no sloping beach or wall.

The pavers were used to construct the vertical walls, with the pavers not appearing to affect the wave probes.

\section{Circular track series 2}

In the circular track series 2, the linear track tow tank cross-section was modeled as a curved track in half scale and only one side of the centerline (width of 888mm); Figure A-10.

The tow tank cross-section was also modeled as a curved track in full scale and only one side of the centerline (width of $1775 \mathrm{~mm}$ ); Figure A-12. This test was used to determine the effect of $L W L / R_{0}$ using model 11-13. 


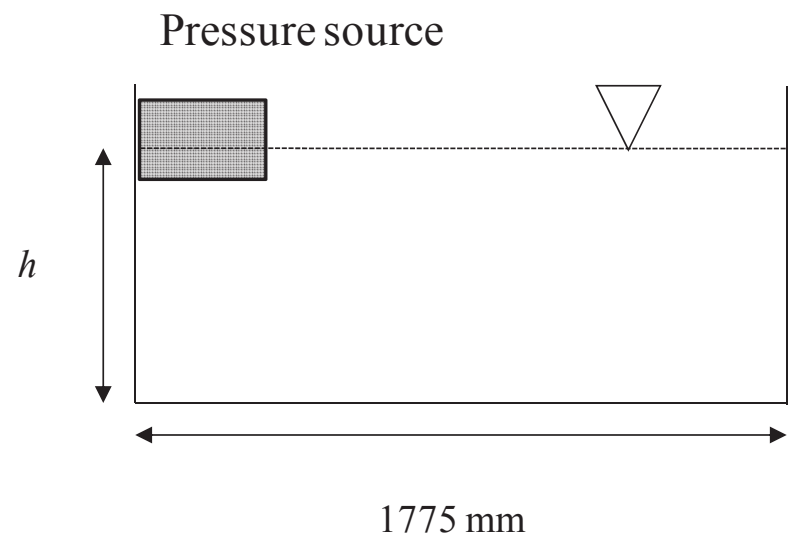

Figure A-12. Circular Series 2 channel cross-section with wall and no sloping beach.

\section{Circular track series 3}

In the circular track series 3 , the effect of the bathymetry on wave transformation and breaking was tested.

\section{Beach slope $(s)=9^{O}$}

For $s=9^{\mathrm{O}}$ :

a. Condition $47 y_{\text {beach }}=550 \mathrm{~mm}$ and $z_{\text {beach }}=150 \mathrm{~mm}$.

b. Condition $48 y_{\text {beach }}=550 \mathrm{~mm}$ and $z_{\text {beach }}=100 \mathrm{~mm}$.

c. Condition $49 y_{\text {beach }}=750 \mathrm{~mm}$ and $z_{\text {beach }}=130 \mathrm{~mm}$. 


\section{Beach slope $(s)=17^{\circ}$}

For $s=17^{\mathrm{O}}$ :

a. Condition $53 y_{\text {beach }}=750 \mathrm{~mm}$ and $z_{\text {beach }}=185 \mathrm{~mm}$.

b. Condition $54 y_{\text {beach }}=572 \mathrm{~mm}$ and $z_{\text {beach }}=130 \mathrm{~mm}$.

c. Condition $55 y_{\text {beach }}=572 \mathrm{~mm}$ and $z_{\text {beach }}=75 \mathrm{~mm}$.

d. Conditions 56 to $58 y_{\text {beach }}=750 \mathrm{~mm}$ and $z_{\text {beach }}=130 \mathrm{~mm}$.

For $y_{\text {beach }}=950 \mathrm{~mm}$ :

a. Conditions 59 and $60 y_{\text {beach }}=950 \mathrm{~mm}$ and $z_{\text {beach }}=130 \mathrm{~mm}$.

b. Condition $61 y_{\text {beach }}=950 \mathrm{~mm}$ and $z_{\text {beach }}=80 \mathrm{~mm}$.

For condition 62 , the beach was fully removed.

To test the conditions 63 and 64 Geosim, the water depth was increased to $500 \mathrm{~mm}$, and a new beach built:

a. Condition $63 y_{\text {beach }}=1500 \mathrm{~mm}$ and $z_{\text {beach }}=290 \mathrm{~mm}$.

b. Condition $64 y_{\text {beach }}=1500 \mathrm{~mm}$ and $z_{\text {beach }}=390 \mathrm{~mm}$. 
Beach slope $(s)=23^{\circ}$

For $s=23^{\mathrm{O}}$ :

a. Condition $50 y_{\text {beach }}=575 \mathrm{~mm}$ and $z_{\text {beach }}=110 \mathrm{~mm}$.

b. Condition $51 y_{\text {beach }}=575 \mathrm{~mm}$ and $z_{\text {beach }}=55 \mathrm{~mm}$.

c. Condition $52 y_{\text {beach }}=750 \mathrm{~mm}$ and $z_{\text {beach }}=130 \mathrm{~mm}$. 


\section{Pressure sources}

The pressure sources used in the linear and circular track scale model experiments are detailed in Table A-1.

\begin{tabular}{|l|l|l|c|c|c|c|}
\hline \multicolumn{1}{|c|}{ Figure } & \multicolumn{1}{|c|}{ Model No. } & $\begin{array}{c}\text { Pressure } \\
\text { Source } \\
\text { Type }\end{array}$ & $\begin{array}{c}\text { Length } \\
{[\mathbf{m m}]}\end{array}$ & $\begin{array}{c}\text { Beam } \\
{[\mathrm{mm}]}\end{array}$ & $\begin{array}{c}\text { Height } \\
{[\mathrm{mm}]}\end{array}$ & $\begin{array}{c}\alpha \\
{[\mathbf{d e g}]}\end{array}$ \\
\hline & $\mathbf{2 0 0 9}$ Series & & & & & \\
\hline Figure A-13 & Model 09-33 & Parabolic & 700 & 300 & 500 & N/A \\
\hline Figure A-14 & Model 09-34 & Parabolic & 700 & 600 & 500 & N/A \\
\hline Figure A-15 & Model 09-35 & Wavedozer & 1500 & 300 & 300 & 14 \\
\hline & 2010 Series & & & & & \\
\hline Figure A-16 & Model 10-24 & Wavedozer & 999 & 176 & 250 & 14 \\
\hline Figure A-17 & Model 10-25 & Wavedozer & 999 & 251 & 250 & 14 \\
\hline Figure A-18 & Model 10-26 & Wavedozer & 1999 & 176 & 250 & 14 \\
\hline Figure A-19 & Model 10-27 & Wavedozer & 1999 & 251 & 250 & 14 \\
\hline & $\mathbf{2 0 1 1 ~ S e r i e s ~}$ & & & & & \\
\hline Figure A-20 & Model 11-10 & Wavedozer & 602 & 75 & 150 & $4-18$ \\
\hline Figure A-21 & Model 11-11 & Wavedozer & 602 & 175 & 150 & 14 \\
\hline Figure A-22 & Model 11-12 & Wavedozer & 602 & 275 & 150 & 14 \\
\hline Figure A-23 & Model 11-13 & Wavedozer & 602 & 150 & 170 & 14 \\
\hline Figure A-24 & Model 12-02 & Wavedozer & 1200 & 275 & 150 & 7 \\
\hline Figure A-25 & Model 12-03 & Wavedozer & 1003 & 550 & 250 & 7 \\
\hline
\end{tabular}

Table A-1. Pressure sources. 


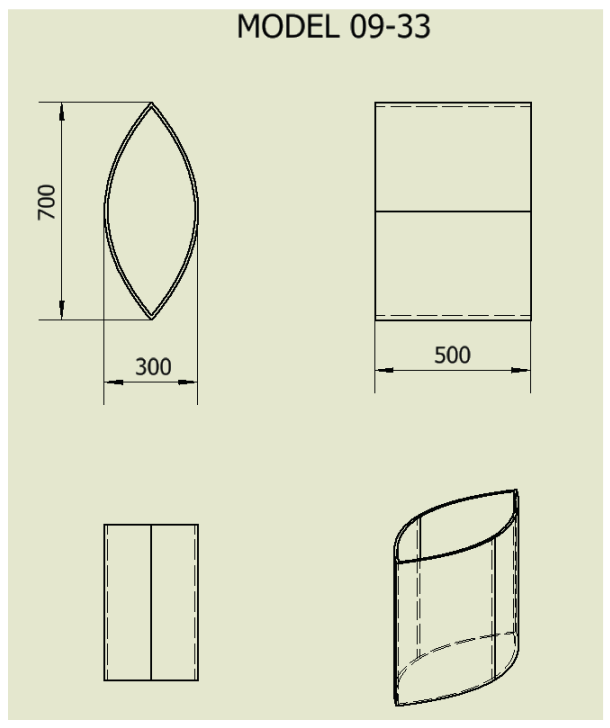

Figure A-13. Model 09-33 parabolic pressure source with $700 \mathrm{~mm}$ length, $300 \mathrm{~mm}$ beam, $500 \mathrm{~mm}$ height.

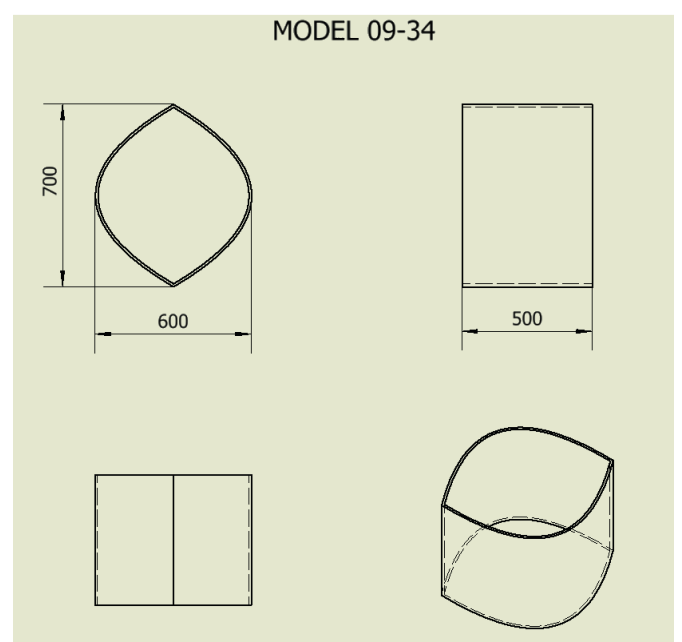

Figure A-14. Model 09-34 parabolic pressure source with 700mm length, $600 \mathrm{~mm}$ beam and, $500 \mathrm{~mm}$ height. 


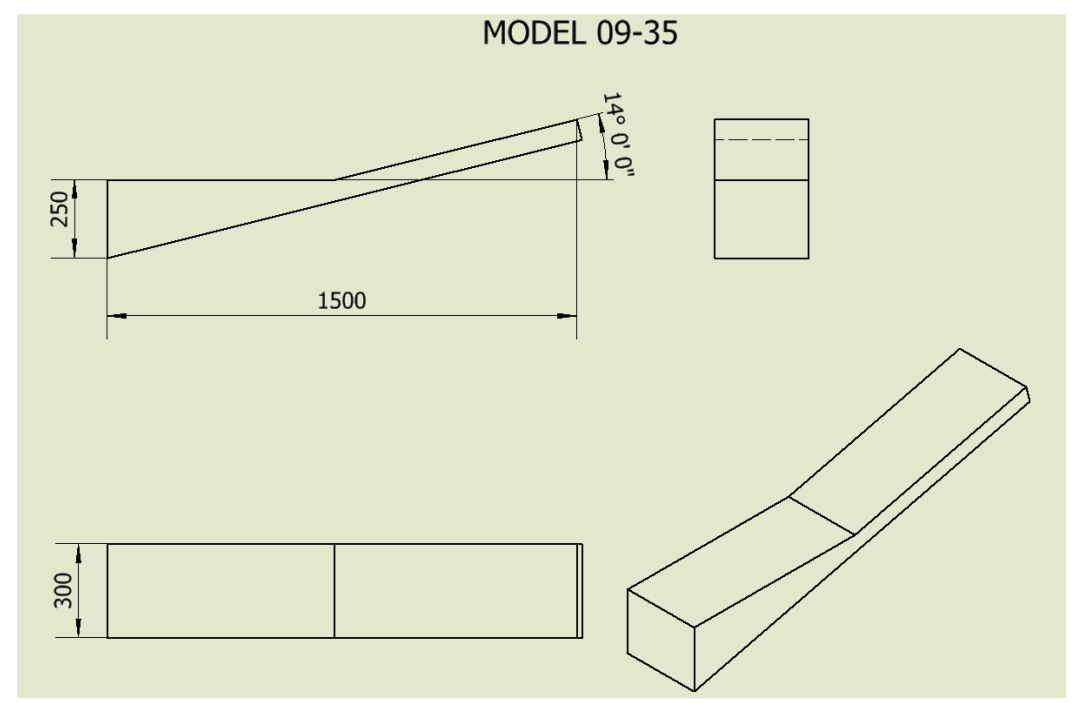

Figure A-15. Model 09-35 wavedozer with $1500 \mathrm{~mm}$ length, 300mm beam and $\alpha=14^{\mathrm{O}}$.

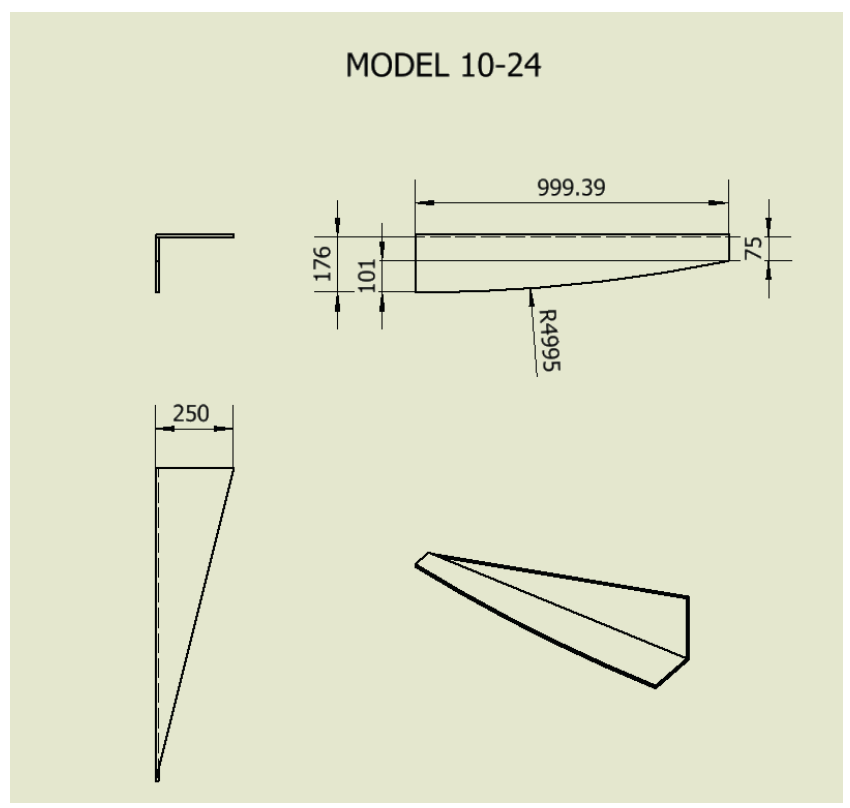

Figure A-16. Model 10-24 wavedozer with $1000 \mathrm{~mm}$ length, $75 \mathrm{~mm}$ beam (bow), $\alpha=14^{\mathrm{O}}$ and $250 \mathrm{~mm}$ height. The $101 \mathrm{~mm}$ wide fill-in to match with the curve wall is shown. 


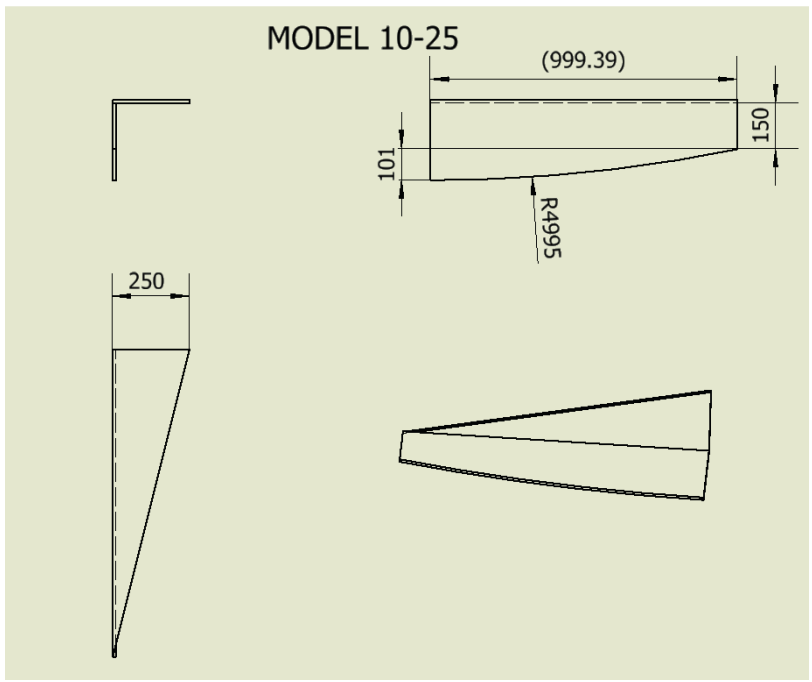

Figure A-17. Model 10-25 asymmetrical wavedozer with $1000 \mathrm{~mm}$ length, $150 \mathrm{~mm}$ beam (at bow), $\alpha=14^{\circ}$ and $250 \mathrm{~mm}$ height.

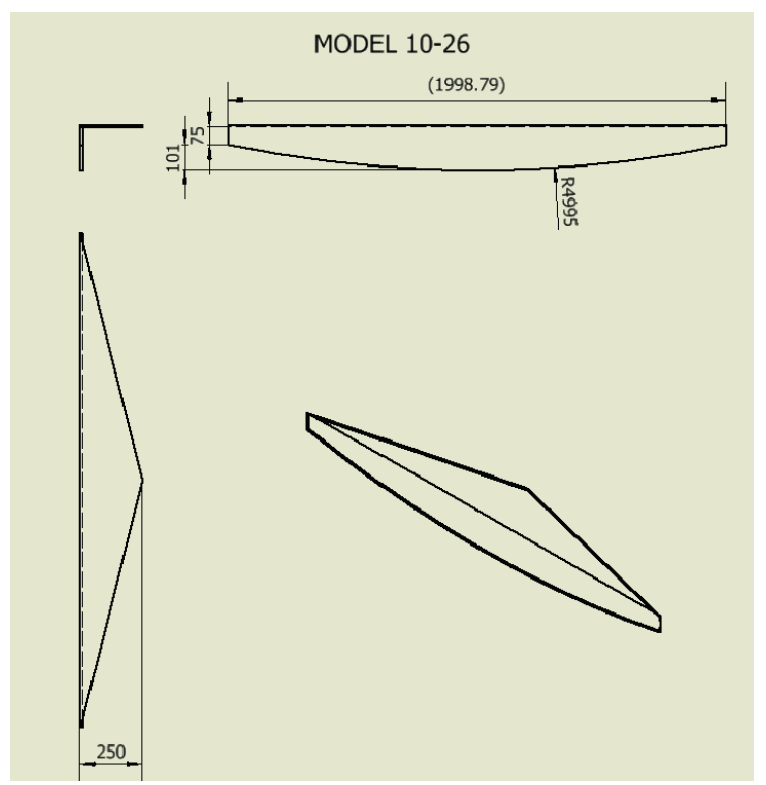

Figure A-18. Model 10-26 symmetrical wavedozer with $2000 \mathrm{~mm}$ length, $75 \mathrm{~mm}$ beam (at bow), $\alpha=14^{\circ}$ and $250 \mathrm{~mm}$ height. 


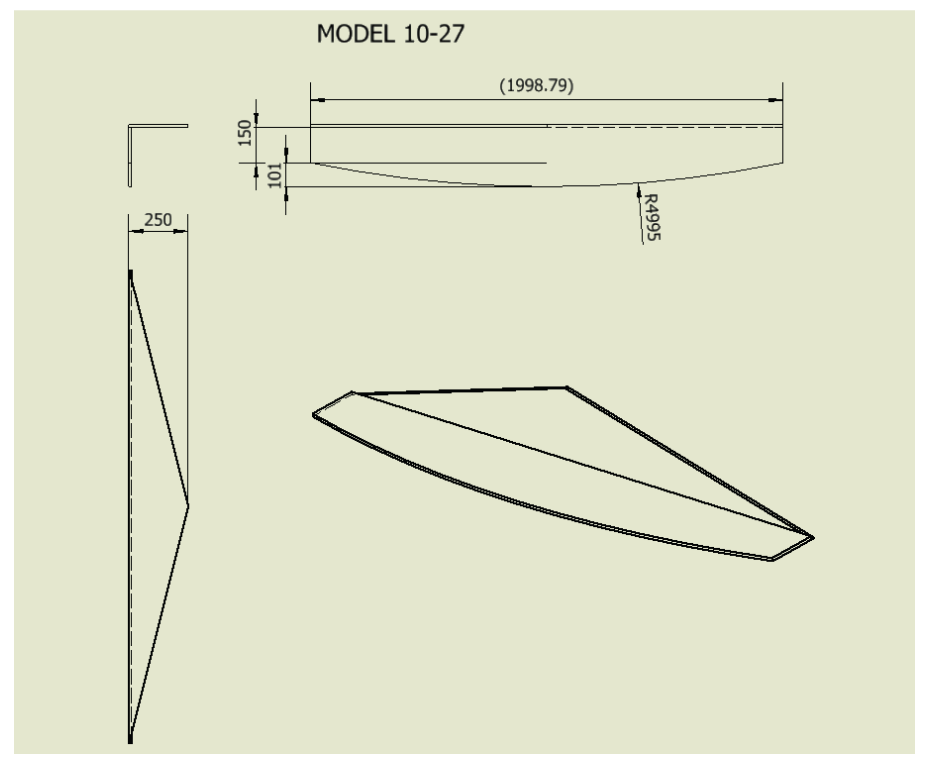

Figure A-19. Model 10-27 symmetrical wavedozer with 2000mm length, 150mm beam (at bow), $\alpha=14^{\mathrm{O}}$ and $250 \mathrm{~mm}$ height.

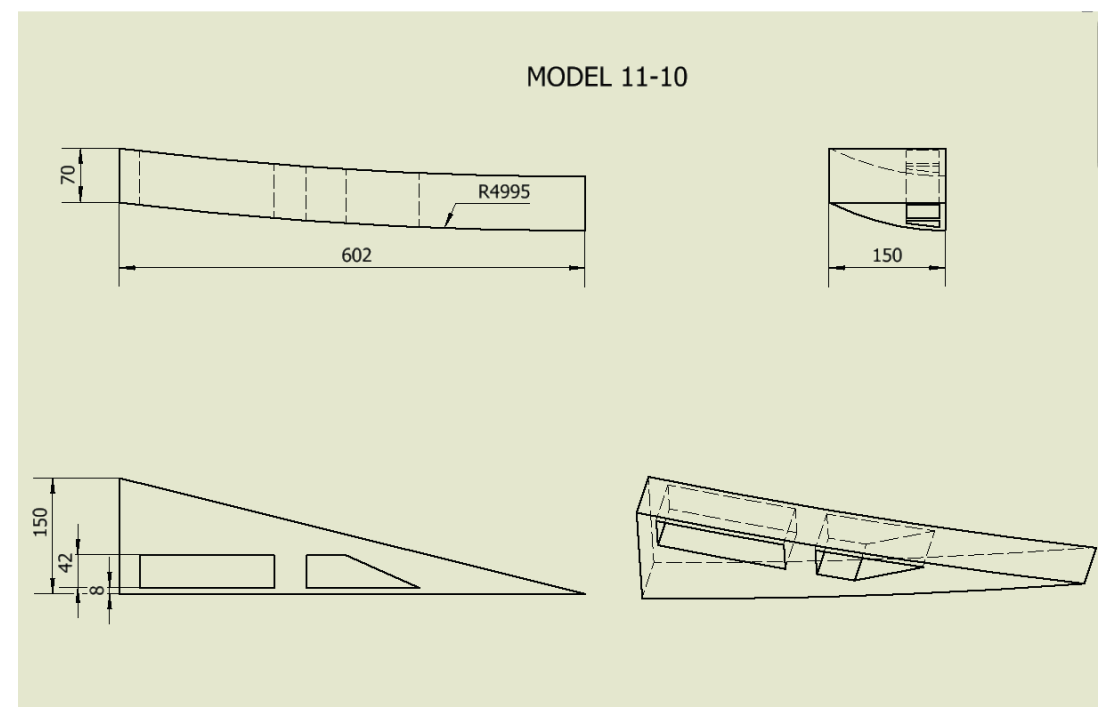

Figure A-20. Model 11-10 curved asymmetrical wavedozer with $602 \mathrm{~mm}$ length, $75 \mathrm{~mm}$ beam, $\alpha=14^{\mathrm{O}}$ and $150 \mathrm{~mm}$ height. 


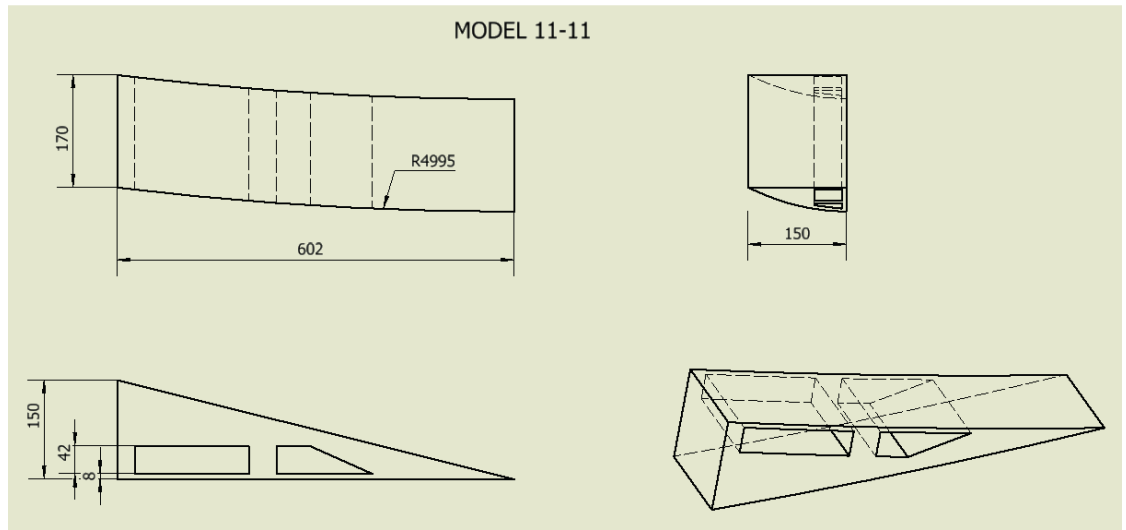

Figure A-21. Model 11-11 curved asymmetrical wavedozer with $602 \mathrm{~mm}$ length, $175 \mathrm{~mm}$ beam, $\alpha=14^{\circ}$ and $150 \mathrm{~mm}$ height.

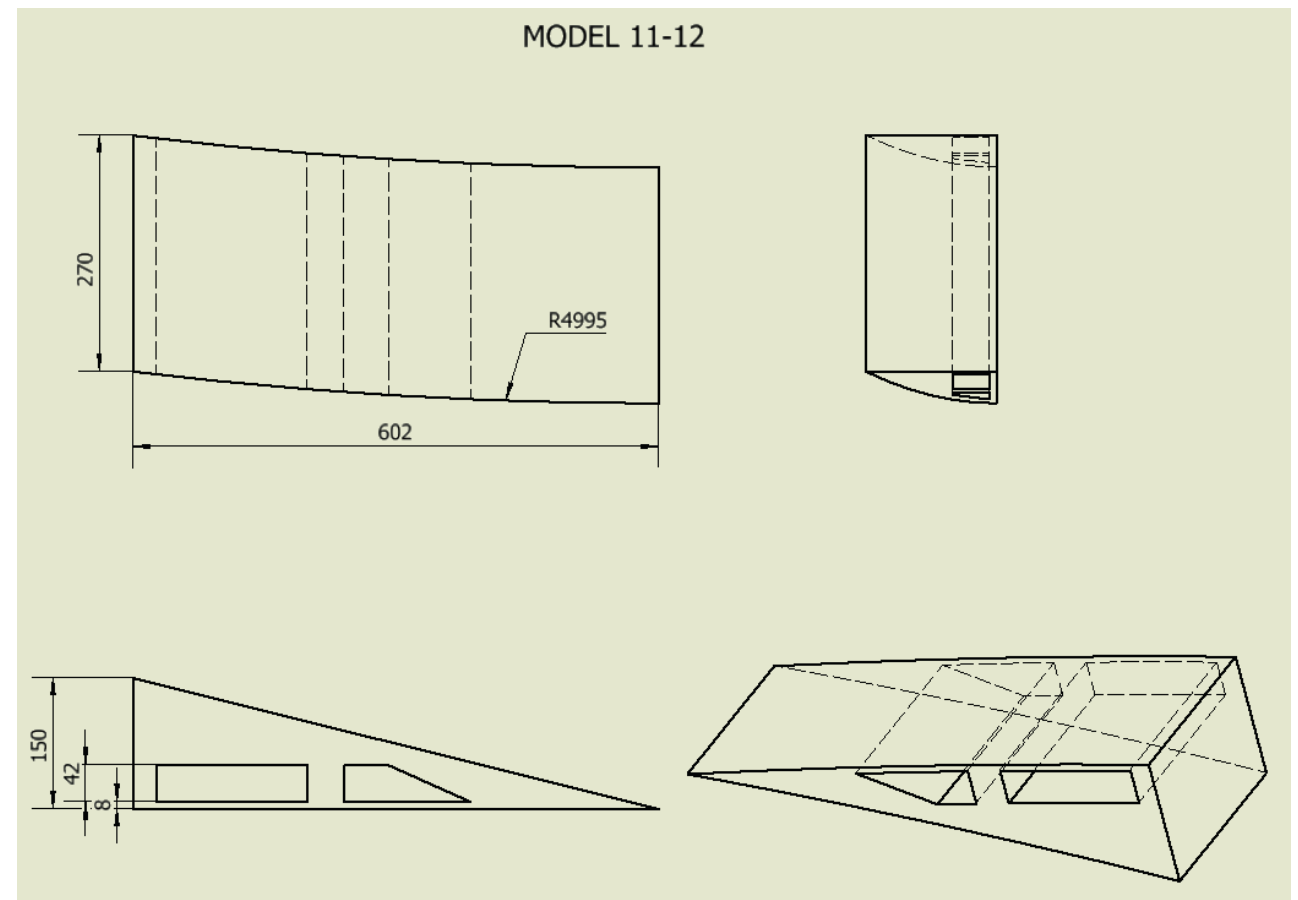

Figure A-22. Model 11-12 curved asymmetrical wavedozer with $602 \mathrm{~mm}$ length, $275 \mathrm{~mm}$ beam, $\alpha=14^{\mathrm{O}}$ and $150 \mathrm{~mm}$ height. 


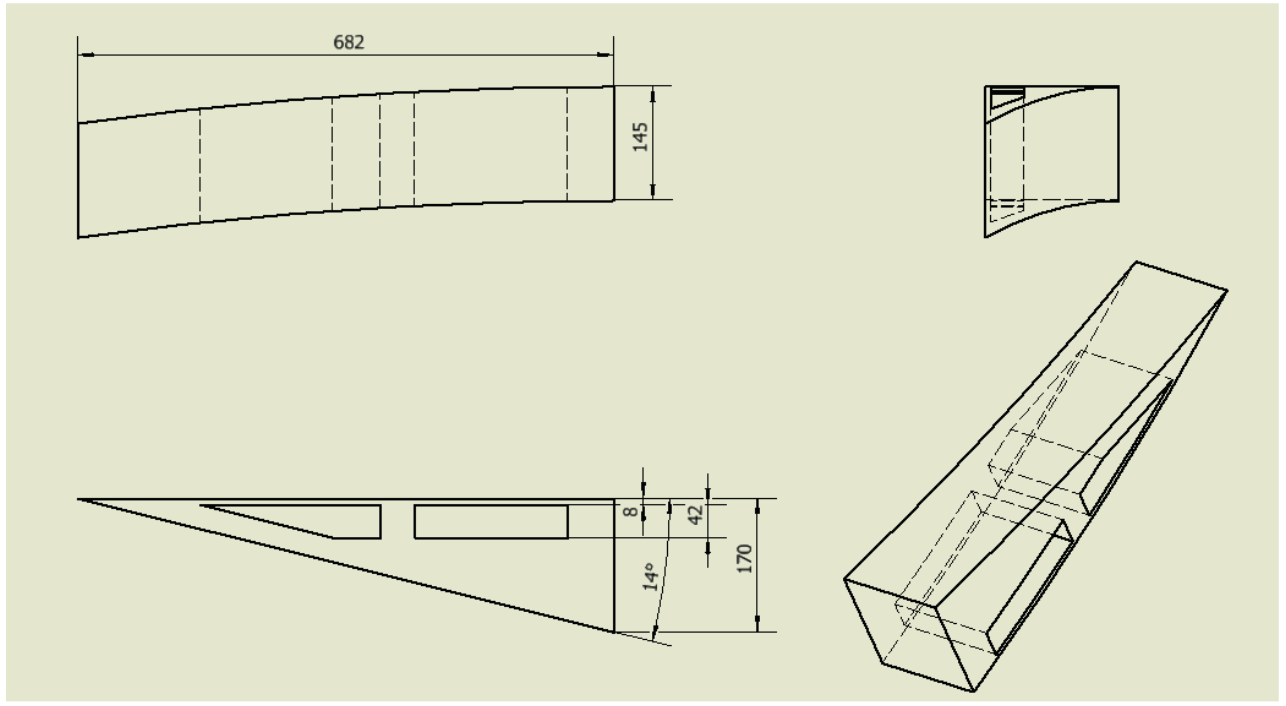

Figure A-23. Model 11-13 curved asymmetrical wavedozer with $682 \mathrm{~mm}$ length, $75 \mathrm{~mm}$ beam, $\alpha=14^{\circ}$ and $170 \mathrm{~mm}$ height.

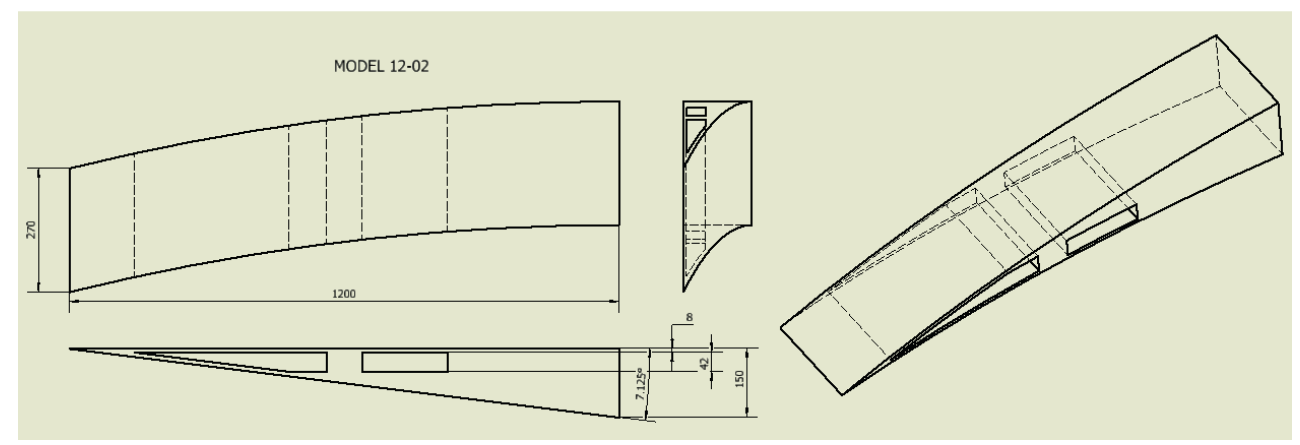

Figure A-24. Model 12-02 curved asymmetrical wavedozer of $1200 \mathrm{~mm}$ length, $275 \mathrm{~mm}$ beam, $\alpha=7^{\circ}$ and $150 \mathrm{~mm}$ height. 


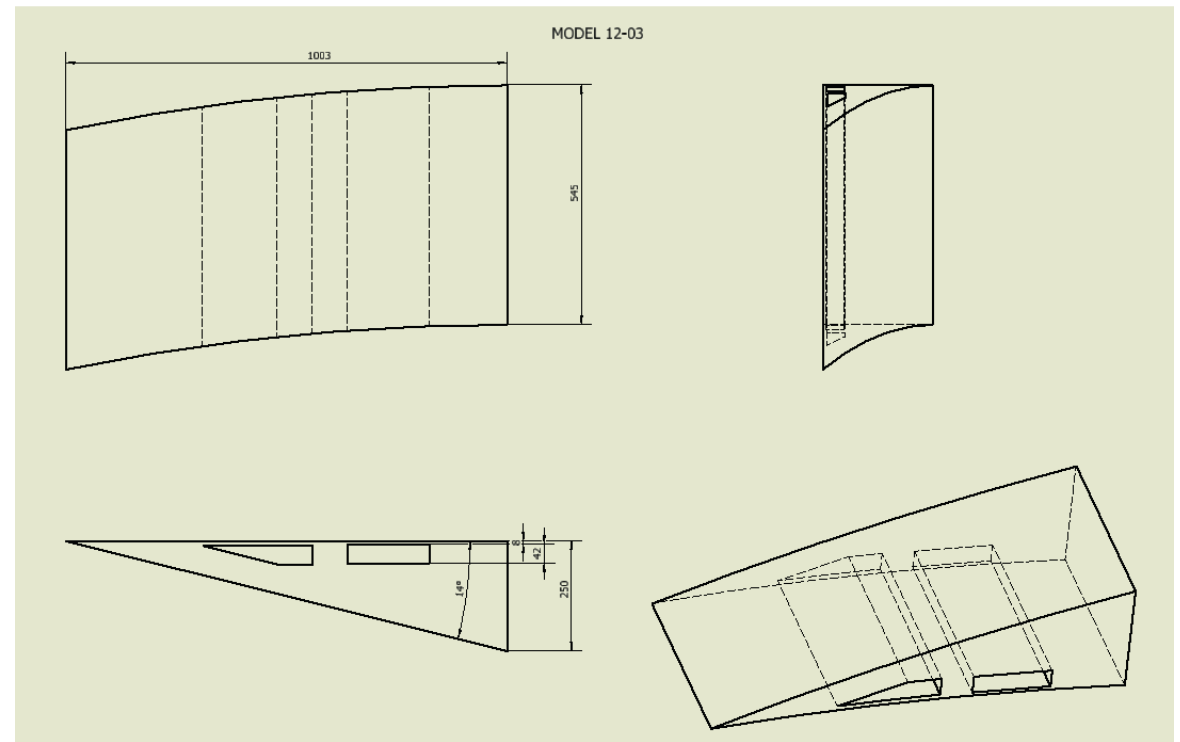

Figure A-25. Model 12-03 curved asymmetrical wavedozer with $1200 \mathrm{~mm}$ length, 550mm beam, $\alpha=7^{\circ}$ and $270 \mathrm{~mm}$ height. 


\section{Accuracy of model setup}

The accuracy of the models was believed to be sufficient for the testing:

a. Water depth $+/-1 \mathrm{~mm}$, using a meniscus probe, checked daily.

b. Bottom unevenness. $+/-3 \mathrm{~mm}$.

c. Model vertical placement. $+/-1 \mathrm{~mm}$ vertical and $+/-5 \mathrm{~mm}$ horizontal.

d. Beach placement. $+/-5 \mathrm{~mm}$ both vertical and horizontal. 


\section{Wave Probes}

The linear track tow tank wave probe array is shown in Figure A-26.

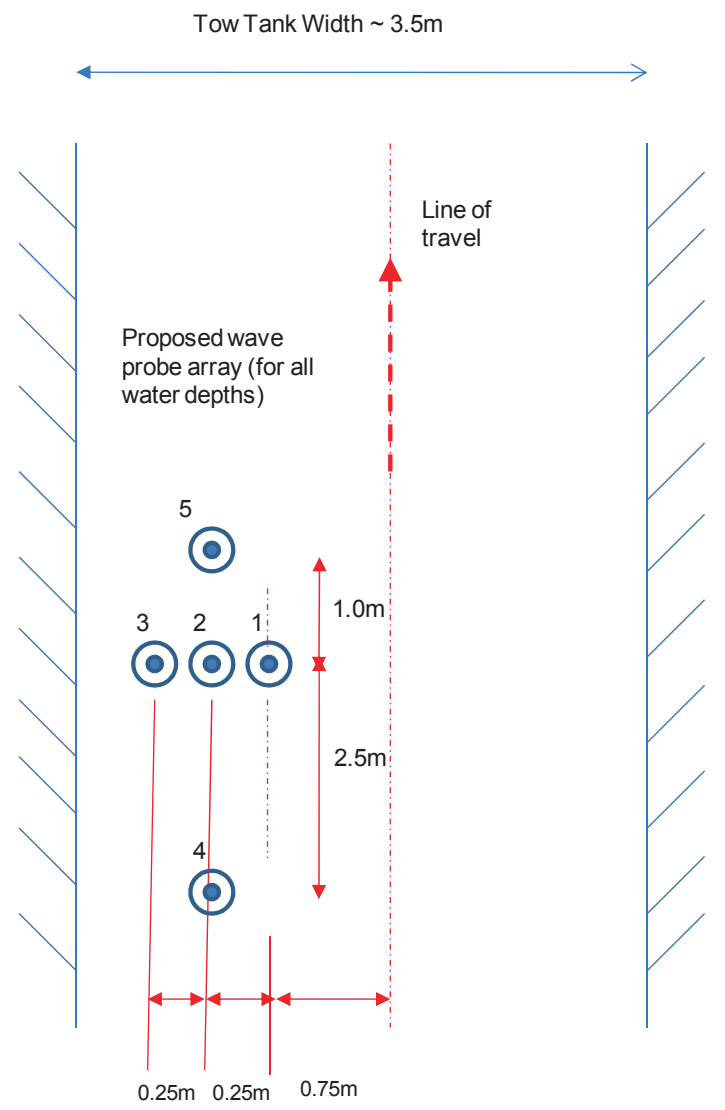

Figure A-26. Tow tank setup. The wave probe array is shown.

The wave probes were in a fixed location 80 metres $(\mathrm{m})$ (WP1, WP2 and WP3) from the start of tow tank. This distance was sufficient to allow the waves to reach a steady state before the pressure source passed the wave probes. 
The circular track scale model wave probe array is shown in Figure A-27.

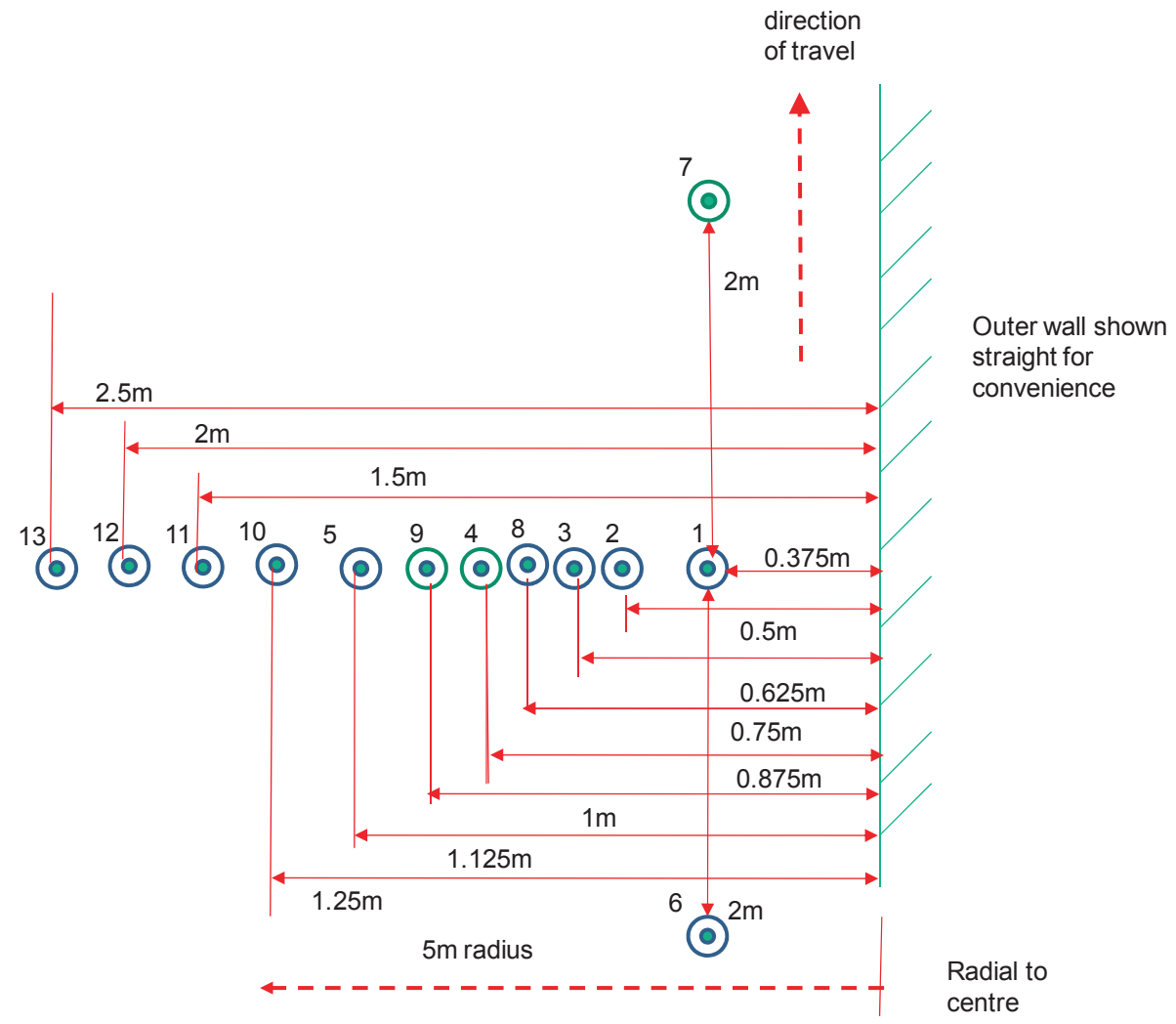

Figure A-27. Circular track scale model wave probe array. 


\section{Arm passing laser}

The models were attached to drive arms. A laser was used to record when each of the four arms passed the main wave probe array. A longer reflector was used to identify arm number 1, Figure A-28. The time trace of the laser results is shown in Figure A-29, with arm number 1 shown as the thicker lines.

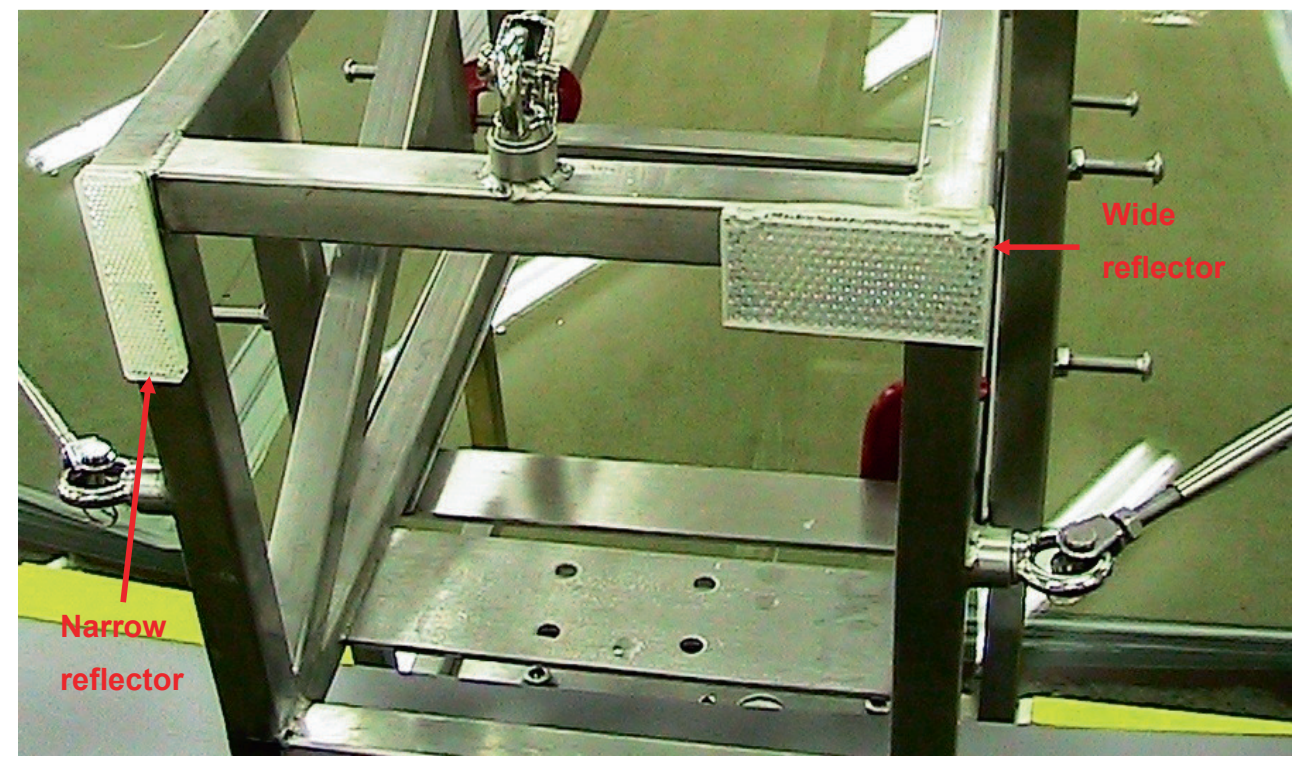

Figure A-28. Arm passing laser reflectors, with the narrow and wide reflectors show on arm number 1 . 


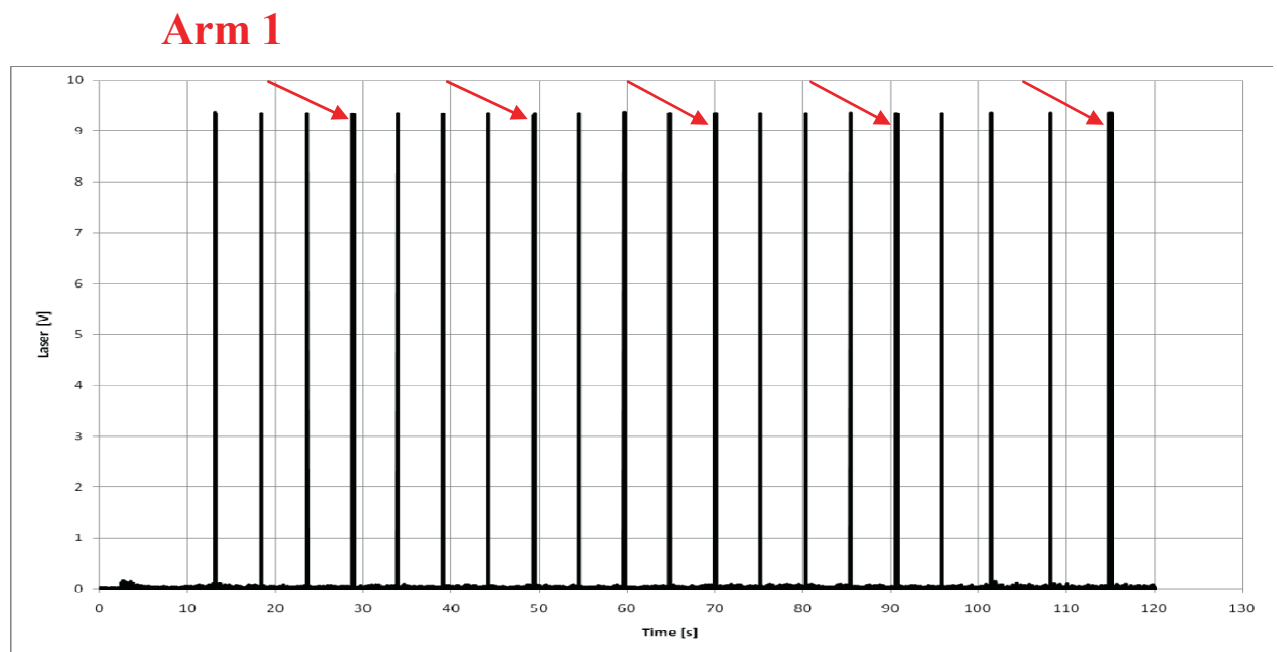

Figure A-29. Example of laser results in volts [V] for the model arm passing. Arm number 1 is the thicker lines as indicted. 


\section{Cameras}

GoPro waterproof cameras were used to conduct the breaking wave qualitative assessment; Figure A-30.
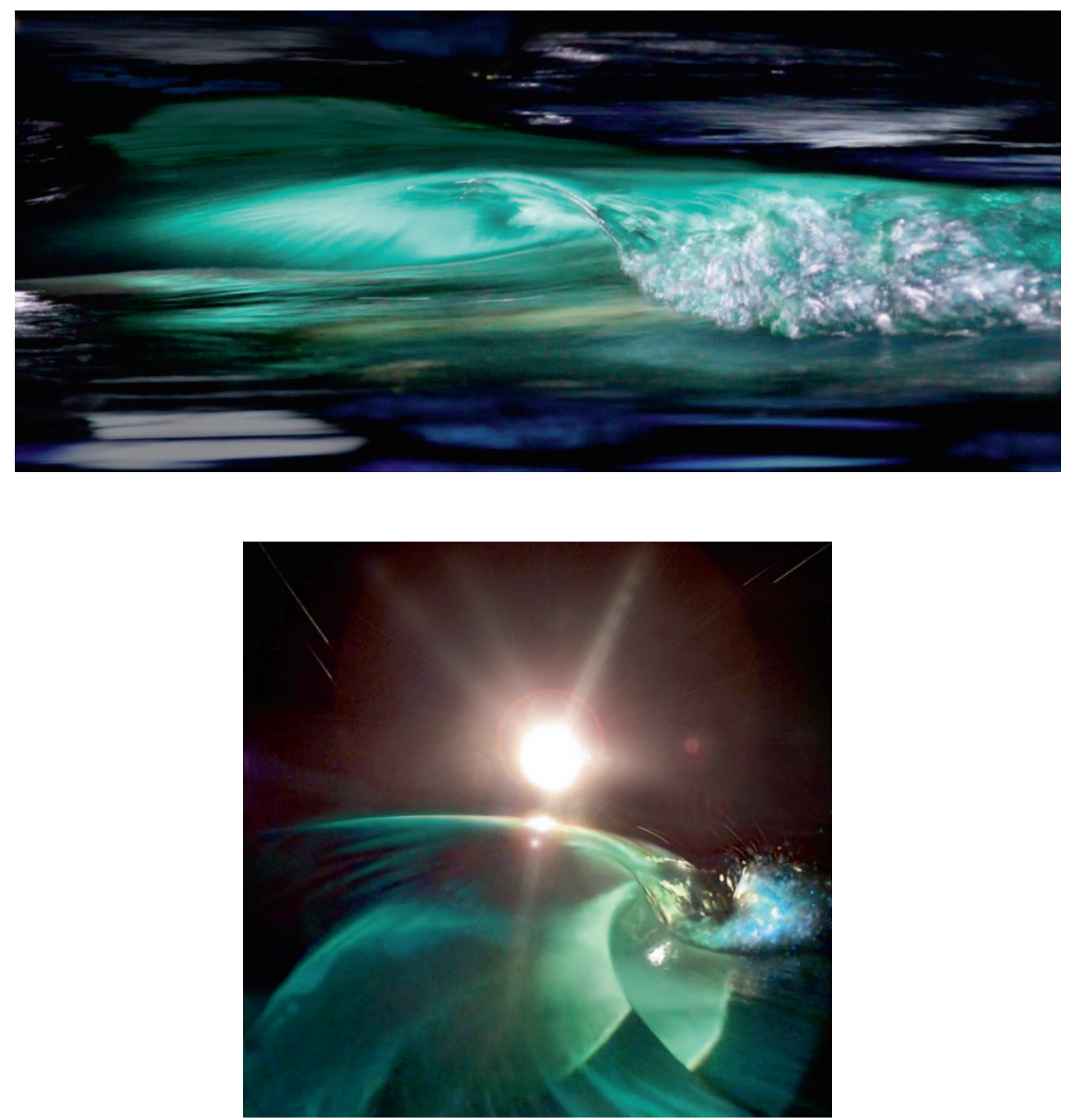

Figure A-30. Waves produced by condition 64 Model 12-03 with $d^{*}=0.2$ in $h_{0}=500 \mathrm{~mm}$ at $F r_{h 0}=0.95$ and $s=17^{\circ}$. 
Filming was also conducted by Liquid Time Pty Ltd to support marketing of the commercial wave pool.

\section{Current}

In the circular track scale model, a Sontek MicroADV Acoustic Doppler Velocimeter (ADV) (http://www.sontek.com/microadv.php) was mounted at $y=375 \mathrm{~mm}$ and $Z=50 \mathrm{~mm}$; Figure A-31, approximately $2 \mathrm{~m}$ from the main wave probe array. The current velocity parallel with the pressure direction of travel $\left(u_{c}\right)$ was analysed using the post processing software WinADV (http://www.sontek.com/sw/winadv.php). $u_{c}$ was determined by taking a 30 second moving average at the end of the each test, once $u_{c}$ reached a steady state.

In the circular track series 1 , to measure $u_{c}$ at the surface at different values of $y$, a measured grid (each 250mm apart) was spaced circumferentially, with floats placed on the surface at different radial positions; Figure A-32. A GoPro camera was used to automatically take photographs every two seconds of the float locations, with the surface current velocity calculated from the results.

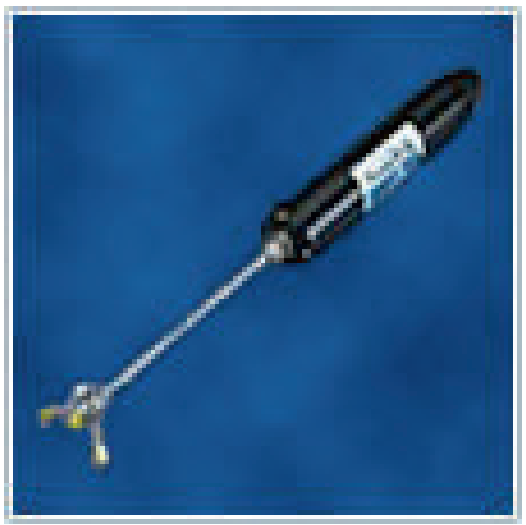

Figure A-31. Acoustic Doppler Velocimeter (ADV). 


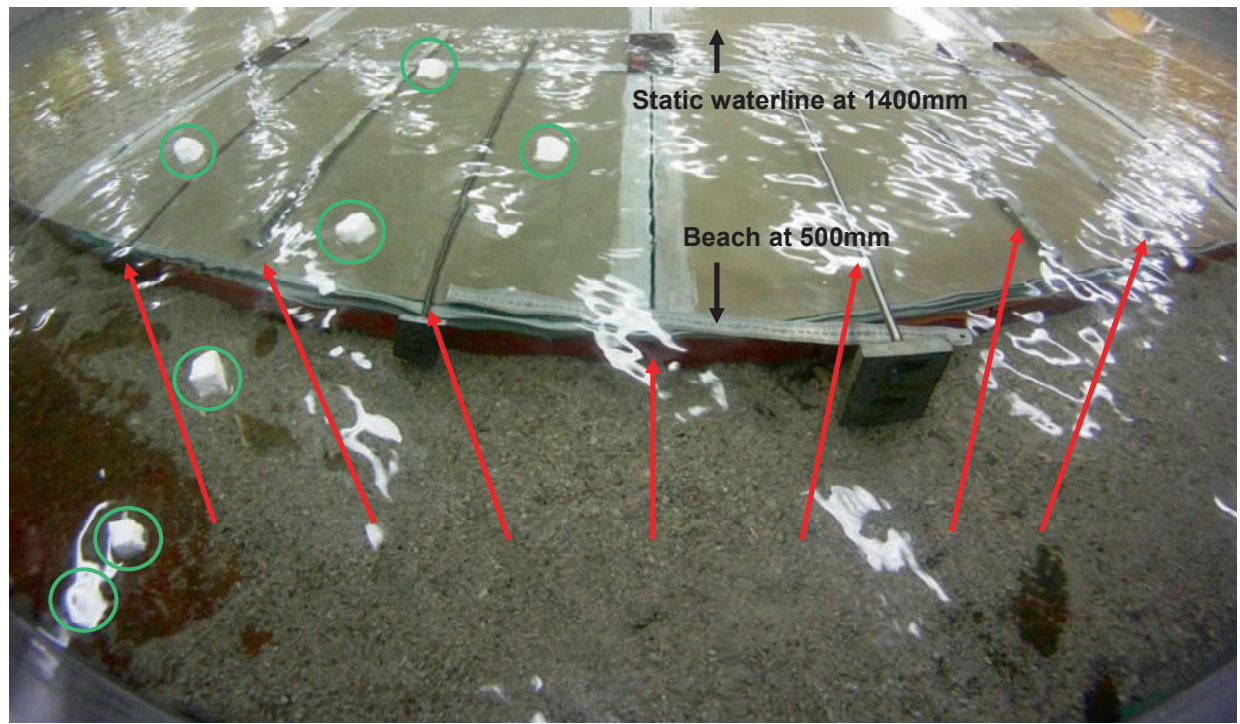

Figure A-32. The surface current measurement grid with $250 \mathrm{~mm}$ spacing, indicated by the arrows. The surface current floats are visible, and highlighted with green circles.

\section{Test procedure}

As shown in Figure A-33, assuming the wave probes were at the 3 o'clock position, the test procedure used was:

a. Settled the tank from the previous run.

b. Started the pressure source at the 2 o'clock position.

c. Reached test speed by the 12 o'clock position.

d. The measurement were taken at the 3 o'clock position. 
e. Following completion of data acquisition, decelerated the pressure source and returned it to the 2 o'clock position.

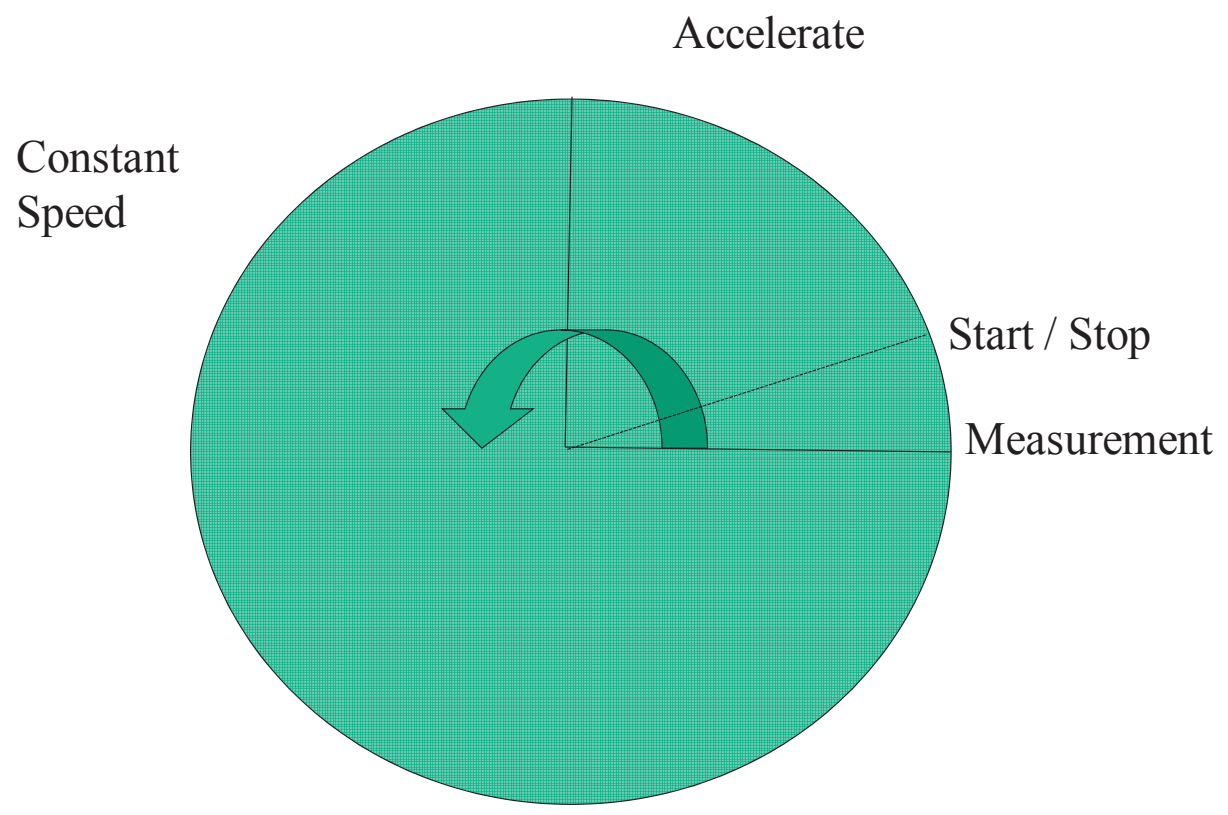

Figure A-33. Test procedure.

\section{Raw results}

An analysis spreadsheet was adapted from one developed by Robbins et. al. [24] to extract the required information from the experimental data in a form suitable for comparison. The process to analyse the surface elevation data from each of the wave probe channels and the velocity gauges was:

a. Within the spreadsheet, raw experimental data for the wave probes, along with data channels for pressure source speed and laser trigger, were imported along with calibration factors and static zero readings. 
b. The surface elevation was calculated from the raw data and calibration factors.

c. The pressure source speed was calculated by averaging over 5 seconds once the speed stabilised.

d. The surface elevation was plotted for each wave probe, and the amplitude of the first wave trough and crest were determined. The spreadsheet was amended to determine the amplitudes automatically, with the results manually validated. 
Annex B Scale model experiments run sheet summary

Page 175

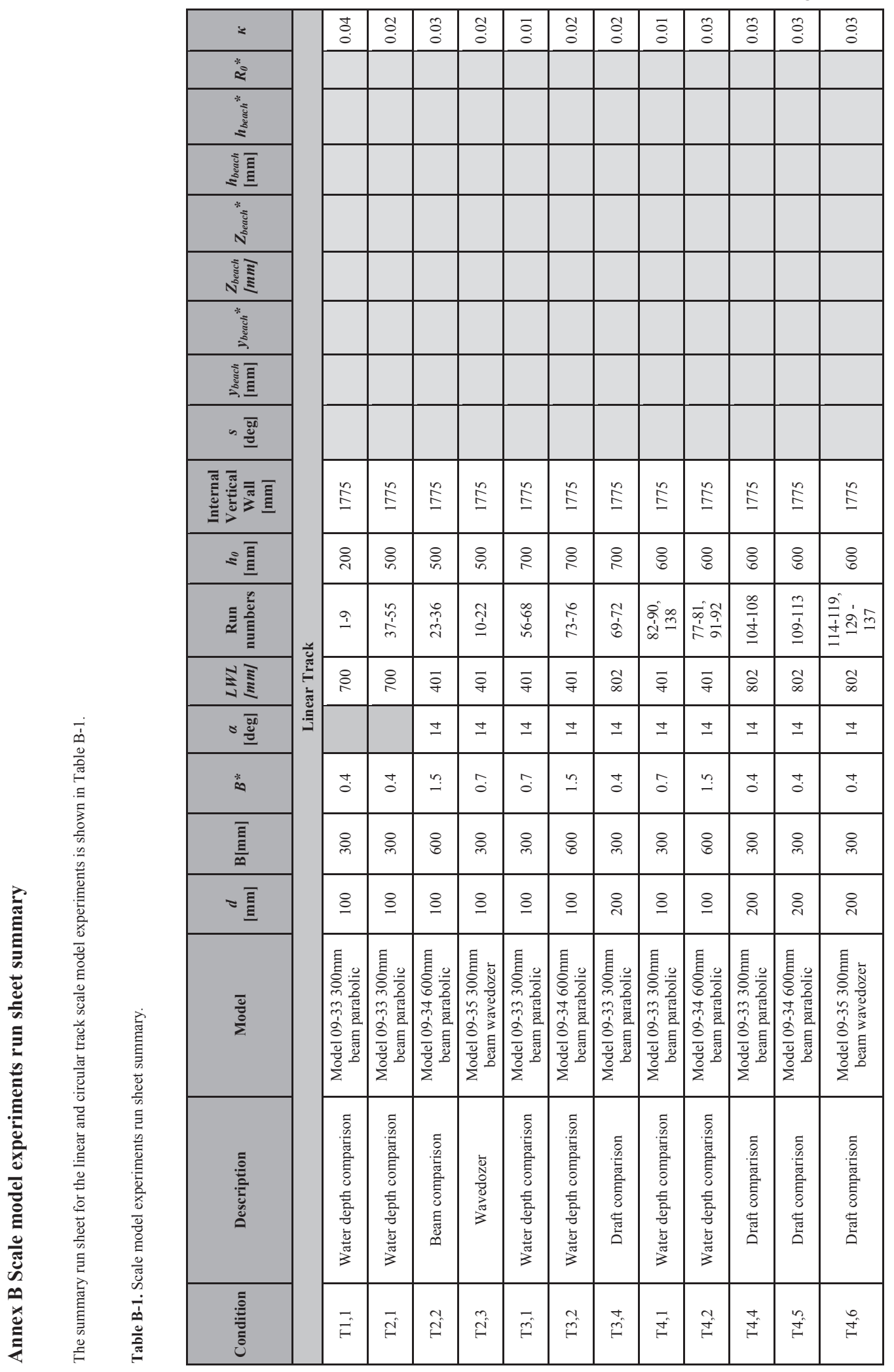


Page 176

\begin{tabular}{|c|c|c|c|c|c|c|c|c|c|c|c|c|c|c|c|c|c|c|c|c|c|}
\hline$=$ & 范 & $\stackrel{t}{0}$ & $\stackrel{0}{0}$ & $\stackrel{t}{0}$ & $\stackrel{\Delta}{0}$ & & $\overline{0}$ & & o. & \begin{tabular}{|l|} 
\\
0 \\
0 \\
0
\end{tabular} & \begin{tabular}{|l|} 
\\
0 \\
0 \\
\end{tabular} & o. & $\frac{1}{0}$ & $\begin{array}{ll}0 \\
0 \\
0\end{array}$ & $\begin{array}{ll}9 \\
0\end{array}$ & & \begin{tabular}{l|l|} 
\\
$\vdots$ \\
0 \\
\end{tabular} & \begin{tabular}{l|l}
0 \\
0 \\
0
\end{tabular} & : & 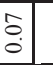 & : \\
\hline$\stackrel{*}{\approx}$ & & & & & & & & & ñ & $i$ & 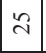 & $\simeq$ & $\infty$ & 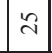 & $\simeq$ & & in & $=$ & กิ & 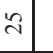 & in \\
\hline 气 & & & & & & & & & $\stackrel{0}{\circ}$ & $\stackrel{0}{\circ}$ & $\stackrel{\circ}{\circ}$ & $\stackrel{\circ}{\circ}$ & $\stackrel{\circ}{\circ}$ & $\stackrel{0}{0}$ & $\stackrel{\circ}{\circ}$ & & $\stackrel{\circ}{\circ}$ & $\stackrel{0}{\circ}$ & $\stackrel{\circ}{\circ}$ & $\begin{array}{l}0 \\
0 \\
0\end{array}$ & $\stackrel{\circ}{\circ}$ \\
\hline 气气 & & & & & & & & & in & : & $\stackrel{2}{\circ}$ & $\stackrel{n}{n}$ & $\stackrel{i}{n}$ & $\stackrel{n}{-1}$ & in & & : & in & in & $\stackrel{n}{n}$ & in \\
\hline " & & & & & & & & & $\stackrel{t}{0}$ & $\stackrel{+}{\circ}$ & $\begin{array}{l}0 \\
0\end{array}$ & $\stackrel{t}{\circ}$ & $\stackrel{t}{0}$ & $\stackrel{+}{0}$ & $\stackrel{\Delta}{0}$ & & $\stackrel{\square}{\circ}$ & $\stackrel{\circ}{\circ}$ & $\stackrel{5}{\circ}$ & $\stackrel{t}{0}$ & $\stackrel{t}{0}$ \\
\hline ง & & & & & & & & & 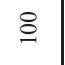 & 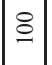 & 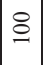 & $\stackrel{\circ}{\circ}$ & 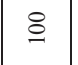 & 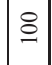 & 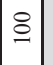 & & 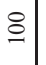 & 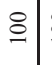 & 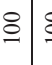 & 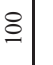 & 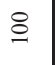 \\
\hline " & & & & & & & & & $\stackrel{n}{i}$ & $\stackrel{2}{i}$ & $\tilde{i}$ & I & $\stackrel{\infty}{\circ}$ & $\stackrel{n}{i}$ & $\cong$ & & ir & $=$ & in & $\stackrel{n}{i}$ & $\tilde{i}$ \\
\hline 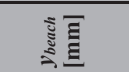 & & & & & & & & & 吕 & 吕 & $\stackrel{8}{i}$ & : & 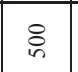 & 号 & is & & $\stackrel{8}{\circ}$ & : & 号 & 品 & : \\
\hline$\sim \underline{\underline{\underline{E}}}$ & & & & & & & & & $a$ & $a$ & $a$ & $a$ & $a$ & $a$ & $a$ & & $a$ & $a$ & $\sigma$ & $a$ & $a$ \\
\hline 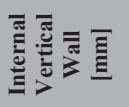 & $\stackrel{n}{\stackrel{2}{I}}$ & $\stackrel{2}{\stackrel{2}{I}}$ & $\stackrel{n}{\stackrel{2}{I}}$ & $\stackrel{n}{\stackrel{2}{I}}$ & $\stackrel{n}{\Xi}$ & & $\stackrel{n}{\Sigma}$ & & & & & & & & & & & & & & \\
\hline$s \overline{\underline{\underline{E}}}$ & \&్రి & \& & \& & \& & \& & & : & & ৫్ & 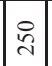 & : & ஜ్ & ஜू & $\ddot{n}$ & 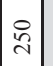 & & ্ֻণ & 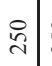 & ถู & : & ๙ุ \\
\hline 吾高 & $\frac{\hat{O}}{\dot{\alpha}}$ & 商 & 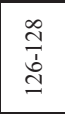 & 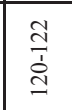 & 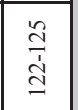 & 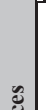 & 랑 & 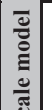 & $\stackrel{I}{I}$ & $\mid \begin{array}{l}\hat{T} \\
\hat{y}\end{array}$ & $\begin{array}{l}\text { ț } \\
\dot{1} \\
0 \\
\text { i } \\
\end{array}$ & 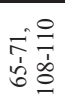 & 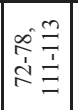 & $\begin{array}{l}\infty \\
2 \\
2 \\
2\end{array}$ & $\mid \begin{array}{l}0 \\
\frac{\partial}{2} \\
\alpha \\
\alpha\end{array}$ & & $\Xi$ & $\cong$ & $\begin{array}{l}\frac{c}{0} \\
\text { bे } \\
=\end{array}$ & 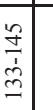 & 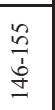 \\
\hline 水 & ઠి & రิ & ठิ & ڤ్తి & $\stackrel{\wp}{0}$ & 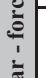 & 宍 & 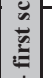 & $\bar{\sim}$ & $\vec{\sim}$ & $\bar{\sim}$ & $\bar{\sigma}$ & కి & $\vec{\sim}$ & $\vec{\sigma}$ & & 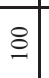 & $\vec{\rho}$ & ळे & $\vec{\sim}$ & $\overrightarrow{\mathrm{N}}$ \\
\hline $8 \stackrel{\bar{g}}{\underline{\underline{g}}}$ & \pm & \pm & \pm & \pm & \pm & . & \pm & 离 & \pm & \pm & \pm & \pm & \pm & \pm & \pm & & \pm & \pm & \pm & $\Xi$ & \pm \\
\hline * & $\stackrel{\circ}{-}$ & $\stackrel{\circ}{\rightarrow}$ & $n$ & ชุ & 3 & & $\hat{o}$ & สิ & $\stackrel{?}{-}$ & $\stackrel{\circ}{0}$ & $a$ & $\stackrel{t}{\circ}$ & ?. & 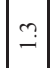 & $\stackrel{\circ}{\circ}$ & & $\stackrel{\infty}{-}$ & $\stackrel{0}{\circ}$ & $?$ & 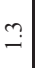 & $\dot{\partial}$ \\
\hline$\overline{\overline{\underline{E}}}$ & \& & \&્ర & ৪్ల & \&్ల & \&్ల & & ৪্ল & & $\bar{ָ}$ & 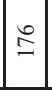 & 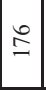 & 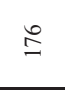 & 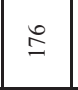 & $\overrightarrow{\mathrm{i}}$ & $\vec{s}$ & & 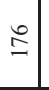 & 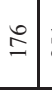 & $\overrightarrow{\widetilde{d}}$ & ָु & 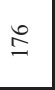 \\
\hline = $\overline{\underline{\underline{E}}}$ & in & $\stackrel{n}{n}$ & in & \&్ల & ప్రి & & 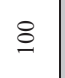 & & in & in & in & $\nsubseteq$ & $\stackrel{n}{n}$ & in & $\stackrel{-}{\circ}$ & & $\approx$ & $\approx$ & in & in & in \\
\hline 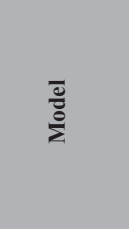 & 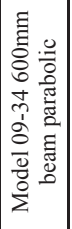 & 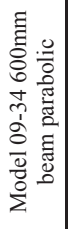 & 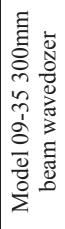 & 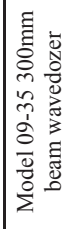 & 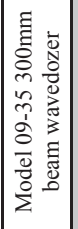 & & 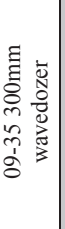 & & $\begin{array}{l}0 \\
\frac{0}{3} \\
n \\
\text { Tे } \\
0 \\
0\end{array}$ & 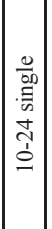 & 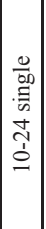 & 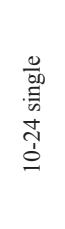 & 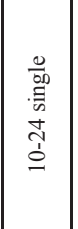 & 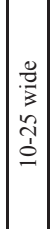 & \begin{tabular}{|c|}
0 \\
0 \\
3 \\
2 \\
$\hat{3}$ \\
0 \\
0
\end{tabular} & & 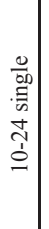 & 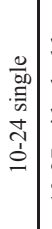 & 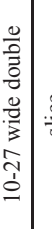 & & 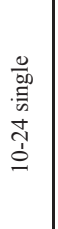 \\
\hline 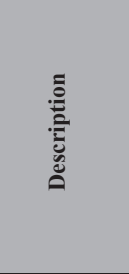 & 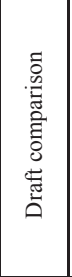 & 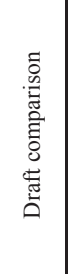 & 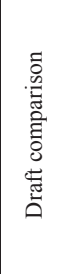 & 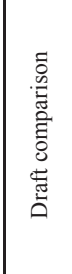 & 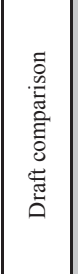 & & 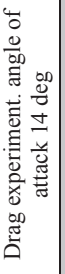 & & 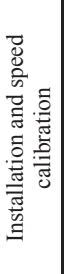 & 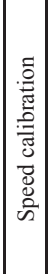 & 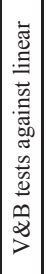 & 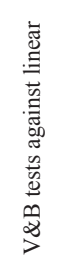 & 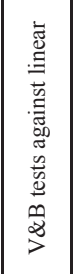 & 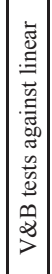 & 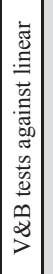 & 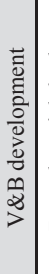 & 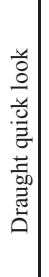 & 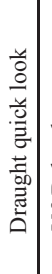 & 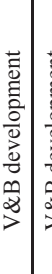 & 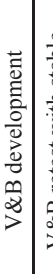 & 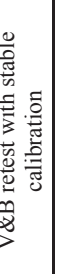 \\
\hline 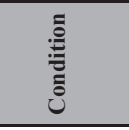 & f & $\begin{array}{l}\infty \\
\dot{f}\end{array}$ & 岌 & $\begin{array}{l}\stackrel{\simeq}{ \pm} \\
\stackrel{f}{t}\end{array}$ & $\stackrel{n}{\stackrel{n}{f}}$ & & $f$ & & - & $\sim$ & $m$ & ナ & in & 0 & $r$ & $\infty$ & $a$ & $\circ$ & $=3$ & $\simeq$ & m \\
\hline
\end{tabular}


Annex B Scale model experiments run sheet summary

Page 177

\begin{tabular}{|c|c|c|c|c|c|c|c|c|c|c|c|c|c|c|}
\hline$=$ & 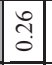 & $\hat{0}$ & $\hat{0}$ & $\begin{array}{ll} \\
0 \\
0\end{array}$ & $\stackrel{n}{0}$ & s. & $\stackrel{0}{0}$ & 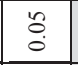 & $\begin{array}{l}0 \\
0 \\
0\end{array}$ & & o. & 0 & 0 & $\overrightarrow{0}$ \\
\hline$\stackrel{*}{\gtrless}$ & 6 & $\ddot{\sim}$ & $\ddot{\sim}$ & $\approx$ & $\ddot{\sim}$ & $\simeq$ & $\ddot{n}$ & $\ddot{\sim}$ & $\approx$ & & in & $\ddot{\sim}$ & in & $\ddot{n}$ \\
\hline " & 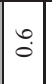 & $\stackrel{\circ}{\circ}$ & : & $\stackrel{\circ}{\circ}$ & $\hat{o}$ & $\hat{o}$ & $\hat{o}$ & 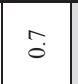 & $\stackrel{0}{0}$ & $\stackrel{\circ}{\circ}$ & & & & \\
\hline 密可 & in & in & $\stackrel{n}{n}$ & 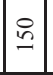 & 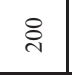 & 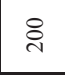 & 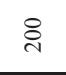 & 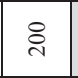 & 욤 & $\stackrel{n}{n}$ & & & & \\
\hline " & $\stackrel{\square}{\circ}$ & $\stackrel{t}{0}$ & $\stackrel{t}{0}$ & $\stackrel{t}{\circ}$ & ?3 & 3 & 3 & ?3 & $\stackrel{\Delta}{0}$ & $\stackrel{t}{0}$ & & & & \\
\hline ป气 & 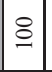 & 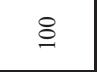 & $\stackrel{8}{\circ}$ & 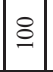 & $\stackrel{8}{\circ}$ & 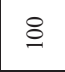 & $\stackrel{8}{ }$ & $\stackrel{8}{\circ}$ & 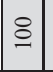 & 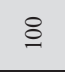 & & & & \\
\hline 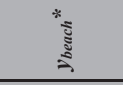 & 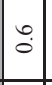 & $\tilde{n}$ & $\stackrel{n}{n}$ & in & $\ddot{n}$ & $\stackrel{\Im}{\Im}$ & $\tilde{i}$ & $\tilde{n}$ & $\stackrel{n}{i}$ & & & & & \\
\hline 气 & : & $\stackrel{\circ}{\circ}$ & : & $\stackrel{\circ}{\circ}$ & 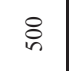 & 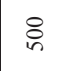 & : & \& & 8 & : & & & & \\
\hline$=\frac{\overline{s 0}}{\underline{\underline{g}}}$ & $a$ & $a$ & $a$ & $a$ & $a$ & $a$ & $a$ & $a$ & $a$ & $a$ & & $\stackrel{2}{\text { z }}$ & $\stackrel{\circ}{\text { z }}$ & \\
\hline 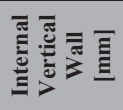 & & & & & & & & & & & $\begin{array}{l}\infty \\
\infty \\
\infty\end{array}$ & $\begin{array}{l}\overline{\bar{\pi}} \\
\stackrel{3}{3} \\
\stackrel{0}{z}\end{array}$ & 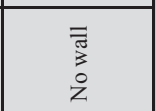 & $\begin{array}{l}\infty \\
\infty\end{array}$ \\
\hline$=\overline{\bar{E}}$ & : & ஜ̀ & ণ্ণ & : & ః्ల & ః्ల & \&్ల & ః्ల & ڤొ & ì & ్ֶ & ڤ్ & ڤ్ & iั \\
\hline 量 & \begin{tabular}{|c|}
$\tilde{n}$ \\
$\hat{b}$ \\
$n$ \\
- \\
\end{tabular} & $\begin{array}{l}\stackrel{8}{\circ} \\
\dot{1} \\
\stackrel{0}{-1}\end{array}$ & $\begin{array}{l}\frac{3}{1} \\
\frac{1}{6}\end{array}$ & 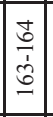 & :ُ & $\stackrel{1}{2}$ & 过吉 & 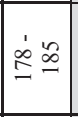 & & $\dot{\infty} \propto$ & $\stackrel{\text { gे }}{\mathrm{N}}$ & ڤ્ટેં & $\stackrel{\dot{d}}{\vec{N}} \stackrel{\vec{N}}{\vec{N}}$ & 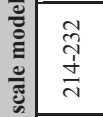 \\
\hline 亲 & ๙ิ & $\vec{\sim}$ & $\overrightarrow{\mathrm{i}}$ & $\vec{i}$ & $\overline{\mathrm{i}}$ & $\bar{q}$ & $\overline{\mathrm{\sim}}$ & $\overline{\mathrm{N}}$ & $\vec{\sim}$ & & $\vec{\sim}$ & $\vec{\sim}$ & $\bar{\sim}$ & 豙 \\
\hline 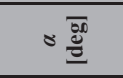 & \pm & \pm & \pm & \pm & \pm & \pm & \pm & \pm & \pm & \pm & \pm & \pm & \pm & 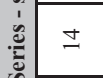 \\
\hline$*$ & $\tilde{3}$ & $\stackrel{m}{3}$ & $\stackrel{?}{-}$ & $\stackrel{?}{-}$ & $\stackrel{m}{-}$ & $\stackrel{t}{0}$ & oे & $\stackrel{?}{-}$ & $\stackrel{?}{-}$ & 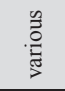 & $\dot{o}$ & $\dot{o}$ & o. & t. \\
\hline$\overline{\overline{\underline{E}}}$ & $\overrightarrow{\grave{n}}$ & $\vec{n}$ & $\overrightarrow{\widetilde{d}}$ & $\vec{s}$ & $\vec{n}$ & 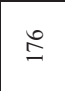 & 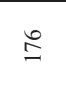 & $\bar{n}$ & $\vec{s}$ & 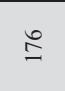 & $\succsim$ & 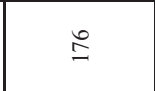 & 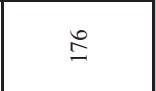 & $\approx$ \\
\hline 咺 & ڤे & in & in & in & in & 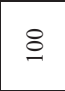 & in & in & in & 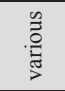 & in & in & in & in \\
\hline 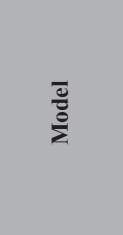 & 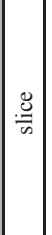 & 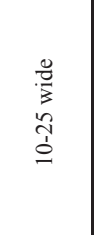 & 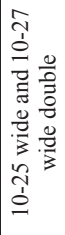 & $\overline{\bar{\sigma}}$ & $\overline{\text { बे }}$ & \begin{tabular}{l}
$\frac{0}{00}$ \\
量 \\
\multirow{1}{*}{} \\
$\stackrel{0}{0}$
\end{tabular} & 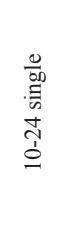 & 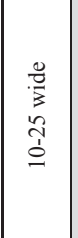 & न & $\begin{array}{l}\stackrel{0}{\pi} \\
3 \\
n \\
\hat{~} \\
0\end{array}$ & 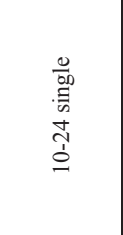 & 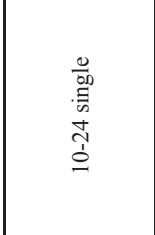 & 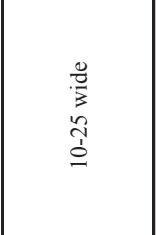 & 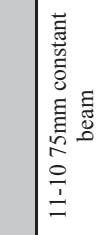 \\
\hline 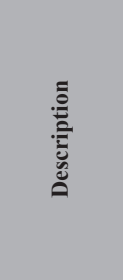 & 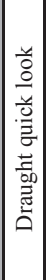 & 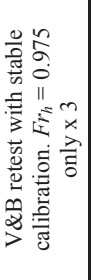 & 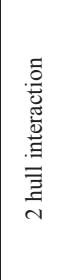 & 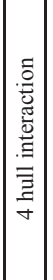 & 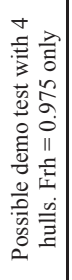 & 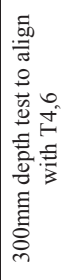 & 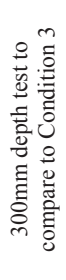 & 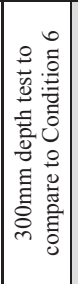 & 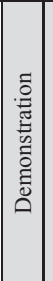 & 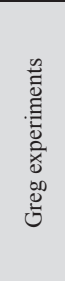 & 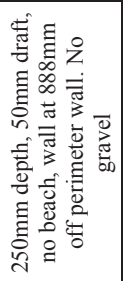 & 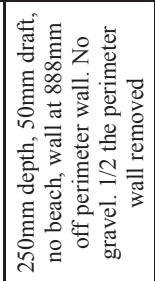 & 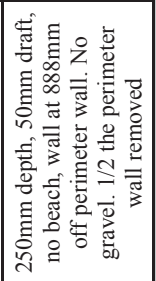 & 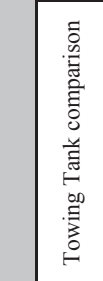 \\
\hline 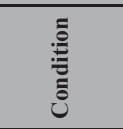 & $\approx$ & 6 & \pm & $\because$ & $\stackrel{\circ}{\sim}$ & $=$ & $\stackrel{\infty}{\sim}$ & $\stackrel{2}{ }$ & & ì & $\vec{\lambda}$ & $\tilde{N}$ & $\tilde{\lambda}$ & $\stackrel{J}{d}$ \\
\hline
\end{tabular}


Page 178

Annex B Scale model experiments run sheet summary

\begin{tabular}{|c|c|c|c|c|c|c|c|c|c|c|c|c|c|c|c|c|}
\hline$=$ & $\stackrel{\mathrm{s}}{\mathrm{c}}$ & $\stackrel{\leftrightarrow}{0}$ & $\overrightarrow{0}$ & 0 & 0 & 0 & 0 & 0 & 0 & $\stackrel{\circ}{\circ}$ & $\stackrel{8}{0}$ & 0 & 0 & 0 & 0 & 0 \\
\hline$\stackrel{\leftrightarrow}{2}$ & $\stackrel{\text { s }}{n}$ & $\ddot{\sim}$ & $\simeq$ & $\simeq$ & ^ิ & $\ddot{\sim}$ & $\ddot{n}$ & $\ddot{\sim}$ & $\stackrel{\text { s }}{n}$ & $\ddot{d}$ & 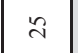 & & & $\simeq$ & $\simeq$ & $\infty$ \\
\hline 气 & & & & & & & & & & ถุ. & & & & & & \\
\hline 害百 & & & & & & & & & & $\stackrel{m}{n}$ & & & & & & \\
\hline 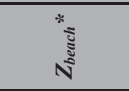 & & & & & & & & & & $\stackrel{\infty}{0}$ & & & & & & \\
\hline งั้ & & & & & & & & & & $\stackrel{\Xi}{\simeq}$ & & & & & & \\
\hline " & & & & & & & & & & $\dot{m}$ & & & & & & \\
\hline 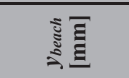 & & & & & & & & & & in & & & & & & \\
\hline 酸 & & & & 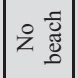 & 啮 & Z & 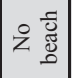 & 它 & z & $=$ & Z & 号 & 宅 & 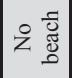 & Z & \& \\
\hline 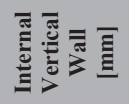 & $\begin{array}{l}\infty \\
\infty \\
\infty\end{array}$ & $\begin{array}{l}\infty \\
\infty\end{array}$ & $\stackrel{\curvearrowleft}{\cong}$ & $\begin{array}{l}\overline{\bar{T}} \\
0 \\
\stackrel{0}{z}\end{array}$ & 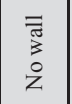 & 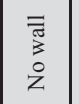 & $\begin{array}{l}\overline{\bar{\pi}} \\
\stackrel{0}{2} \\
\dot{z}\end{array}$ & $\begin{array}{l}\overline{\bar{J}} \\
\bar{\xi} \\
\dot{z}\end{array}$ & $\begin{array}{l}\overline{\bar{N}} \\
\hat{3} \\
\dot{z}\end{array}$ & $\begin{array}{l}\overline{\bar{J}} \\
\overline{3} \\
\stackrel{0}{Z}\end{array}$ & $\begin{array}{l}\overline{\bar{T}} \\
\stackrel{5}{3} \\
\dot{z}\end{array}$ & 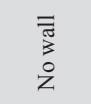 & $\begin{array}{l}\bar{\pi} \\
3 \\
0 \\
\dot{z}\end{array}$ & $\begin{array}{l}\overline{\bar{J}} \\
\dot{3} \\
0 \\
\dot{z}\end{array}$ & $\begin{array}{l}\overline{\bar{\pi}} \\
\text { 3े } \\
\dot{2}\end{array}$ & $\begin{array}{l}\overline{\bar{J}} \\
\dot{3} \\
0 \\
\text { z }\end{array}$ \\
\hline$=\overline{\underline{E}}$ & ஜ్ & ஜू & \& & 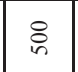 & \& & \& & \& & ஜू & ڤ్ & ฌె & ஜे & ڤ్ & ஜू & ஜ్ & \&ั & ஷั \\
\hline 焉咅 & 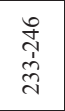 & 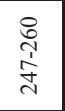 & $\begin{array}{c}\stackrel{N}{T} \\
\stackrel{i}{0} \\
\end{array}$ & $\begin{array}{l}\mathscr{n} \\
\stackrel{N}{N} \\
\stackrel{N}{\sim}\end{array}$ & 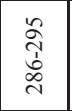 & 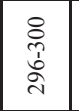 & $\begin{array}{l}\dot{0} \\
0 \\
\dot{0} \\
\dot{0} \\
0\end{array}$ & $\begin{array}{l}\text { ते } \\
\text { dे } \\
\text { m }\end{array}$ & $\begin{array}{l}\text { ते } \\
\text { ले } \\
\text { ले } \\
\text { n. }\end{array}$ & $\begin{array}{l}\underset{7}{2} \\
\underset{\sim}{\pi}\end{array}$ & 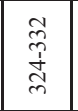 & $\begin{array}{l}\text { y } \\
m \\
\hat{n} \\
m \\
m\end{array}$ & $\begin{array}{l}\infty \\
\stackrel{\infty}{+} \\
\stackrel{\omega}{\omega} \\
m\end{array}$ & 苻 & $\begin{array}{l}n \\
\hat{n} \\
0 \\
\text { m }\end{array}$ & లె \\
\hline 棓 & $\overline{\mathrm{N}}$ & $\vec{\sim}$ & $\vec{q}$ & $\bar{q}$ & $\vec{\sim}$ & $\bar{\sim}$ & $\bar{\sim}$ & $\bar{\sim}$ & $\bar{\sim}$ & $\vec{\sim}$ & $\bar{\sim}$ & 道量 & 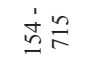 & \& & \& & $\tilde{\sigma}$ \\
\hline$ه \stackrel{\bar{g}}{\underline{\underline{g}}}$ & \pm & \pm & \pm & \pm & \pm & \pm & \pm & \pm & $\Xi$ & \pm & \pm & $\dot{+} \stackrel{\infty}{=}$ & $\dot{r} \stackrel{\infty}{\longrightarrow}$ & r & r & in \\
\hline$*$ & ò & $\stackrel{+}{-}$ & $\stackrel{t}{\circ}$ & $\stackrel{t}{\circ}$ & $\stackrel{t}{\circ}$ & o. & $\stackrel{+}{-}$ & $\stackrel{+}{-}$ & oे & $\stackrel{+}{-}$ & $\stackrel{t}{\circ}$ & $\tilde{o}$ & 3 & ชี & $\tilde{o}$ & $\stackrel{t}{0}$ \\
\hline$\overline{\overline{\underline{\underline{E}}}}$ & $\stackrel{n}{=}$ & $\stackrel{\sim}{\varkappa}$ & $\stackrel{n}{n}$ & in & $\approx$ & $\stackrel{n}{\cong}$ & $\stackrel{\sim}{\varkappa}$ & $\stackrel{\approx}{\approx}$ & $\cong$ & $\stackrel{\sim}{\varkappa}$ & $\approx$ & 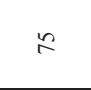 & $\approx$ & $\approx$ & $\stackrel{\sim}{\approx}$ & $\stackrel{\sim}{\varkappa}$ \\
\hline 酯 & in & in & 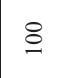 & 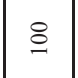 & in & in & in & in & in & in & in & in & in & in & in & in \\
\hline $\begin{array}{l}\bar{\Xi} \\
\sum_{\bar{z}}\end{array}$ & 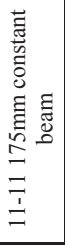 & 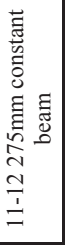 & 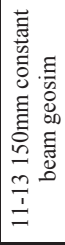 & 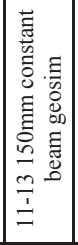 & 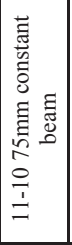 & 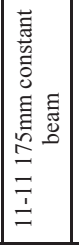 & 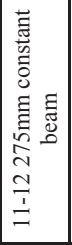 & 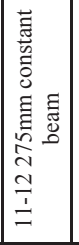 & 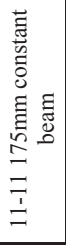 & 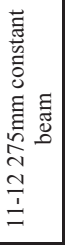 & 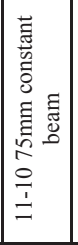 & 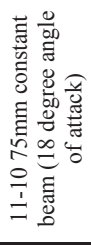 & 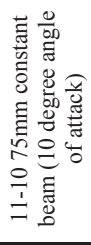 & 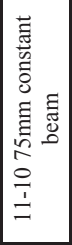 & 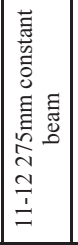 & 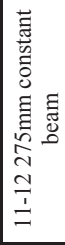 \\
\hline 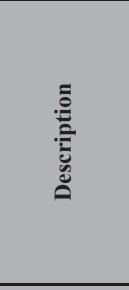 & 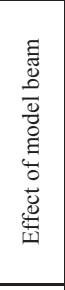 & 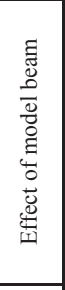 & 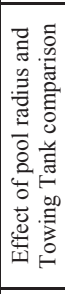 & 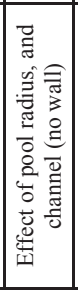 & 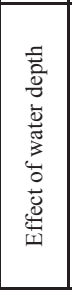 & 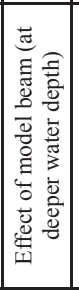 & 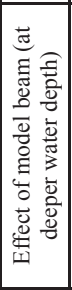 & 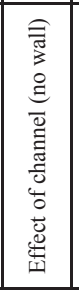 & 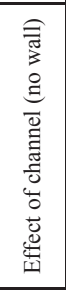 & $\begin{array}{l}\overline{0} \\
\bar{E} \\
D \\
\overrightarrow{0} \\
\vec{E} \\
0\end{array}$ & 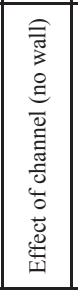 & 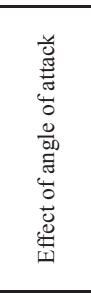 & 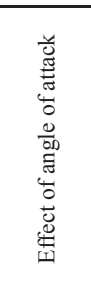 & 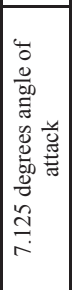 & 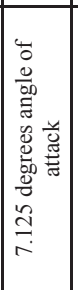 & 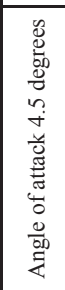 \\
\hline 童 & $\ddot{\sim}$ & $\stackrel{\sim}{\sim}$ & $\hat{\sim}$ & $\stackrel{\infty}{\sim}$ & ते & in & $\vec{m}$ & లె & $\hat{m}$ & m & $\approx$ & $\stackrel{n}{n}$ & $\hat{n}$ & $\underset{m}{\infty}$ & ले & q \\
\hline
\end{tabular}


Annex B Scale model experiments run sheet summary

Page 179

\begin{tabular}{|c|c|c|c|c|c|c|c|c|c|c|c|c|c|c|c|}
\hline$=$ & 0 & 0 & 0 & $\begin{array}{l}0 \\
0\end{array}$ & $\stackrel{0}{\circ}$ & & $\begin{array}{l}\infty \\
0 \\
0\end{array}$ & o. & $\begin{array}{l}0 \\
0\end{array}$ & \begin{tabular}{|l|}
0 \\
0 \\
0
\end{tabular} & \begin{tabular}{|l|}
0 \\
0 \\
0 \\
\end{tabular} & \begin{tabular}{|l|} 
\\
0 \\
0
\end{tabular} & o. & 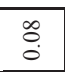 & s. \\
\hline$\stackrel{*}{*}$ & $\leadsto$ & 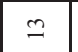 & $=$ & 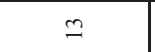 & $\cong$ & & $\simeq$ & $\simeq$ & $\simeq$ & $\simeq$ & $\simeq$ & $\simeq$ & $\simeq$ & $\simeq$ & $\simeq$ \\
\hline " & & & & $\tilde{n}$ & กุ & & $\stackrel{?}{9}$ & $\stackrel{8}{\circ}$ & $\stackrel{\infty}{+}$ & 足 & $\mid \begin{array}{l}\infty \\
\stackrel{0}{0} \\
\end{array}$ & 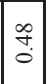 & ঙ̊ & $\stackrel{\infty}{\stackrel{\infty}{0}}$ & $\stackrel{R}{i}$ \\
\hline 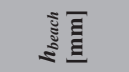 & & & & 요 & $\stackrel{0}{\dddot{m}}$ & & $\stackrel{8}{\circ}$ & in & తి & 守 & $\cong$ & తి & 8 & తి & $\stackrel{n}{=}$ \\
\hline " & & & & $\stackrel{\infty}{\stackrel{\infty}{0}}$ & $\stackrel{\infty}{\stackrel{0}{0}}$ & & $\stackrel{\circ}{\circ}$ & $\stackrel{t}{\circ}$ & $\tilde{n}$ & 莳 & तี & 它 & $\stackrel{t}{\stackrel{0}{0}}$ & กี & 3 \\
\hline ป气 & & & & 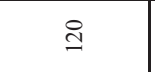 & $\stackrel{\text { తి }}{1}$ & & $\stackrel{i}{n}$ & 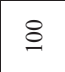 & 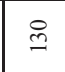 & 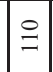 & $i$ & $\stackrel{i}{9}$ & $\stackrel{\infty}{\sim}$ & $\stackrel{\oplus}{\sim}$ & $\therefore$ \\
\hline * & & & & $\stackrel{9}{-}$ & $\stackrel{9}{-}$ & & $\stackrel{\Xi}{\leftrightarrows}$ & $\stackrel{ \pm}{-}$ & $\stackrel{9}{9}$ & \pm & $\stackrel{+}{-}$ & 9 & 9 & $\stackrel{+}{-}$ & $\stackrel{ \pm}{-}$ \\
\hline 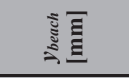 & & & & in & in & & in & in & in & 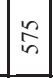 & $\stackrel{\approx}{i n}$ & in & $\stackrel{i}{n}$ & $\underset{n}{n}$ & $\stackrel{i}{i n}$ \\
\hline 酸 & 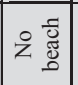 & 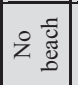 & $\gtreqless \frac{\bar{s}}{\mathscr{g}}$ & $=$ & $=$ & & $a$ & $a$ & $a$ & 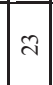 & $\tilde{\imath}$ & $\approx$ & $=$ & $=$ & $=$ \\
\hline 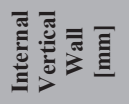 & $\begin{array}{l}\overline{\bar{\pi}} \\
\stackrel{3}{3} \\
\stackrel{2}{z}\end{array}$ & $\begin{array}{l}\overline{\bar{\pi}} \\
0 \\
\dot{z}\end{array}$ & 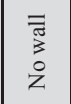 & $\begin{array}{l}\overline{\bar{\pi}} \\
\stackrel{3}{3} \\
\stackrel{0}{z}\end{array}$ & 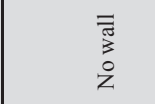 & & 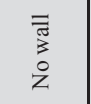 & $\begin{array}{l}\overline{\bar{N}} \\
0 \\
\stackrel{0}{z}\end{array}$ & $\begin{array}{l}\overline{\bar{J}} \\
\bar{z} \\
0 \\
\dot{z}\end{array}$ & \begin{tabular}{|l|}
$\bar{z}$ \\
$\frac{\pi}{3}$ \\
0 \\
$z$
\end{tabular} & $\begin{array}{l}\overline{\widetilde{\pi}} \\
\dot{3} \\
0 \\
\dot{z}\end{array}$ & \begin{tabular}{|l|}
$\overline{\tilde{J}}$ \\
$\dot{3}$ \\
0 \\
$\dot{z}$
\end{tabular} & $\begin{array}{l}\overline{\bar{N}} \\
0 \\
0 \\
\dot{z}\end{array}$ & $\begin{array}{l}\overline{\bar{T}} \\
\bar{y} \\
\dot{z}\end{array}$ & 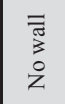 \\
\hline s画 & ఝั & 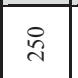 & $\grave{n}$ & in & ڤి & & ஜे & 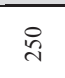 & 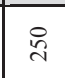 & : & 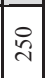 & 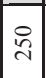 & ஜั & ڤ్ & in \\
\hline 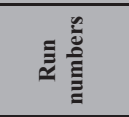 & 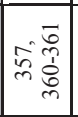 & $\stackrel{\infty}{m}$ & हे & 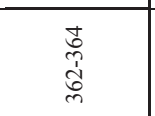 & 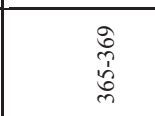 & 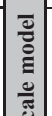 & 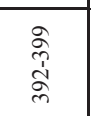 & 字守 & 㝘享 & \begin{tabular}{|l|}
\multirow{7}{*}{} \\
$\frac{7}{9}$ \\
\end{tabular} & 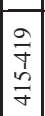 & 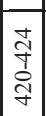 & भें જે & 管孛 & 尚宇 \\
\hline 害 & $\stackrel{\infty}{\infty}$ & $\underset{\sim}{\infty}$ & $\underset{q}{\sigma}$ & 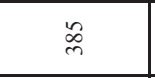 & 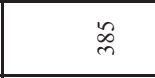 & 童 & \& & ஓे & \&্+ & 文 & 字 & 字 & \& & \&্ণ & \& \\
\hline $8 \stackrel{\bar{g}}{\underline{\underline{g}}}$ & $r$ & $a$ & $r$ & $r$ & $r$ & 㝘 & r & r & $r$ & -1 & -1 & $n$ & r & r & $r$ \\
\hline *ै & ó & $\hat{o}$ & $\stackrel{\circ}{\circ}$ & $\hat{o}$ & $\hat{o}$ & ثีं & $\hat{o}$ & $\hat{o}$ & $\hat{0}$ & $\hat{\circ}$ & $\hat{0}$ & $\hat{\circ}$ & $\hat{o}$ & $\hat{o}$ & $\hat{o}$ \\
\hline$\overline{\overline{\underline{E}}}$ & $\stackrel{n}{\stackrel{\sim}{\sim}}$ & $\stackrel{\approx}{\approx}$ & $\stackrel{\approx}{\approx}$ & $\stackrel{\sim}{\sim}$ & $\stackrel{\sim}{\approx}$ & & $\stackrel{\text { ch }}{\text { ch }}$ & $\stackrel{n}{\sim}$ & $\stackrel{\overbrace{}}{\curvearrowright}$ & $\stackrel{\sim}{\approx}$ & $\stackrel{n}{\sim}$ & $\stackrel{n}{a}$ & 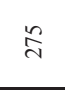 & $\stackrel{\curvearrowright}{\curvearrowright}$ & $\stackrel{n}{\sim}$ \\
\hline 咺 & in & 8 & 8 & in & in & & in & in & in & in & in & in & in & in & in \\
\hline 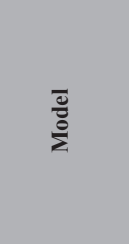 & 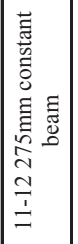 & 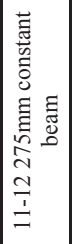 & 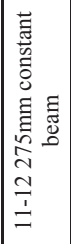 & 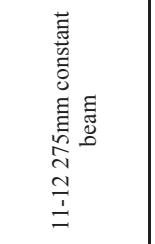 & 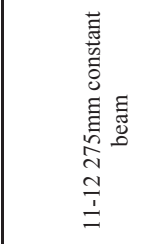 & & 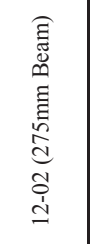 & 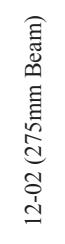 & 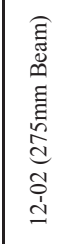 & 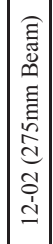 & 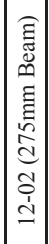 & 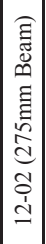 & 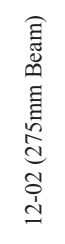 & 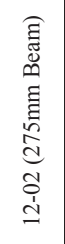 & 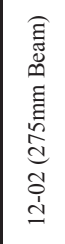 \\
\hline 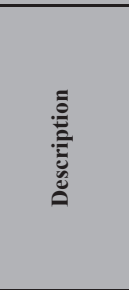 & 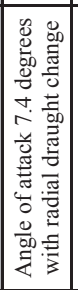 & 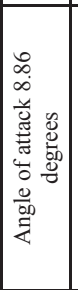 & 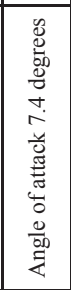 & 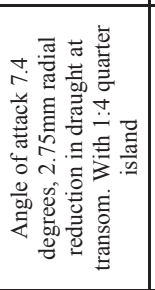 & 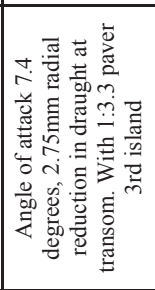 & & 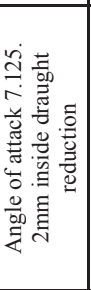 & 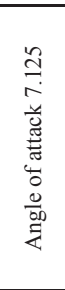 & 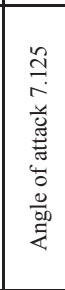 & 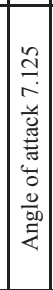 & 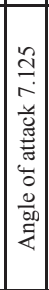 & 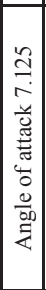 & 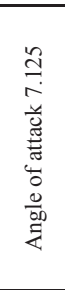 & 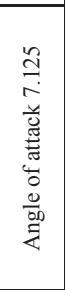 & 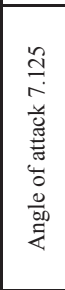 \\
\hline 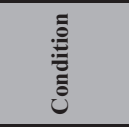 & $F$ & F & $\mathscr{f}$ & 7 & rq & & F & $\stackrel{\infty}{+}$ & g & in & $\vec{n}$ & $\approx$ & $n$ & $\ddot{n}$ & $i n$ \\
\hline
\end{tabular}


Page 180

Annex B Scale model experiments run sheet summary

\begin{tabular}{|c|c|c|c|c|c|c|c|c|c|}
\hline$=$ & $\mid \begin{array}{l}0 \\
0 \\
0\end{array}$ & \begin{tabular}{|l|l|} 
\\
\end{tabular} & $\begin{array}{l}0 \\
: \\
0\end{array}$ & : & & $\stackrel{\circ}{0}$ & 0 & ${ }_{0}^{0}$ & : \\
\hline : & $\approx$ & $\simeq$ & $\simeq$ & $\simeq$ & & $\simeq$ & $\simeq$ & 6 & 6 \\
\hline sू & $\stackrel{\infty}{0}$ & $\hat{n}$ & $\begin{array}{l}n \\
n \\
o\end{array}$ & $\stackrel{\infty}{+}$ & $\stackrel{\infty}{\stackrel{+}{0}}$ & : & & fี. & तु \\
\hline s: & తి & 守 & $\stackrel{\circ}{\curvearrowleft}$ & ปิ & ఫิ & 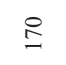 & & $\stackrel{\circ}{\sim}$ & $\stackrel{\circ}{=}$ \\
\hline ง & กิ & f. & $\begin{array}{l}0 \\
0 \\
0 \\
0\end{array}$ & ת. & $\approx$ & స్ & & $\mid \begin{array}{l}\infty \\
\stackrel{2}{0} \\
0\end{array}$ & $\stackrel{\infty}{\stackrel{0}{0}}$ \\
\hline งิํํำ & $\stackrel{\oplus}{9}$ & $\stackrel{\circ}{-2}$ & $\stackrel{\circ}{9}$ & $\stackrel{\overbrace{}}{\check{2}}$ & $\stackrel{0}{\rightarrow}$ & $\infty$ & & \) & ஓे \\
\hline$\cong$ & $\stackrel{-}{-}$ & 9 & 9 & $\stackrel{\dot{i}}{\mathrm{i}}$ & $\stackrel{\text { 교 }}{\rightarrow}$ & $\stackrel{+}{\mathrm{i}}$ & & 9 & $\stackrel{9}{-}$ \\
\hline 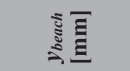 & in & $\stackrel{\circ}{\circ}$ & $\stackrel{2}{n}$ & \%ু & sू & 员 & & 总 & 总 \\
\hline 酸 & $=$ & $=$ & $=$ & $=$ & $=$ & 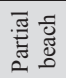 & $\gtrless_{\tilde{z}}^{\circ}$ & $=$ & $=$ \\
\hline 哥 & \begin{tabular}{|l}
$\overline{\bar{F}}$ \\
0 \\
0 \\
$\check{Z}$
\end{tabular} & 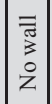 & 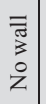 & $\begin{array}{l}\overline{7} \\
\bar{z} \\
0 \\
z \\
z\end{array}$ & $\begin{array}{l}\overline{\bar{\pi}} \\
\stackrel{3}{3} \\
0 \\
\dot{z}\end{array}$ & $\begin{array}{l}\overline{\bar{T}} \\
\text { है } \\
\text { Z }\end{array}$ & 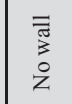 & 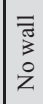 & 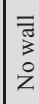 \\
\hline$s \overline{\underline{E}}$ & i̊ & $\underset{\mathbf{v}}{\stackrel{a}{*}}$ & $\begin{array}{l}\stackrel{\infty}{\infty} \\
\stackrel{\sim}{\sim}\end{array}$ & i̊ & ্ֻণ & ఊి & ஜั & in & 吕 \\
\hline 产高 & $\begin{array}{l}\text { 寺 } \\
\text { 章 } \\
\text { 多 }\end{array}$ & $\begin{array}{c}\text { 寺 } \\
\text { 守 } \\
\text { 等 }\end{array}$ & 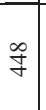 & $\begin{array}{l}\hat{6} \\
+1 \\
\text { gे }\end{array}$ & \begin{tabular}{l}
$\Re$ \\
\multirow{f}{+}{} \\
\multirow{f}{+}{}
\end{tabular} & 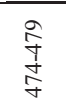 & 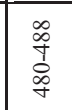 & $\begin{array}{l}\text { ta } \\
\text { वे } \\
\text { वे } \\
\text { के }\end{array}$ & $\begin{array}{l}\vec{b} \\
b \\
\dot{d} \\
\sigma\end{array}$ \\
\hline$\widehat{N}$ & \& & 字 & ఫे & 京 & 字。 & \&্ণ & \& & ¿ & ঃ \\
\hline $8 \overline{\underline{g}}$ & r & - & $r$ & $r$ & r & r & $r$ & - & r \\
\hline$*$ & $\hat{o}$ & $\hat{o}$ & $\hat{0}$ & $\ddot{\circ}$ & $\mid \begin{array}{l}0 \\
0 \\
0\end{array}$ & $\ddot{o}$ & $\hat{o}$ & $\hat{o}$ & í \\
\hline$\overline{\overline{\underline{E}}}$ & $\stackrel{\curvearrowright}{\varkappa}$ & $\stackrel{\overbrace{}}{\sim}$ & $\stackrel{\check{c}}{\mathrm{i}}$ & $\stackrel{\sim}{\approx}$ & 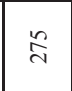 & $\stackrel{\sim}{\approx}$ & $\stackrel{\sim}{\sim}$ & in & in \\
\hline ○西 & in & in & in & in & $\dot{8} 8$ & in & in & 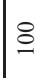 & 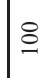 \\
\hline $\begin{array}{l}\bar{\Xi} \\
\sum \\
\sum\end{array}$ & 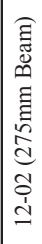 & 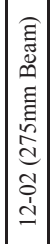 & 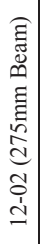 & 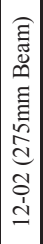 & 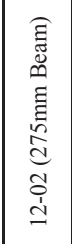 & 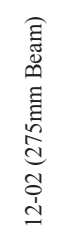 & 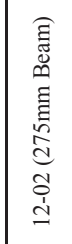 & 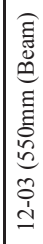 & 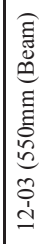 \\
\hline 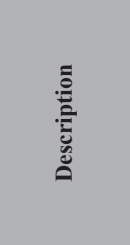 & 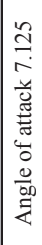 & 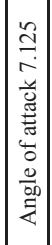 & 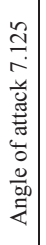 & 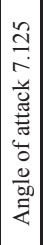 & 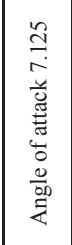 & 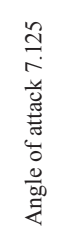 & 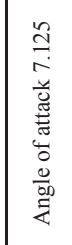 & 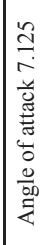 & 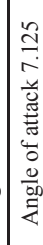 \\
\hline 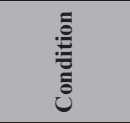 & $\stackrel{\circ}{i}$ & in & $\infty$ & in & 8 & $\vec{\sigma}$ & ชิ & 8 & t \\
\hline
\end{tabular}




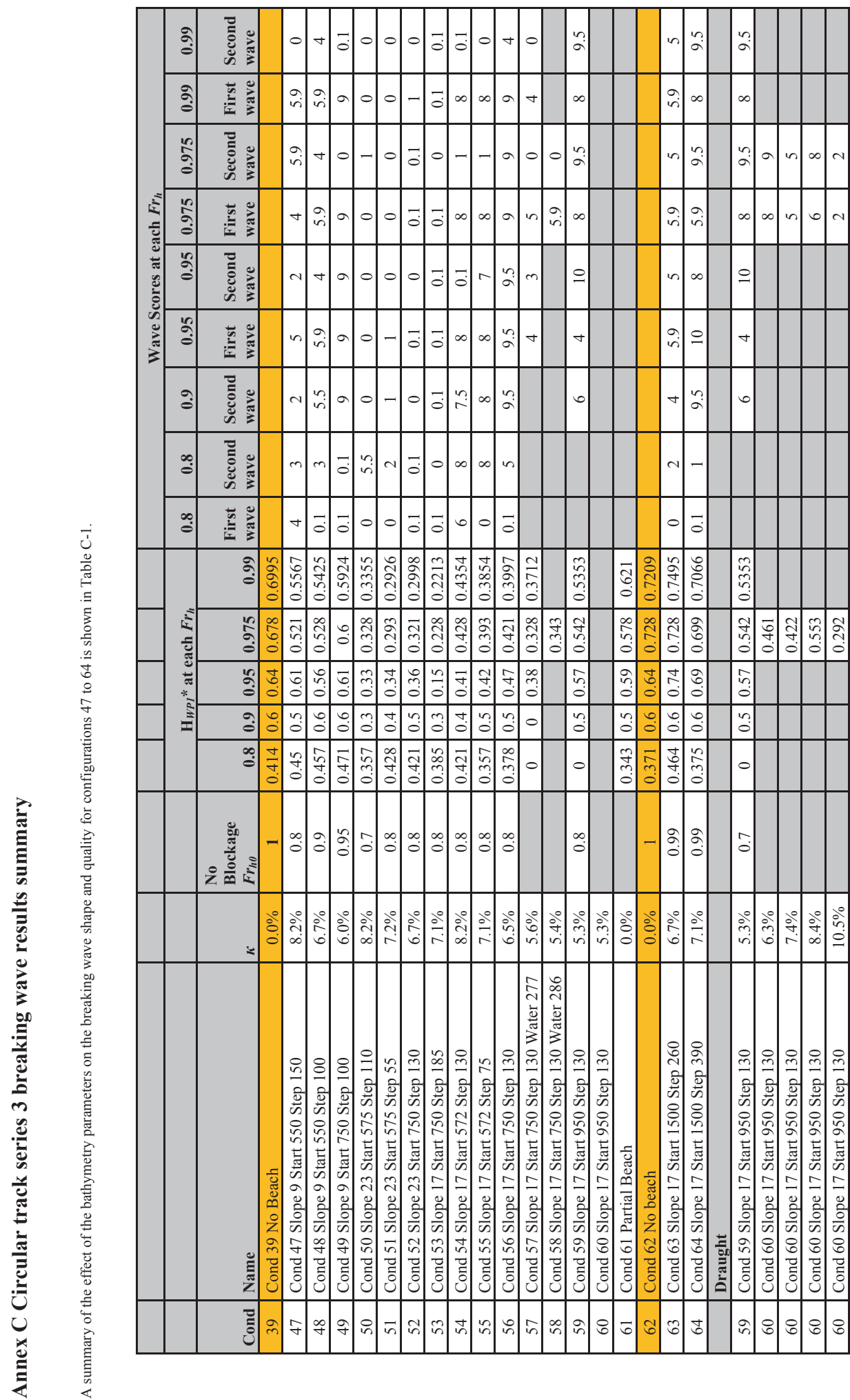


Page 183

Annex C Circular track series 3 breaking wave results summary 


\section{Curriculum Vitae}

Steven Anthony Schmied

\section{Date and place of birth}

12 July 1971.

Melbourne, Australia.

\section{Secondary Education}

Hampton High School, Victoria, Australia, 1984 - 1985.

Melbourne High School, Victoria, Australia, 1986 - 1989.

\section{Tertiary Education}

Bachelor of Engineering (Aerospace, Honours), Royal Melbourne Institute of Technology (RMIT) University, Victoria, Australia, 1990 - 1993. Awarded 1994.

Master of Business Administration (Capital Project Management), University of Southern Queensland, Queensland, Australia, 1995 - 1997. Awarded 1998.

Master of Engineering (Computing), Deakin University, Victoria, Australia, 2000 - 2001. Awarded 2001. 


\section{Professional Experience}

Mr Steven Schmied is a Chartered Fellow of Engineer Australia, who is a recognised expert in the definition of new capabilities, formulating acquisition strategies and the managing the subsequent implementation of the project. Mr Schmied's clients include State and Federal governments, and associated industries, both within Australia and overseas. Mr Schmied has also been the engineering team leader, a senior engineer and / or the project manager of major defence and other projects.

Mr Schmied is the project manager and chief engineer for the Webber Wave Pool project; www.webberwavepools.com. This project has patented and is commercialising the surfing wave pool design presented in this thesis.

Mr Schmied is a director of the University of Tasmania Foundation.

The research for this thesis was conducted at the University of Tasmania Australian Maritime College and Delft University of Technology, Netherlands.

\section{Employment History}

Aug 2013 - Present. Director, University of Tasmania Foundation.

Jan 2013 - Present. Frazer-Nash Consultancy Ltd.

Nov 2011 - Present. Schmied Consulting.

Sep 2006 - Nov 2011. SYPAQ Systems Pty Ltd.

Nov 2001 - Sep 2006. Ball Solutions Group. 
Nov 2001 - Present. Australian Army Reserve.

Dec 1992 - Nov 2001. Australian Army.

\section{Journal Publications}

Schmied, S.A., Binns, J., Renilson, M.R., Thomas, G., Macfarlane, G. and Huijsmans, R. 2010, A Novel Method For Generating Continuously Surfable Waves, Marine Technology Society Journal, March / April 2010, Volume 44 Number 2.

Schmied, S.A., Binns, J., Renilson, M.R., Thomas, G., Macfarlane, G. and Huijsmans, R., A Novel Method for Generating Continuously Surfable Waves-Comparison of Predictions With Experimental Results, Journal of Ocean, Offshore and Arctic Engineering (JOMAE), 22 May 2013, Vol. 135 Issue 3.

\section{Other Publications}

Schmied, S.A., Binns, J., Renilson, M.R., Thomas, G., Macfarlane, G. and Huijsmans, R. 2011, A Novel Method For Generating Continuously Surfable Waves, 30th International Conference on Ocean, Offshore and Arctic Engineering, Rotterdam, the Netherlands.

Binns, J., Schmied, S.A., Renilson, M.R., Thomas, G., Macfarlane, G. and Huijsmans, R. 2012, A Novel Method For Generating Continuously Surfable Waves, Pacific 2012, Sydney, Australia.

Javanmardi, M., Binns, J., Schmied, S.A., Renilson, M.R., Thomas, G. and Huijsmans, R. 2012, The Formation of Surfable Waves in a Circular Wave Pool - Comparison of Numerical and Experimental Approaches, 31 st International Conference on Ocean, Offshore and Arctic Engineering, Rio de Janeiro, Brazil. 
Schmied, S.A., Binns, J., Renilson, M.R., Thomas, G., Macfarlane, G. and Huijsmans, R. 2013, A Novel Method For Generating Continuously Surfable Waves, 32th International Conference on Ocean, Offshore and Arctic Engineering, Nantes, France. 